\title{
Enantioselective Intermolecular Aminoalkynylation of Styrenes via Copper-Catalyzed Radical Relay
}

\author{
Zhoumi Hu, ${ }^{\mathrm{a}, \mathrm{b}}$ Liang Fu, ${ }^{\mathrm{b}}$ Pinhong Chen, ${ }^{\mathrm{b}}$ Weiguo Cao, ${ }^{* \mathrm{a}}$ Guosheng Liu ${ }^{* \mathrm{~b}}$ \\ ${ }^{a}$ Department of Chemistry, Innovative Drug Research Center, Shanghai University, Shanghai, \\ 200444, PR China. \\ ${ }^{b}$ State Key Laboratory of Organometallic Chemistry, and Shanghai Hongkong Joint Laboratory \\ in Chemical Synthesis, Center for Excellence in Molecular Synthesis, Shanghai Institute of \\ Organic Chemistry, Chinese Academy of Sciences, 345 Lingling Road, Shanghai, 200032, China. \\ Email: gliu@mail.sioc.ac.cn; wgcao@staff.shu.edu.cn
}

\section{Table of Contents}

1. NMR spectra of Substrates and Products

2. HPLC Analysis of Products 


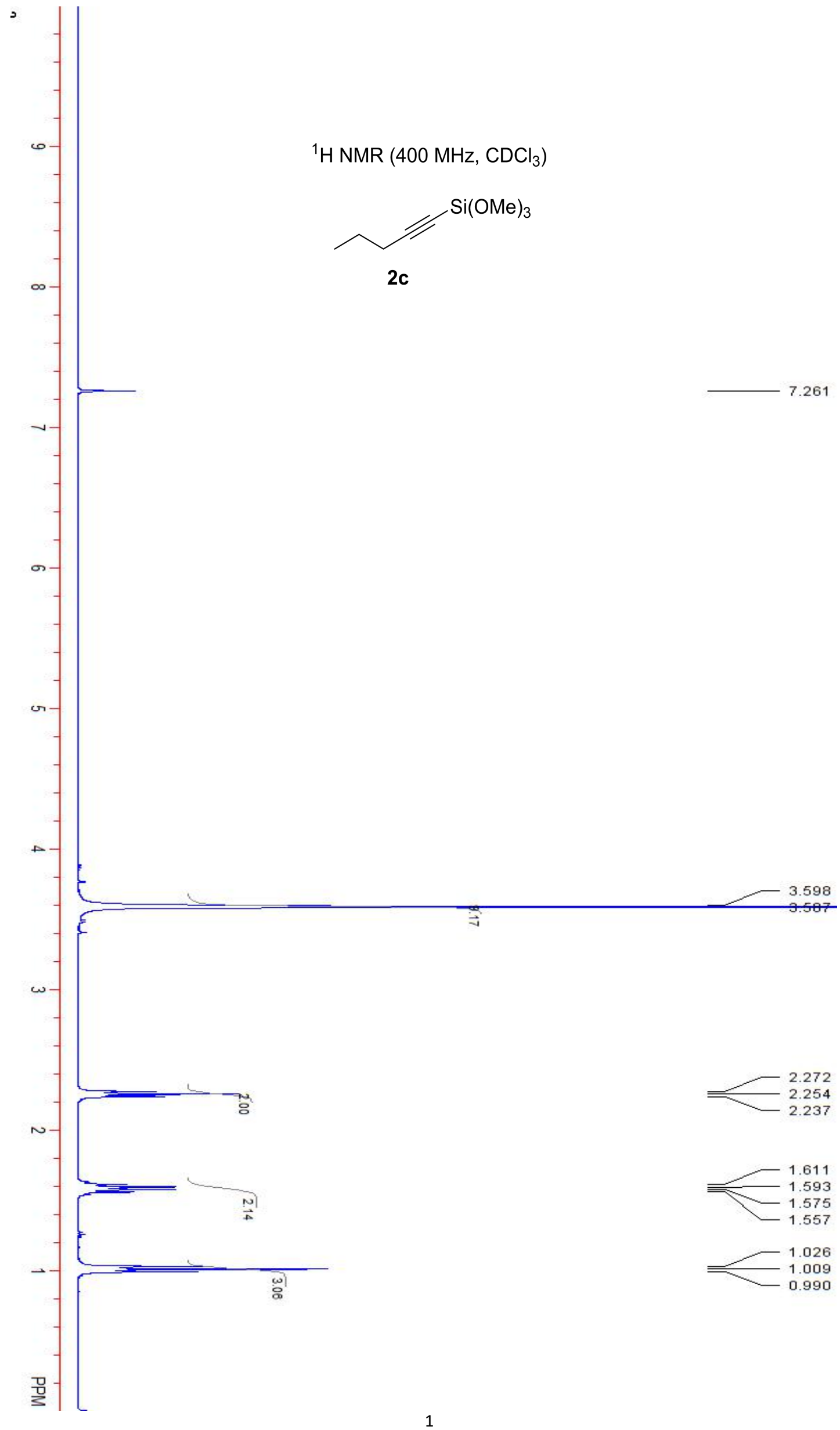



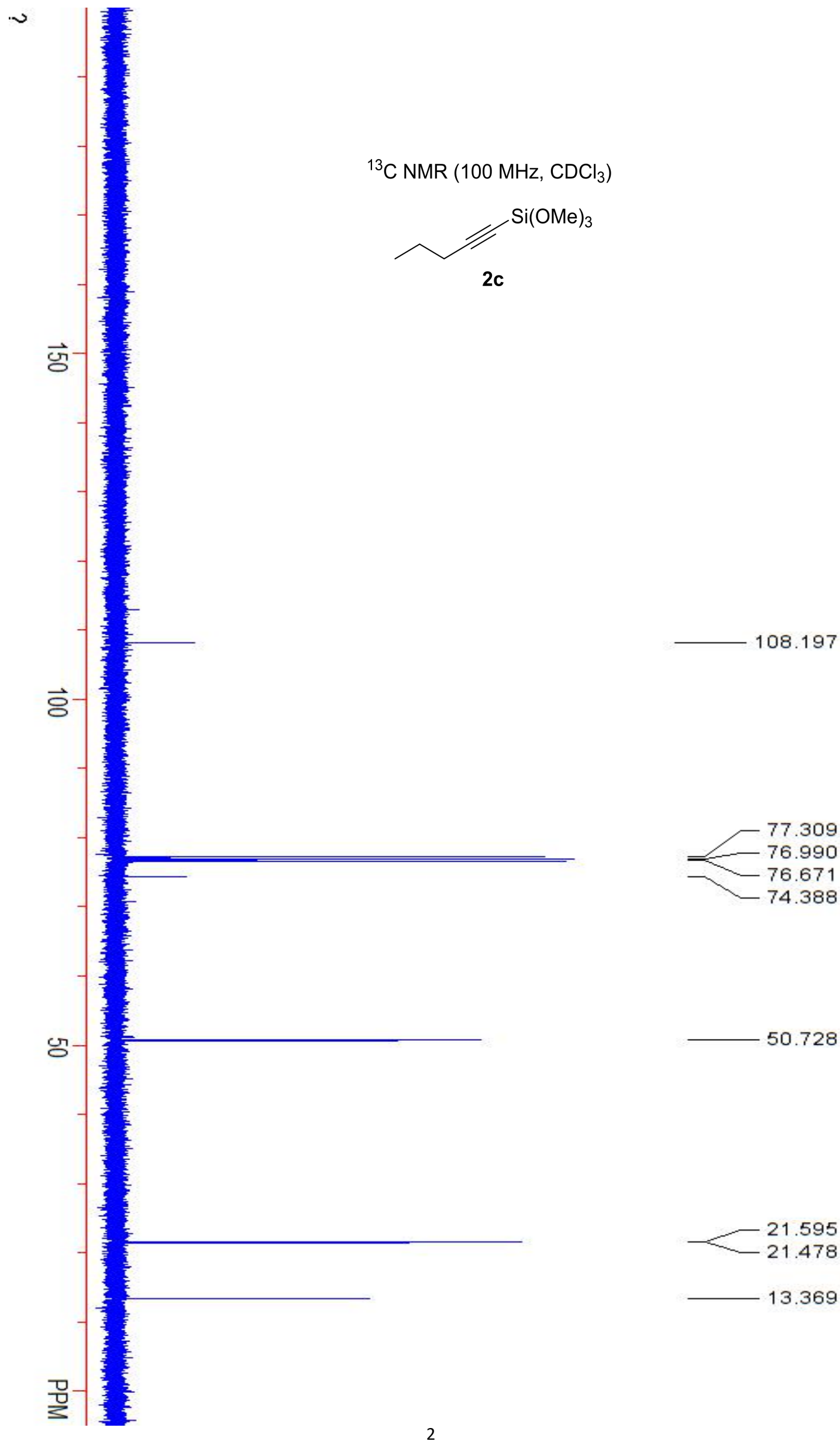

50.728

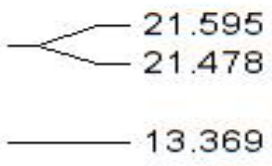




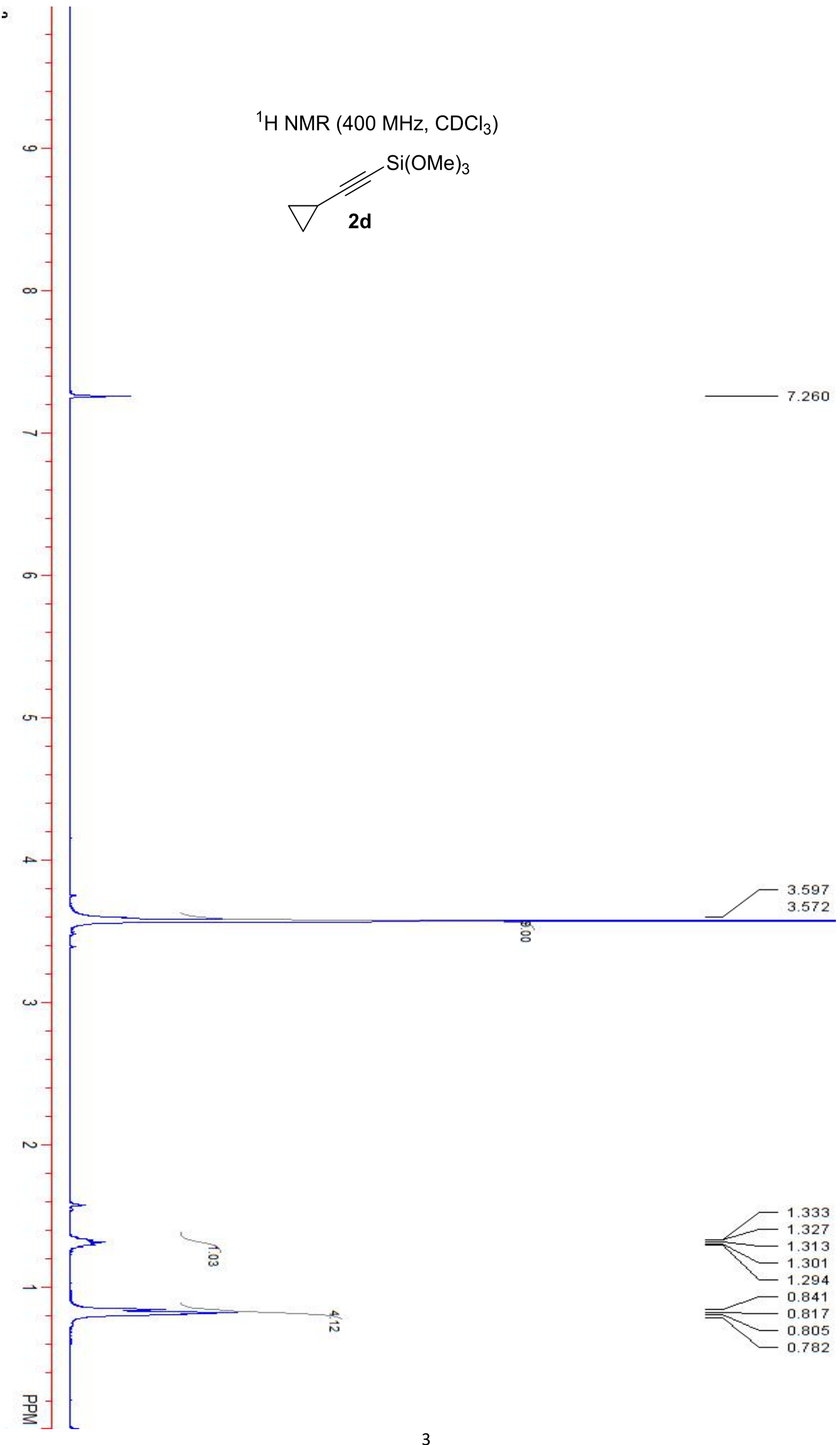




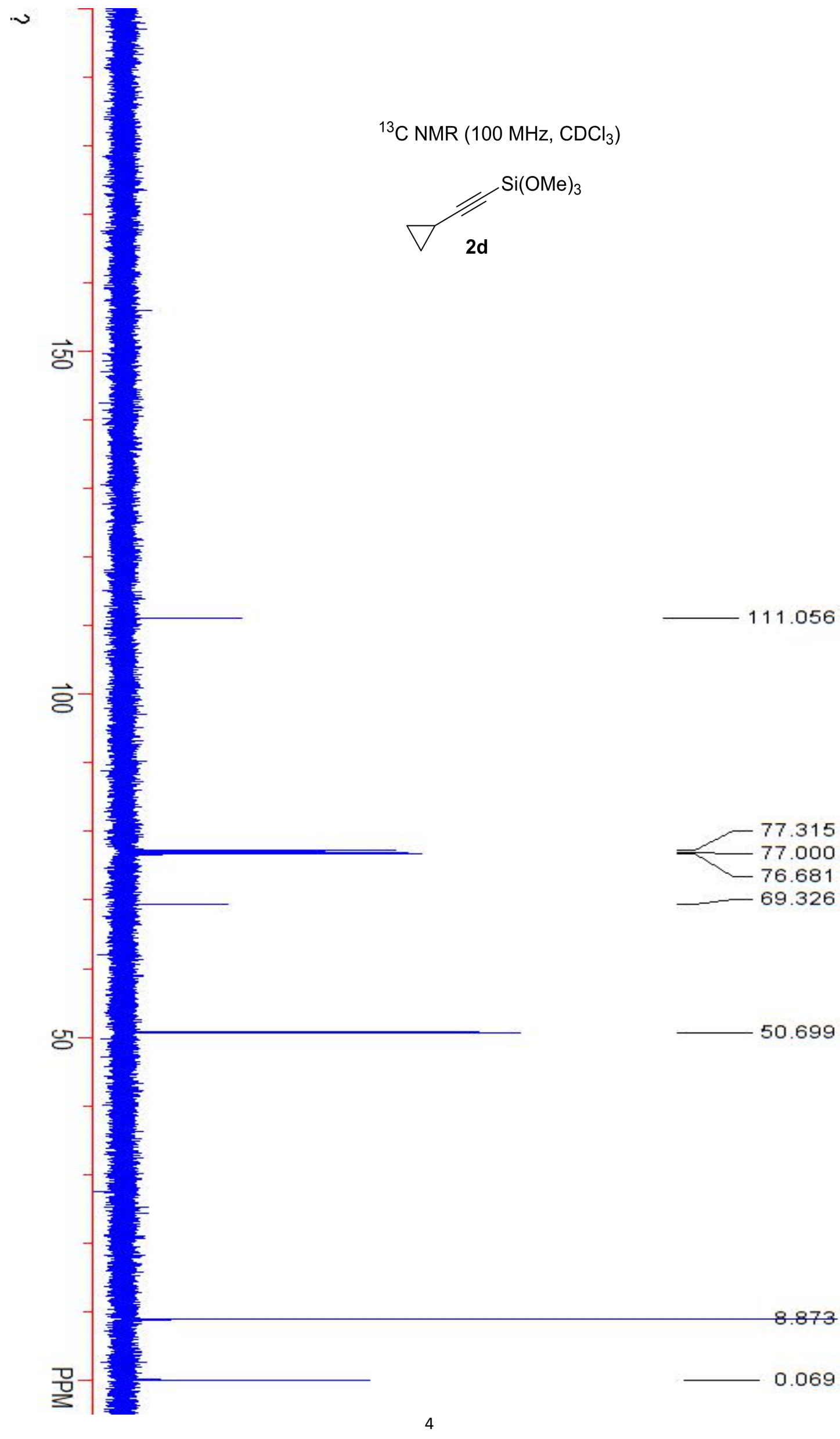




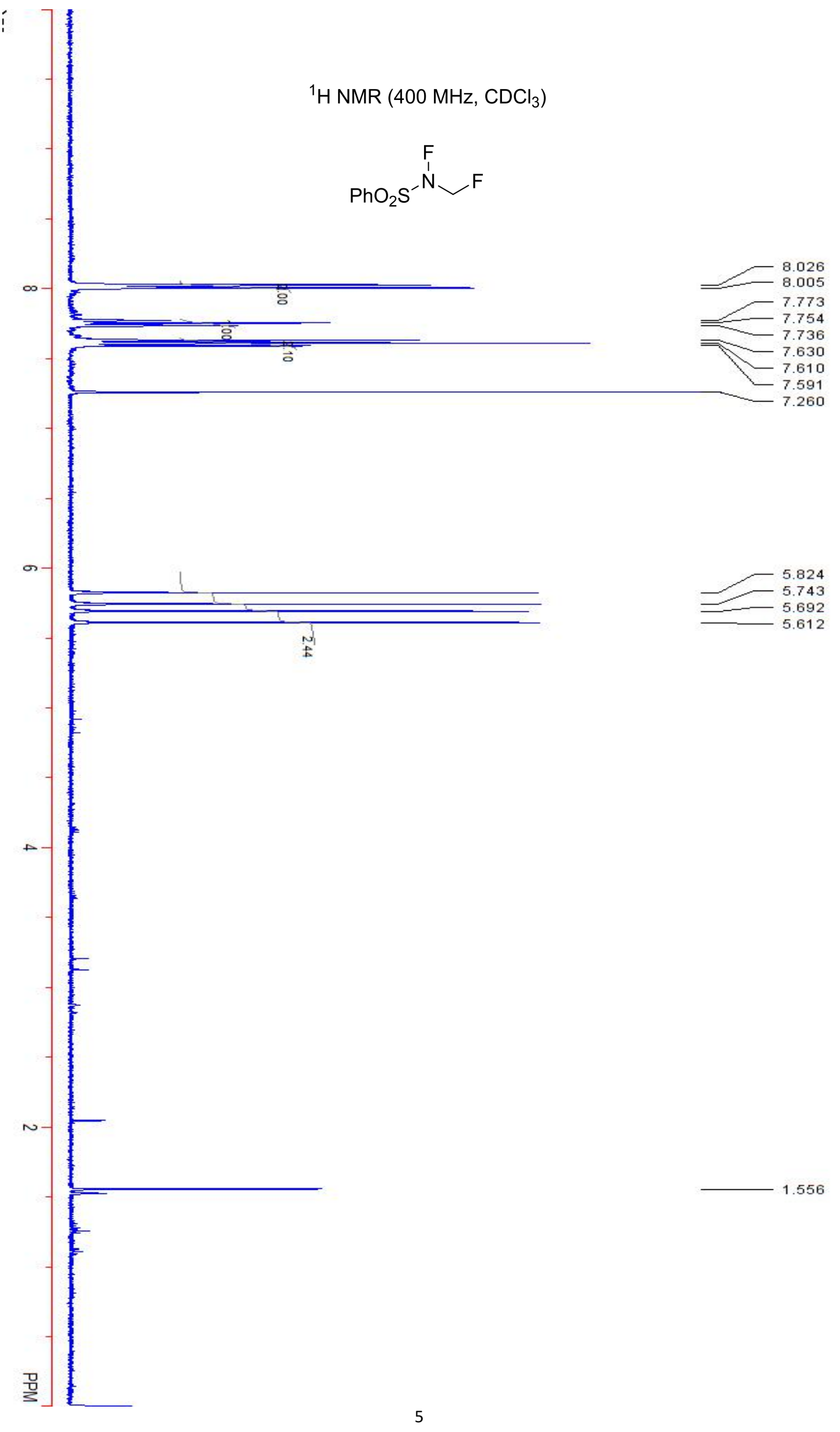



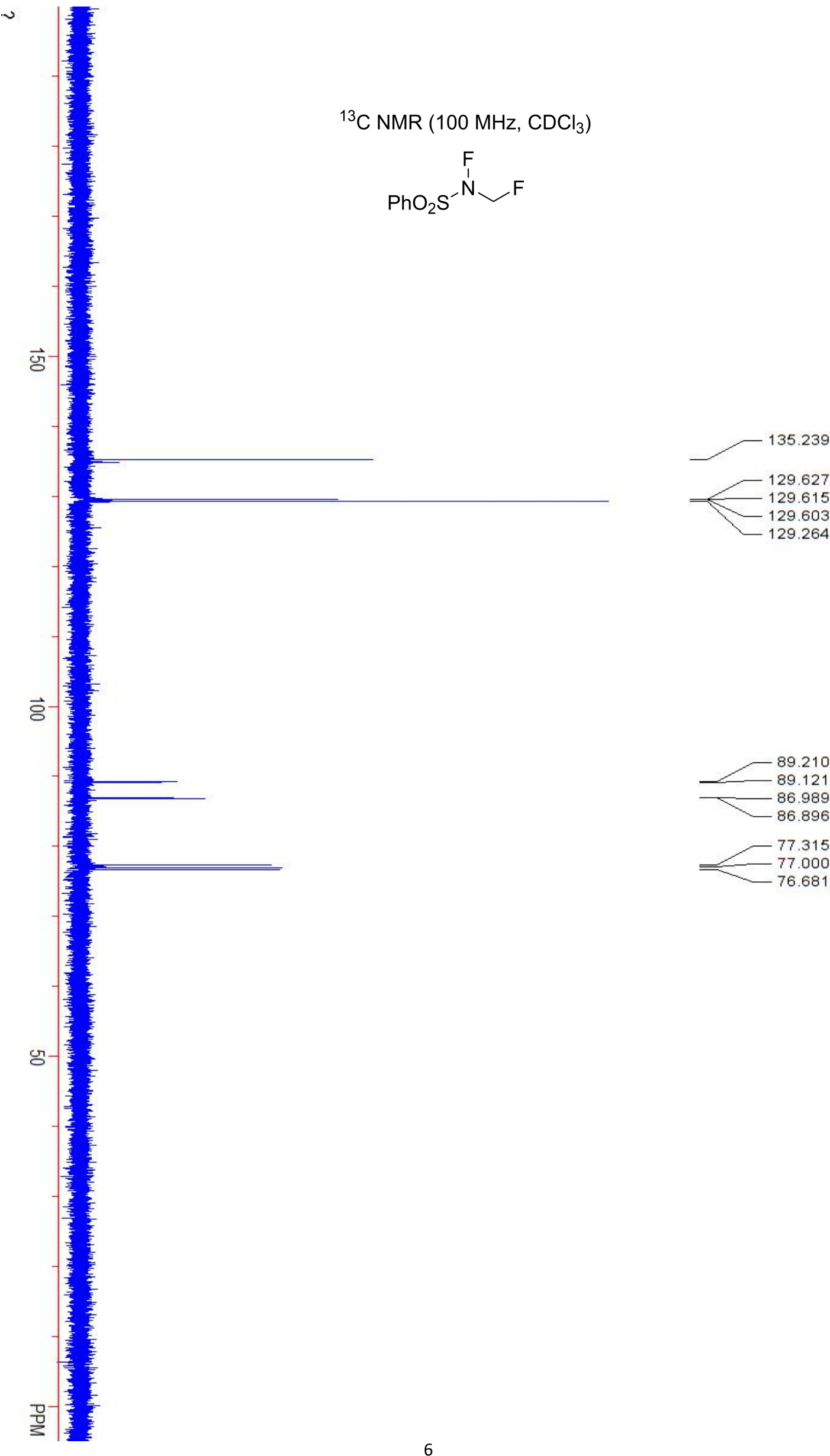
$\left.{ }^{19} \mathrm{~F} \mathrm{NMR} \mathrm{(376} \mathrm{MHz,} \mathrm{CDCl}_{3}\right)$<smiles>O=S(=O)(O)N(F)CF</smiles>

த்

客

o-

$-$

ज्ञ $\mathrm{PhO}_{2} \mathrm{~S}^{-\mathrm{N}} \mathrm{F}$
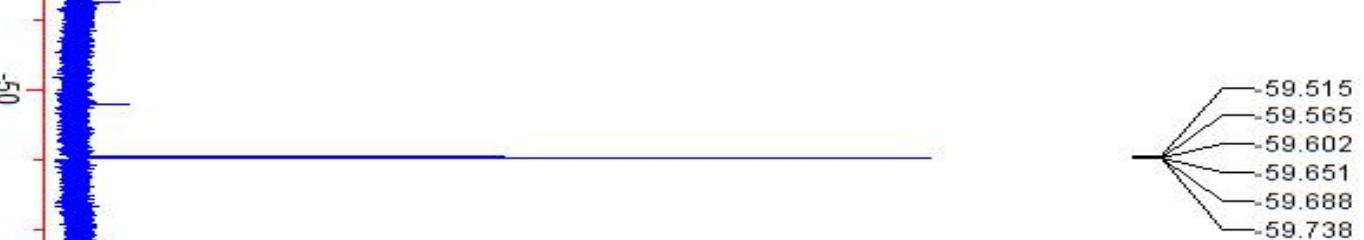

亏ั

艺 


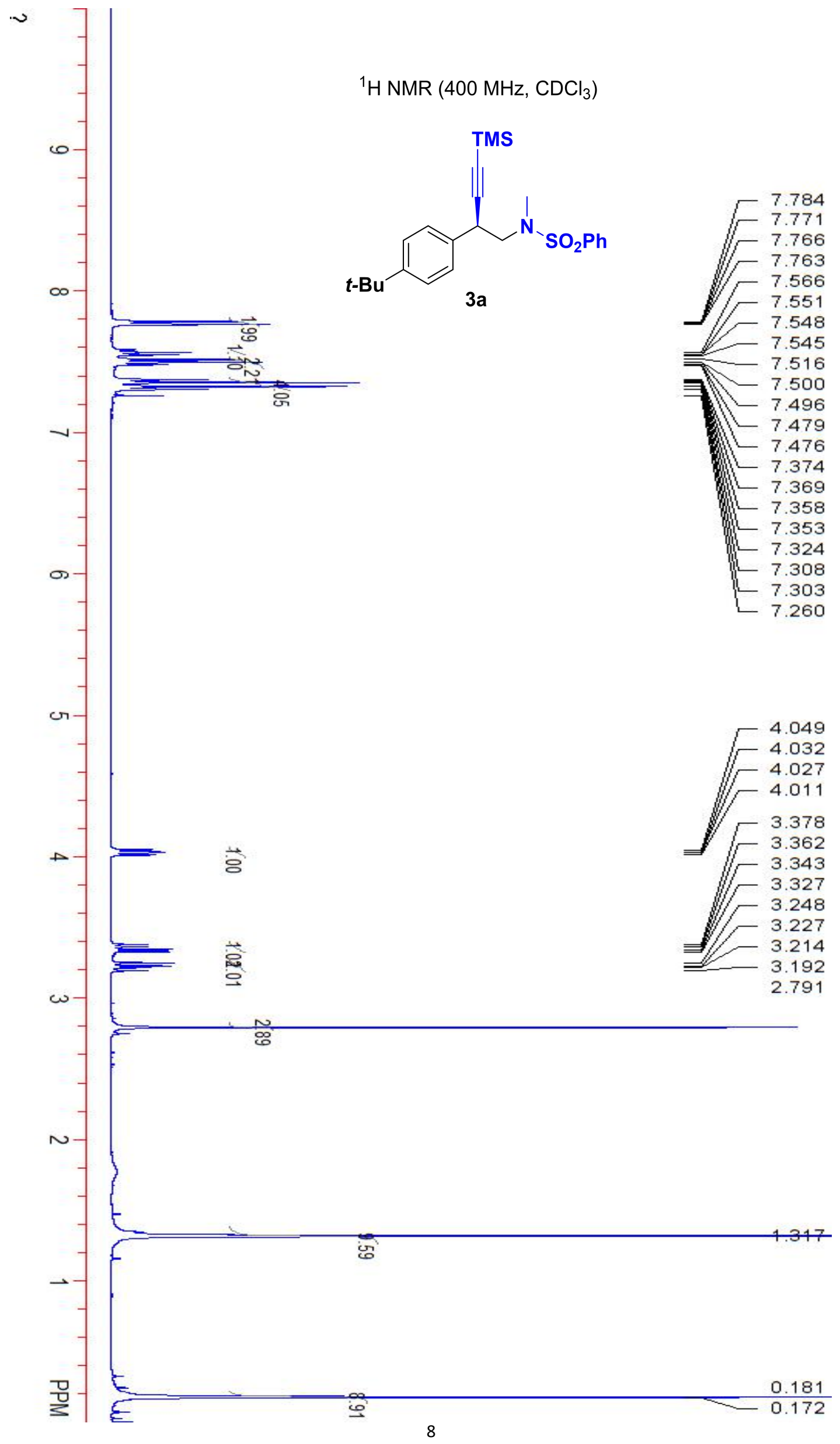




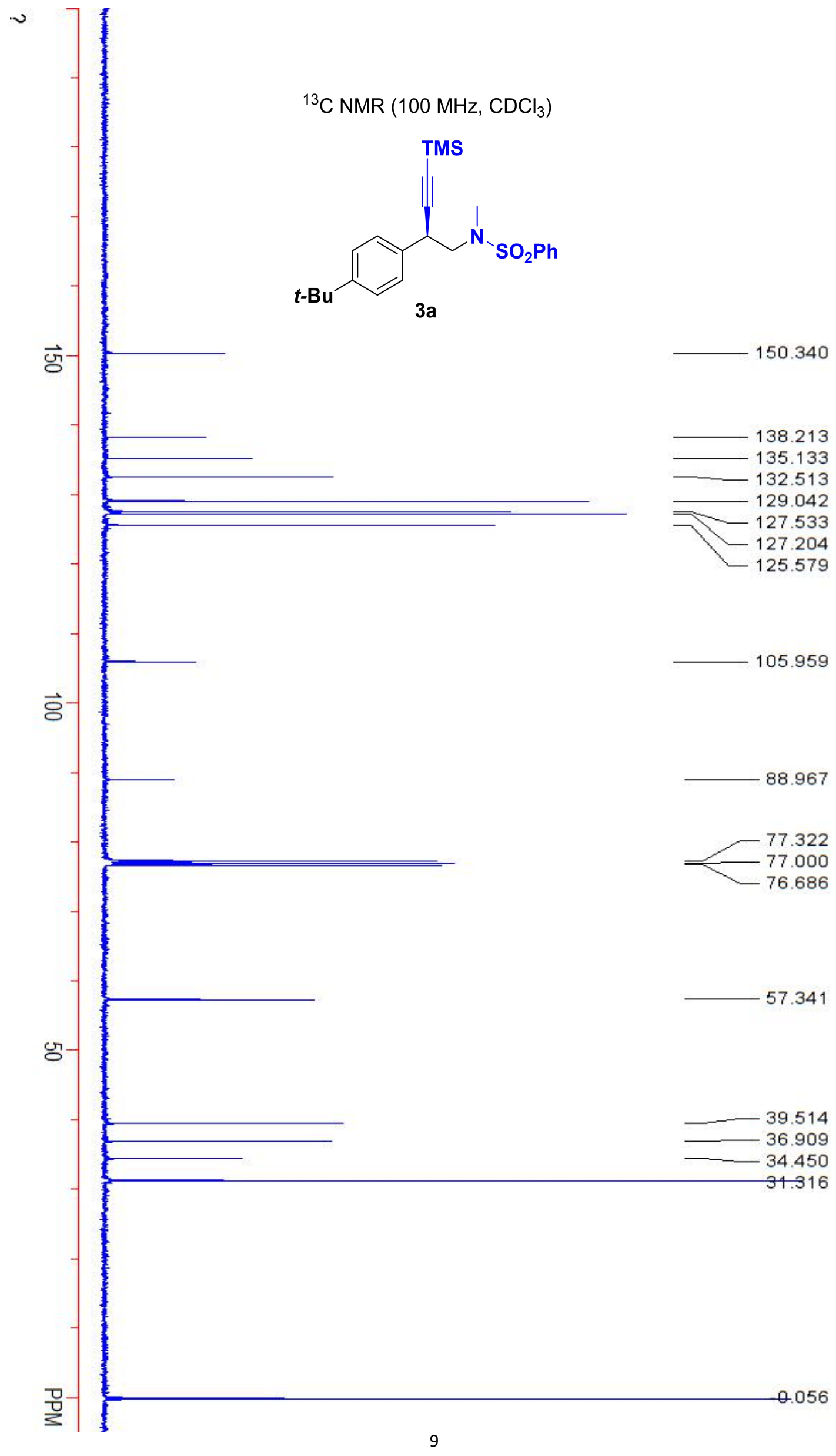




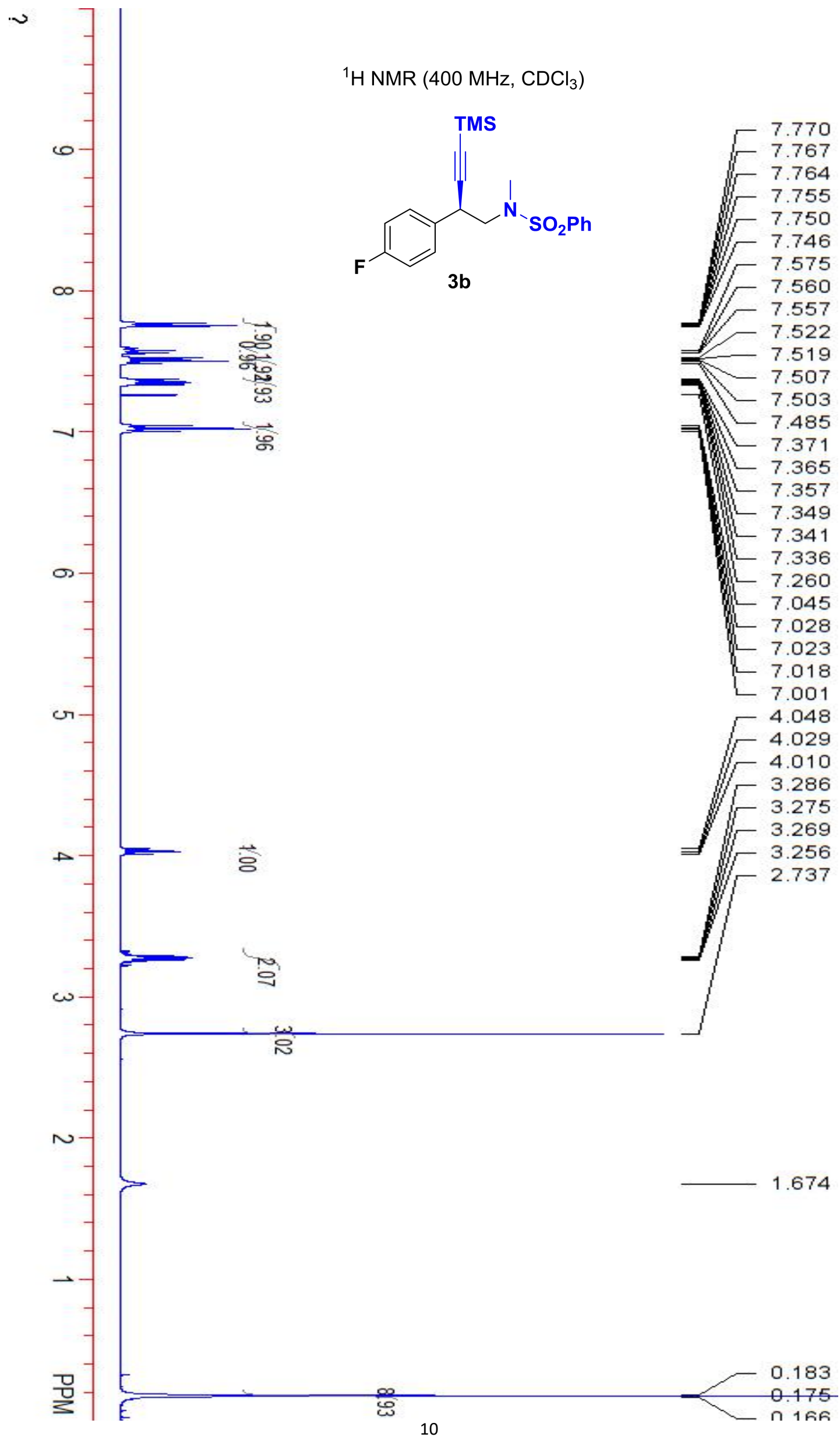




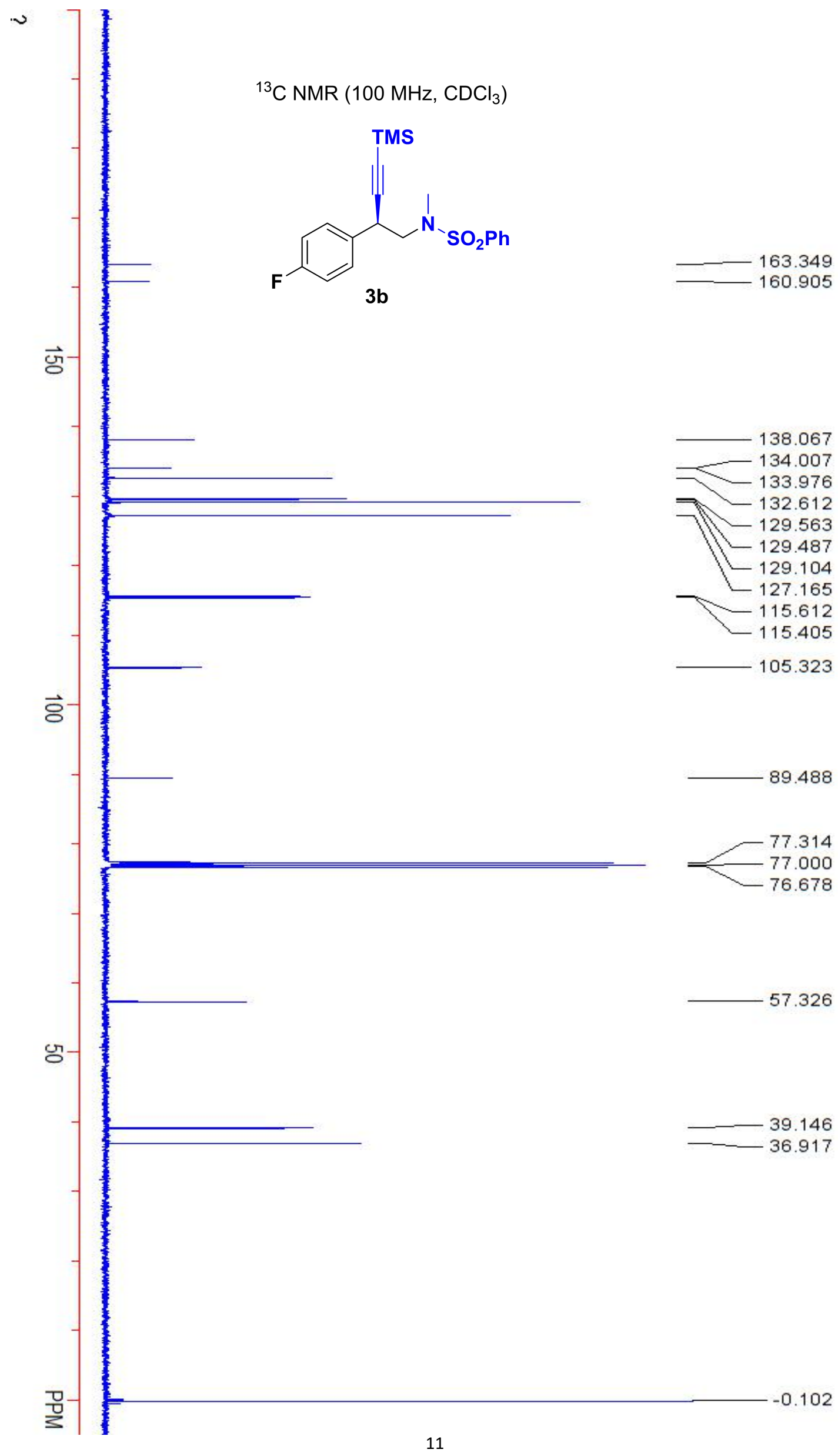



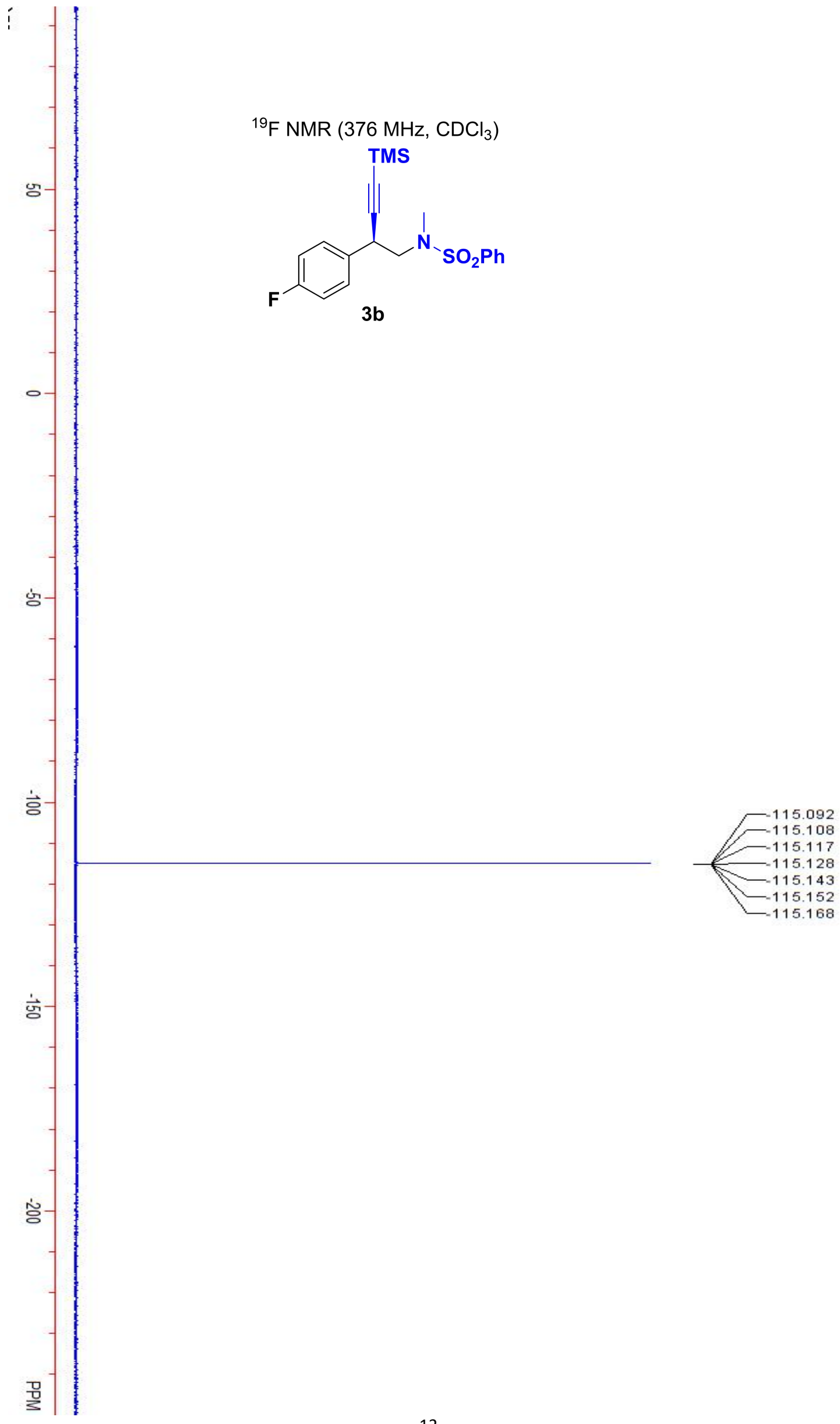


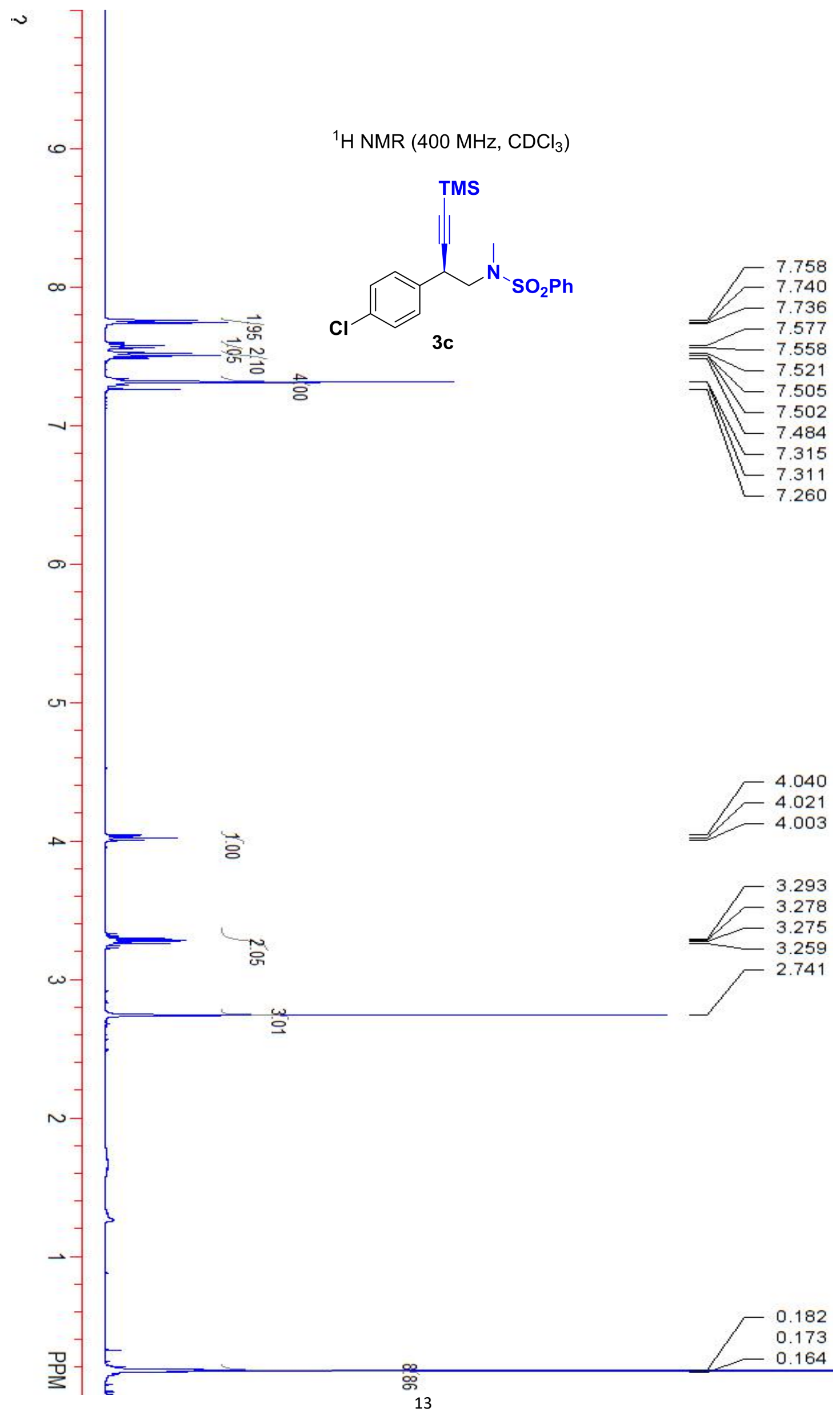




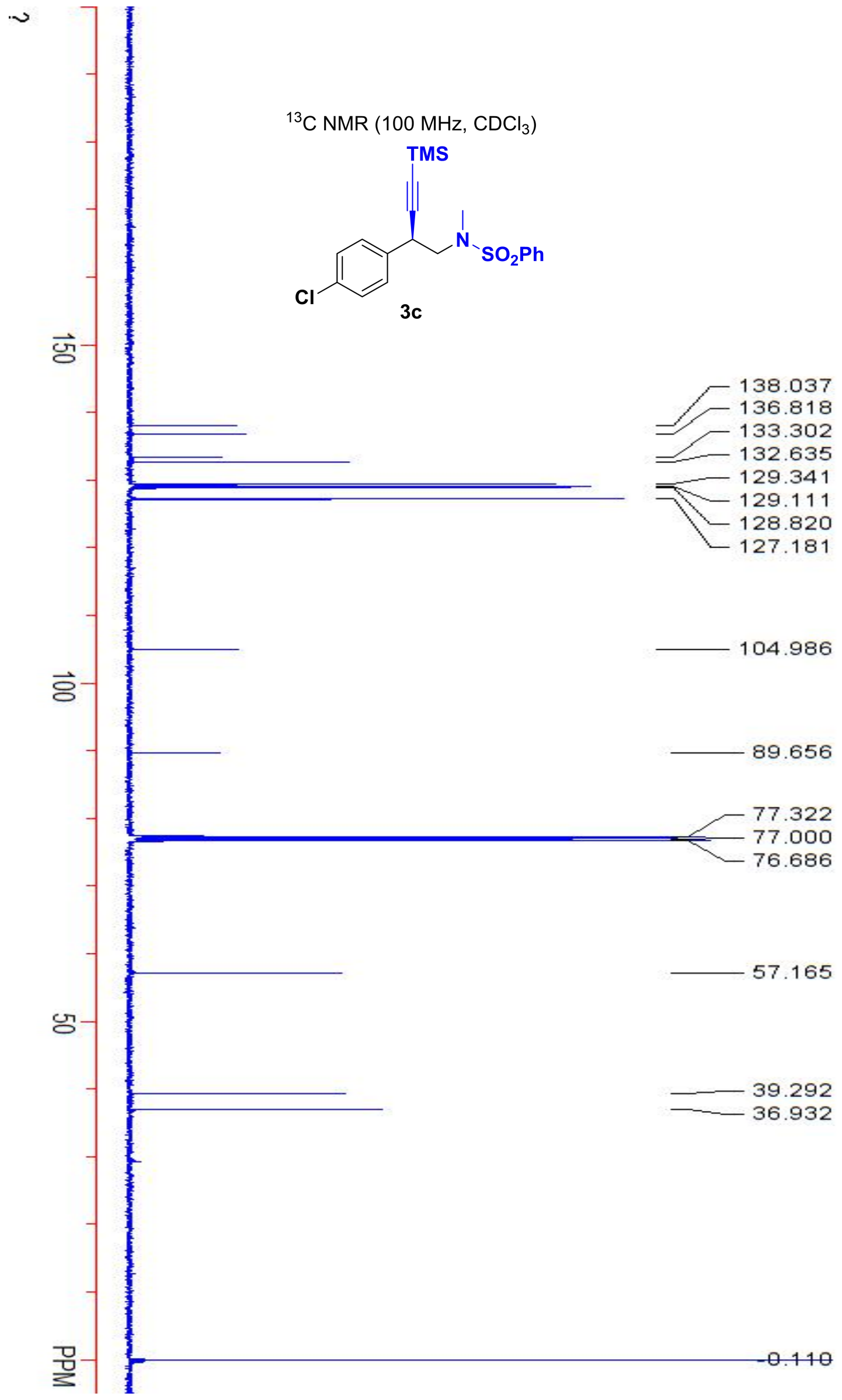




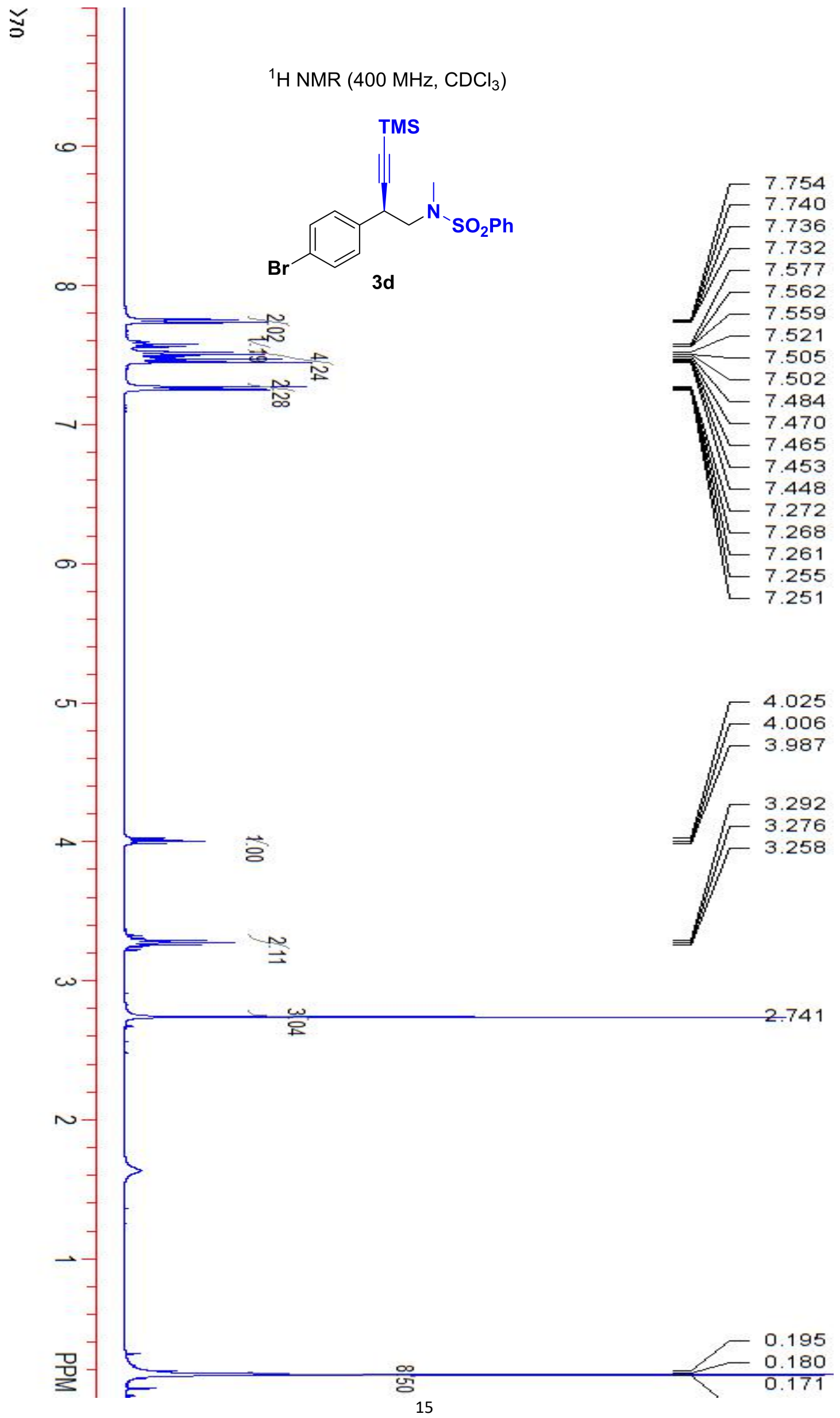




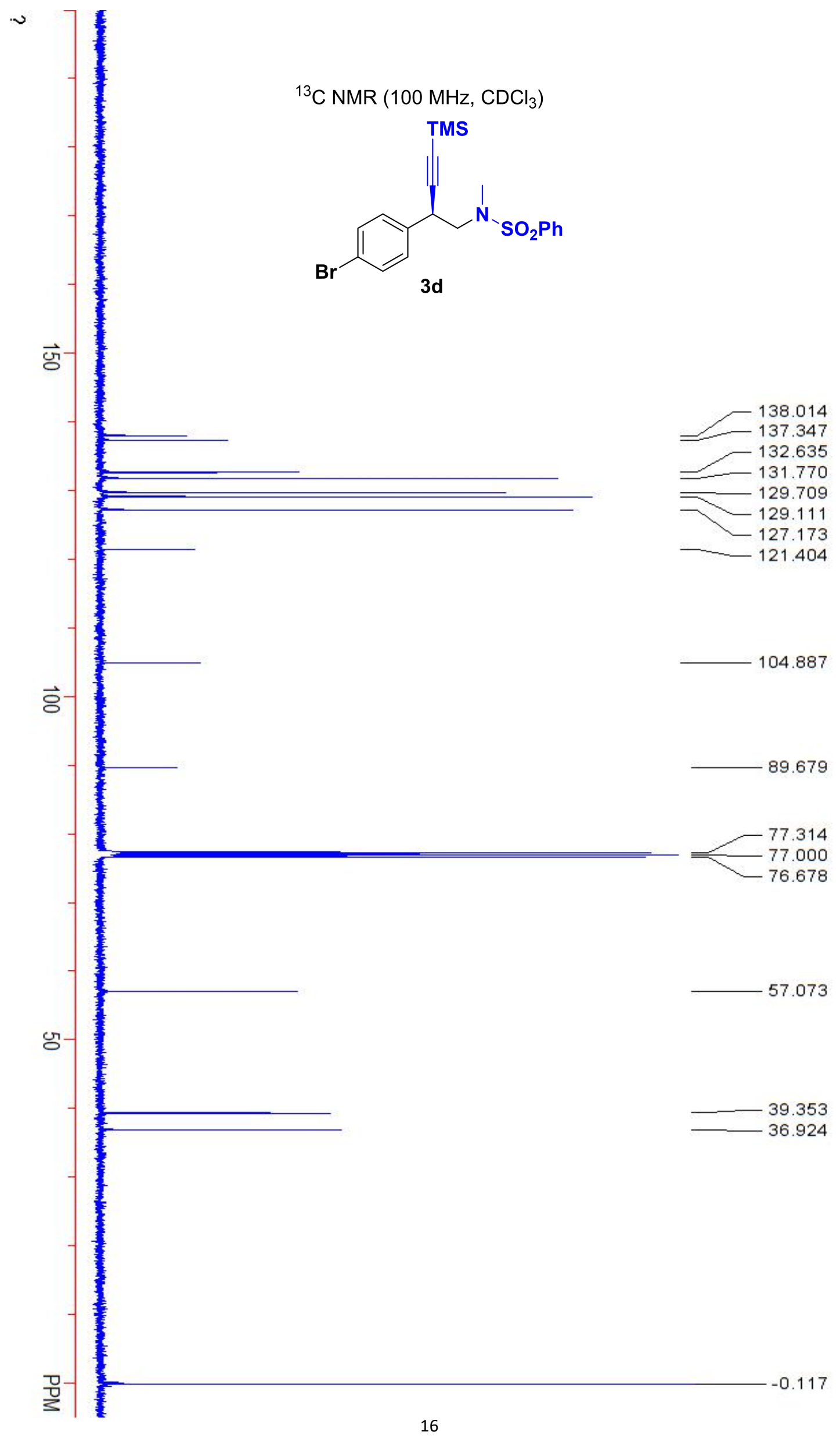




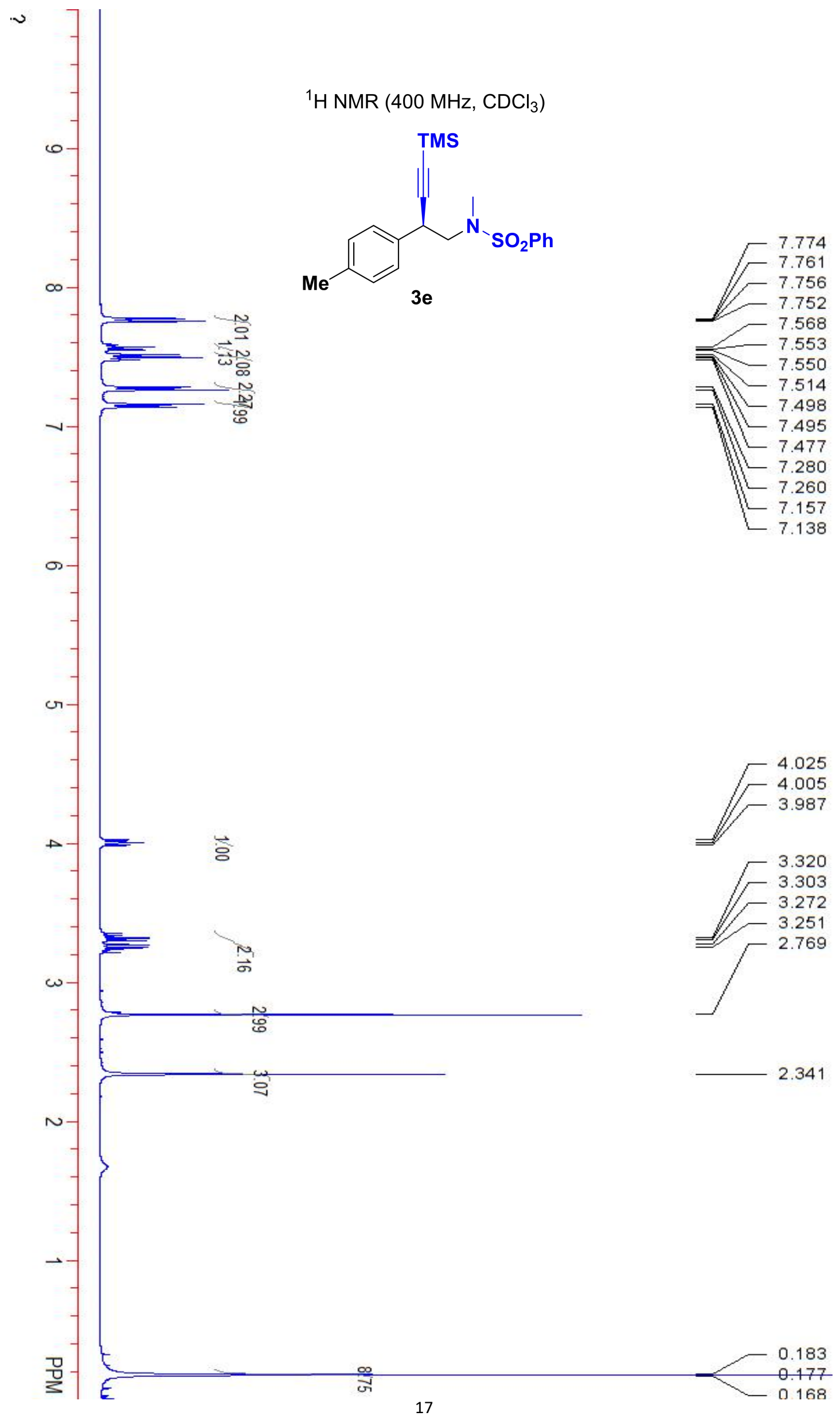




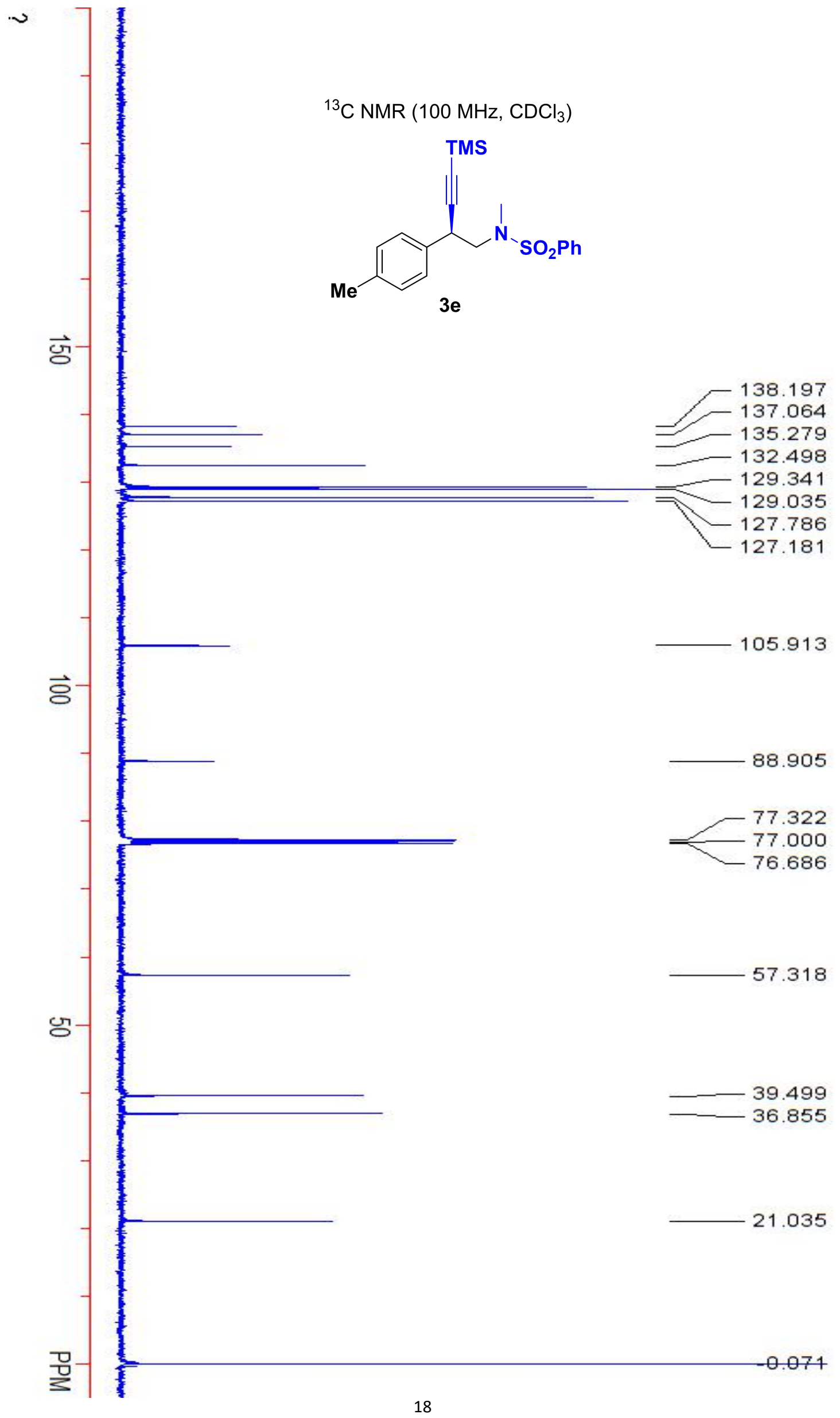




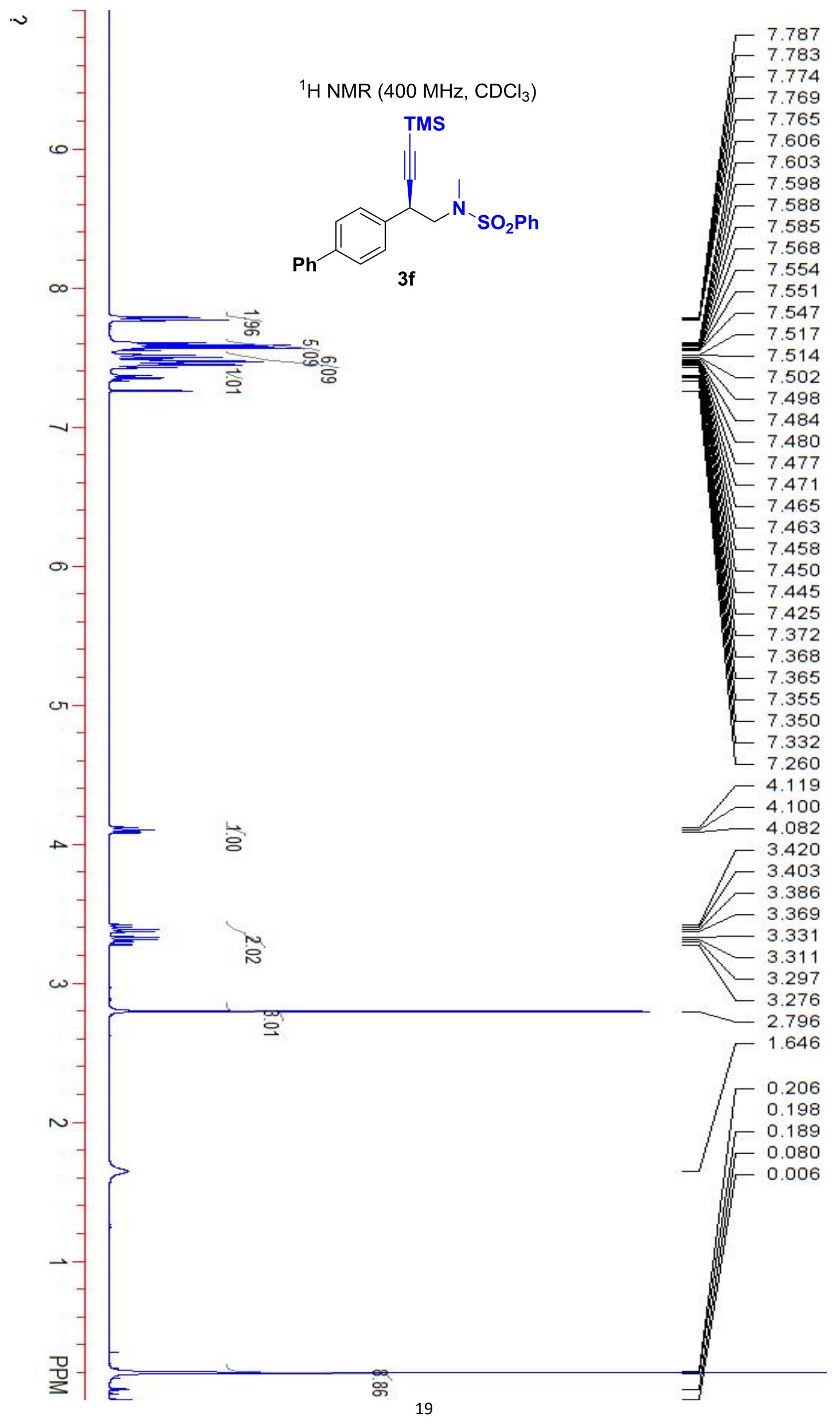




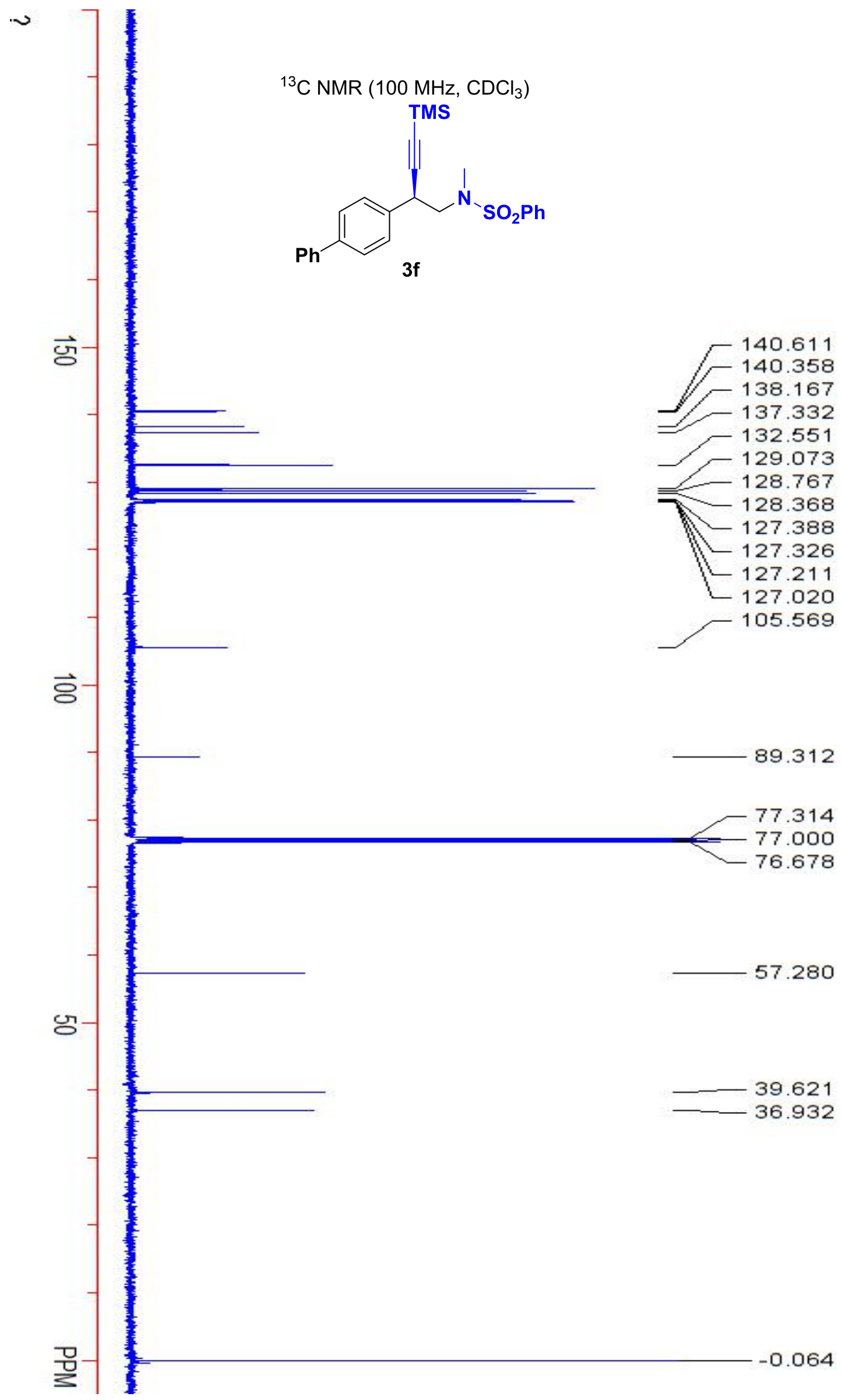




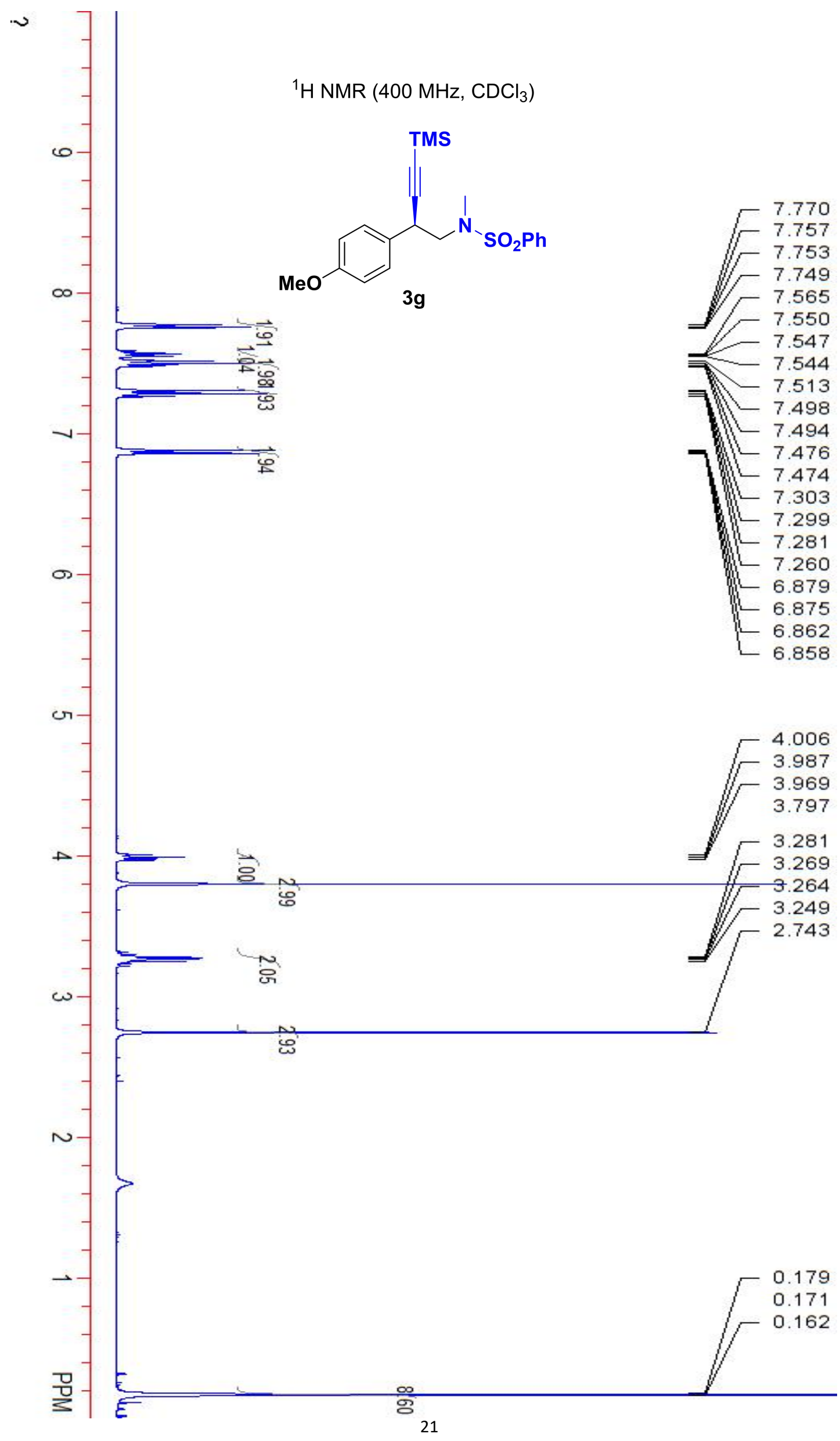




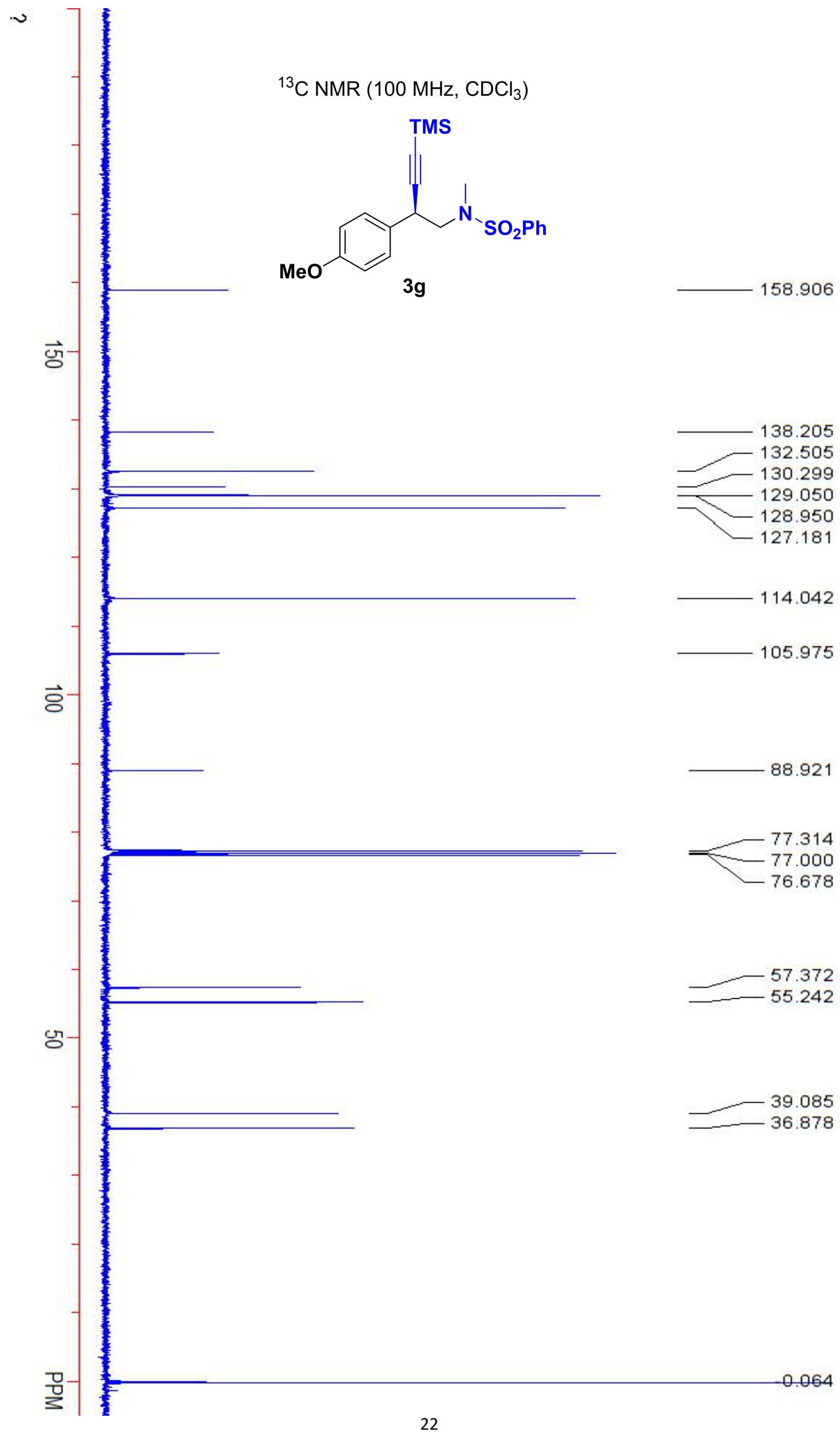




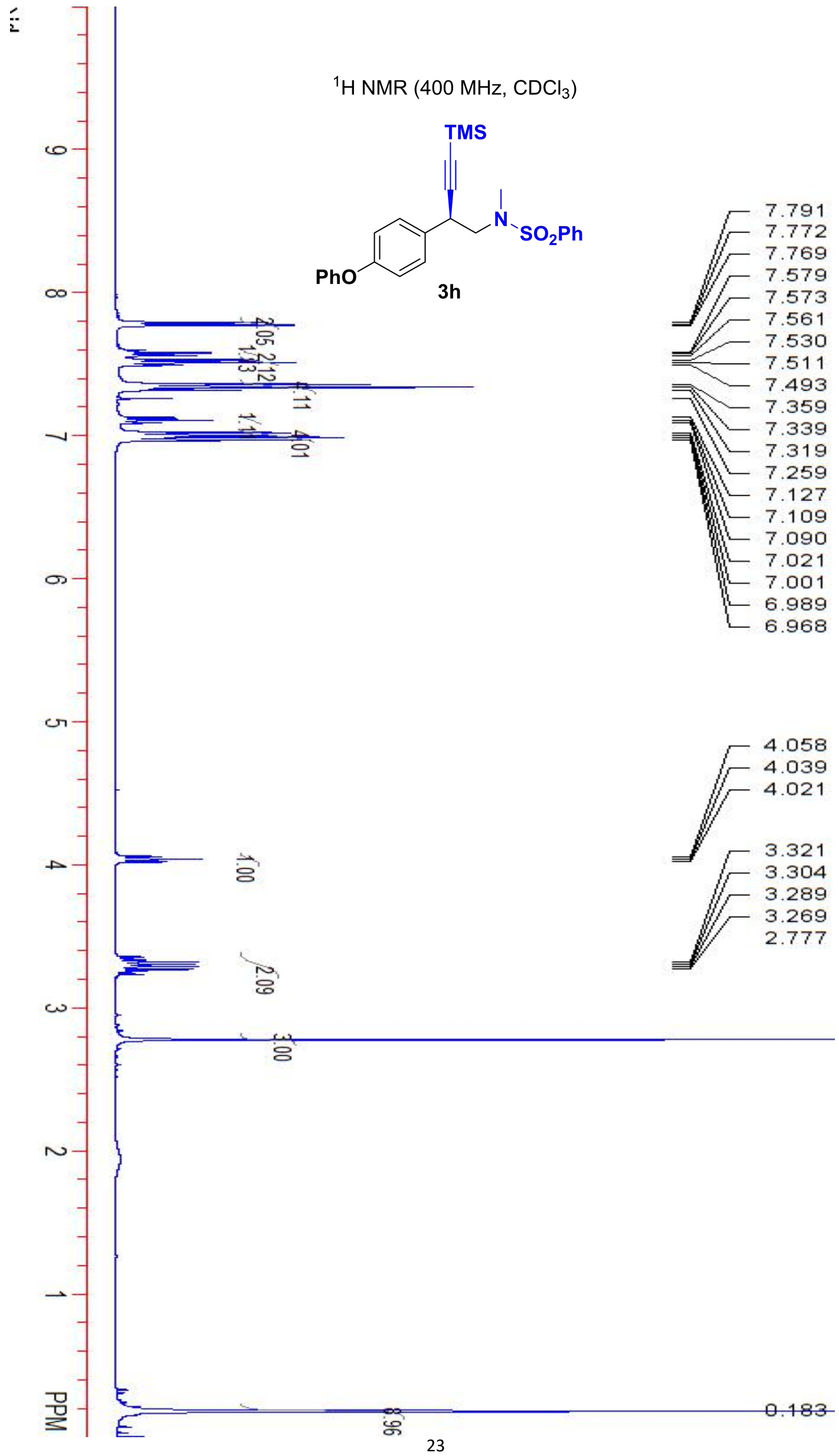




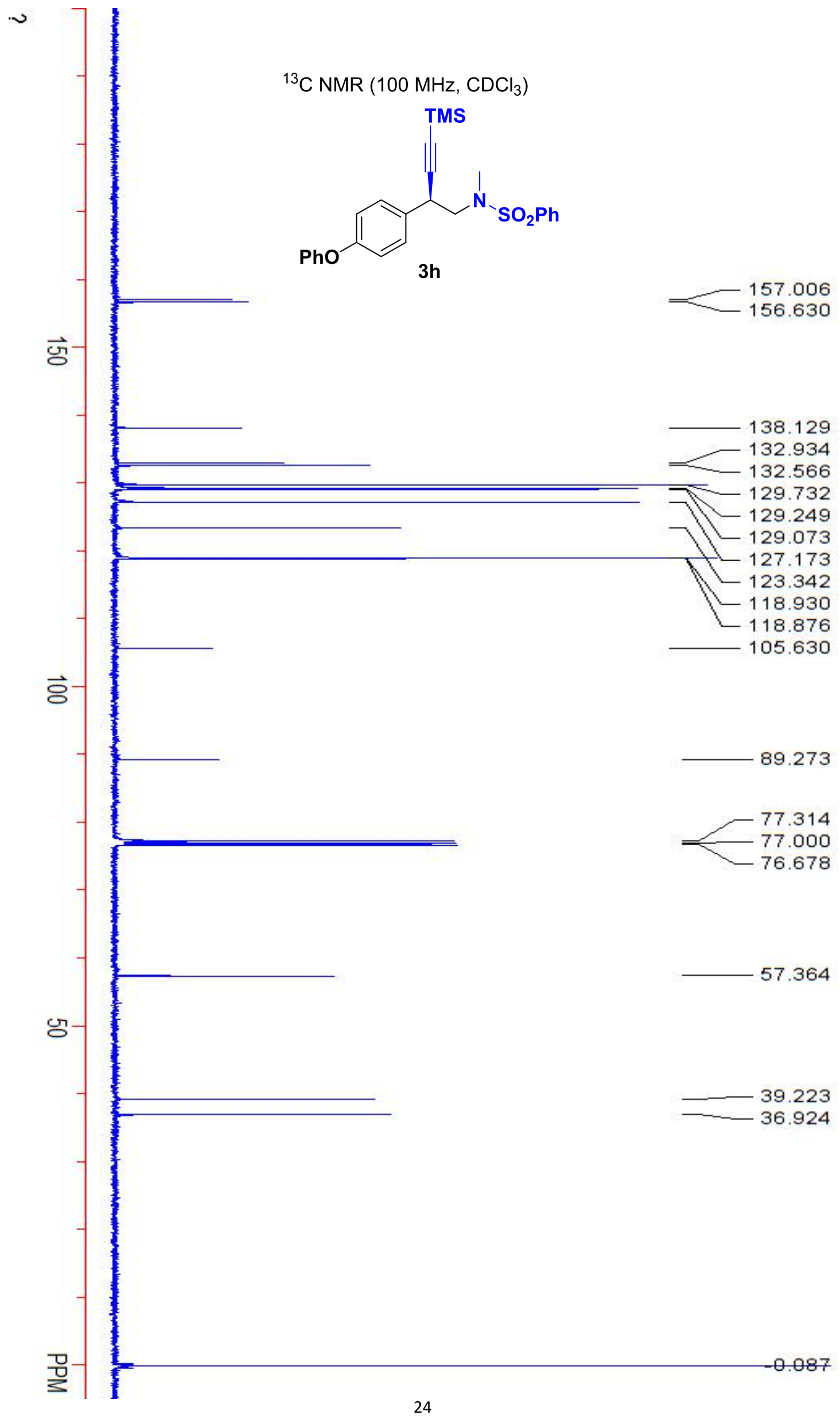




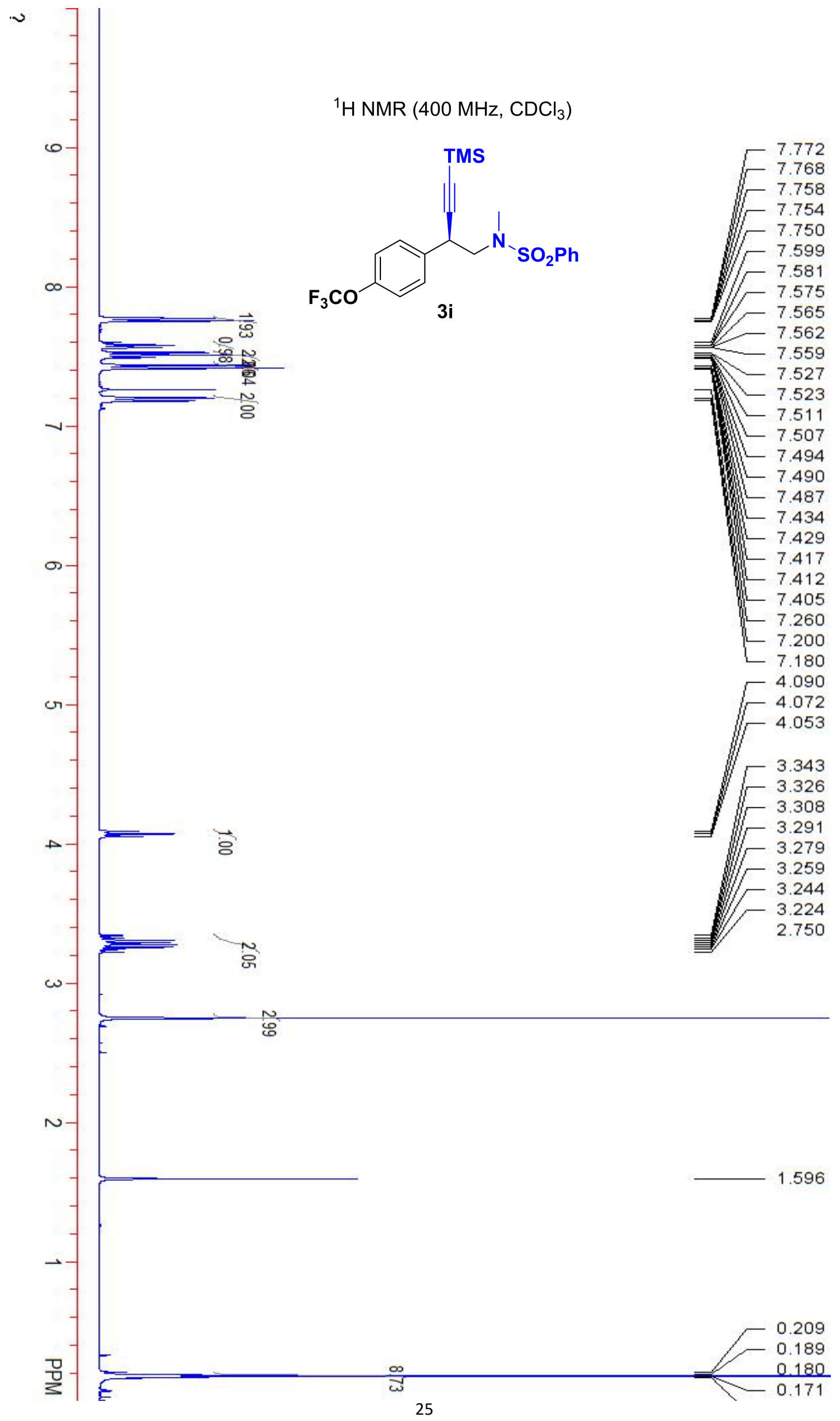




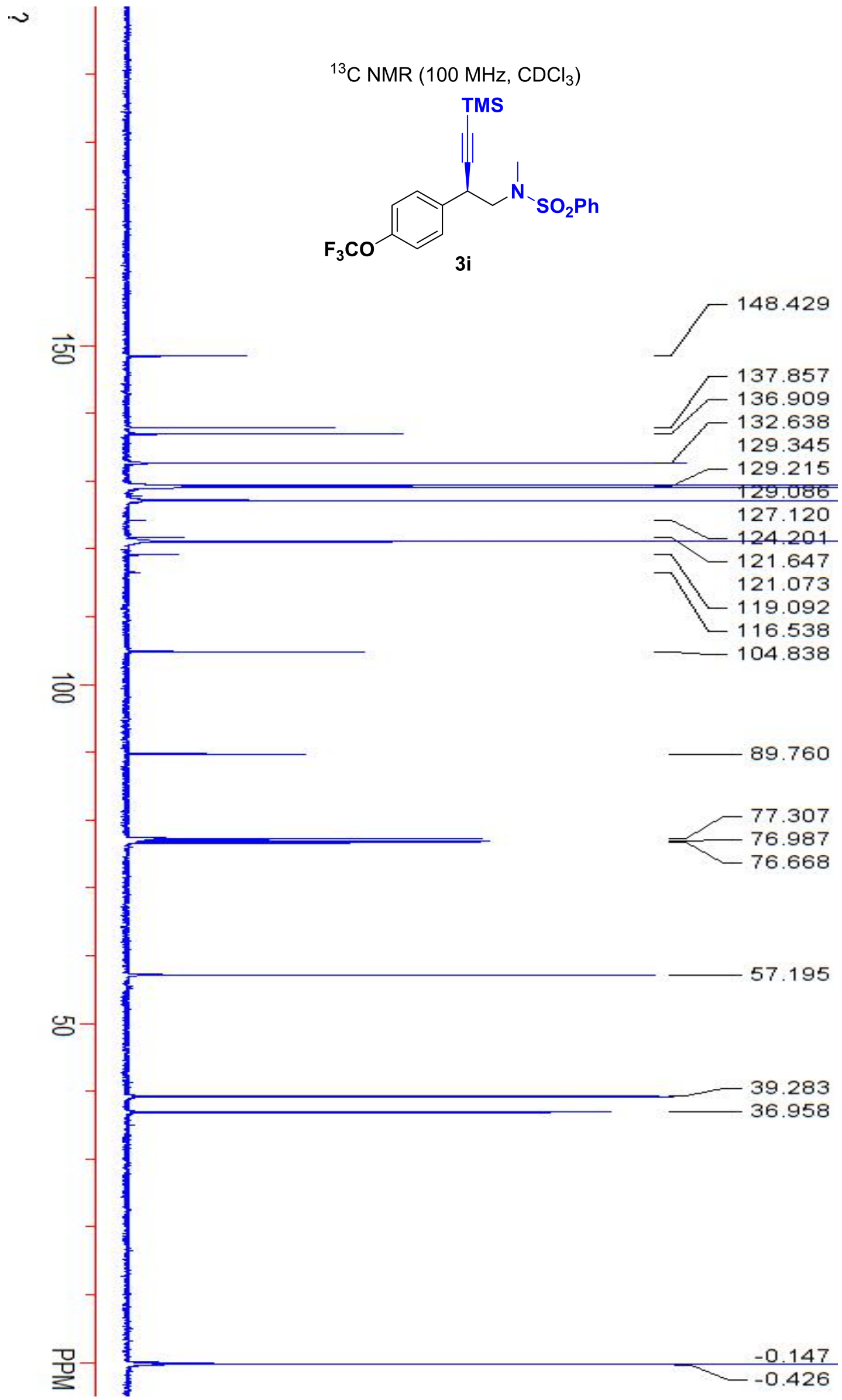




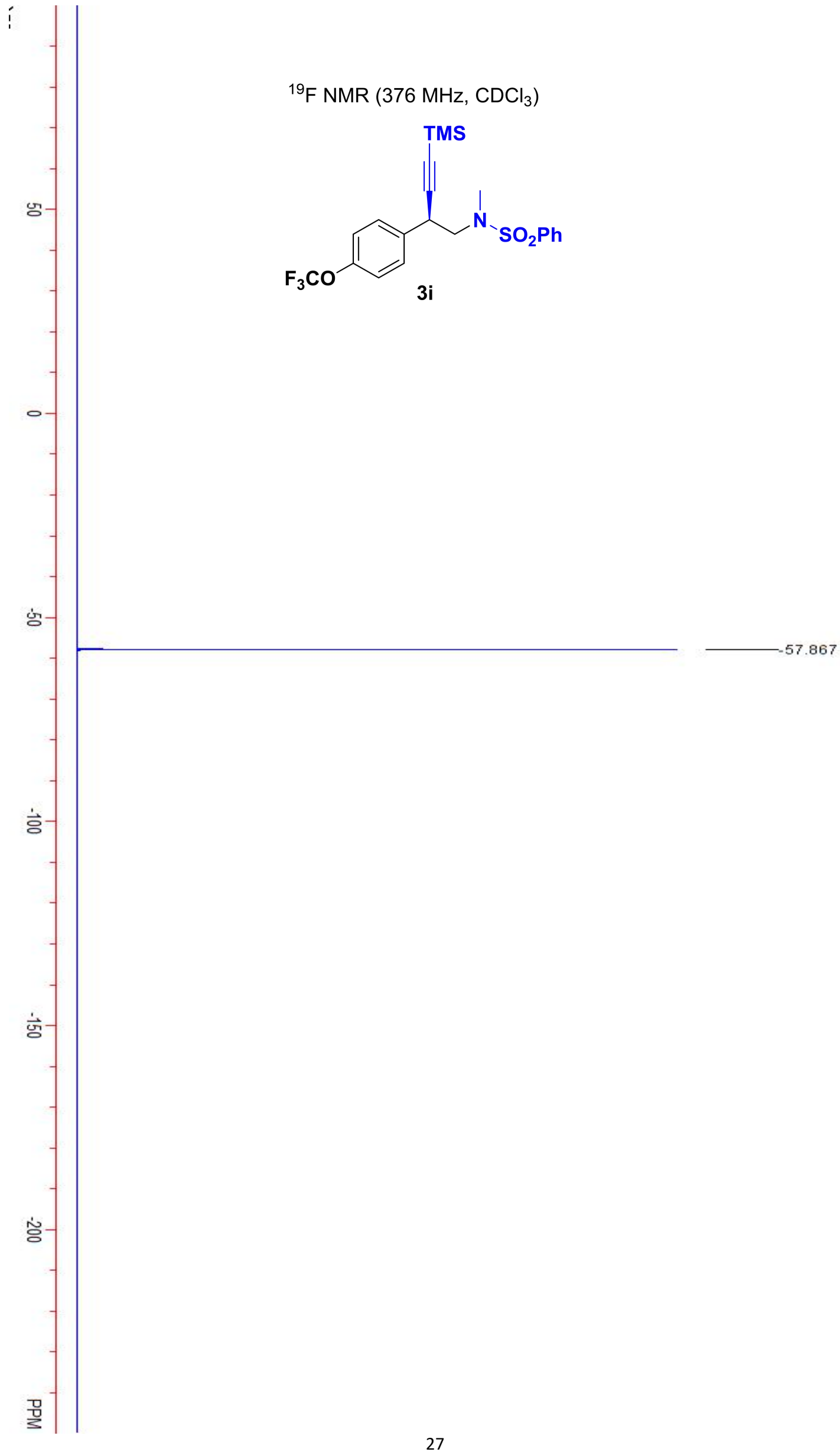




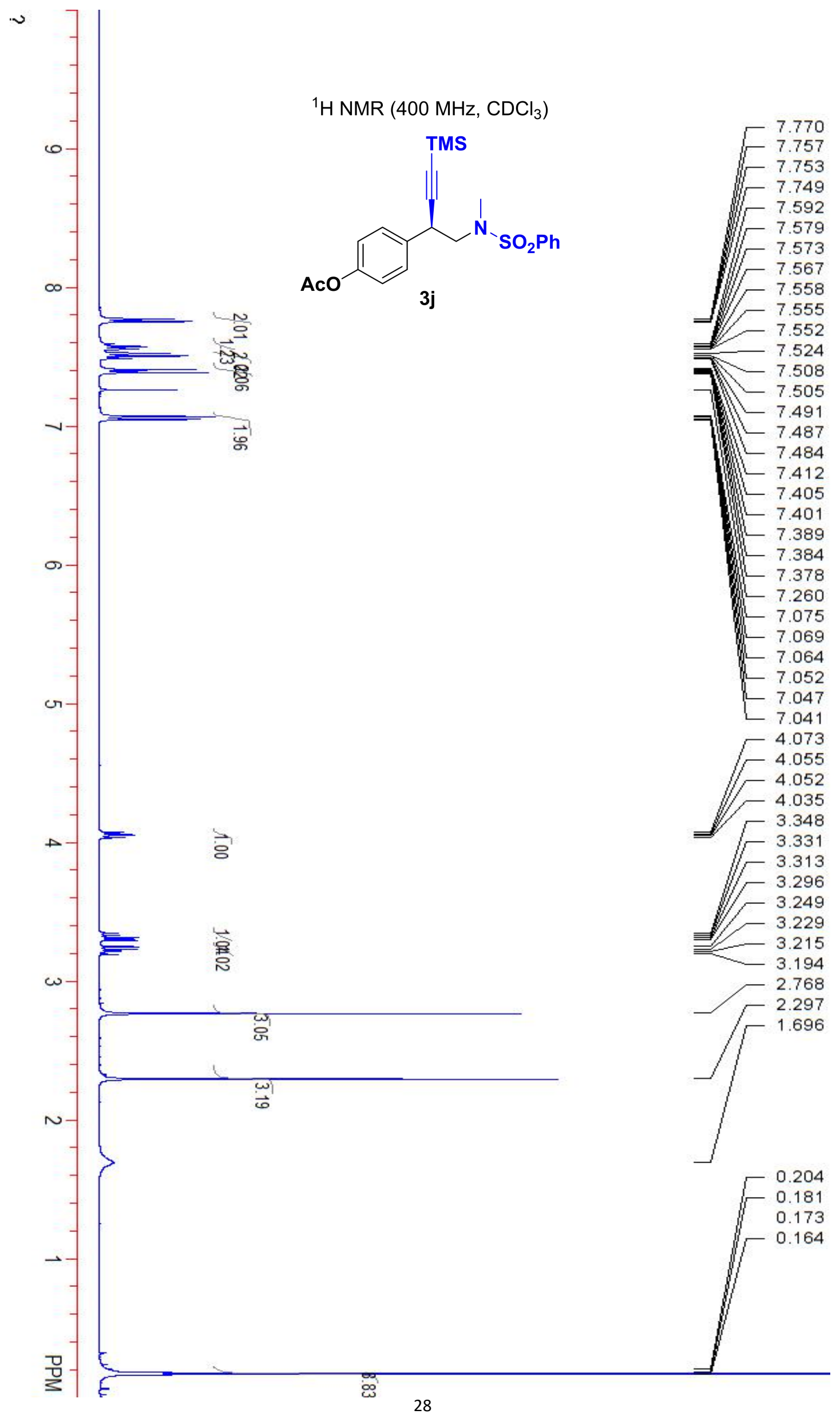




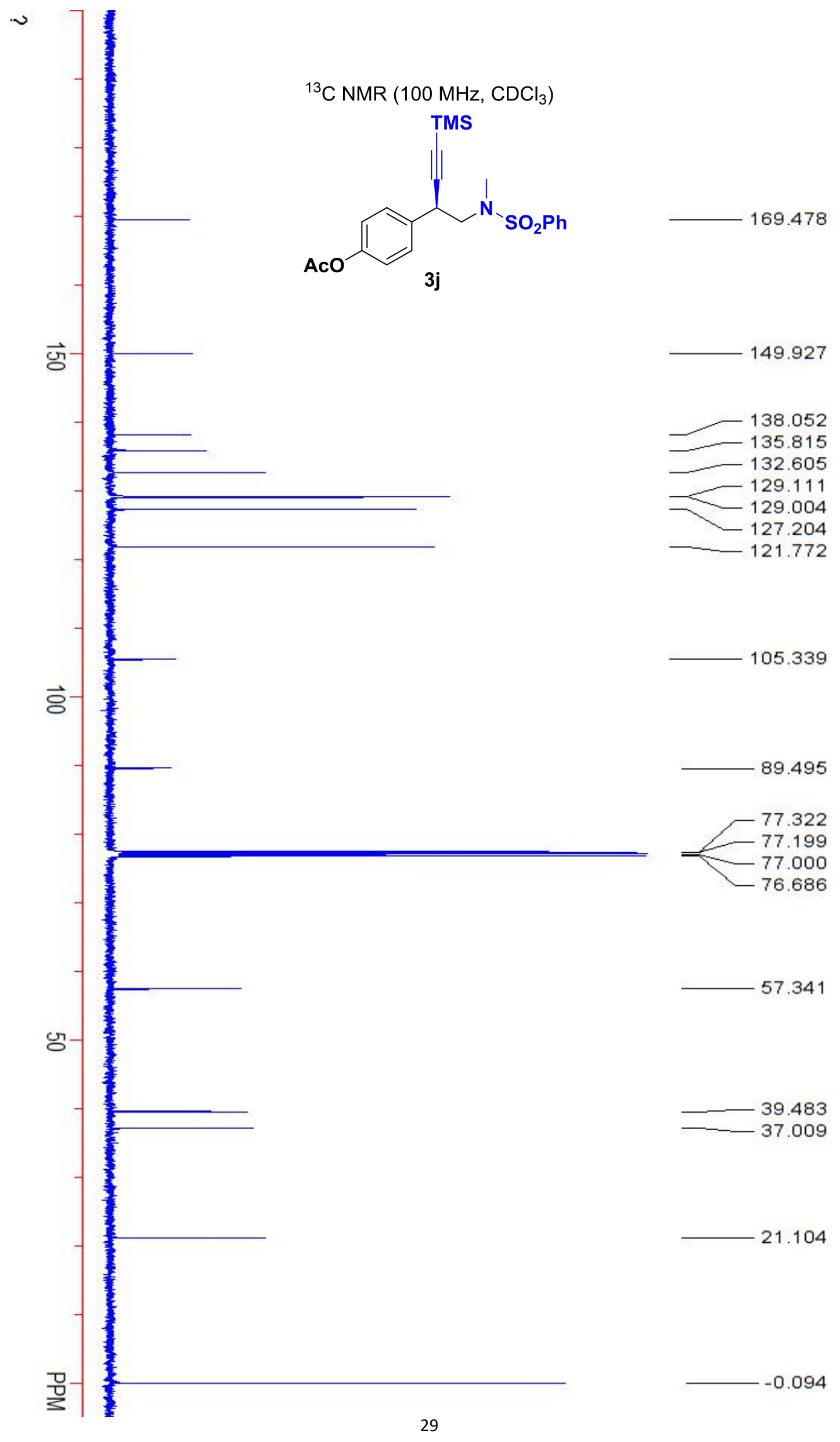




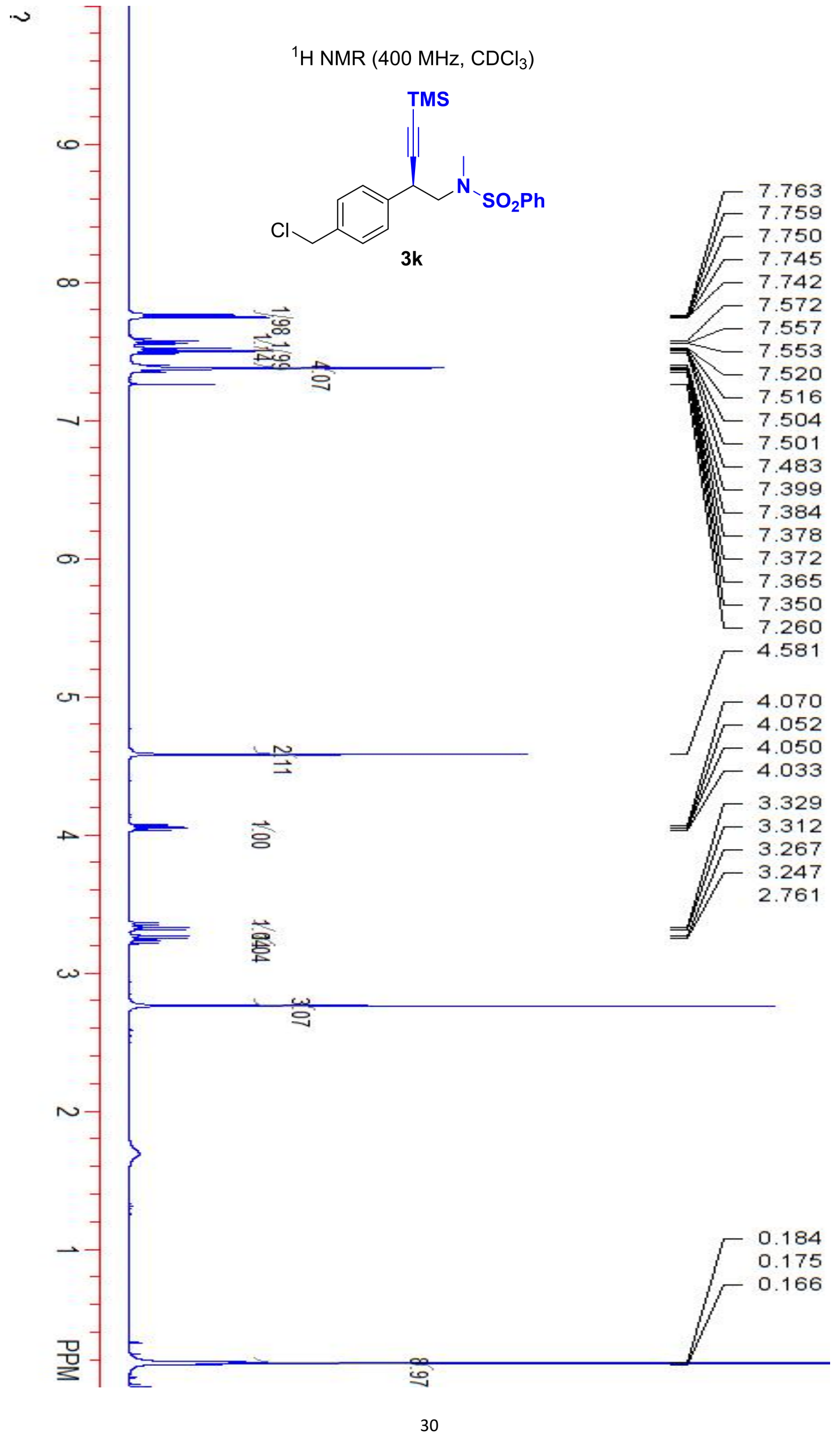




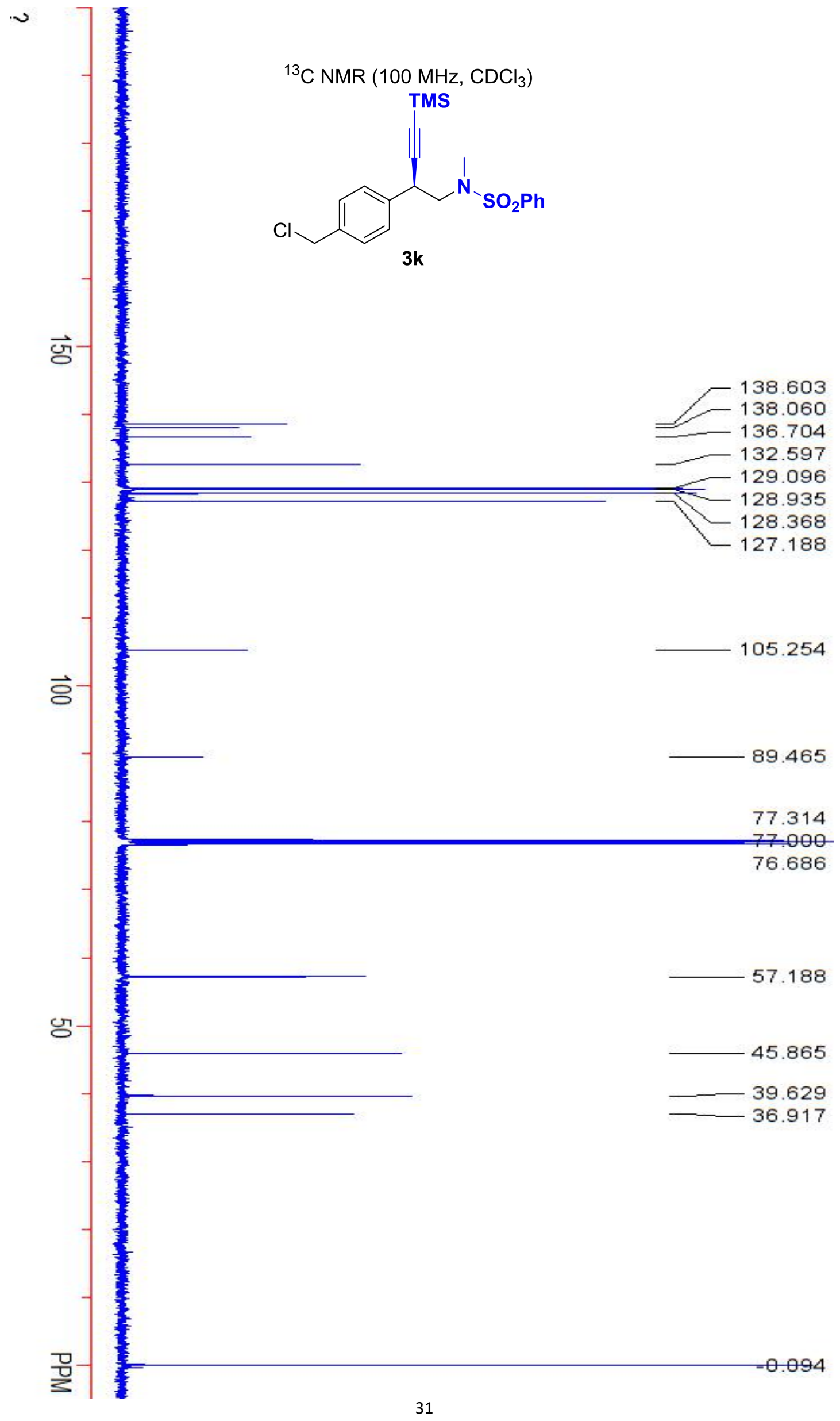




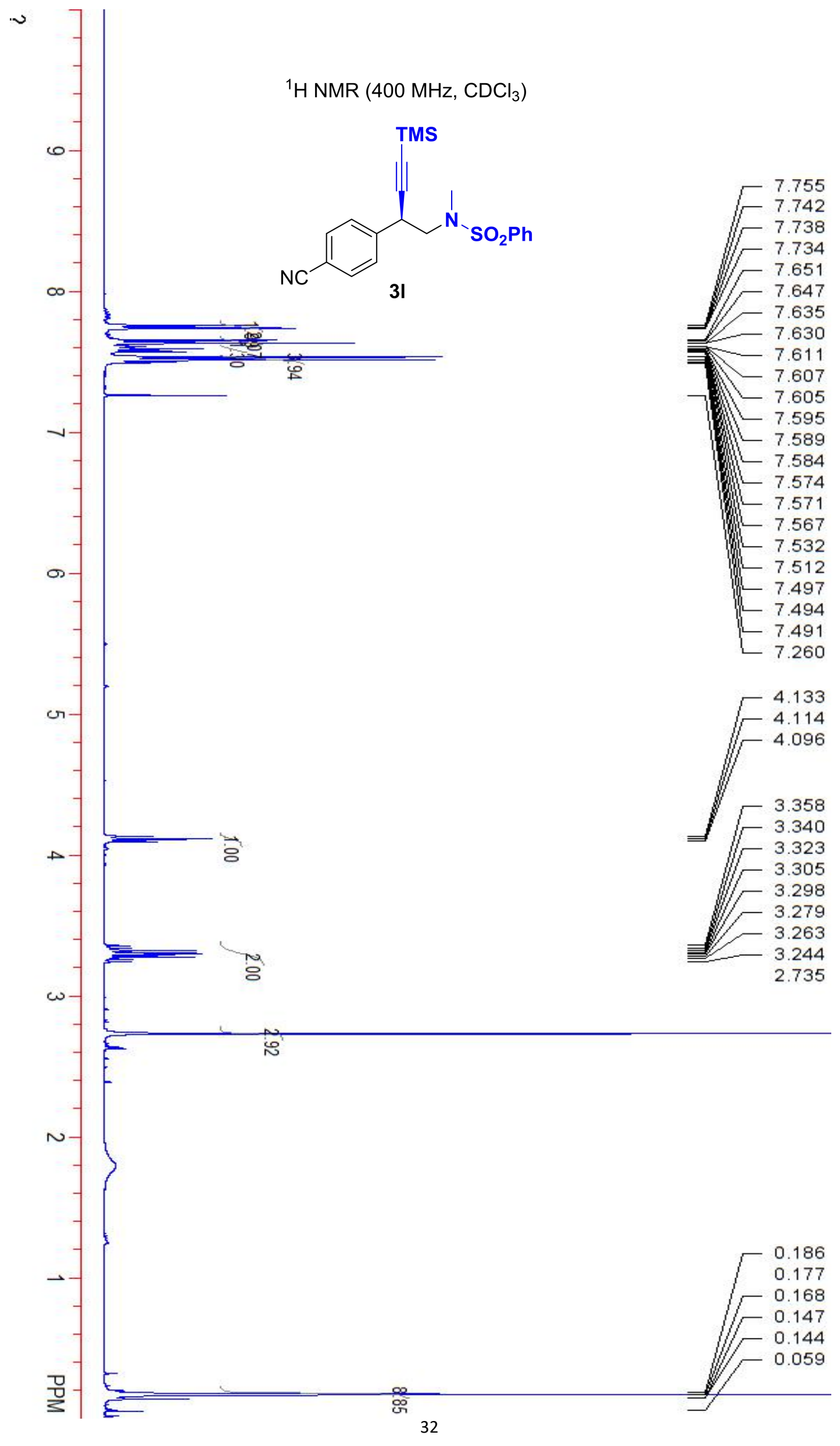




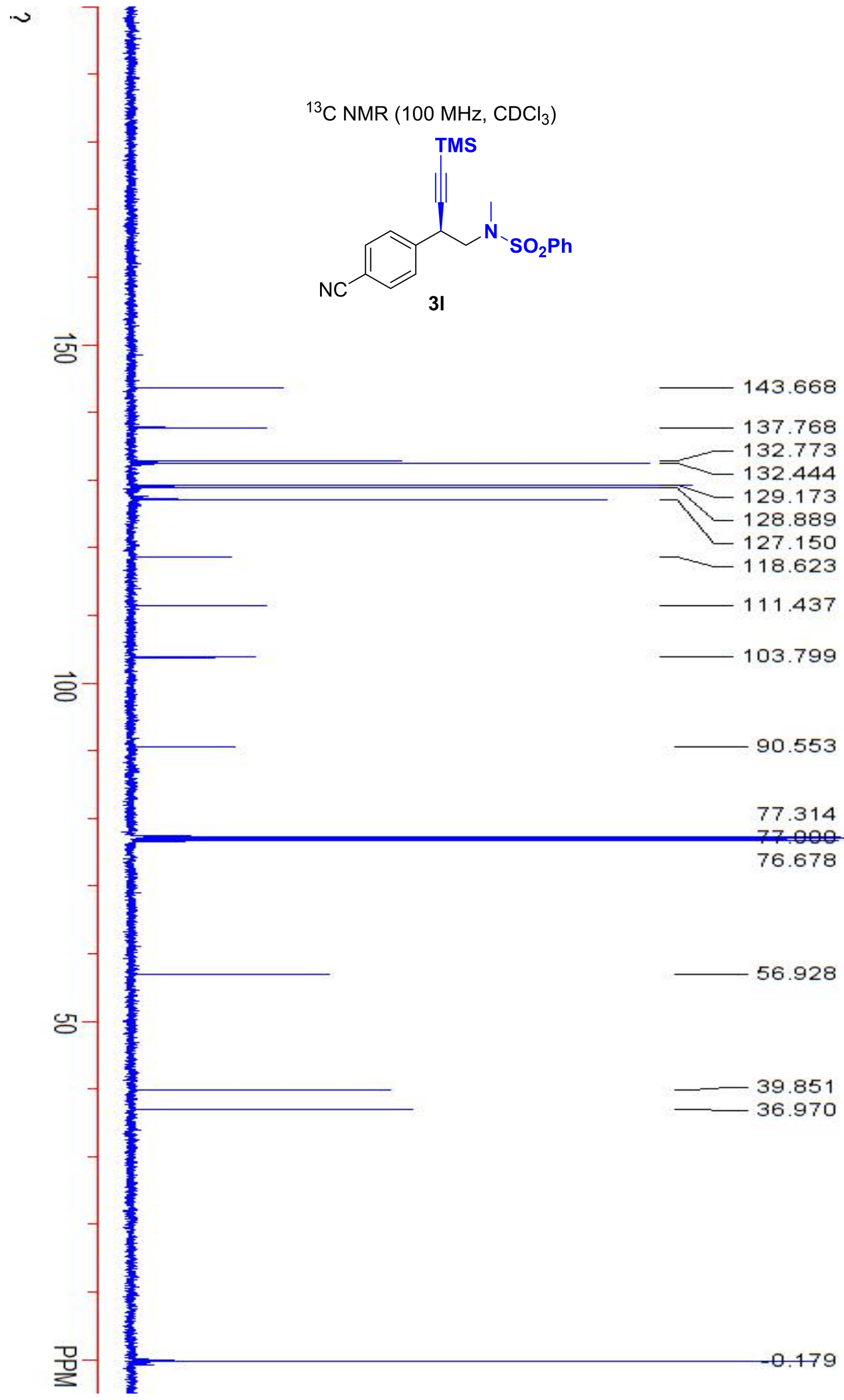




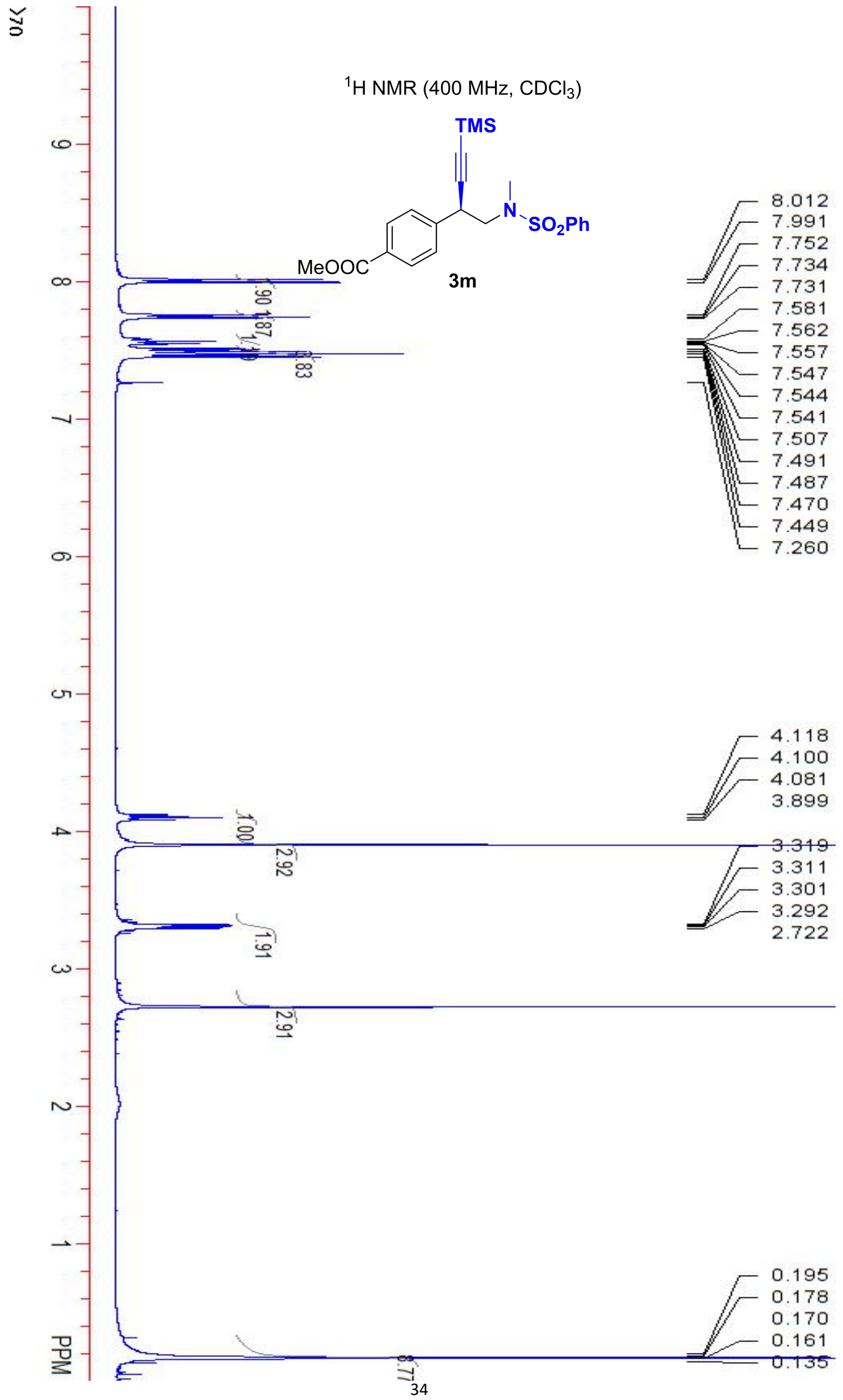




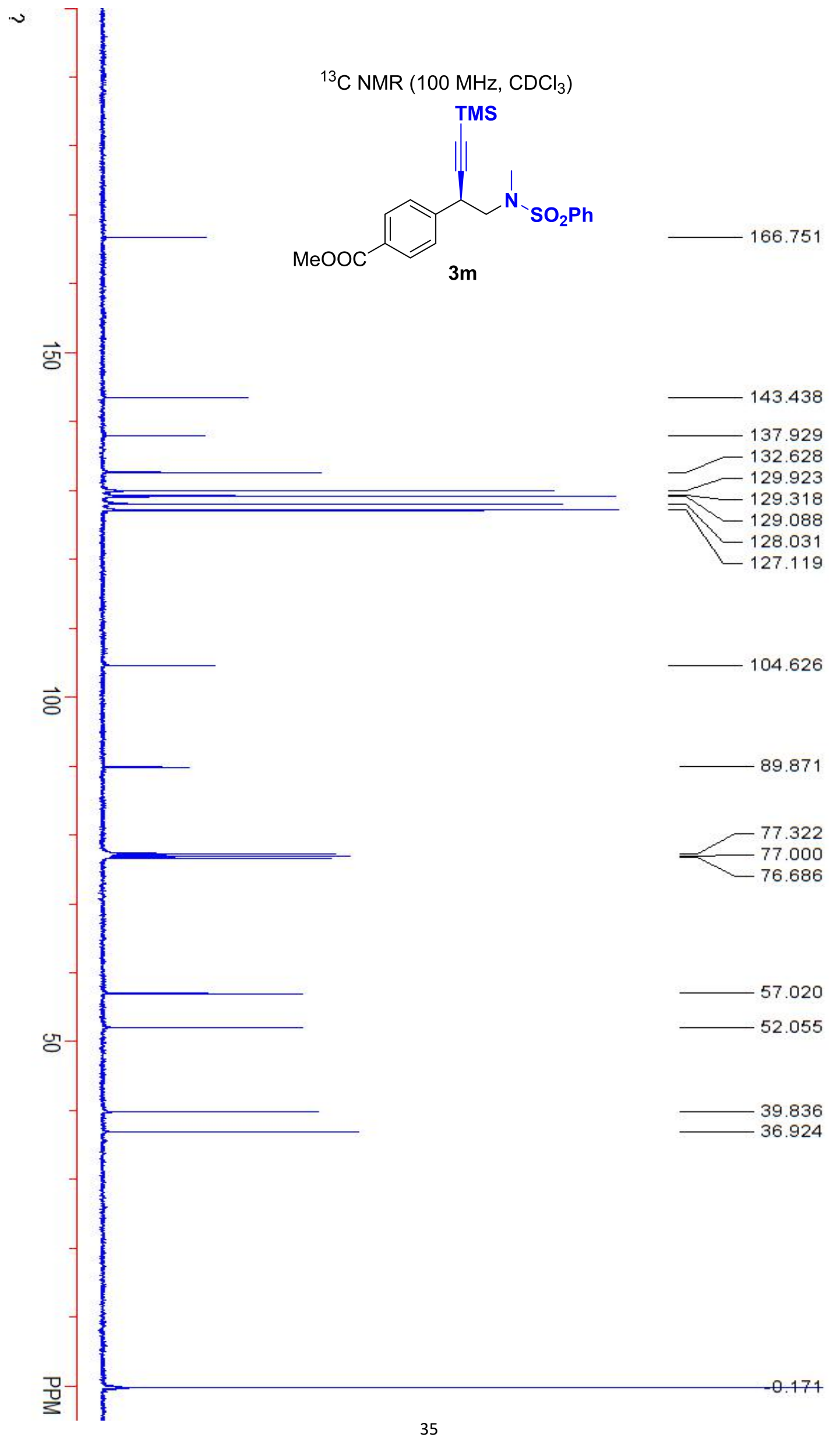




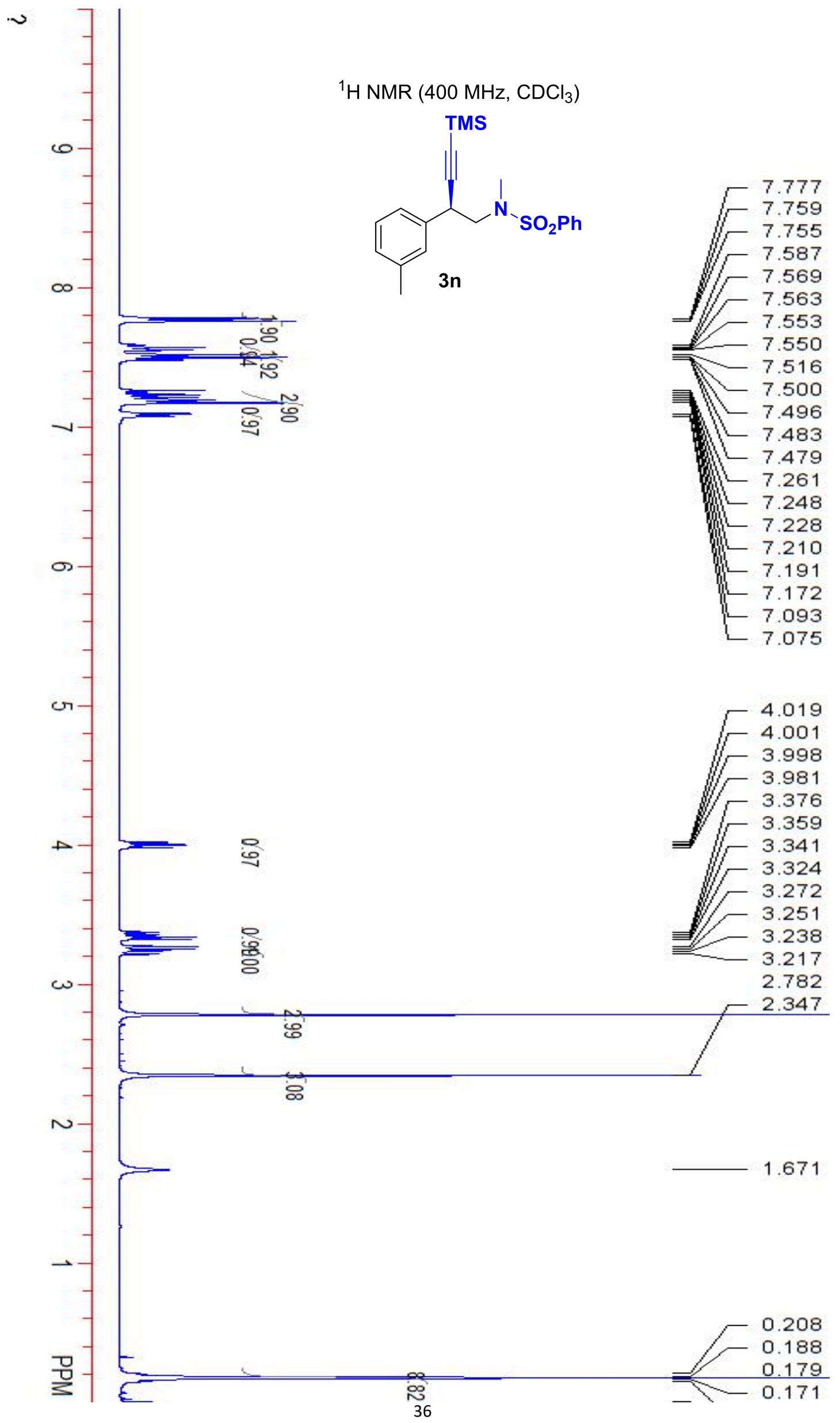




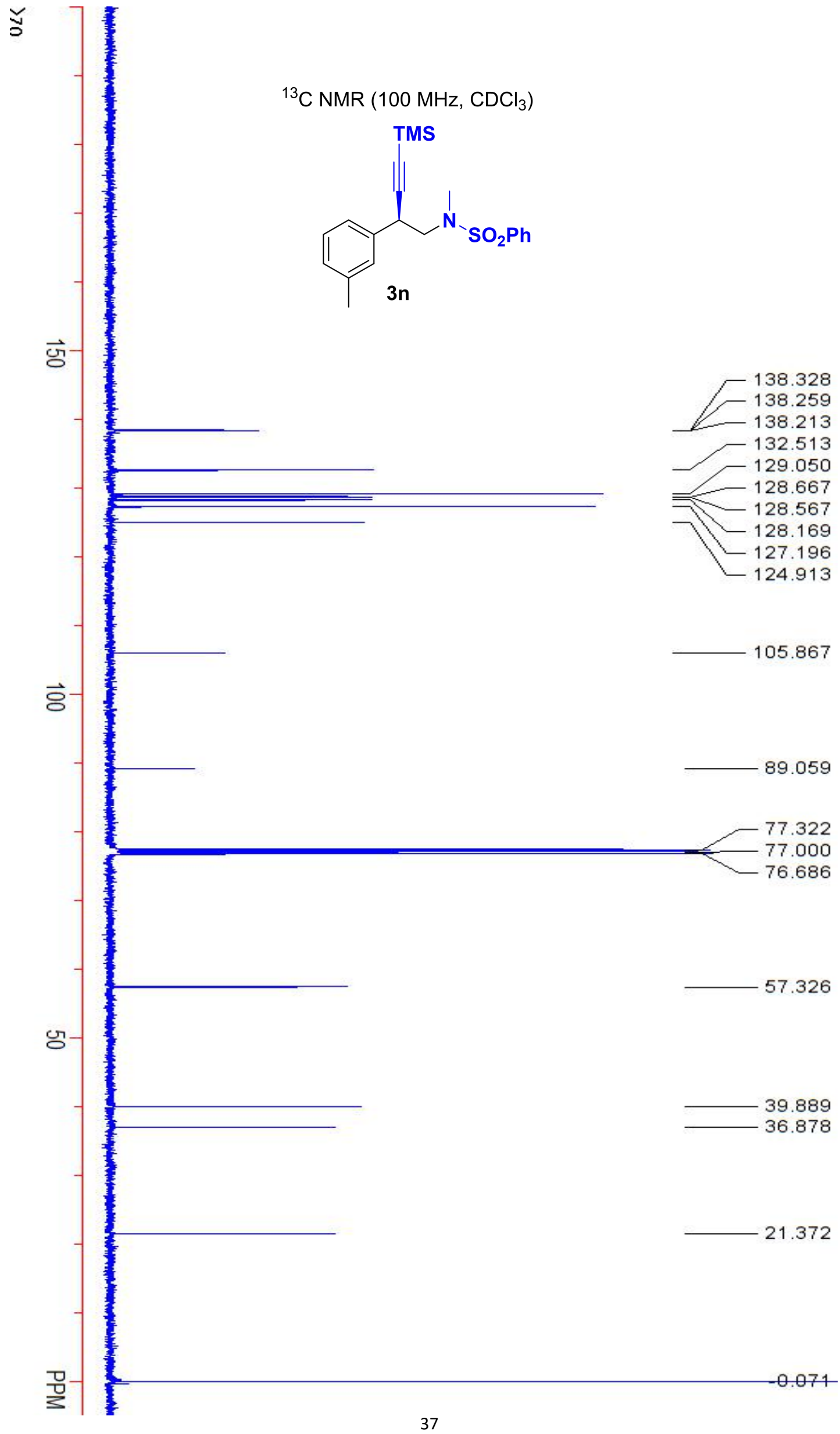




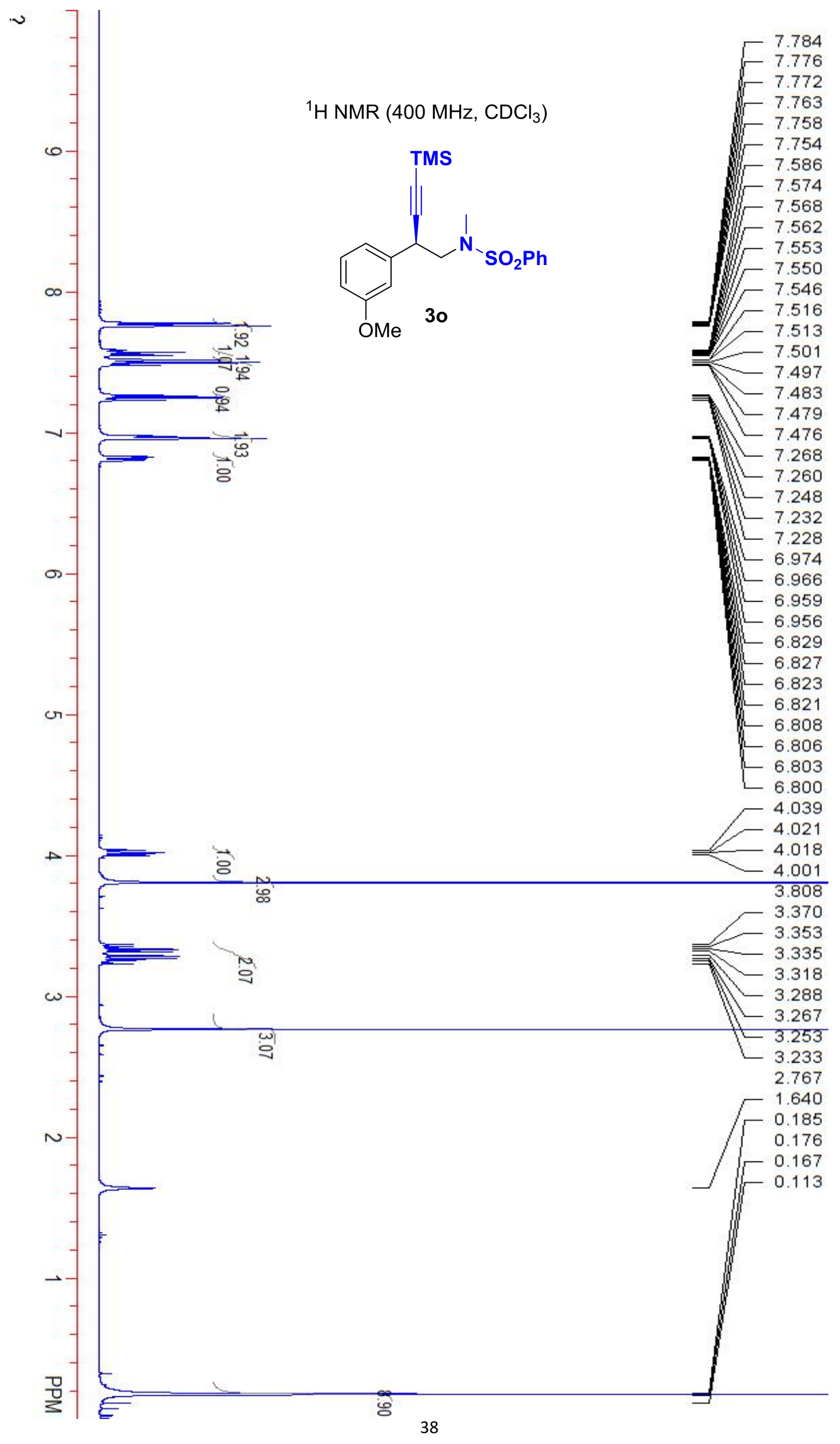




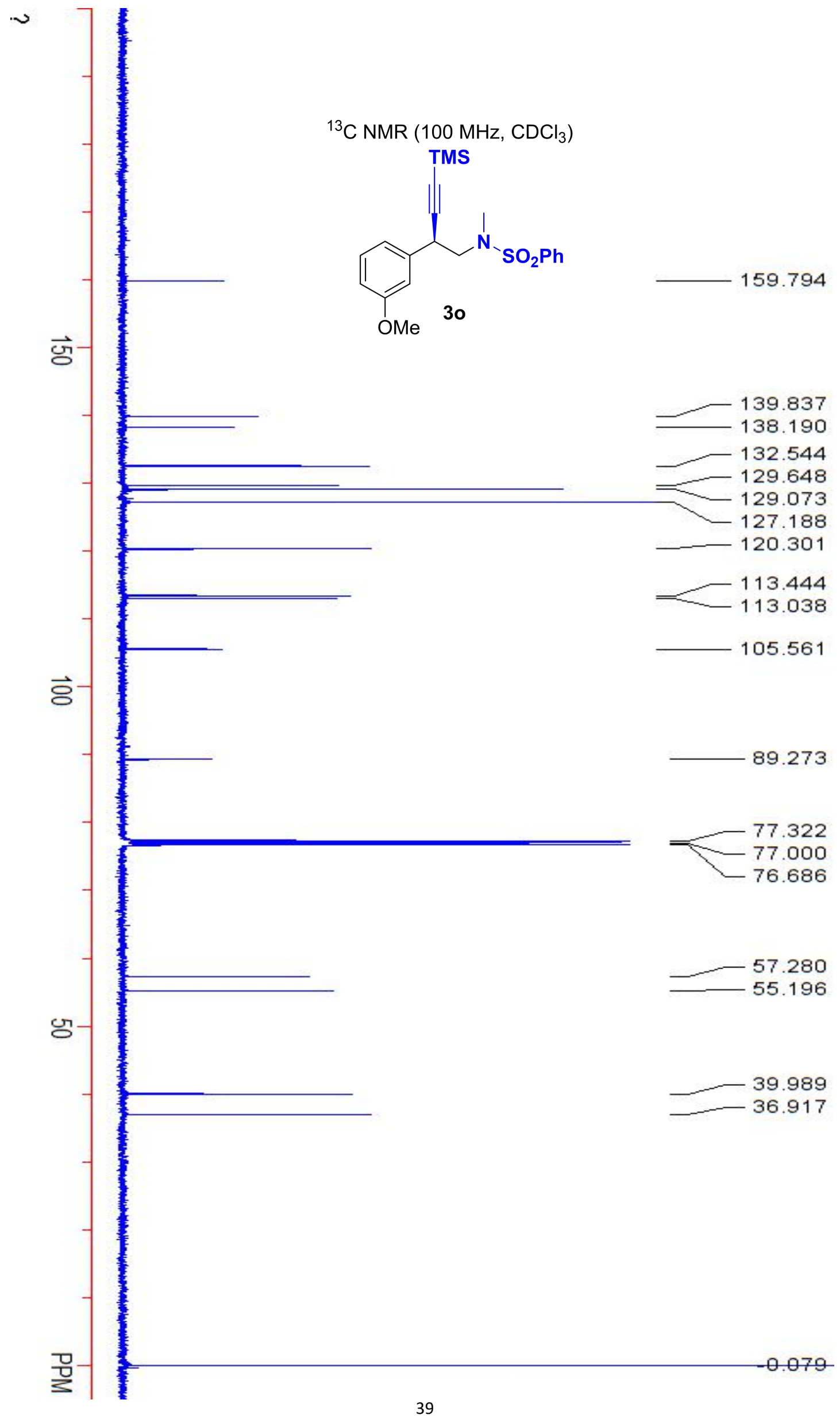




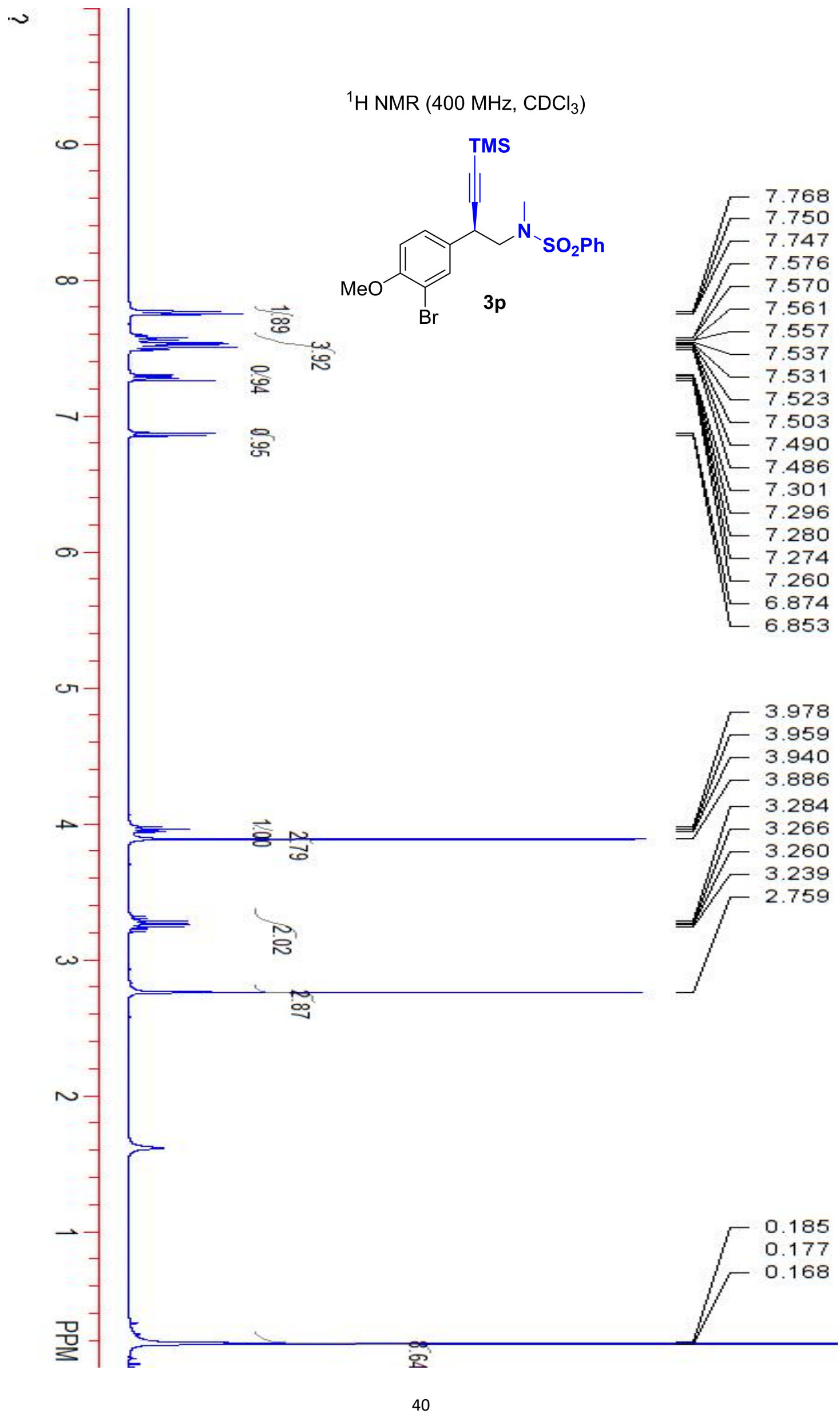


$\check{~}$

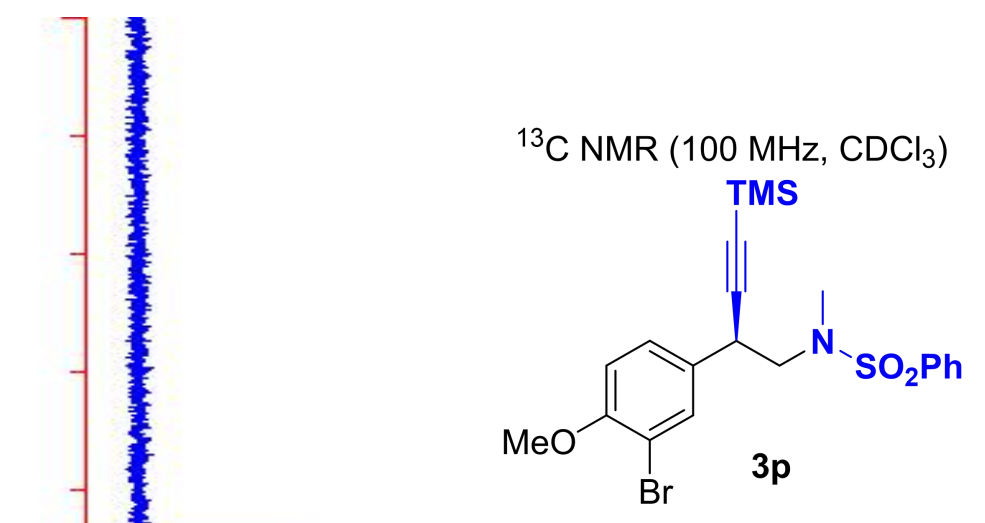

155.213

$\vec{\sigma}$

8

믈

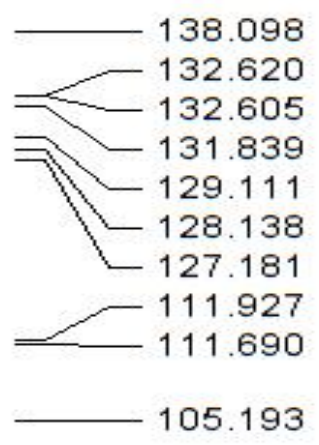

89.641

77.322

77.207

77.000

76.686

57.204

56.261

38.702

36.932

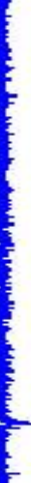

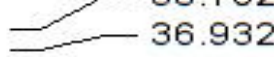

$-0.102$ 


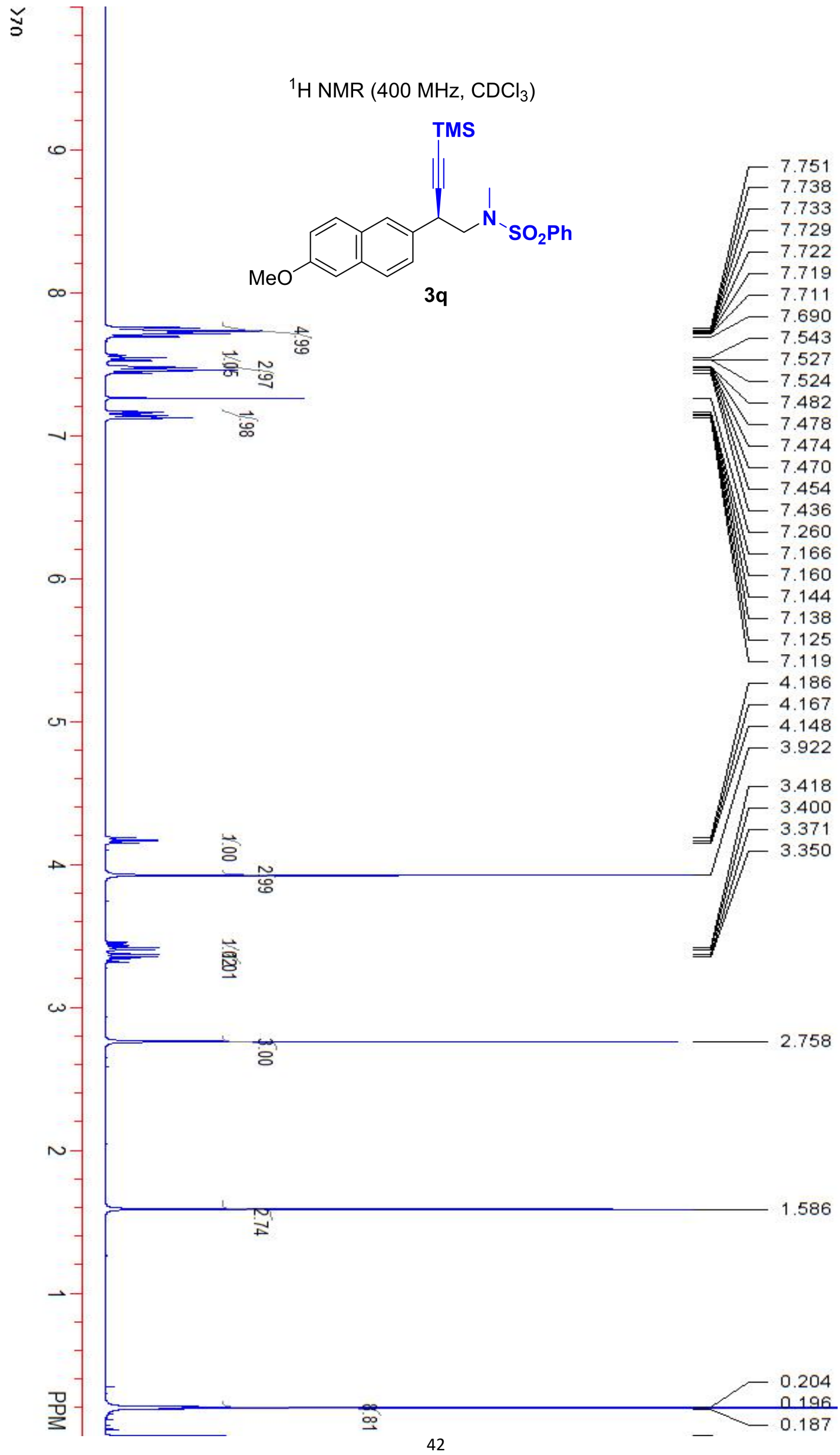




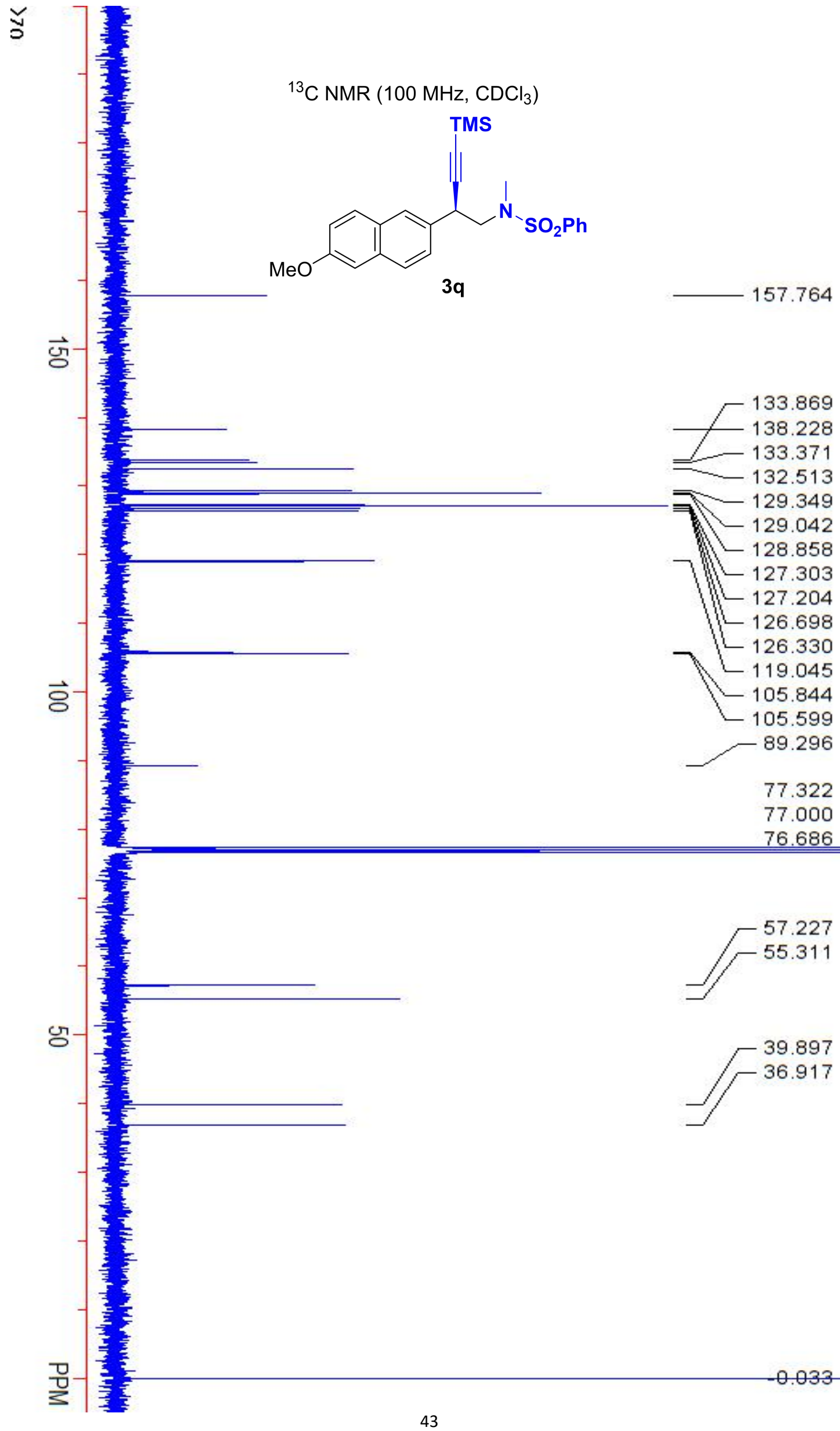




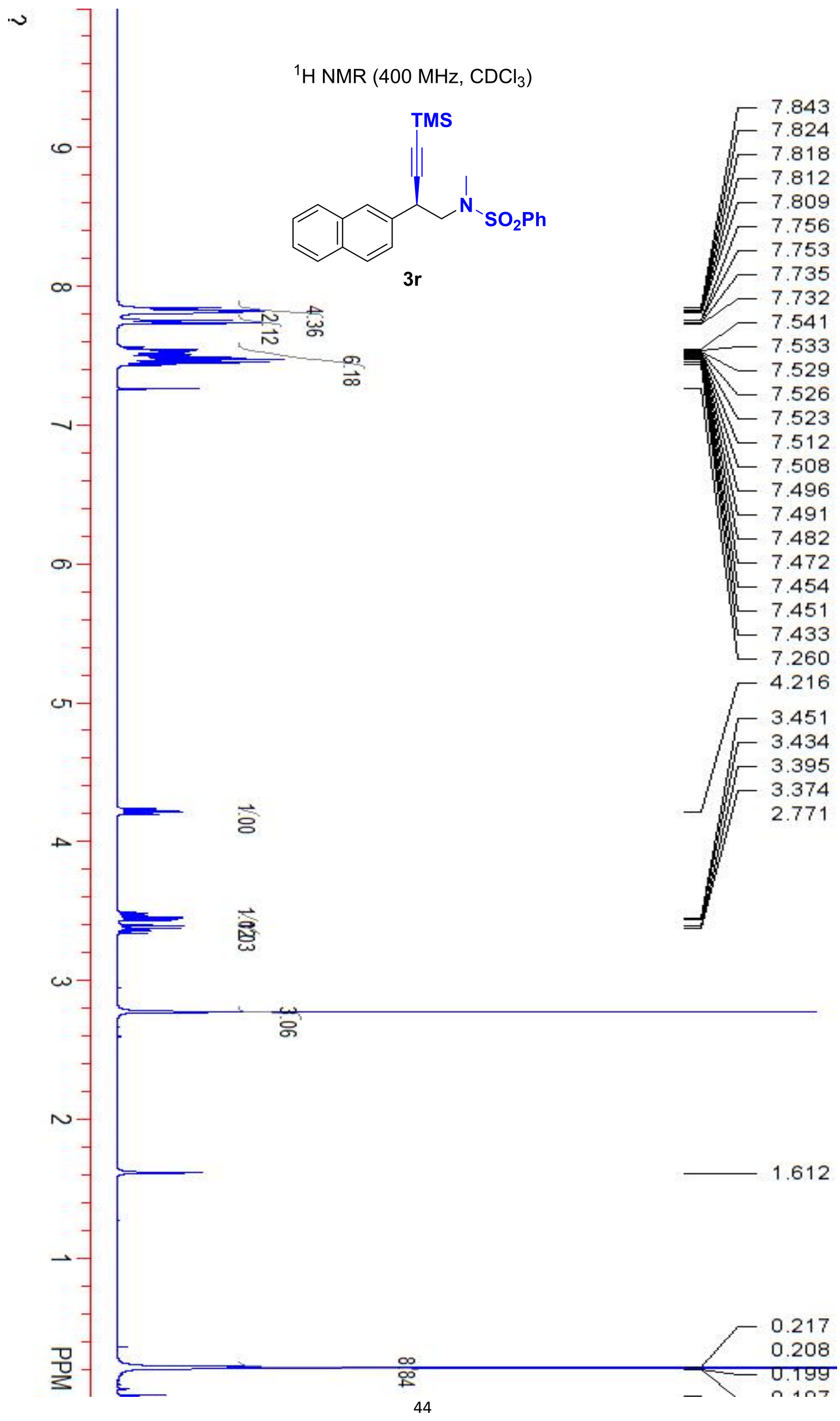




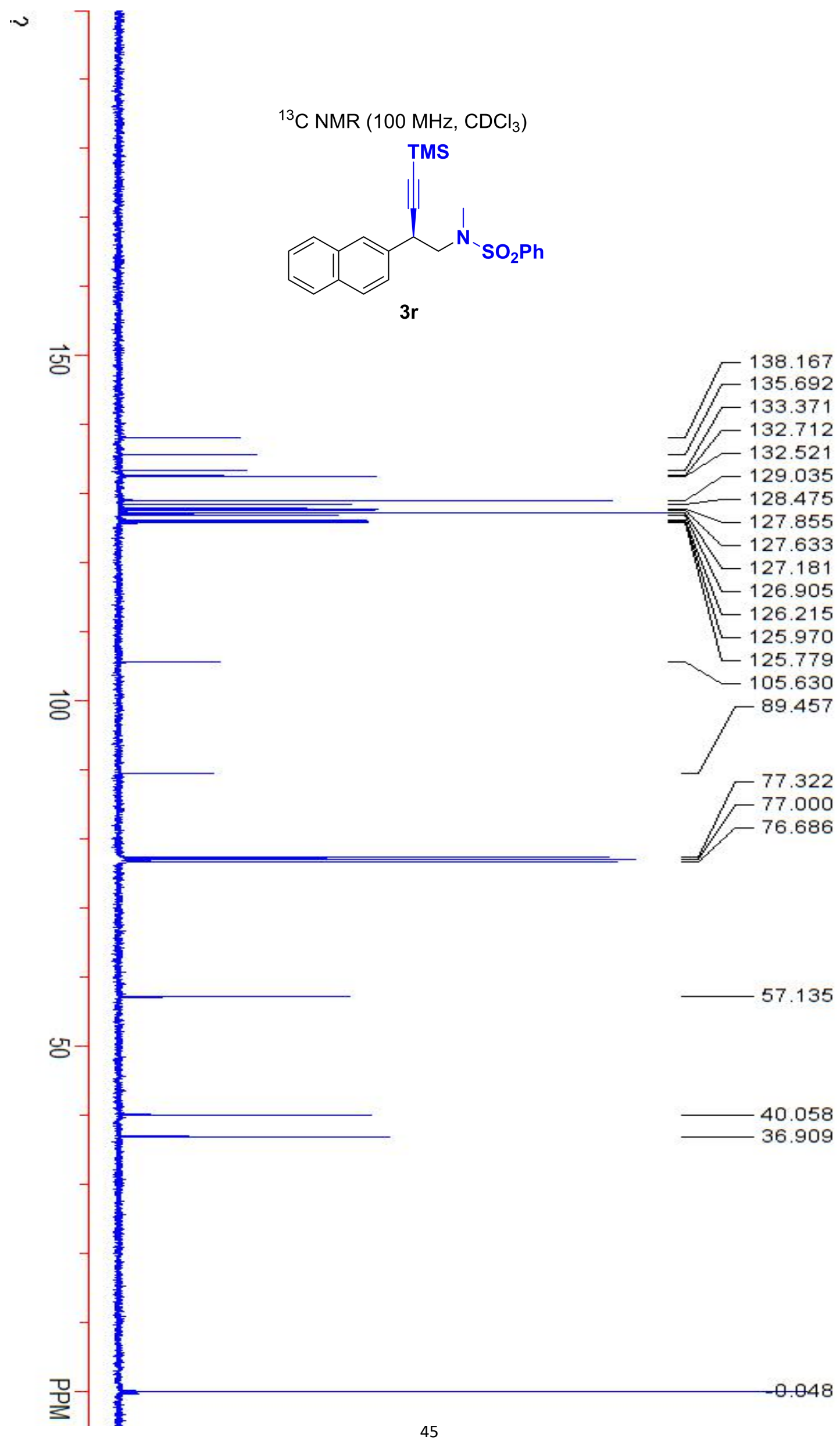




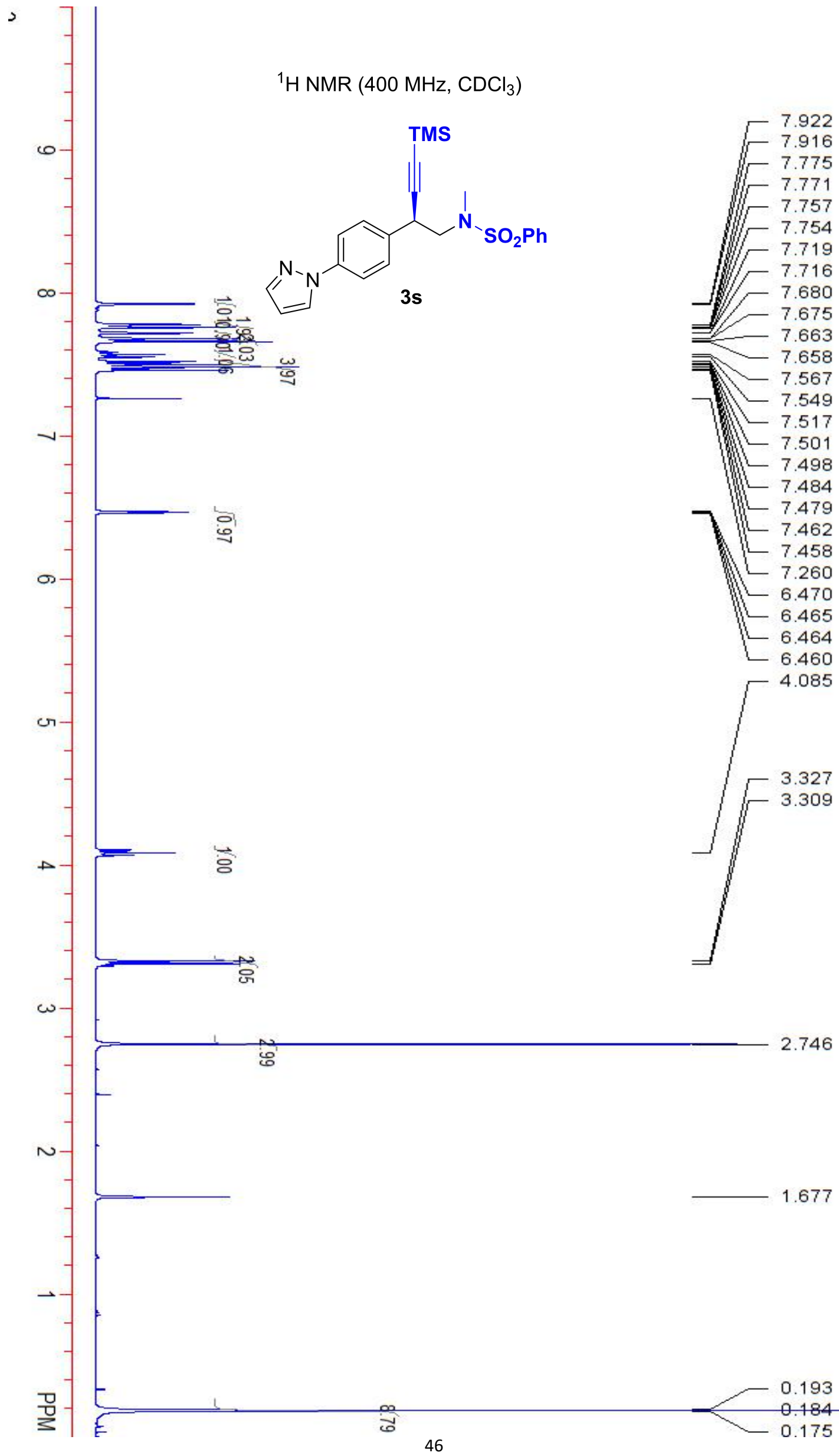


$\check{J}$
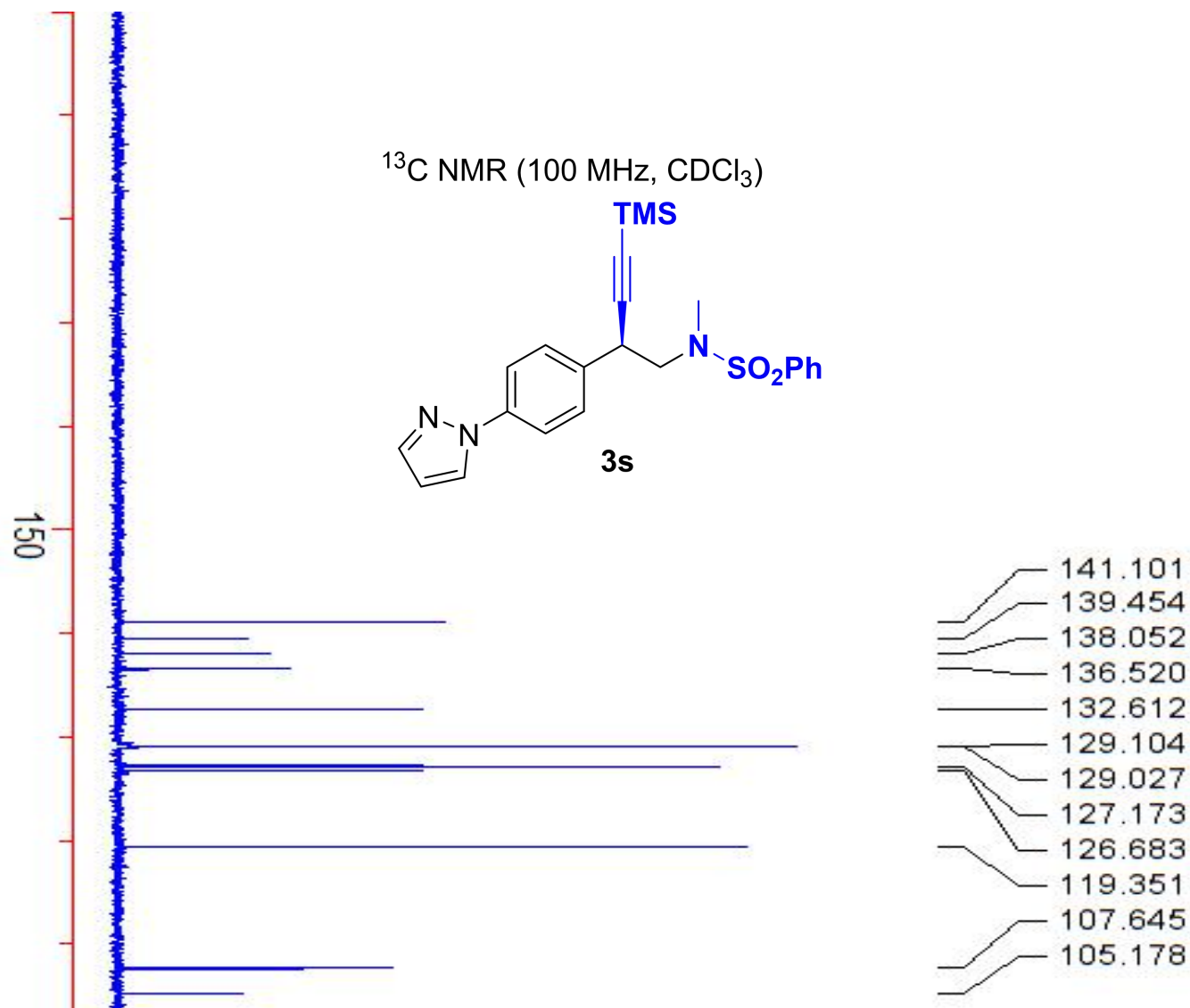

$\overrightarrow{8}$

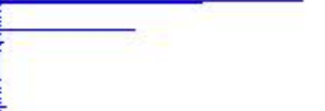

89.580

77.314

77.000

76.678

8

믈 


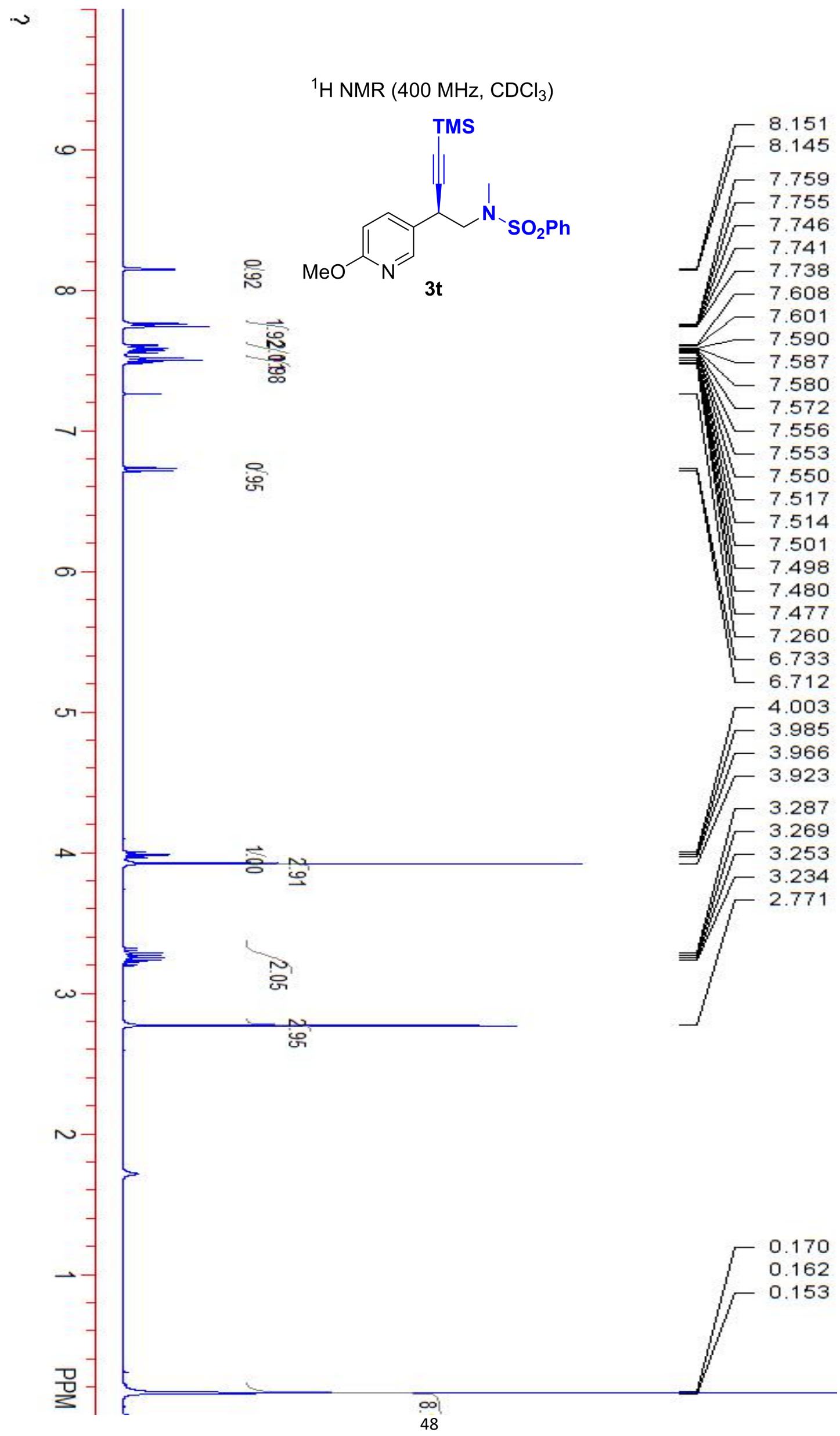




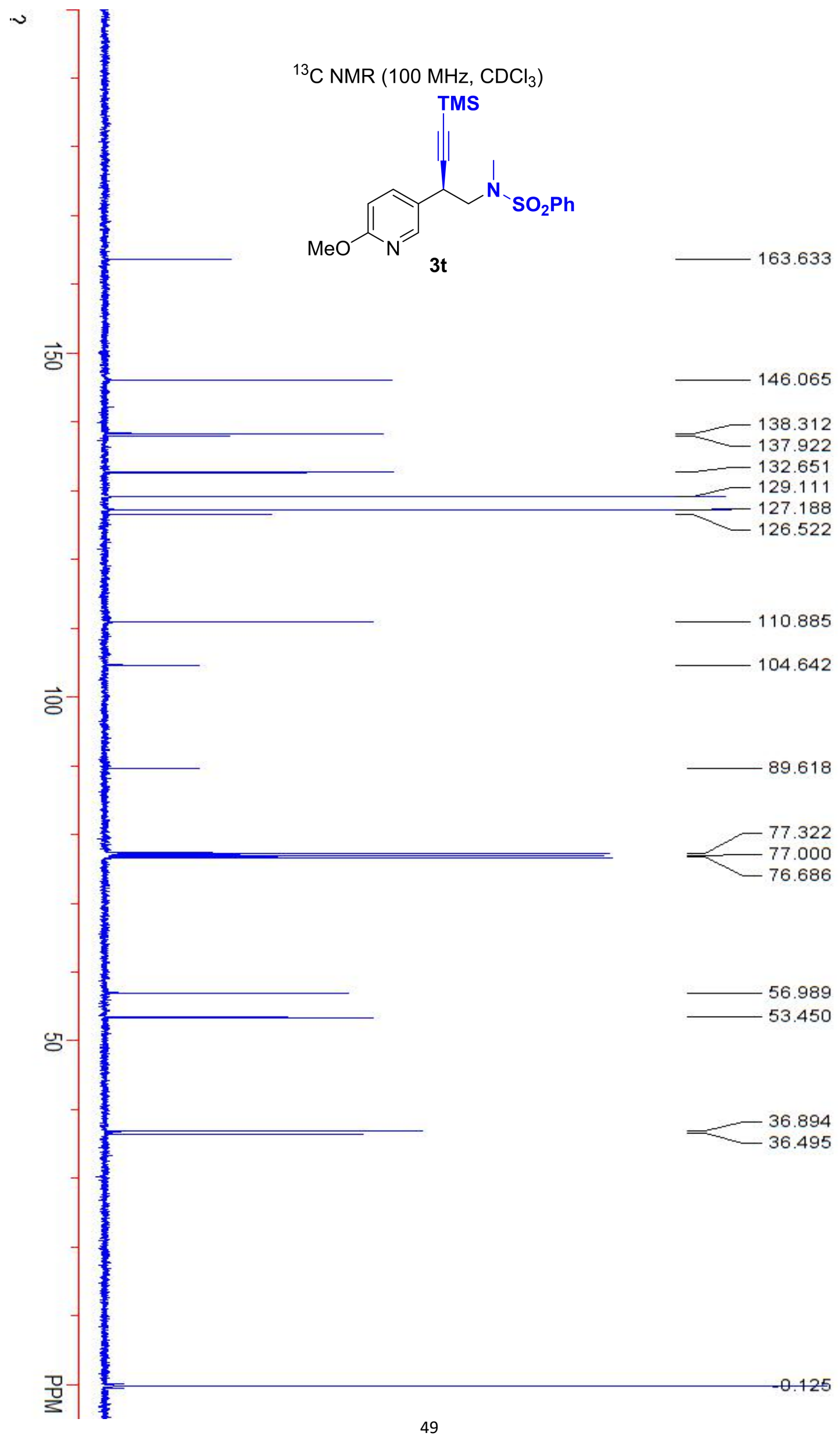




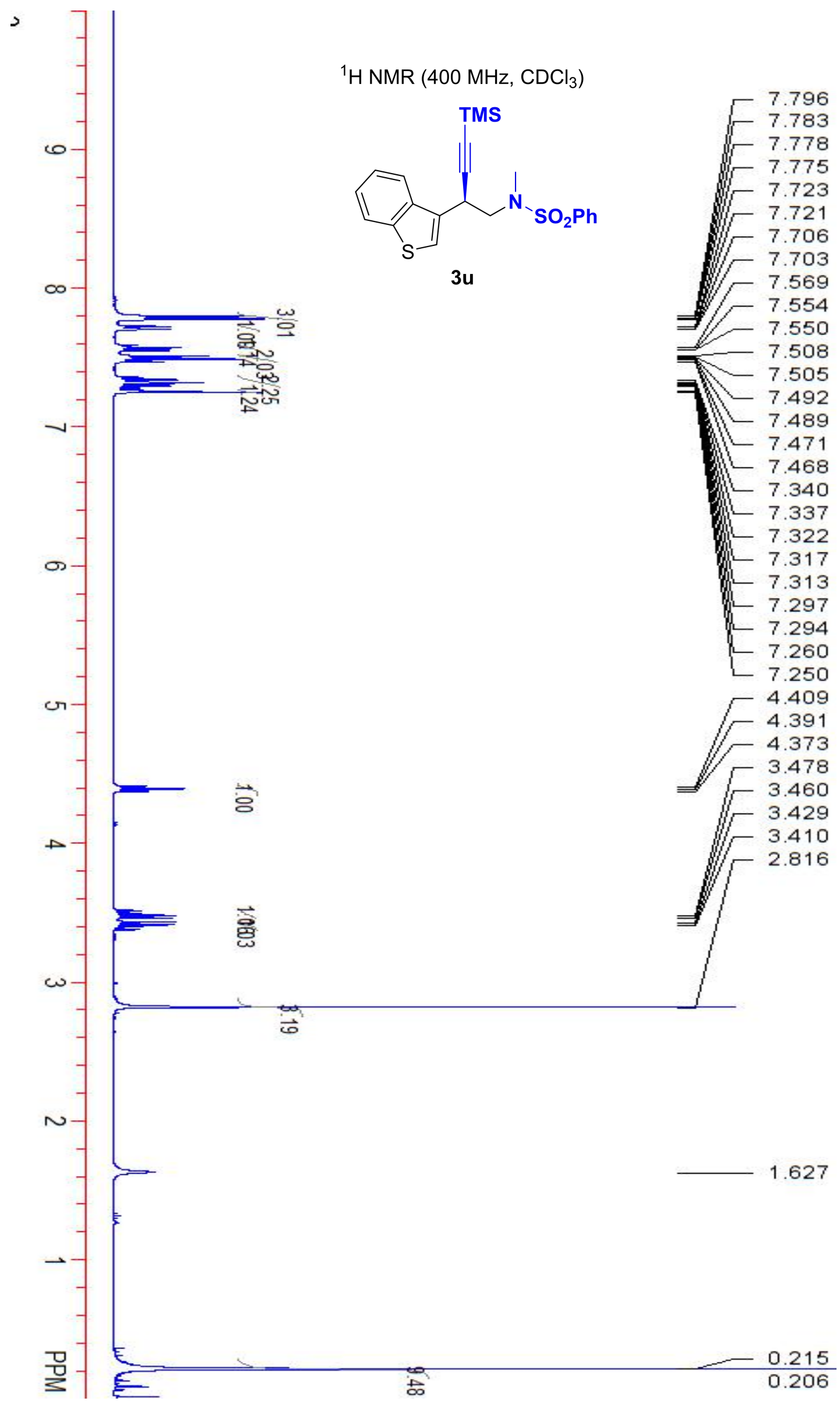




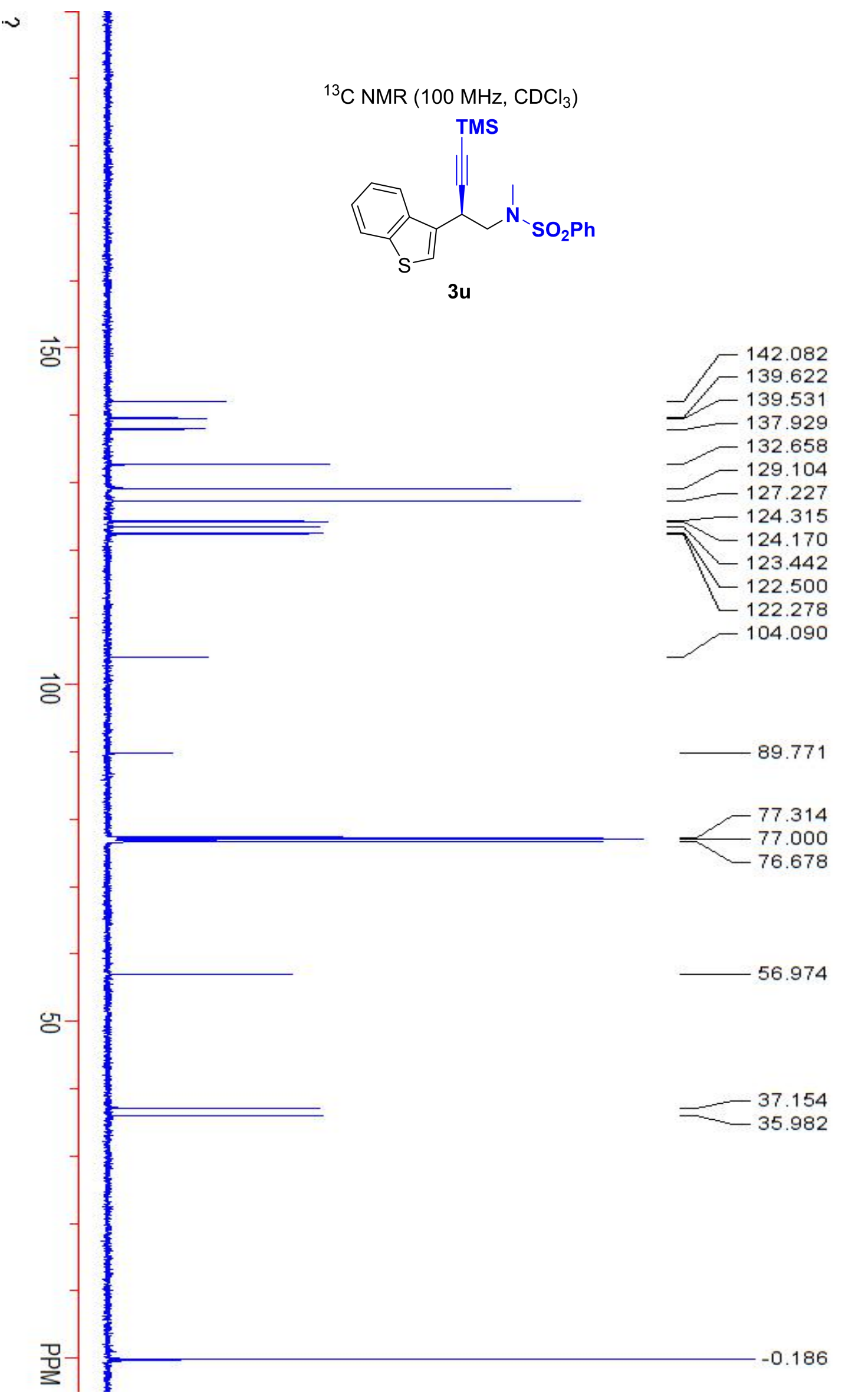




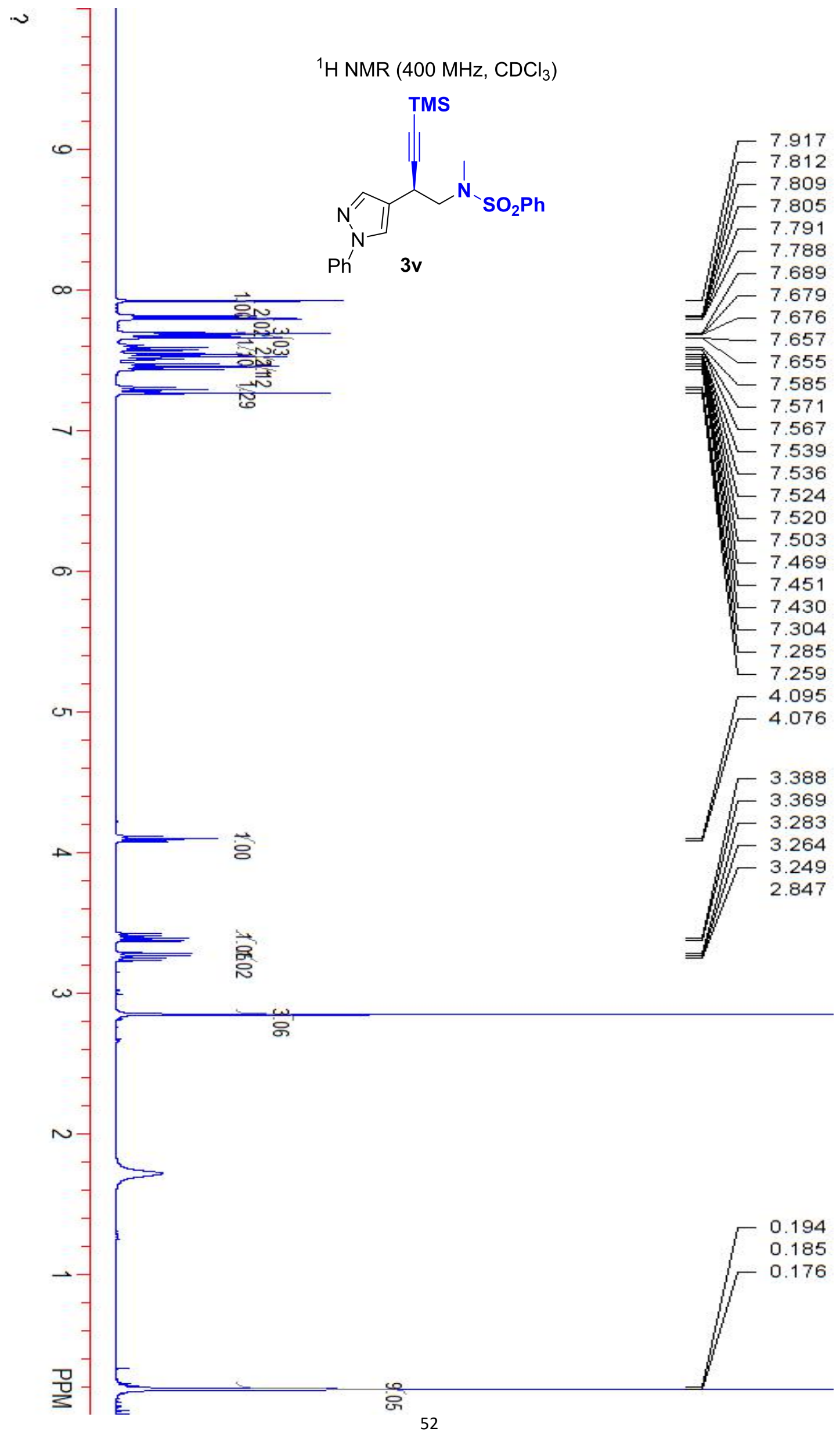


$\check{0}$

${ }^{13} \mathrm{C}$ NMR $\left(100 \mathrm{MHz}, \mathrm{CDCl}_{3}\right)$<smiles>CN(C[C@@H](C#CC(C)(C)C)c1cnn(-c2ccccc2)c1)S(=O)(=O)c1ccccc1</smiles>

$\overrightarrow{\text { जु }}$

$\mathrm{Ph}^{\prime} \quad 3 v$

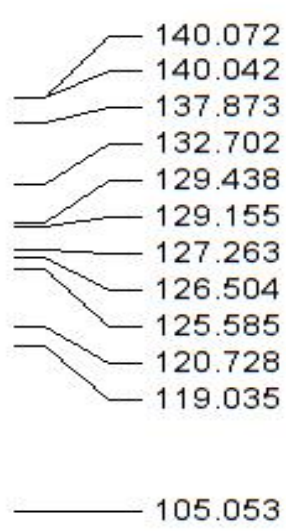

88.214

77.327

77.05

76.691

56.412

당

물

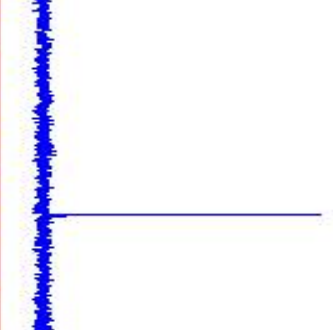

30.012

$-0.089$ 


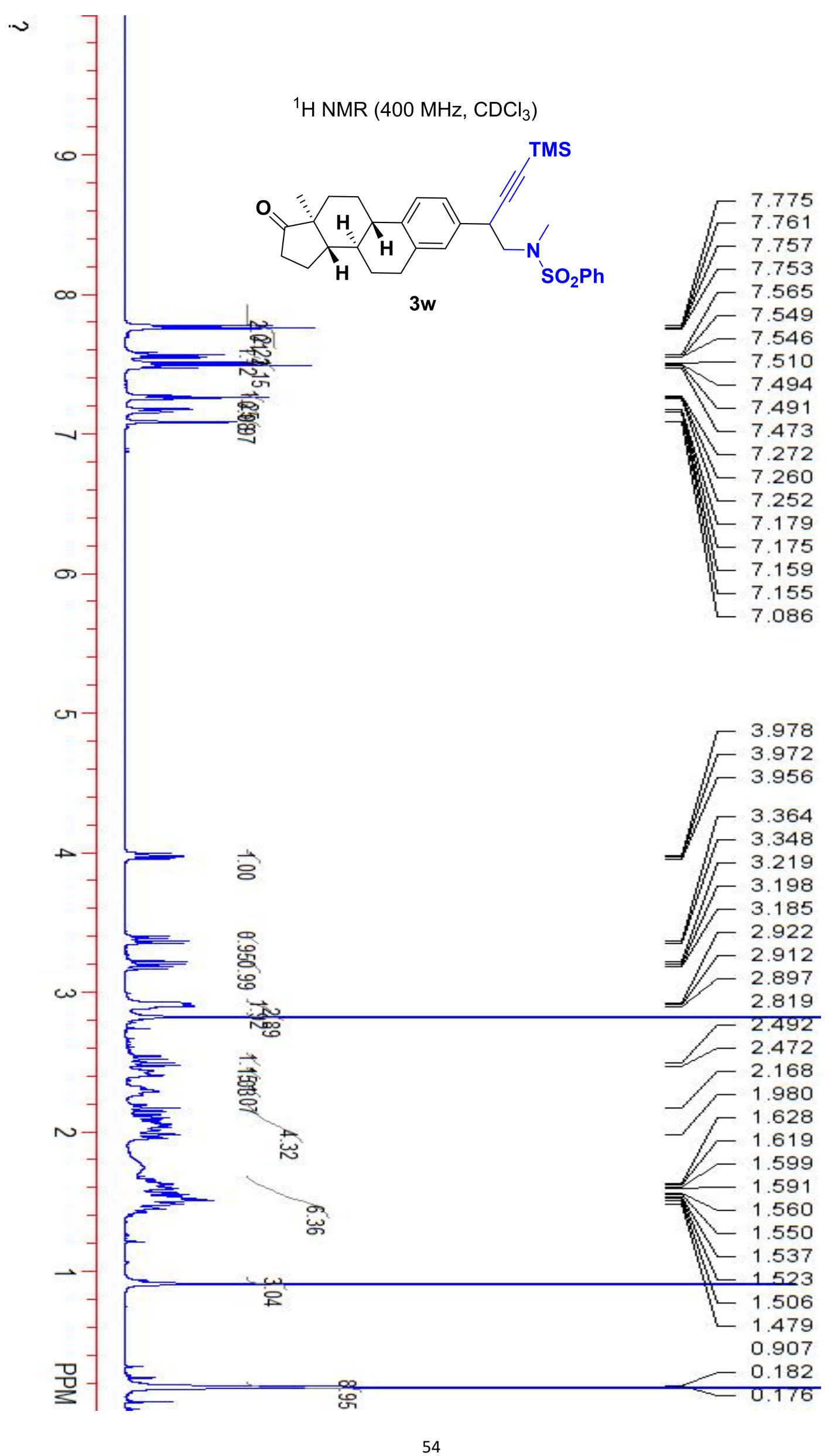



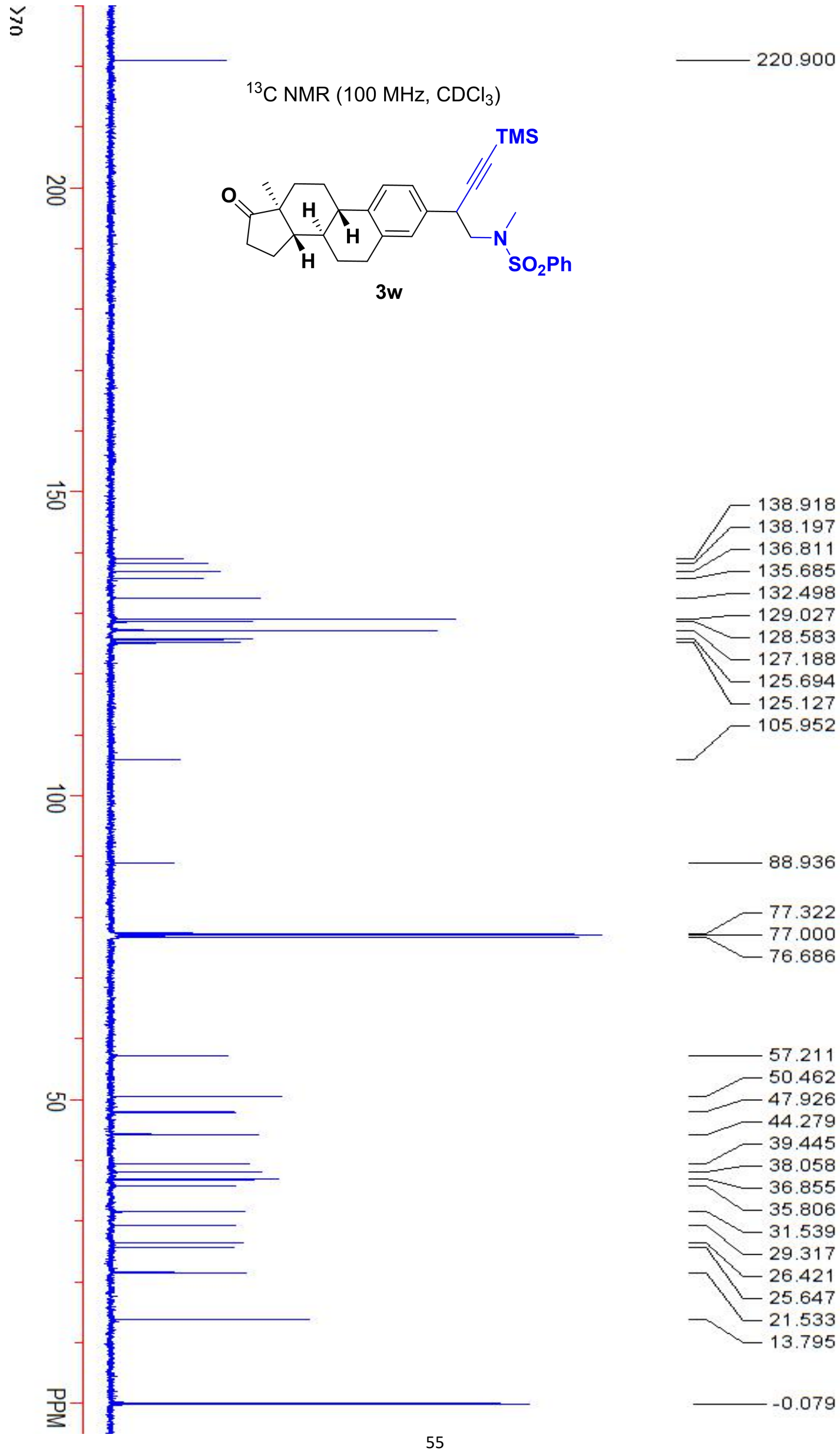

88.936

77.322

77.000

$-76.686$

57.211

50.462

47.926

44.279

39.445

38.058

36.855

35.806

31.539

29.317

26.421

25.647

$-21.533$

$-13.795$

$-0.079$ 


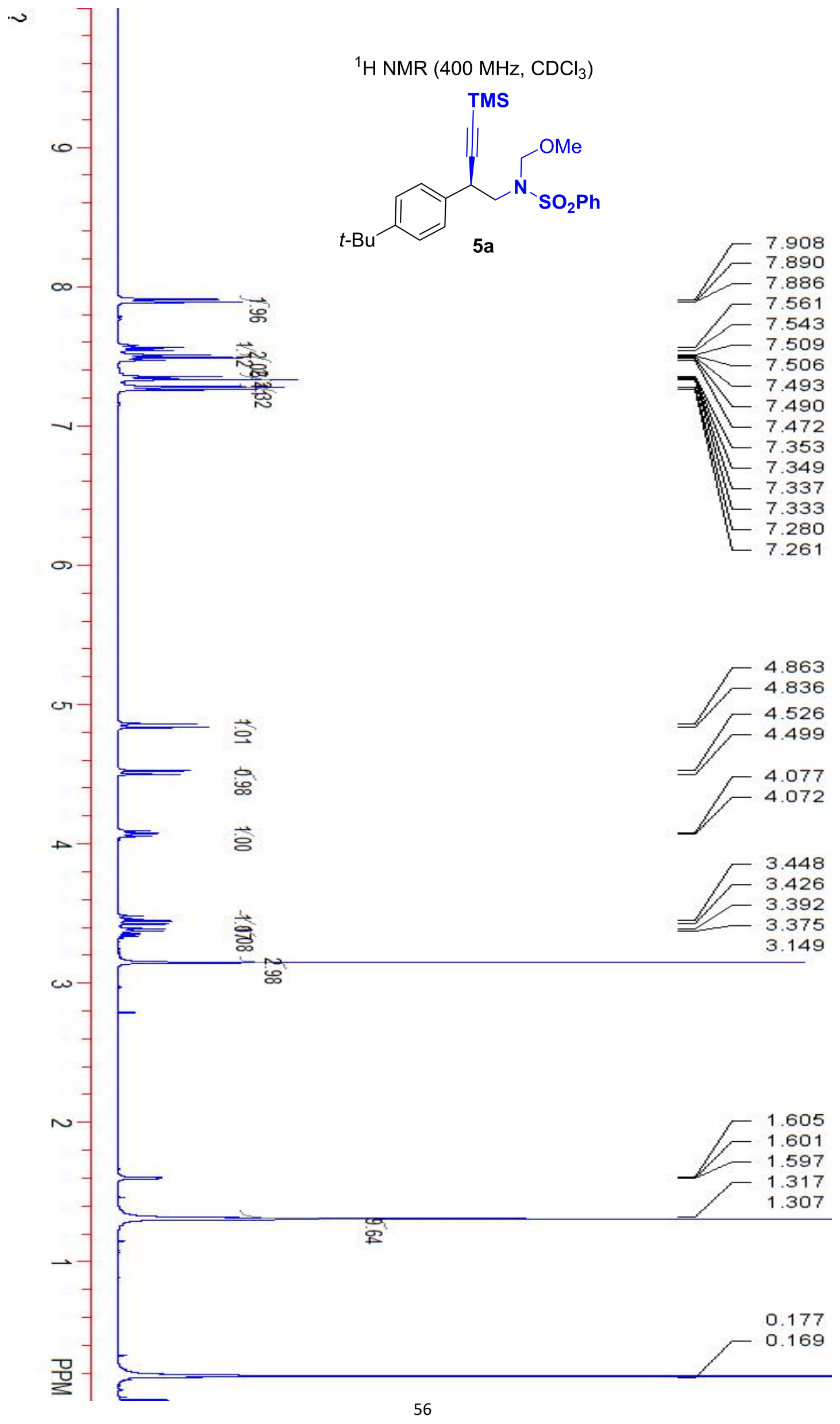




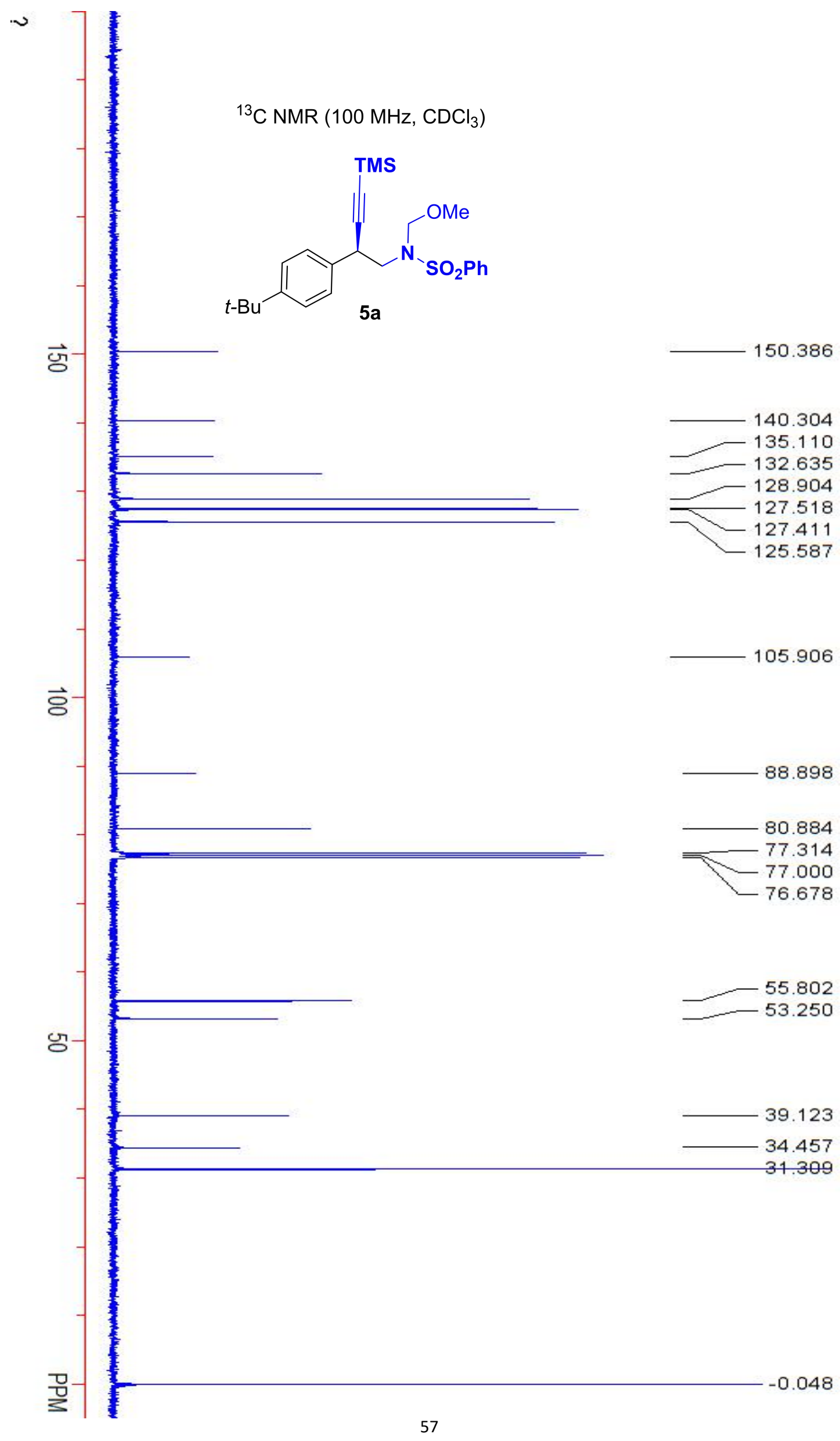




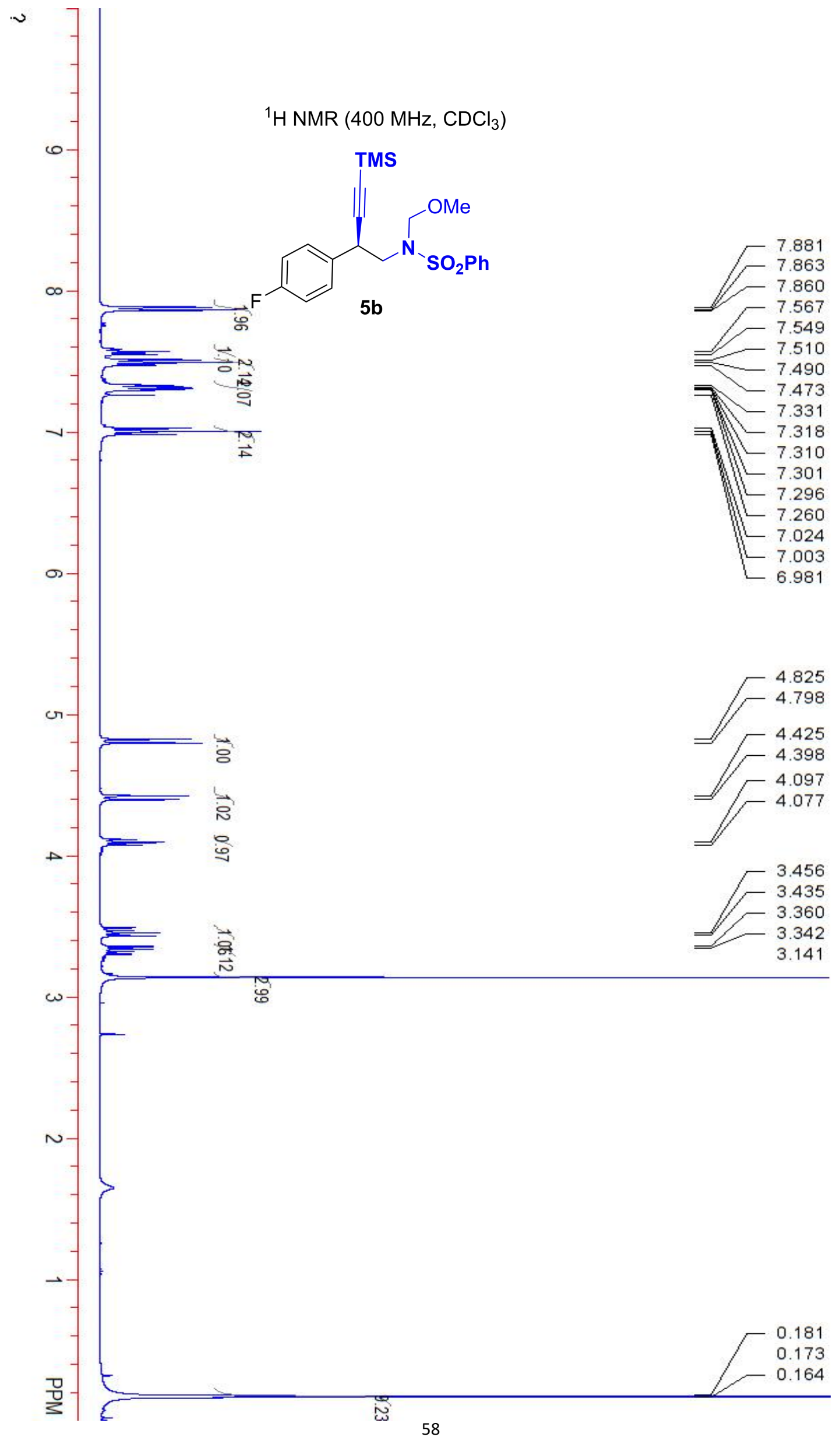




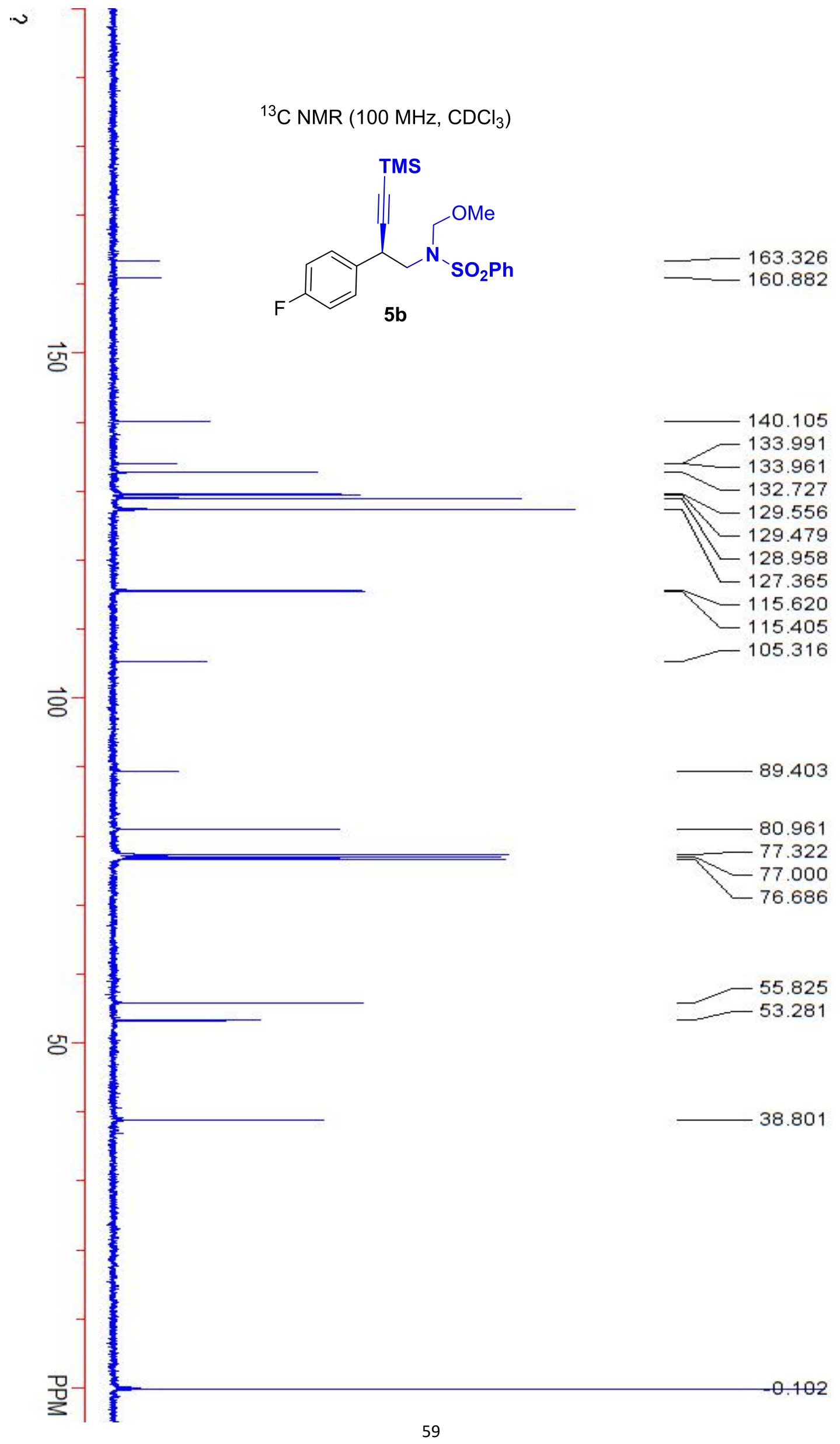


${ }^{19} \mathrm{~F} \mathrm{NMR}\left(376 \mathrm{MHz}, \mathrm{CDCl}_{3}\right)$

당

த்

$\dot{\bar{\delta}}$

它

ธัธ

苛<smiles>COCN(C[C@H](C#CC(C)(C)C)c1ccc(F)cc1)S(=O)(=O)c1ccccc1</smiles>

$5 b$

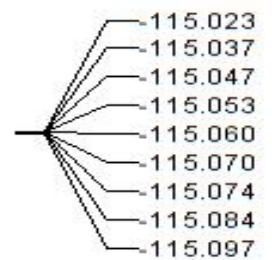




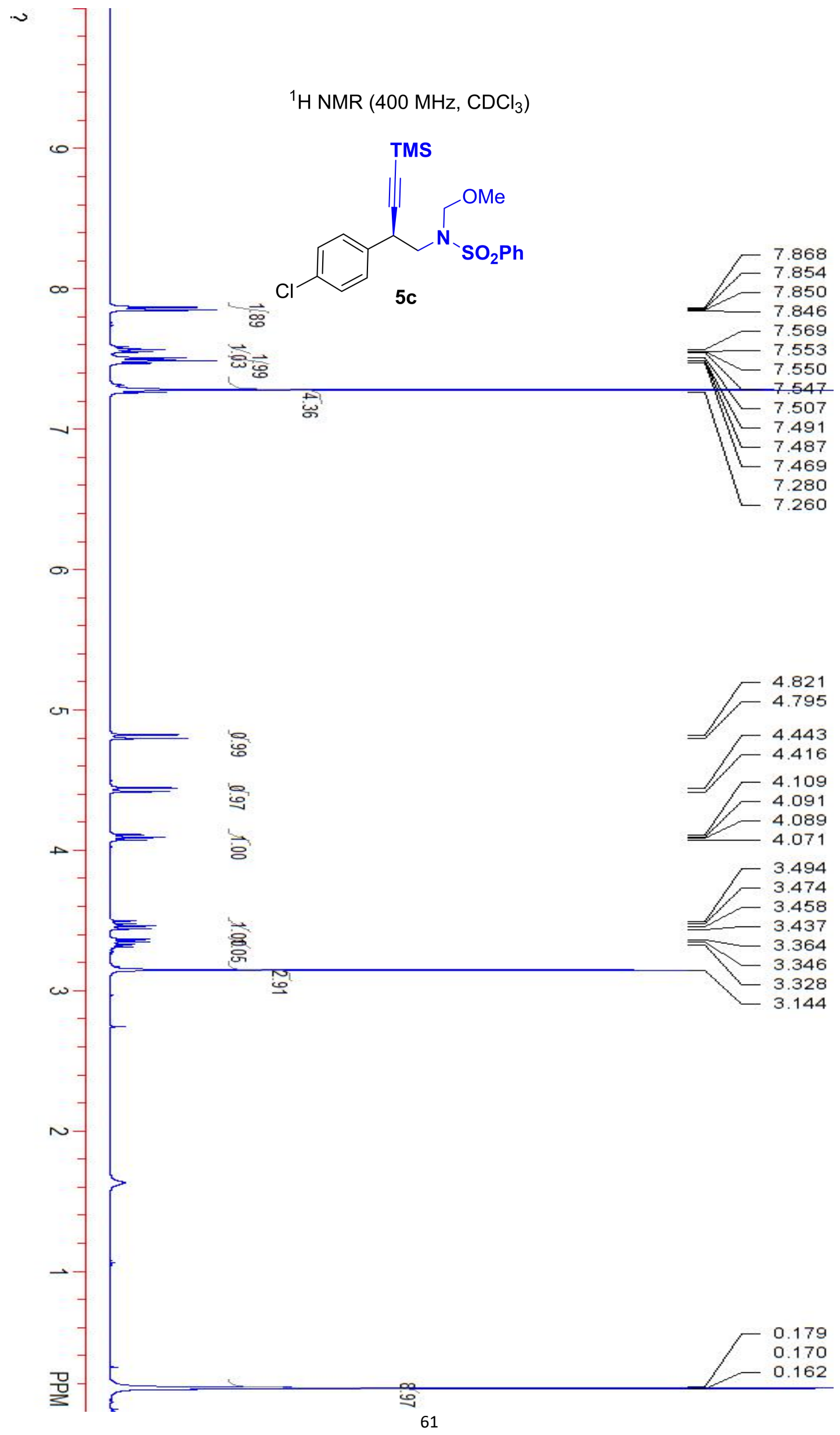




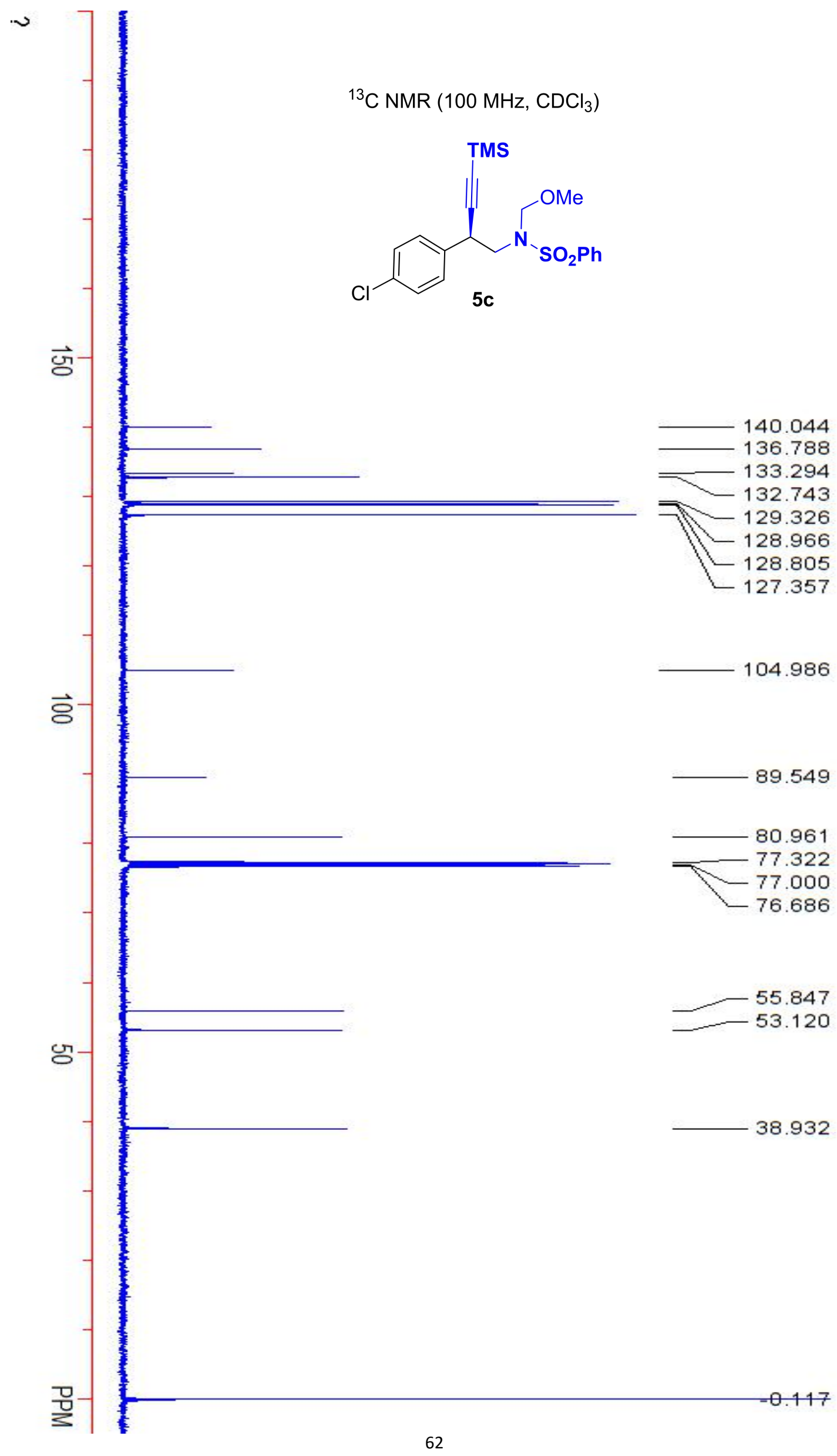




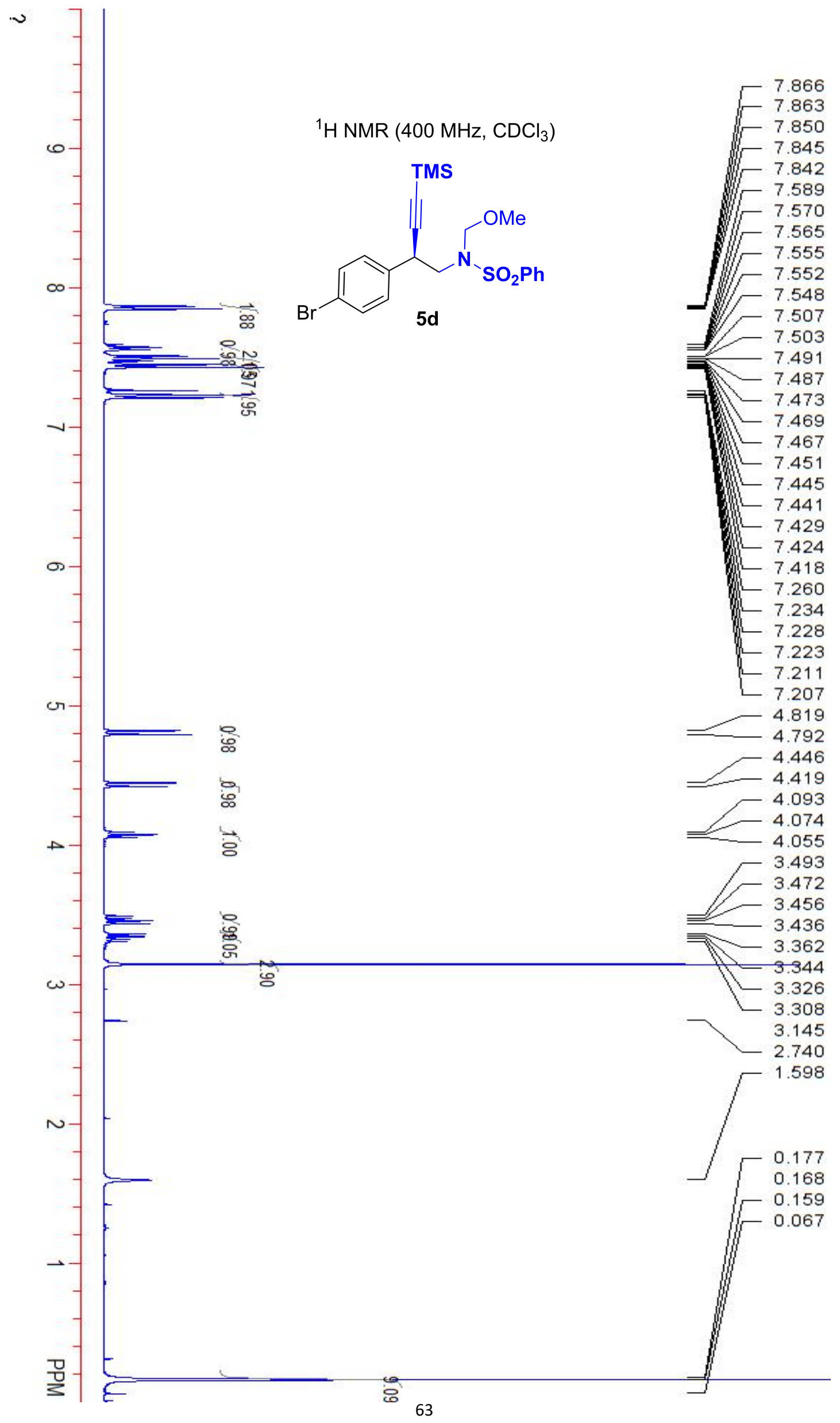




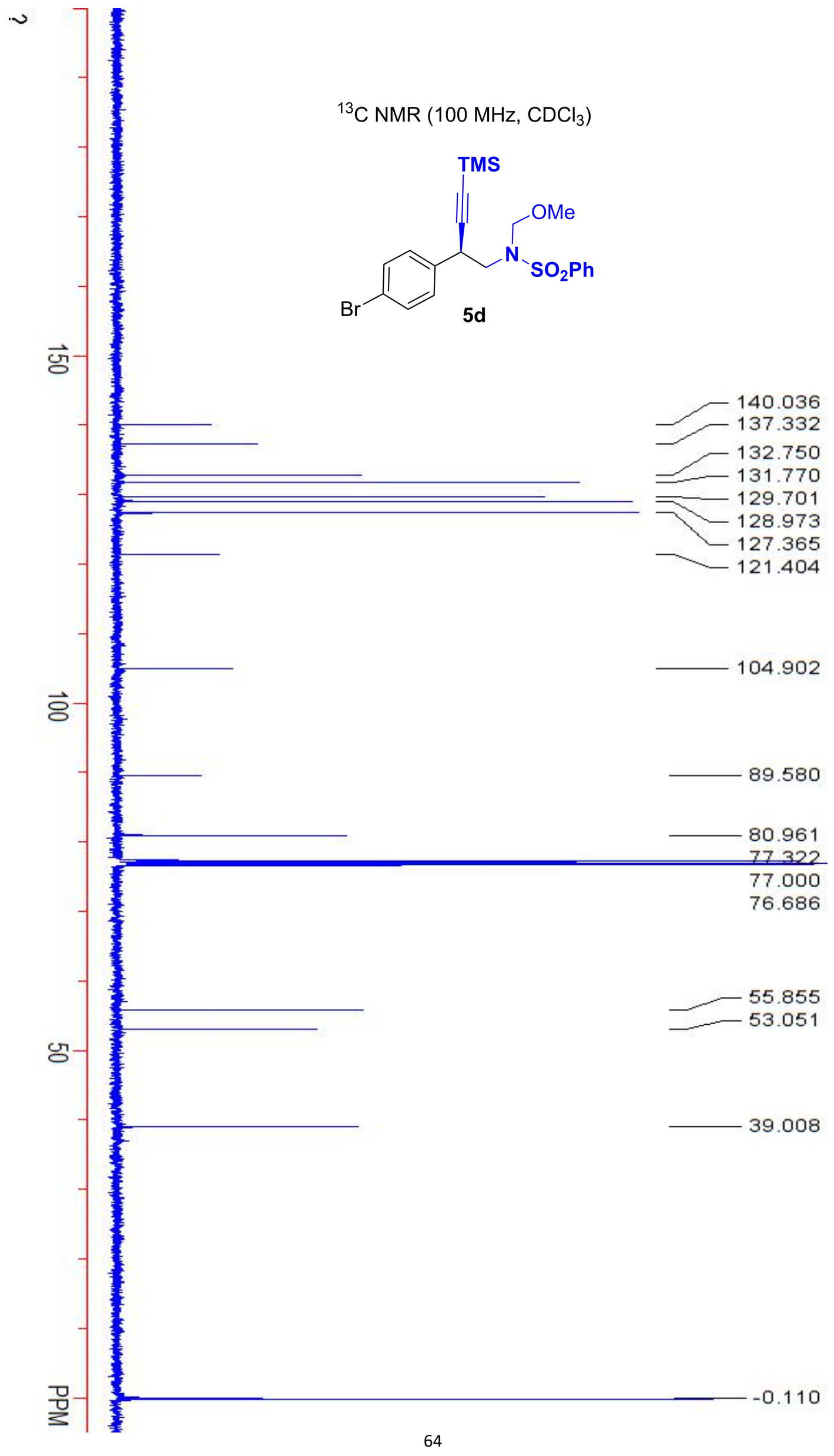




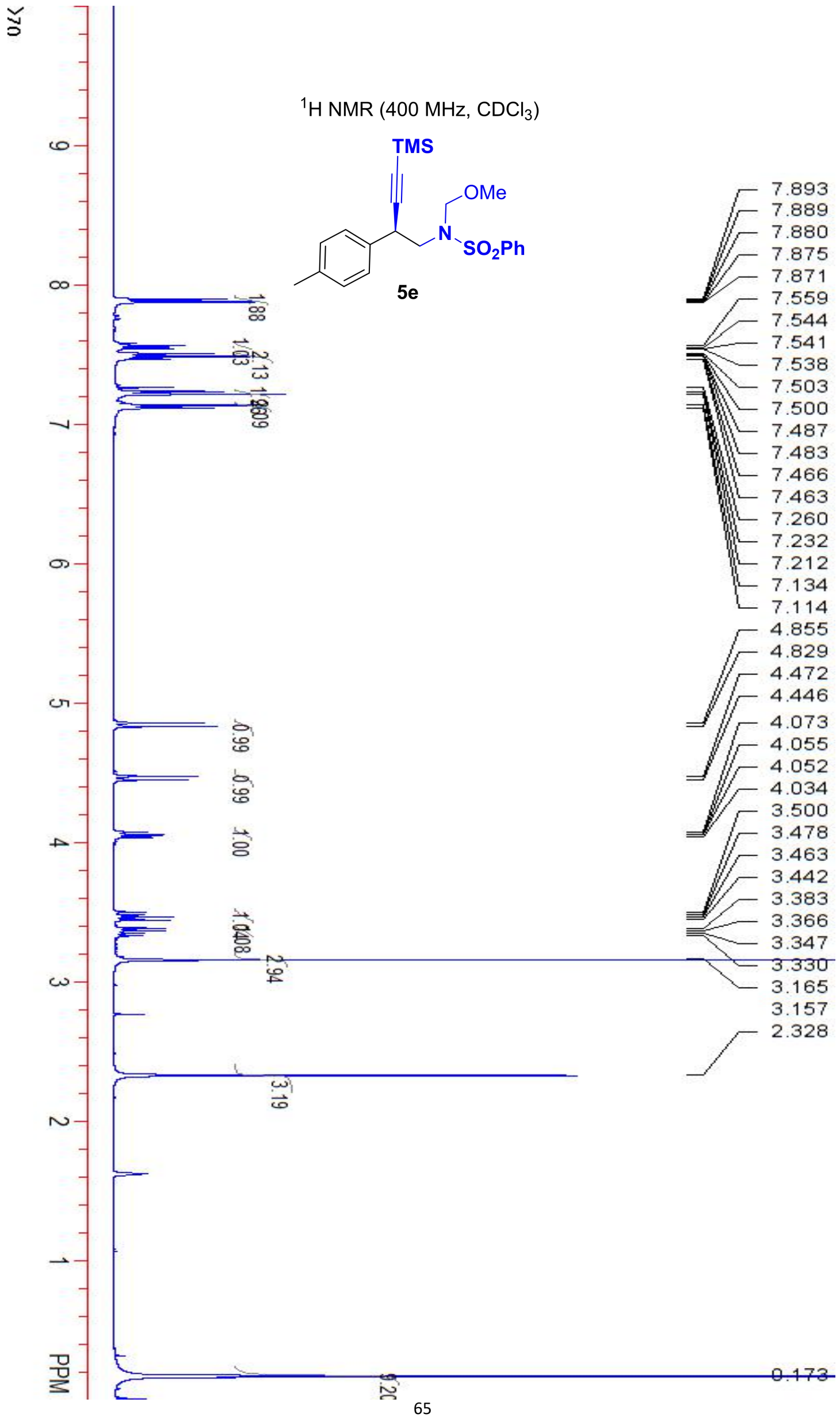




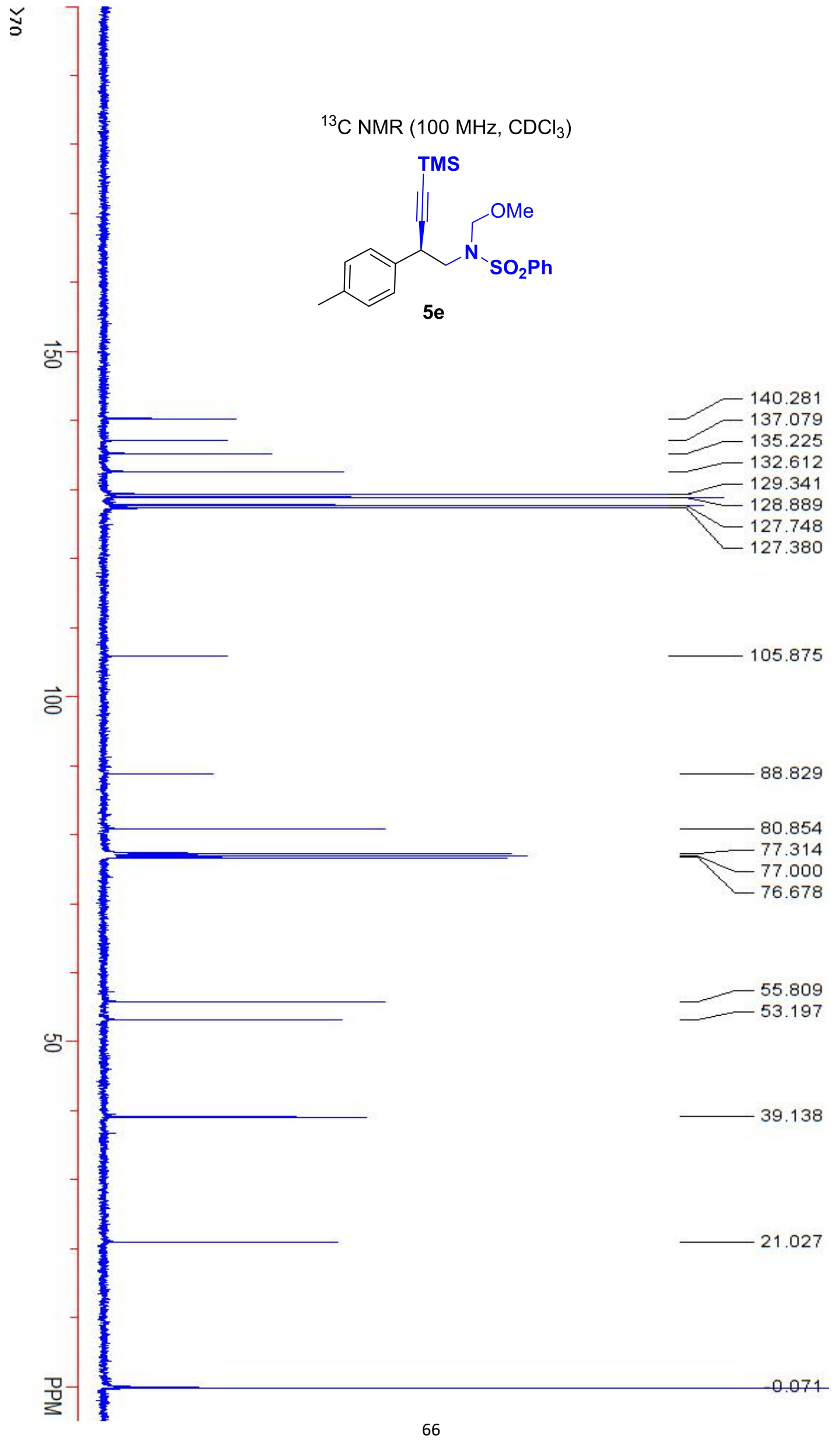




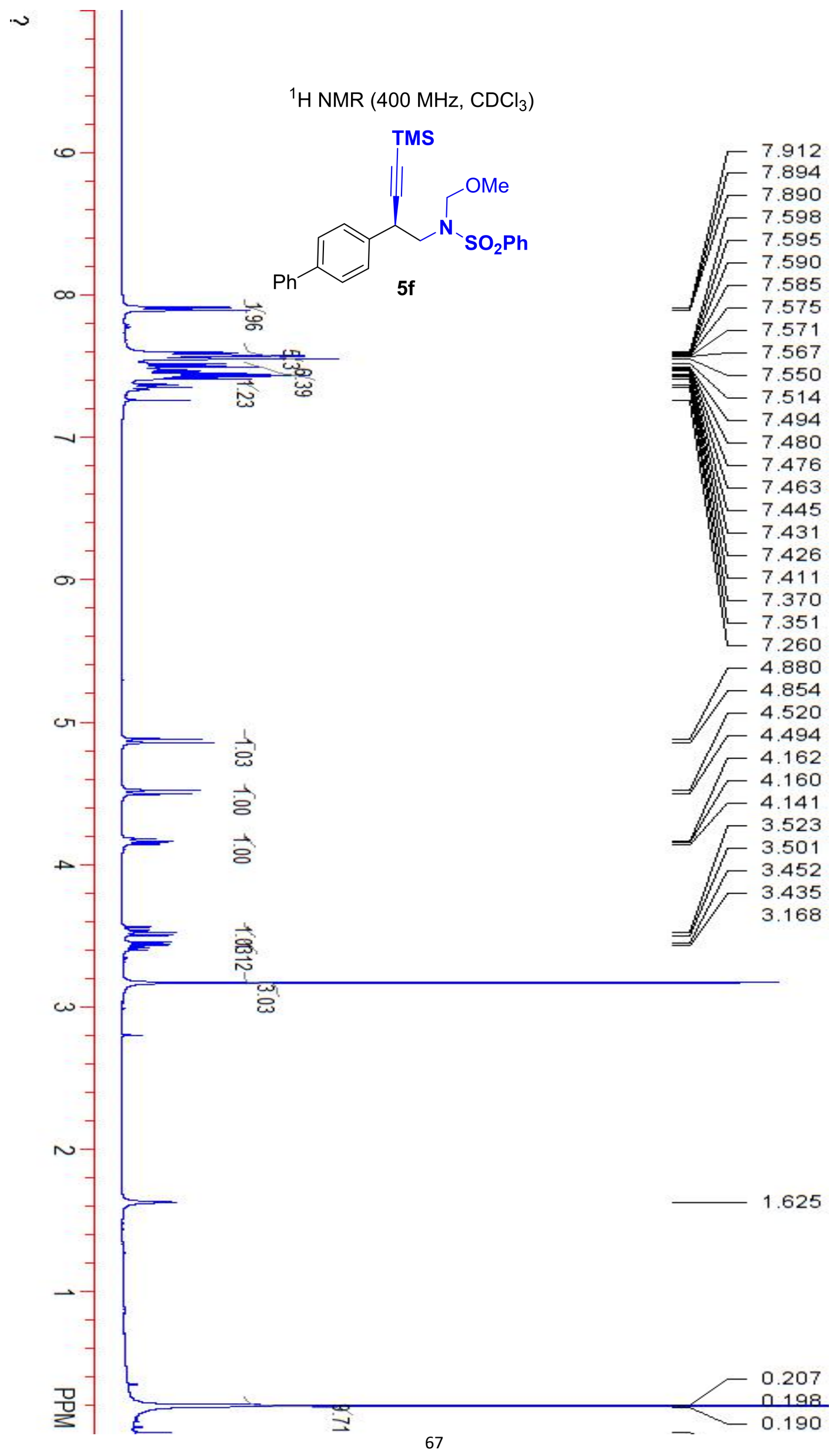




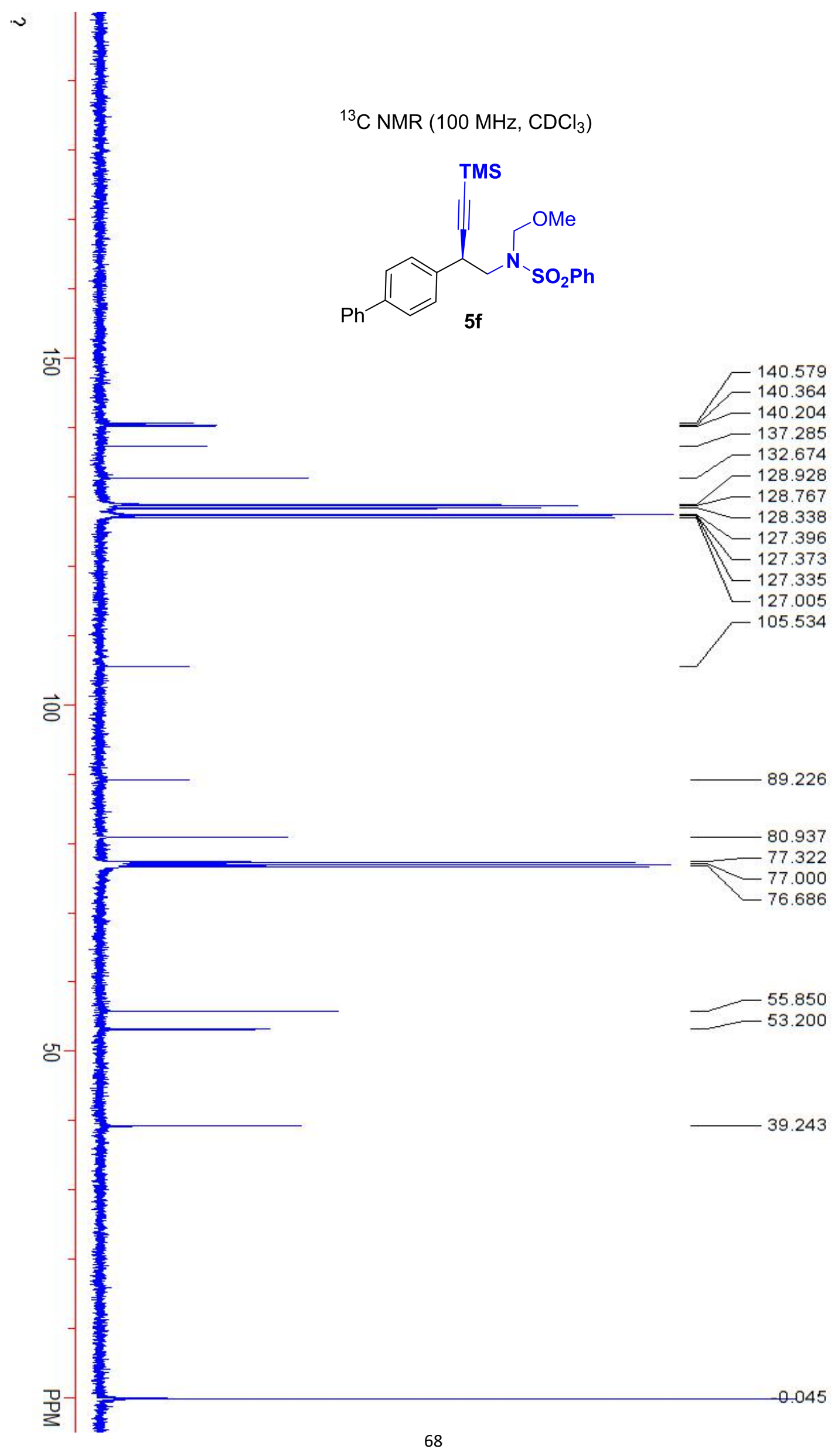




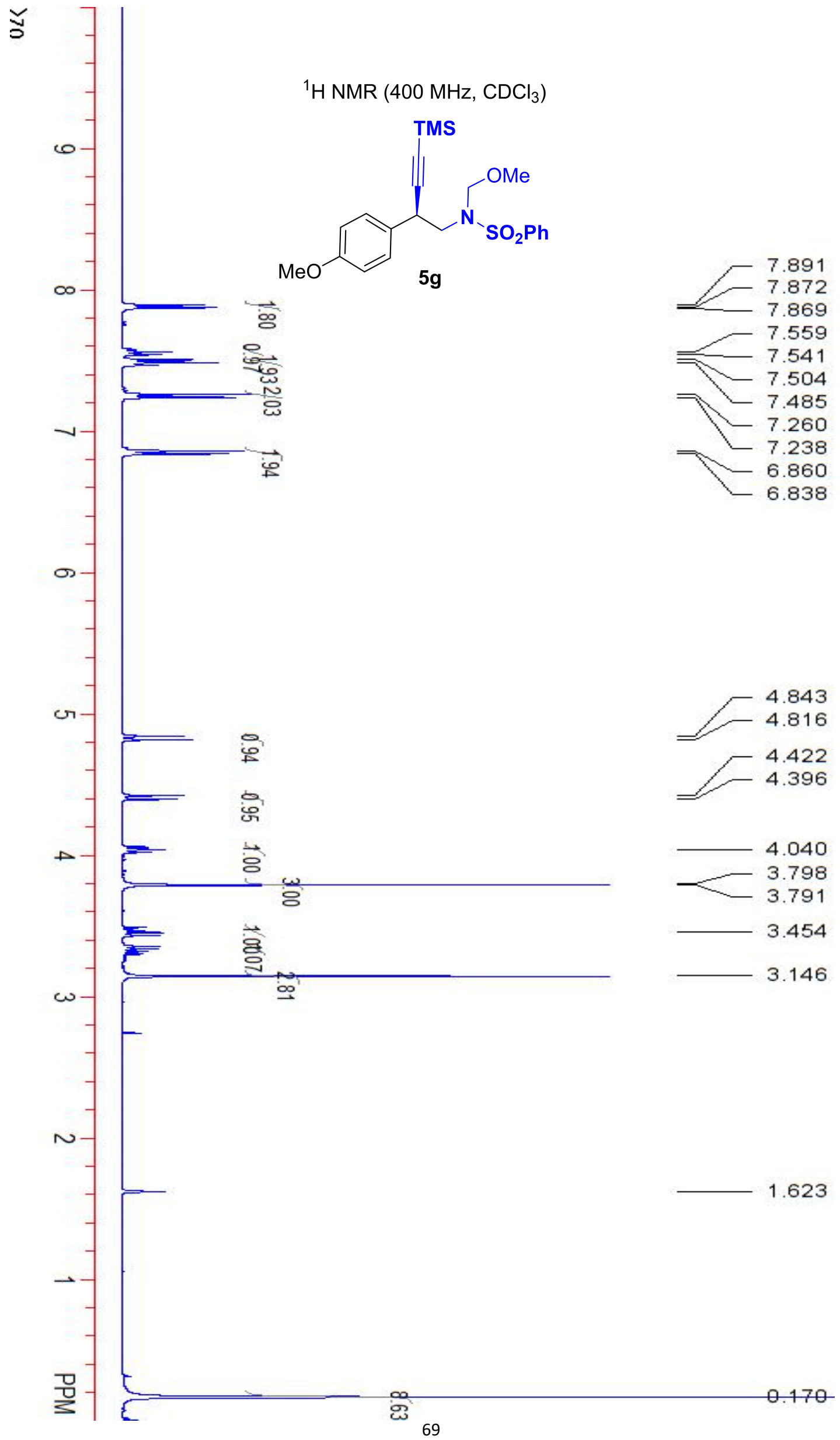




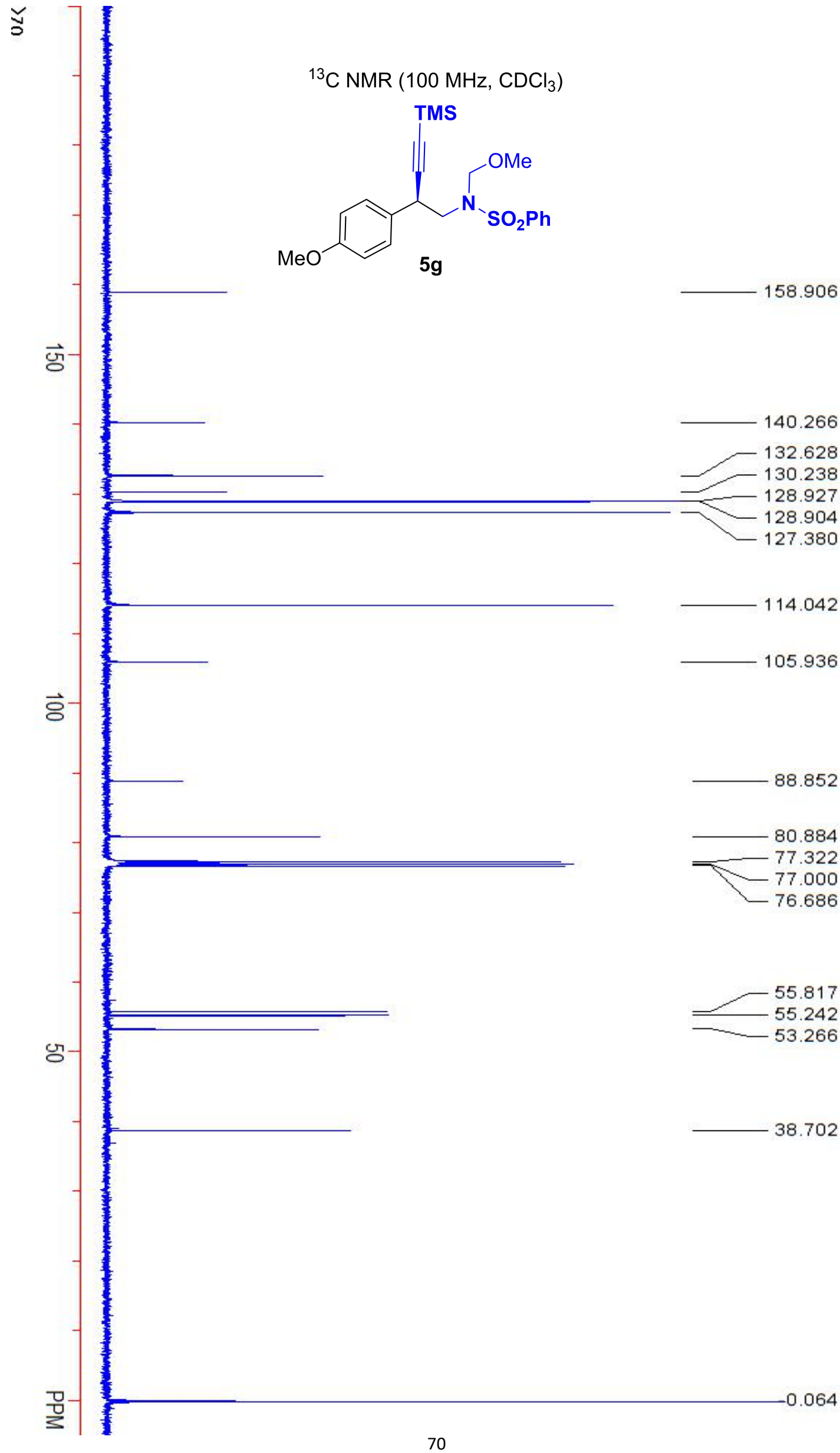




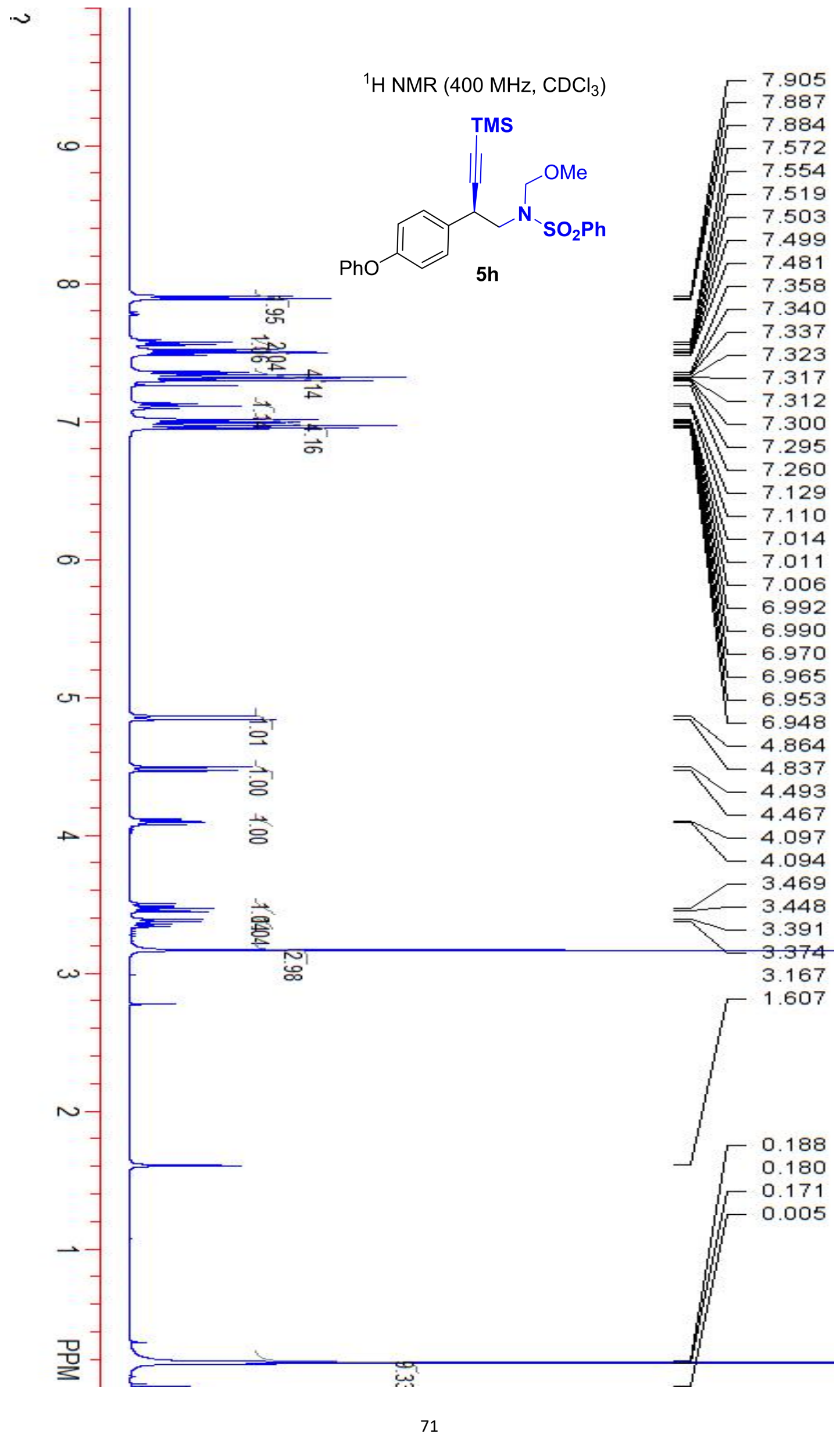




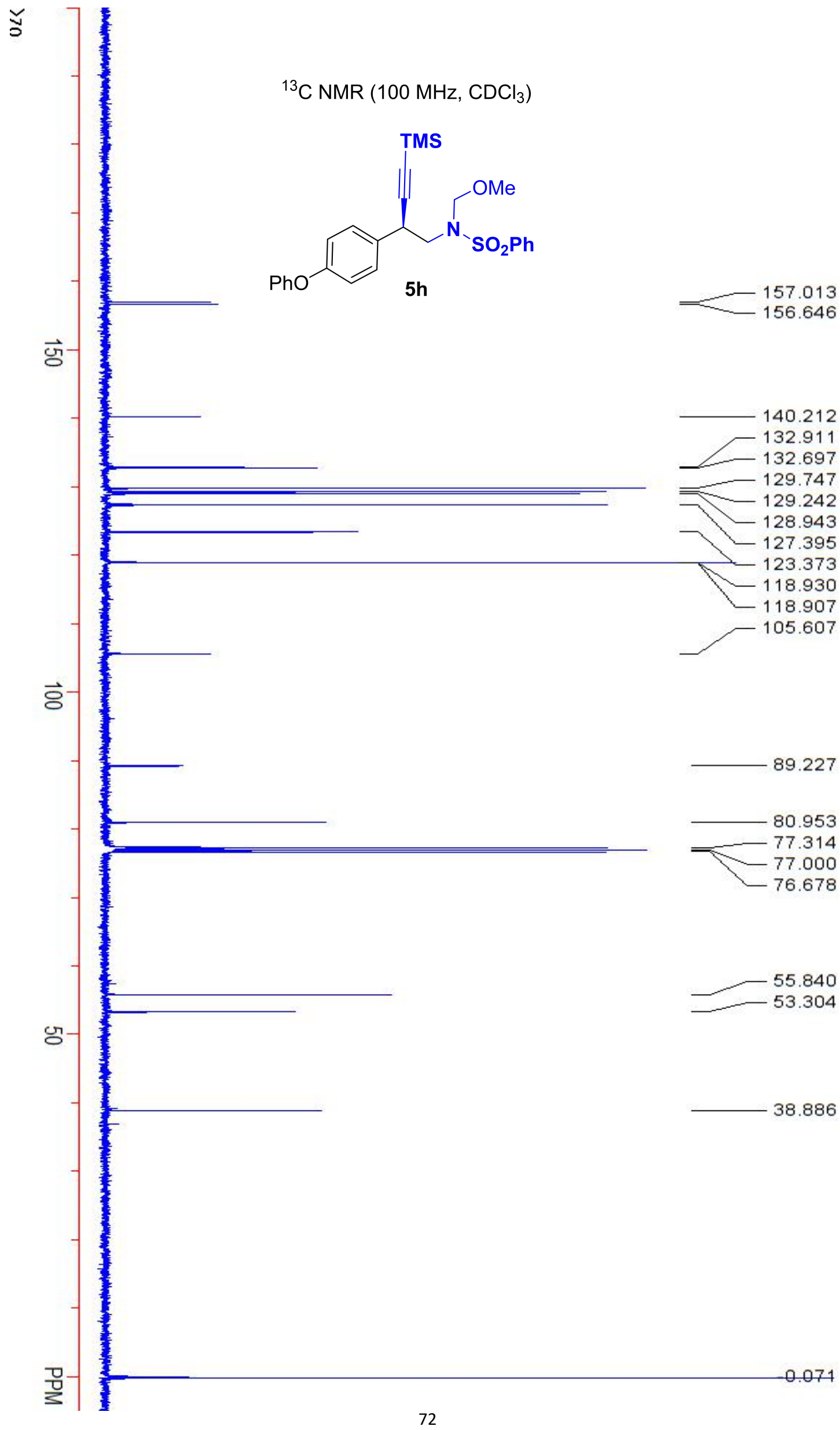


$\check{J}$

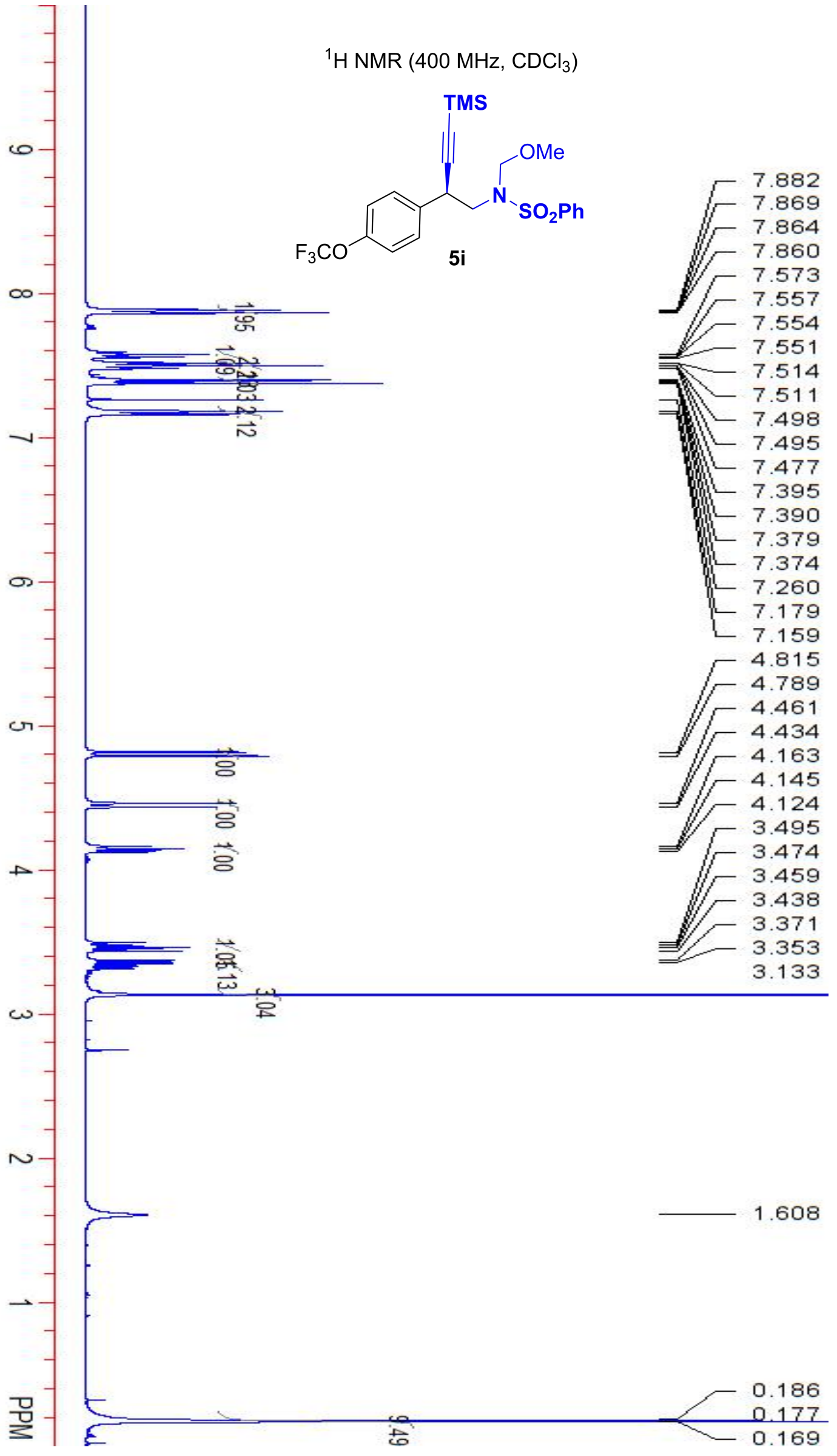


$\check{У}$

${ }^{13} \mathrm{C}$ NMR $\left(100 \mathrm{MHz}, \mathrm{CDCl}_{3}\right)$<smiles>COCN(C[C@H](C#CC(C)(C)C)c1ccc(OC(F)(F)F)cc1)S(=O)(=O)c1ccccc1</smiles>

$\overrightarrow{~ ज ् ञ ~}$

8

89.746

81.035

77.005

76.691

55.830

$=-53.263$

당

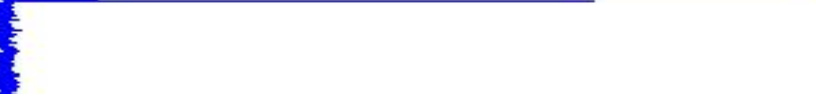

38.975

믈

$-0.112$ 
${ }^{19} \mathrm{~F} \mathrm{NMR}\left(376 \mathrm{MHz}, \mathrm{CDCl}_{3}\right.$ )<smiles>CC#C[C@@H](CN(COC)S(=O)(=O)c1ccccc1)c1ccc(OC(F)(F)F)cc1</smiles>

'ं 


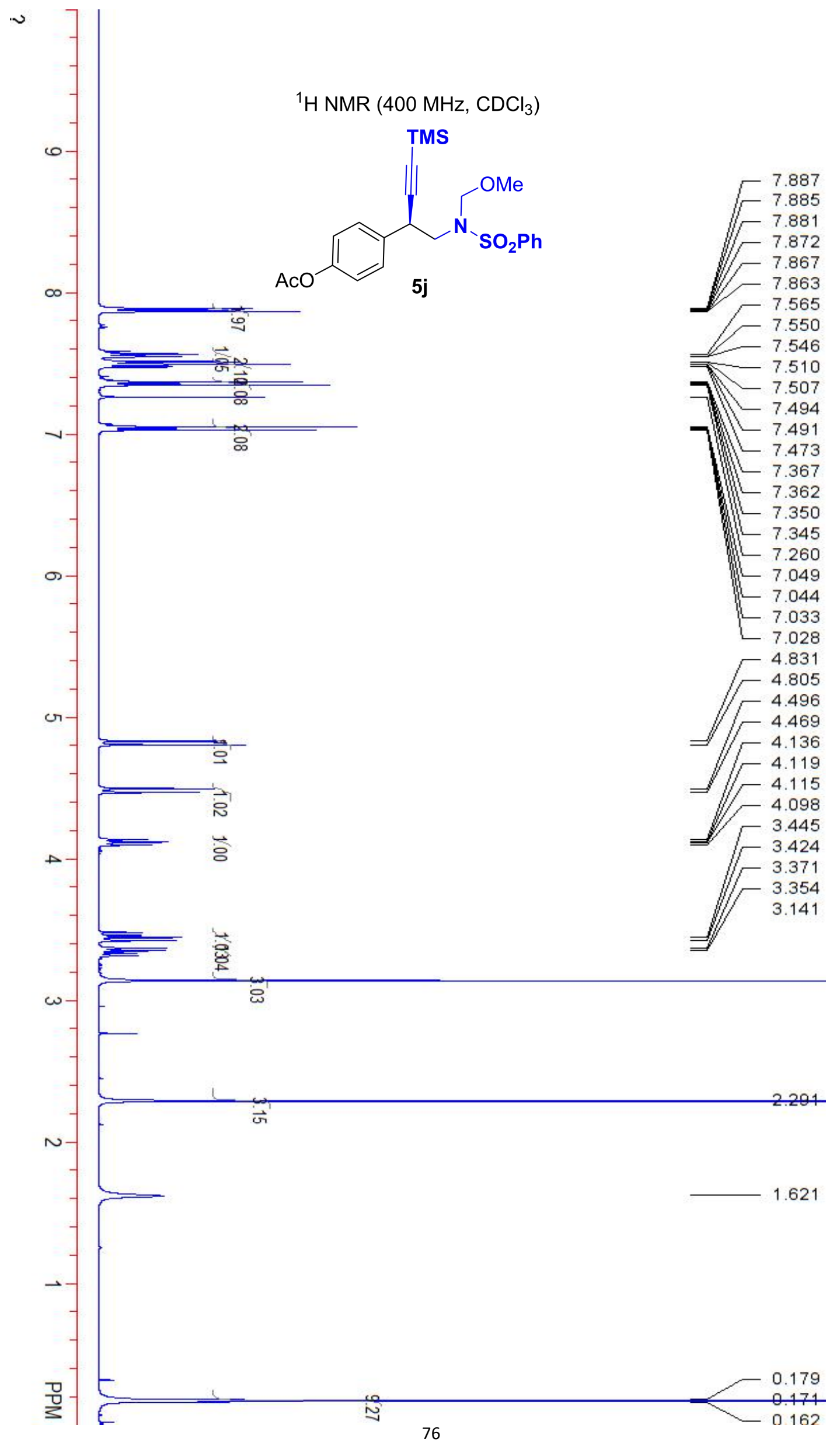




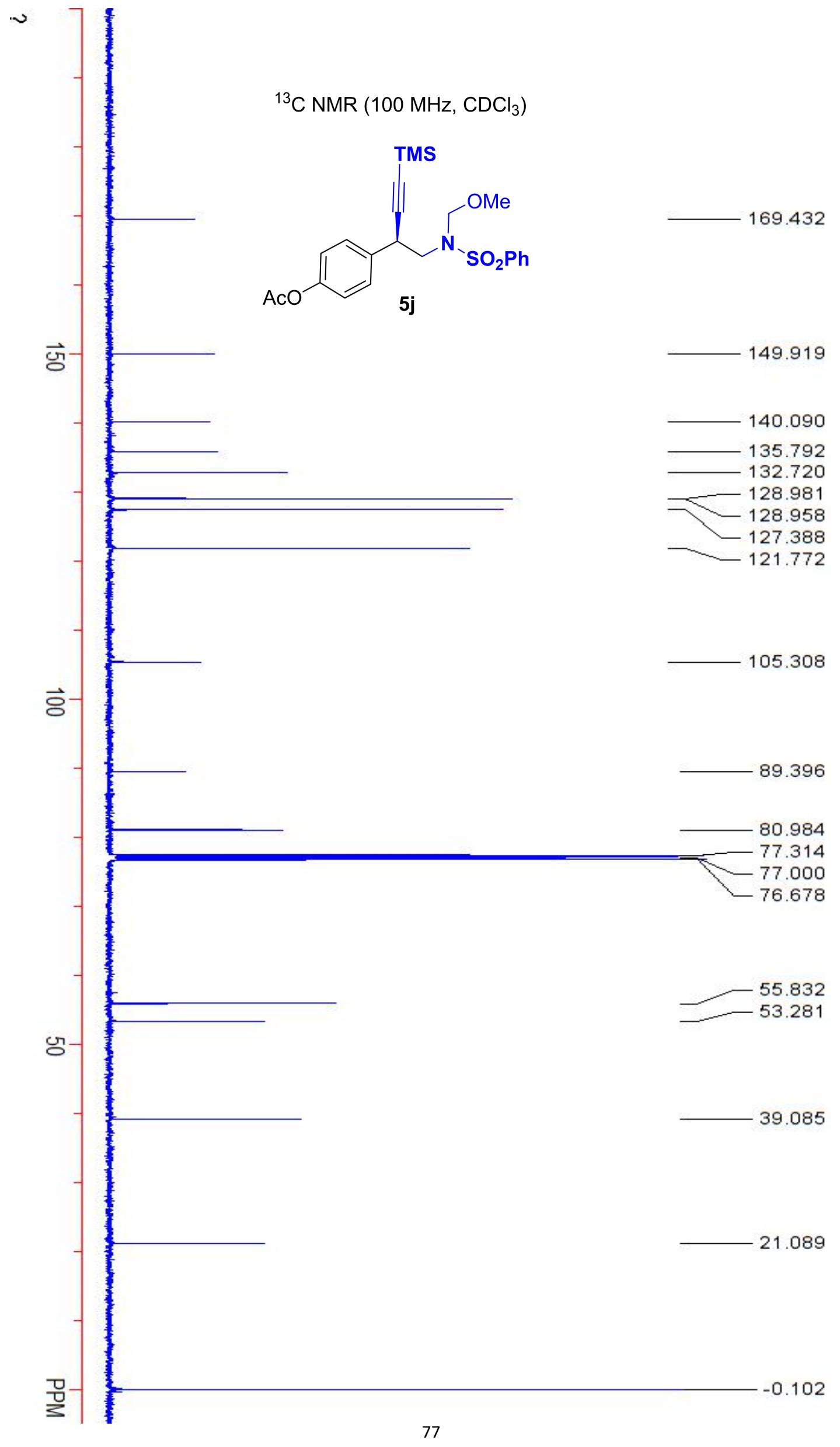




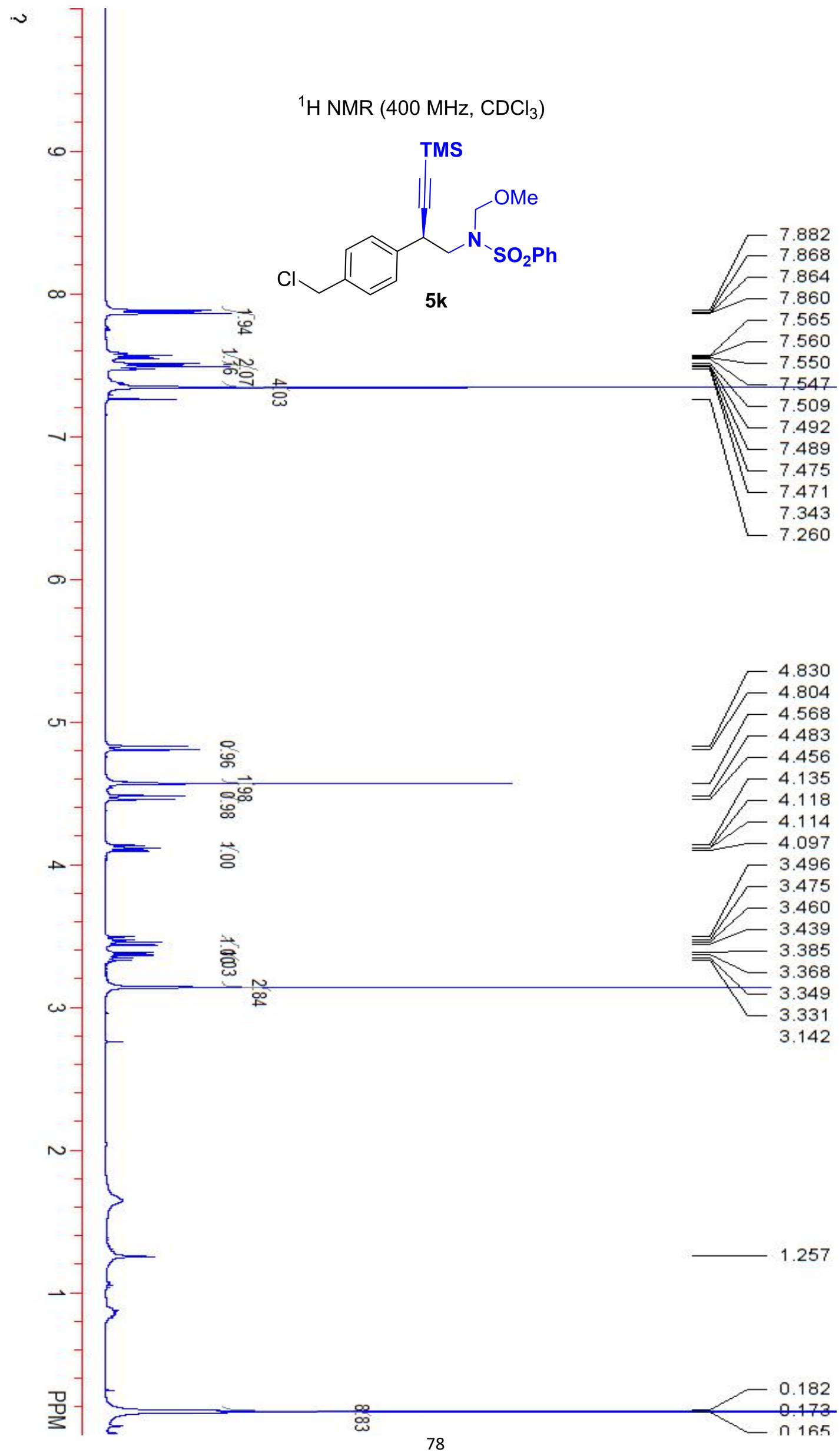



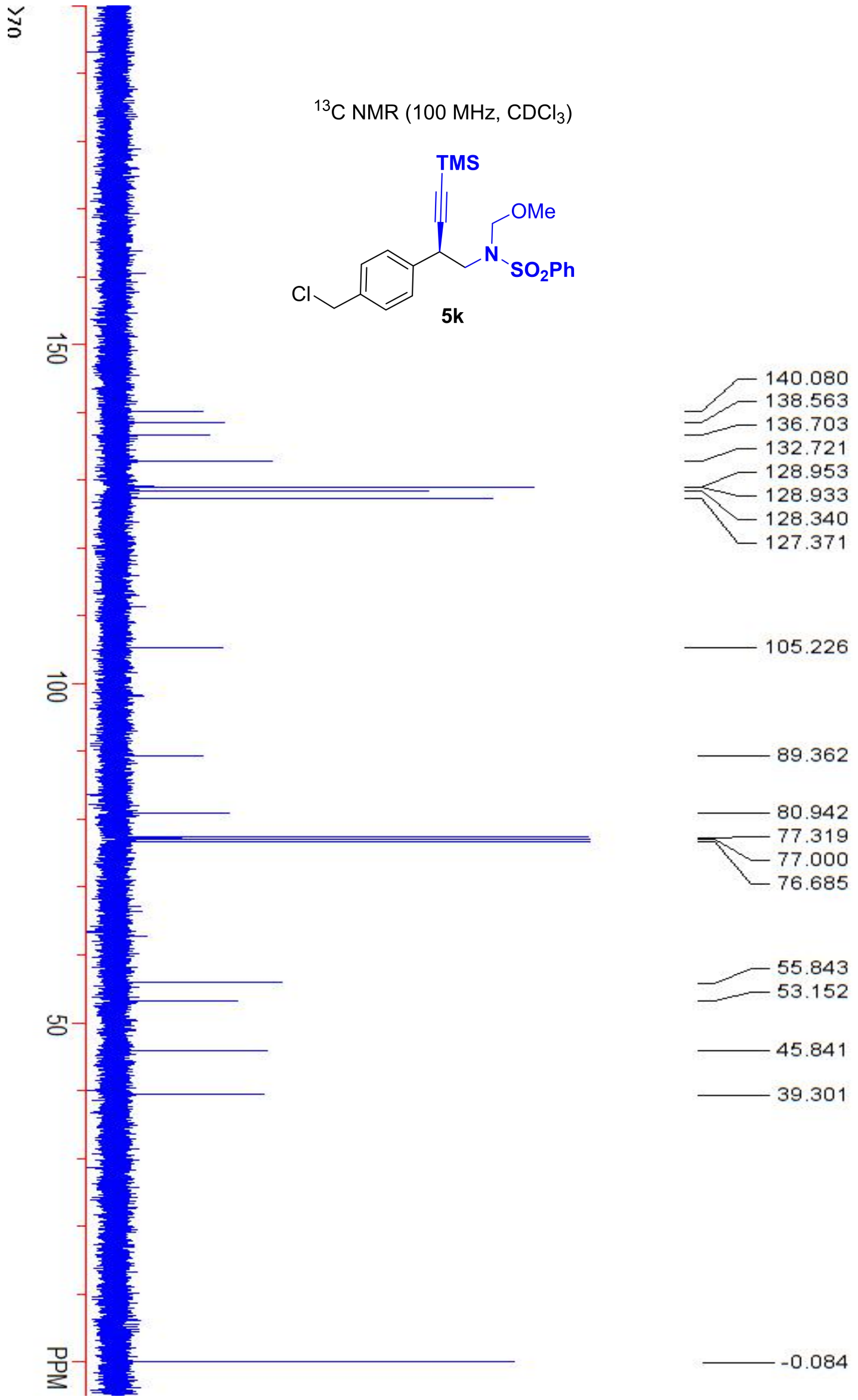

105.226

89.362

80.942

77.319

77.000

$-76.685$

55.843

53.152

45.841

39.301

$-0.084$ 


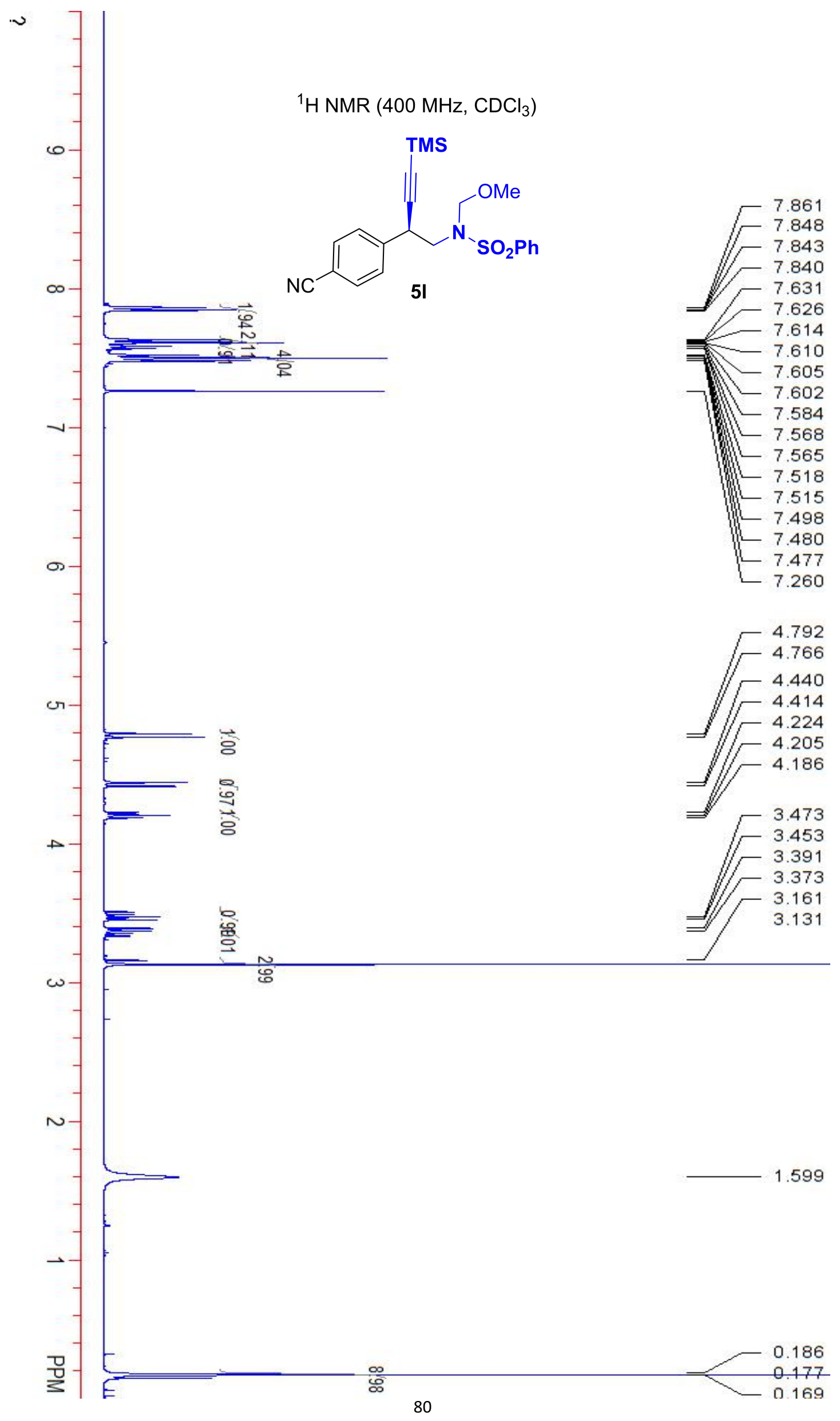




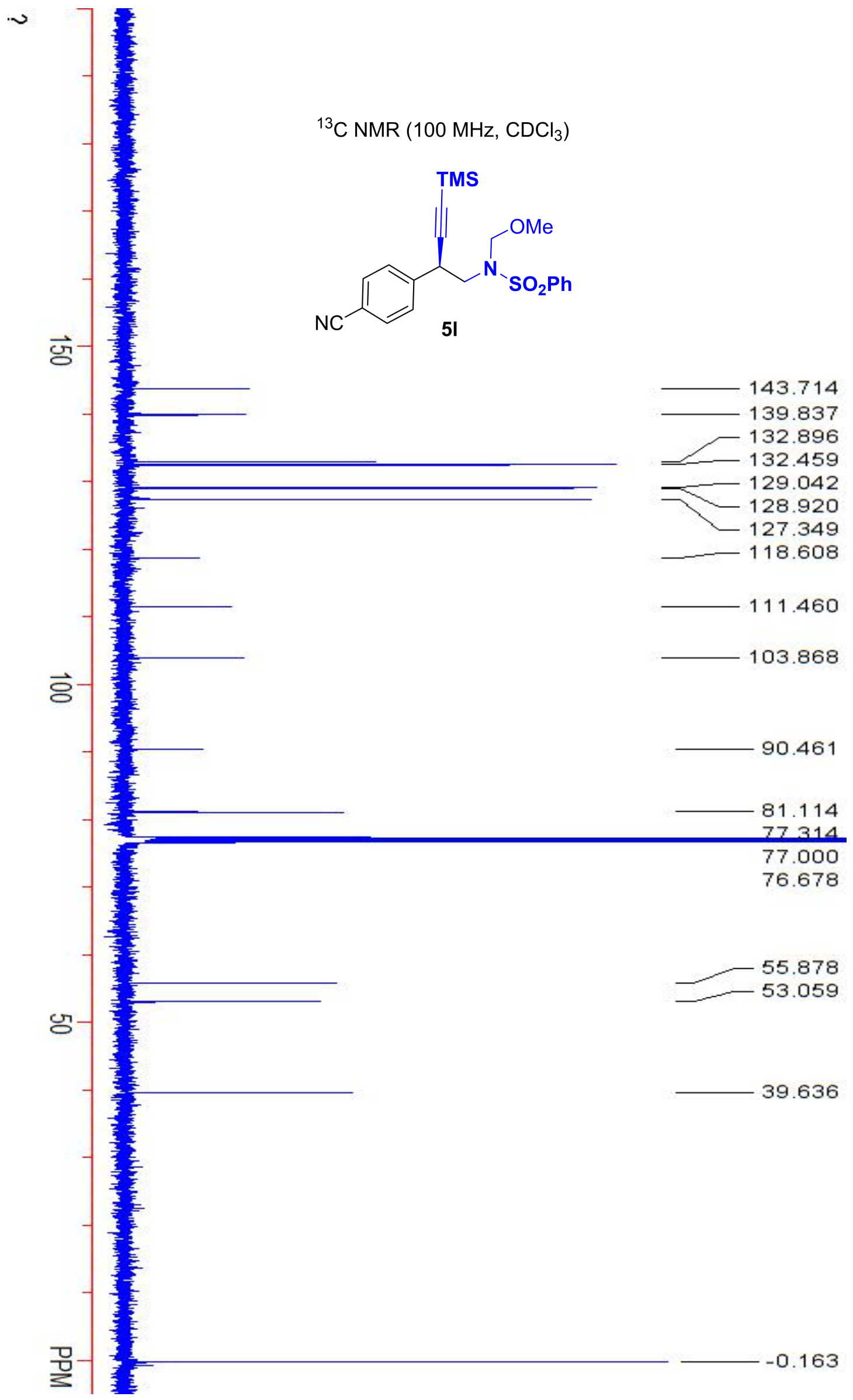




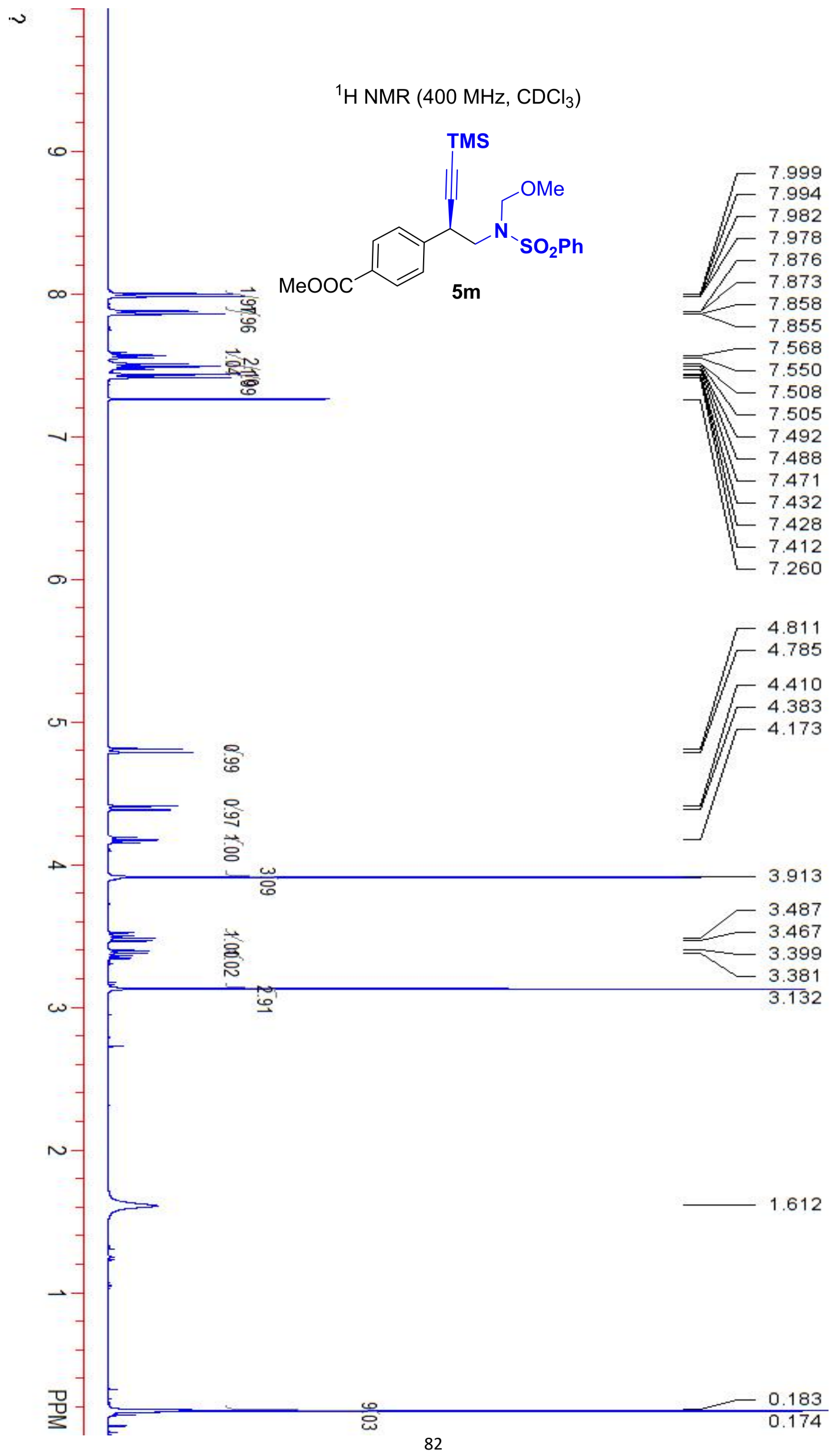


$\check{5}$

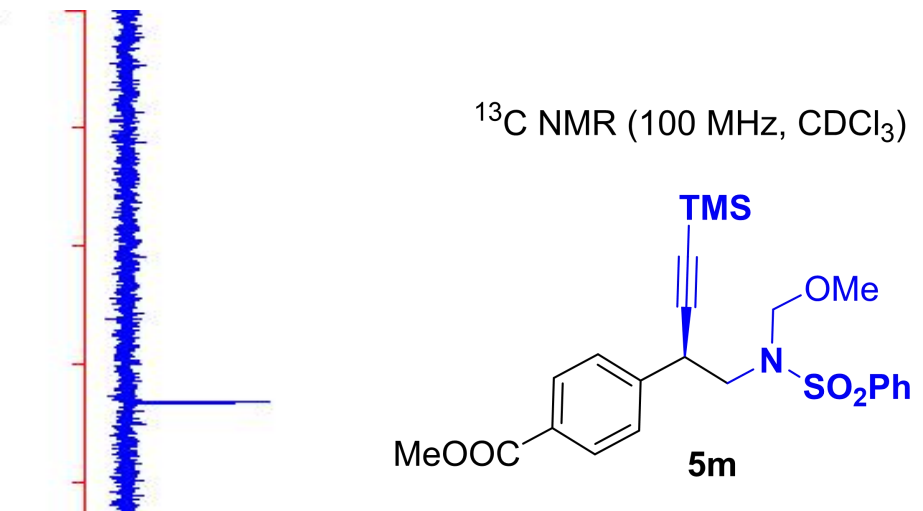

ज़

$\overrightarrow{8}$

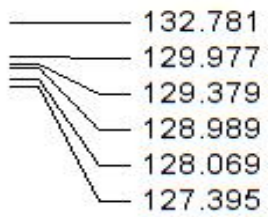

104.672

89.848

81.007 77.314

77.000

76.678

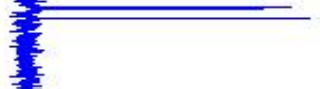

$-55.855$

53.021

52.124

39.567

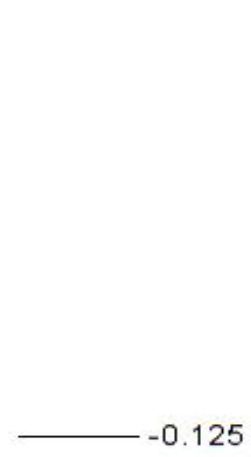




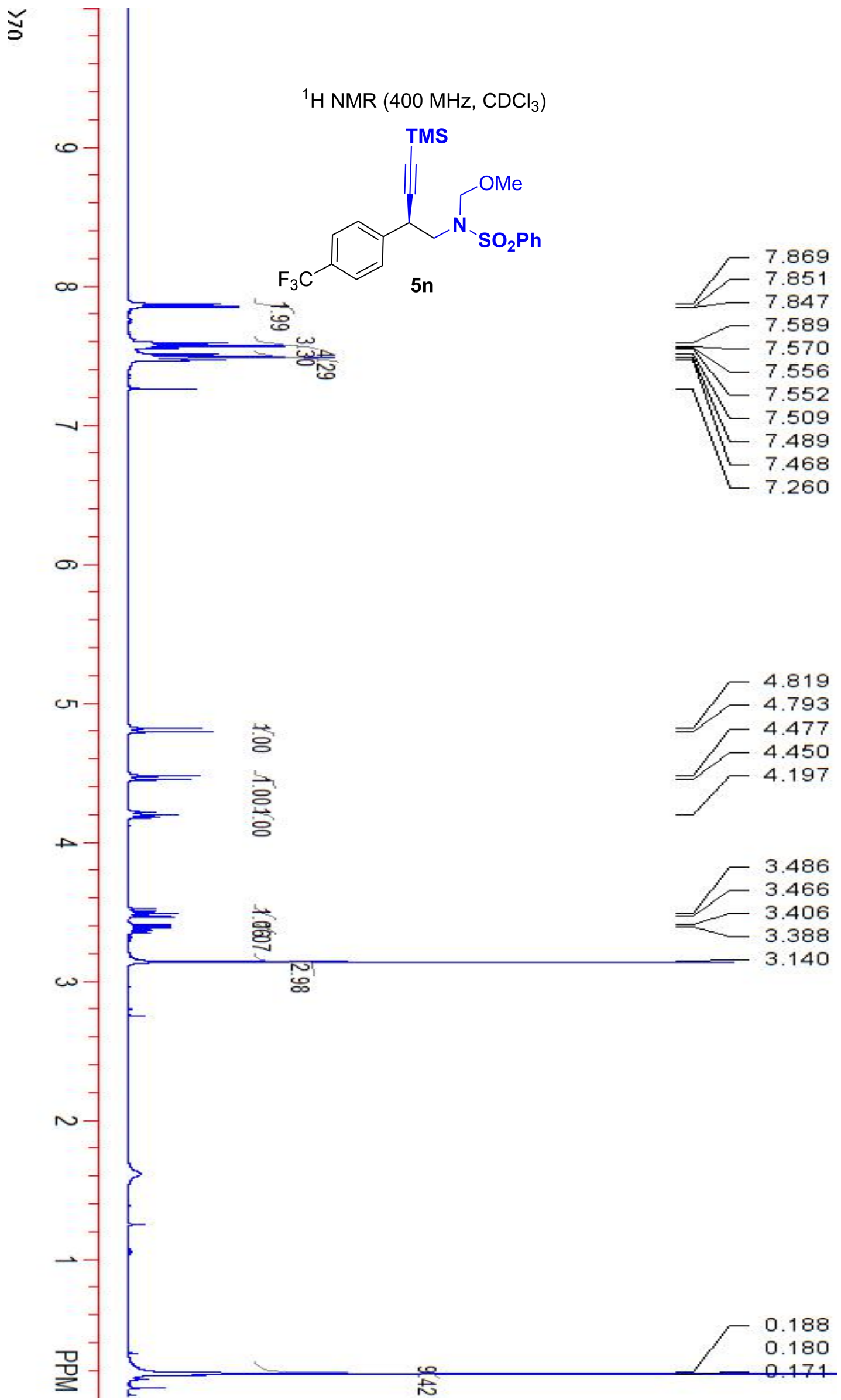




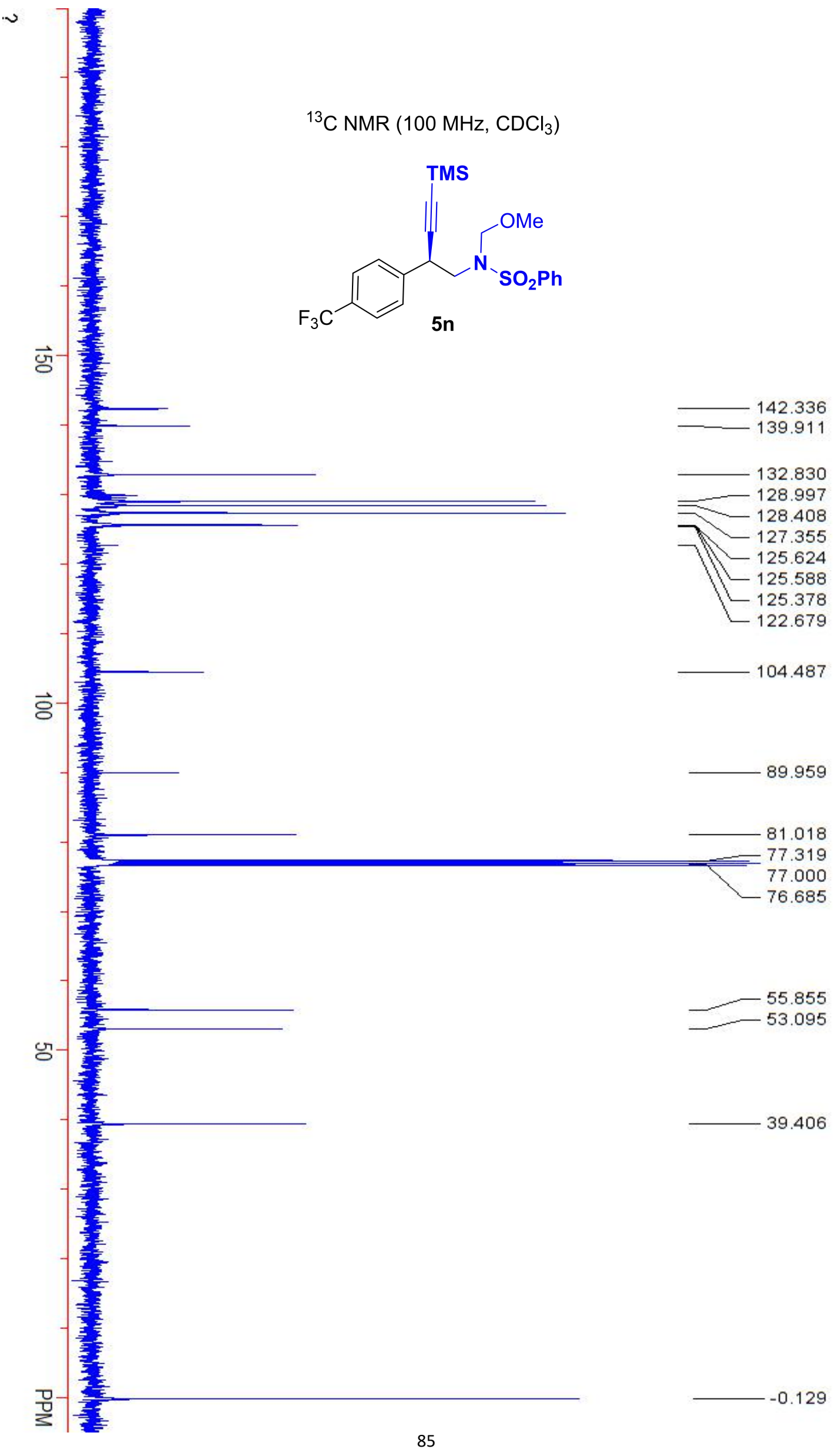




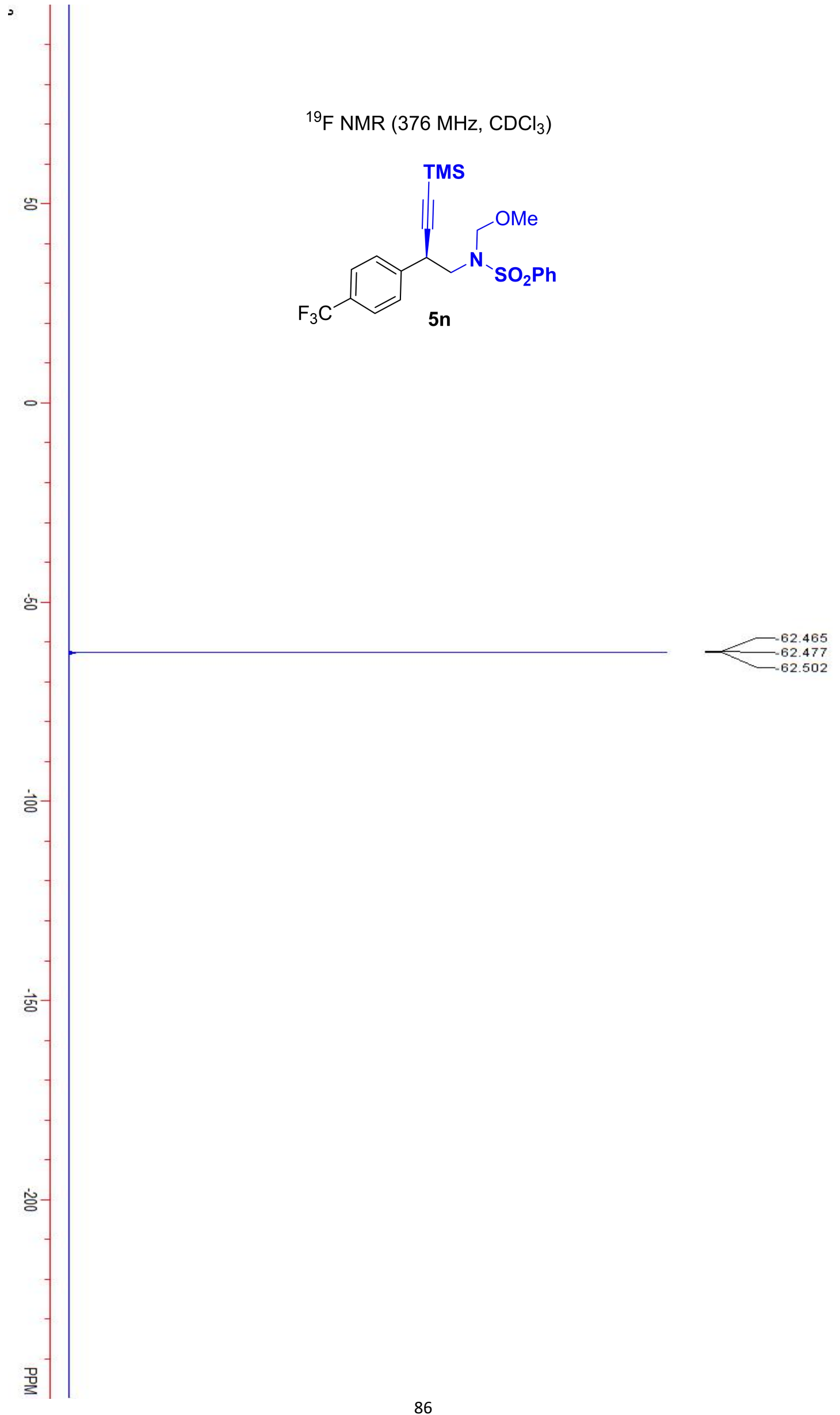




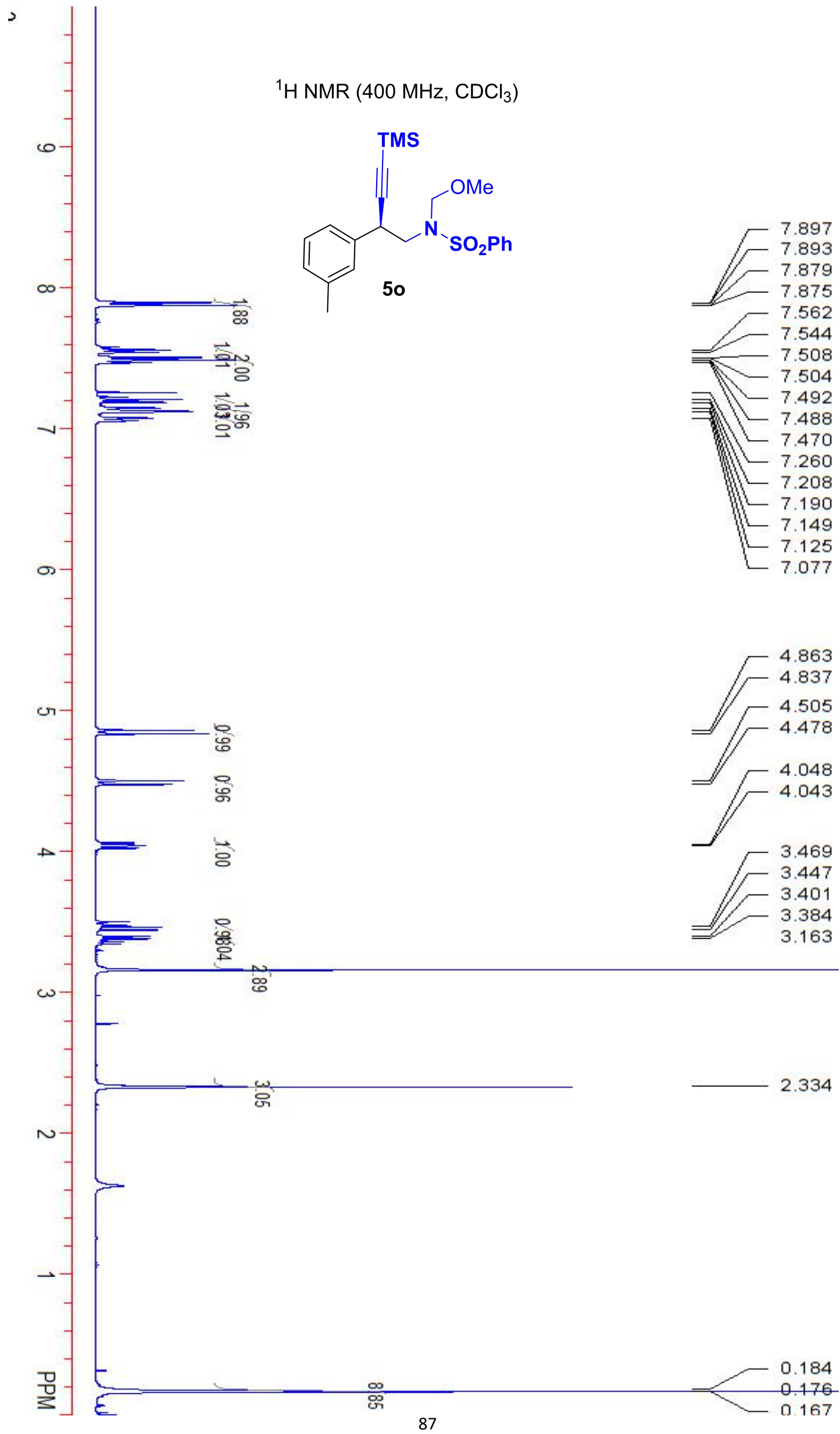




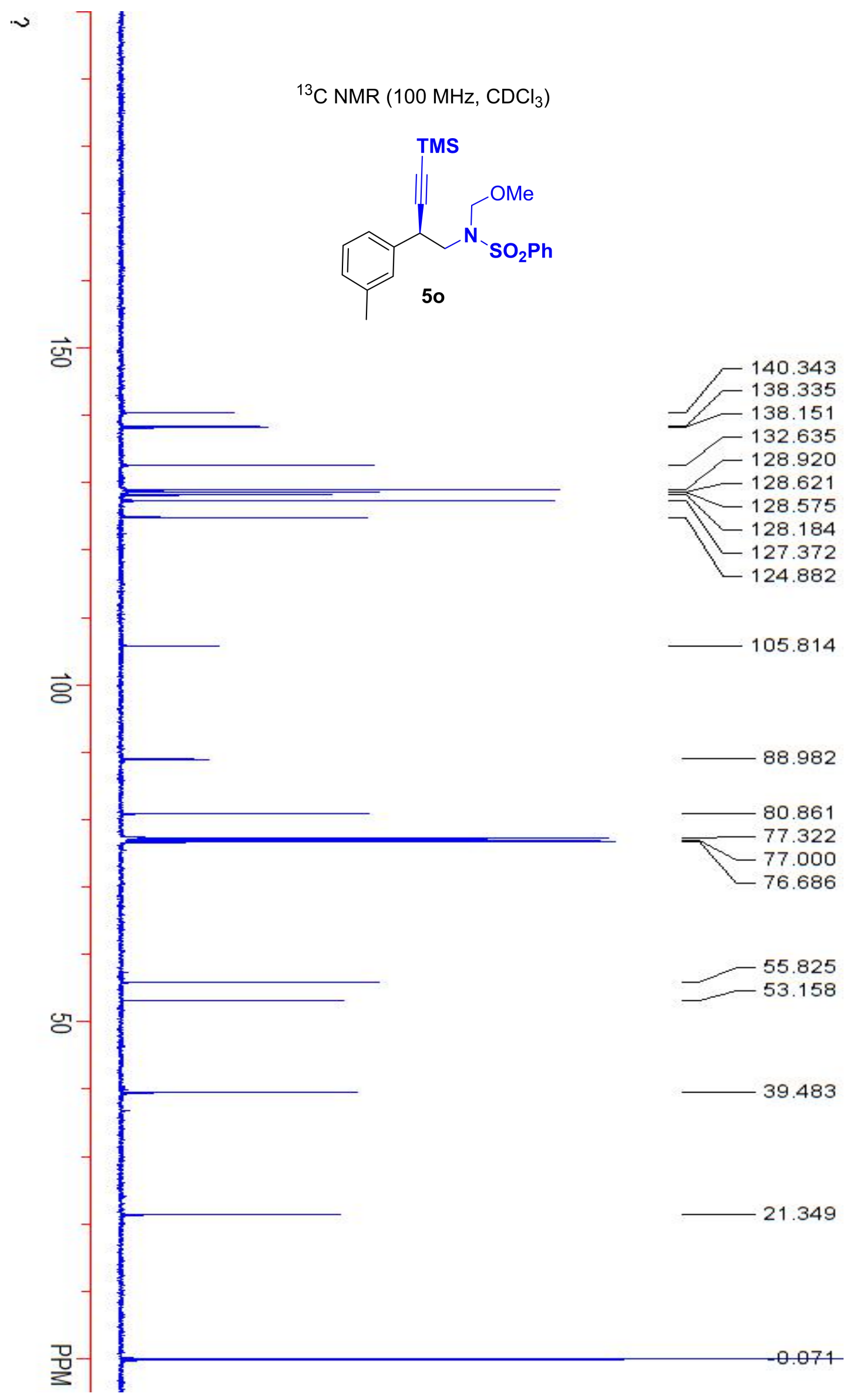




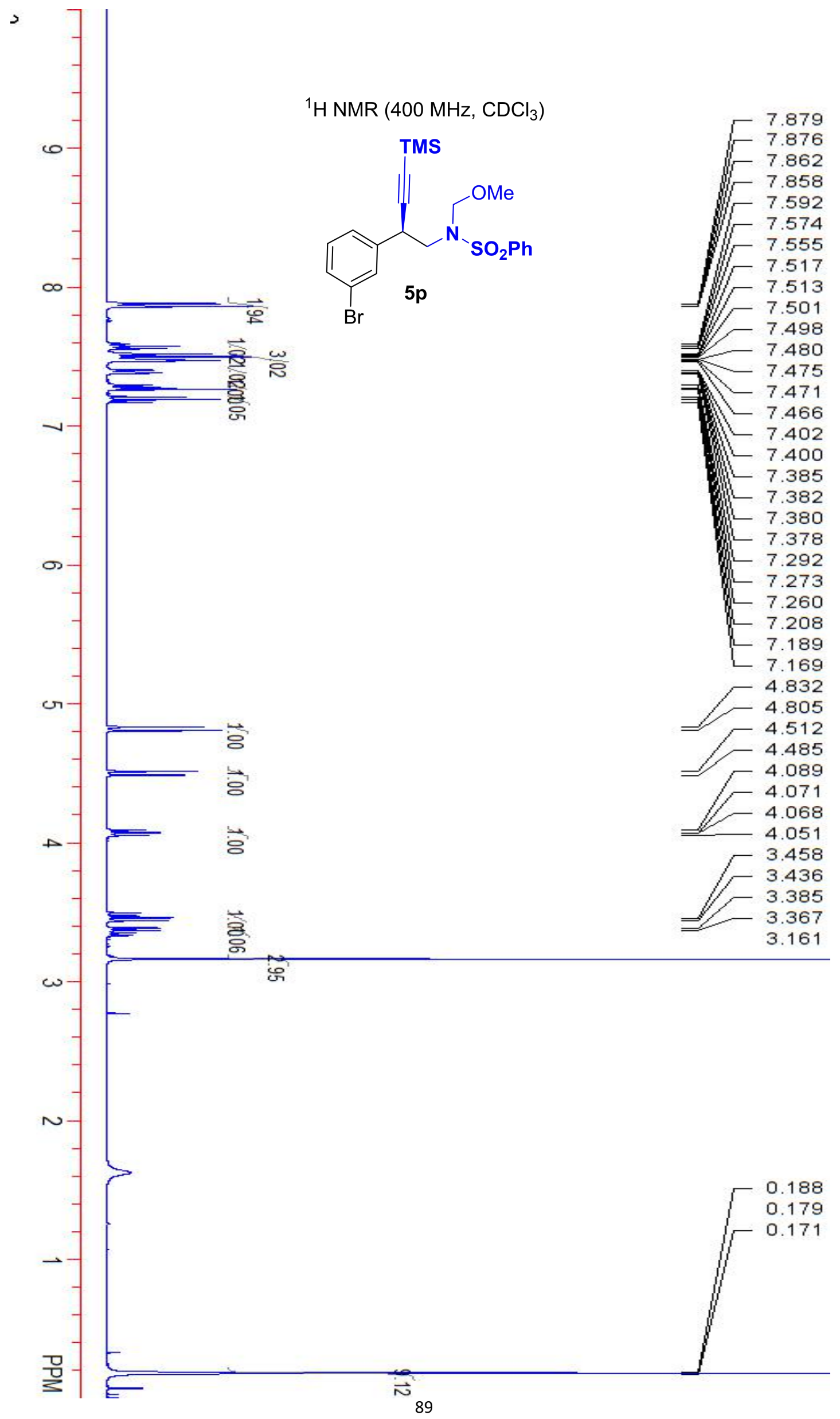



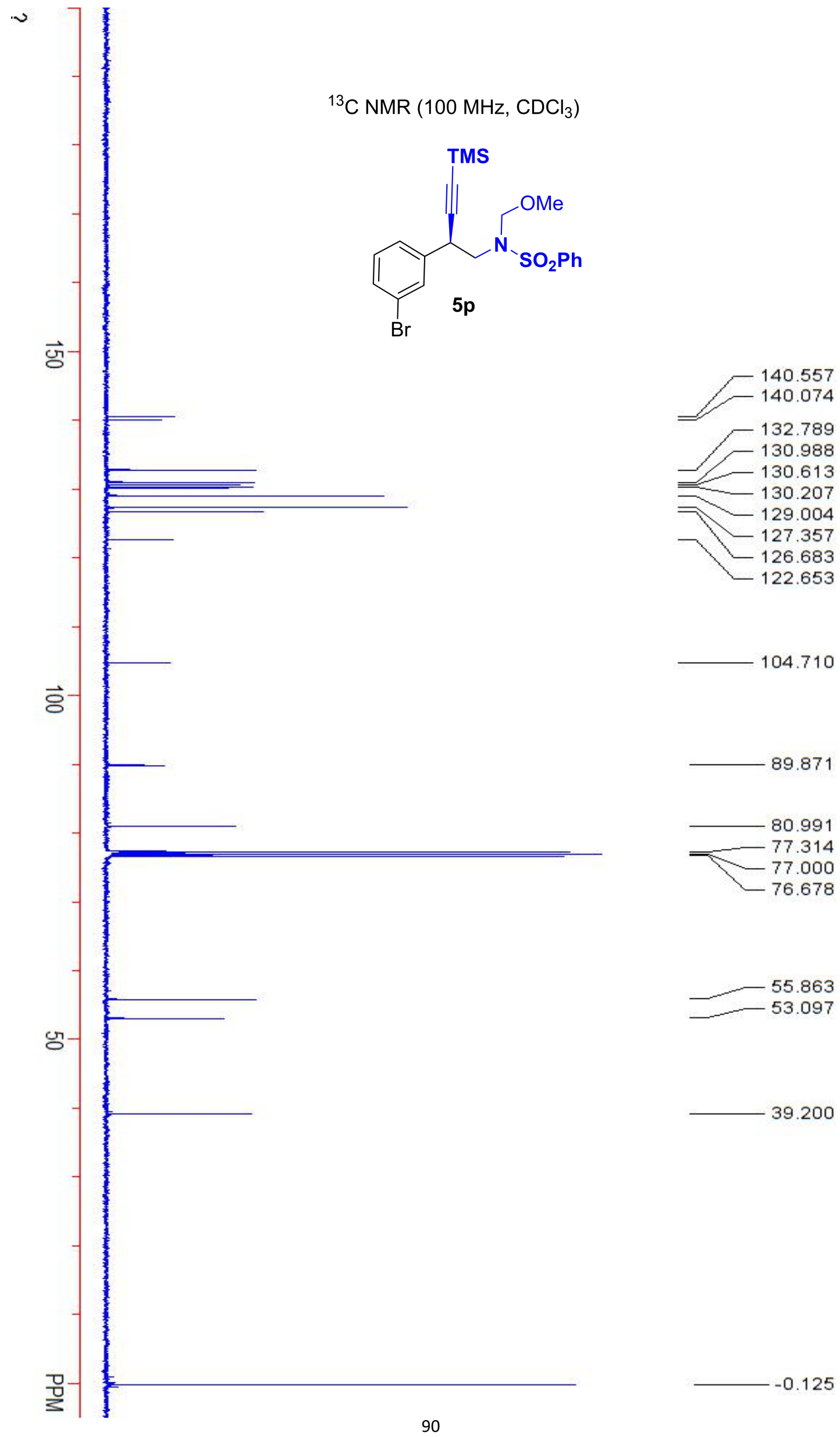

104.710

89.871
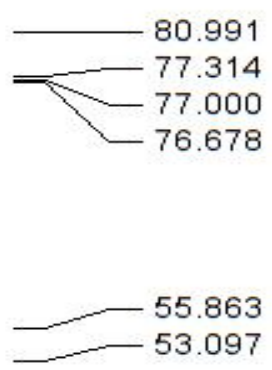

39.200 


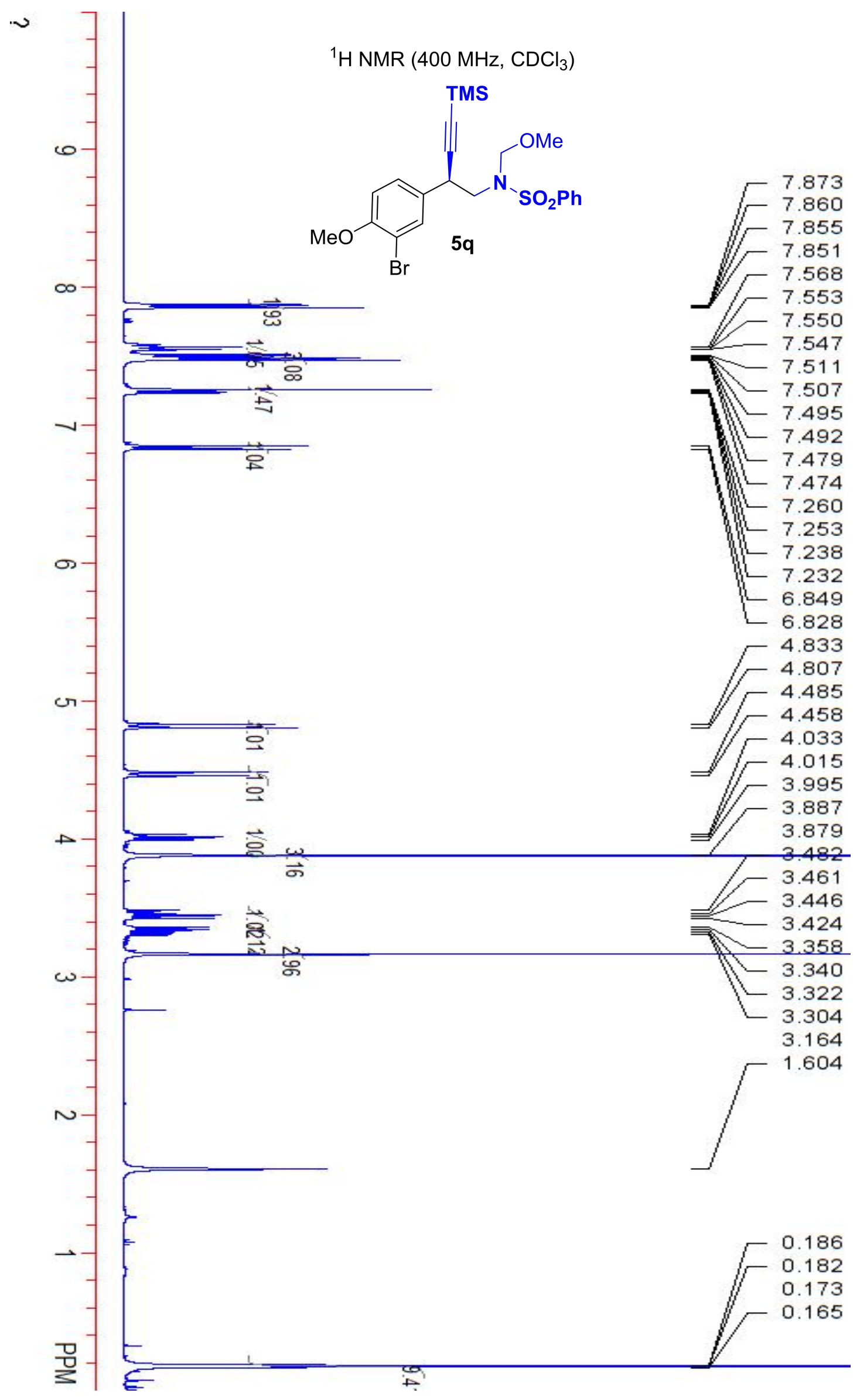


$\check{כ}$

${ }^{13} \mathrm{C} \mathrm{NMR}\left(100 \mathrm{MHz}, \mathrm{CDCl}_{3}\right)$<smiles>CC#C[C@@H](CN(COC)S(=O)(=O)c1ccccc1)c1ccc(OC)c(Br)c1</smiles>

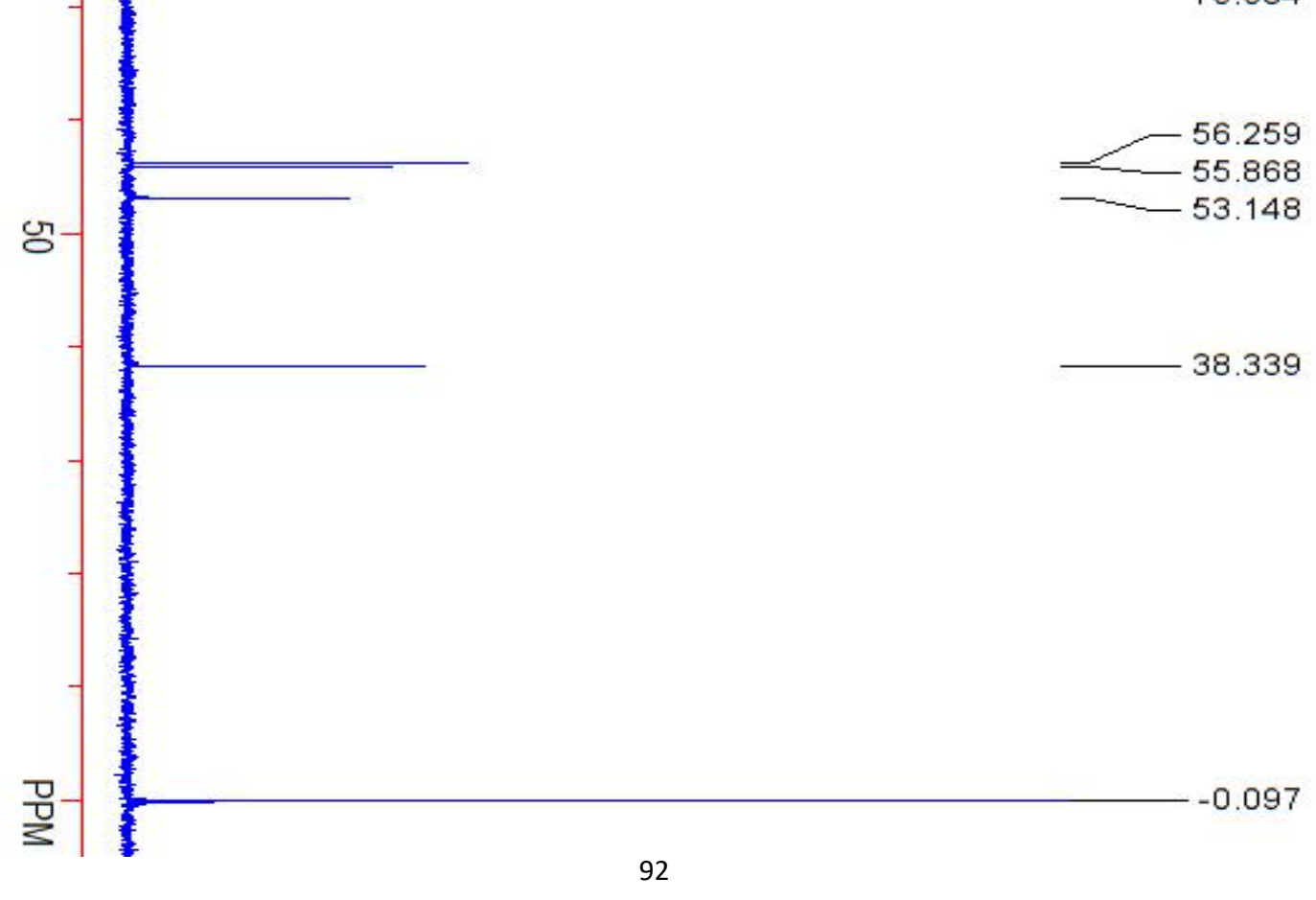




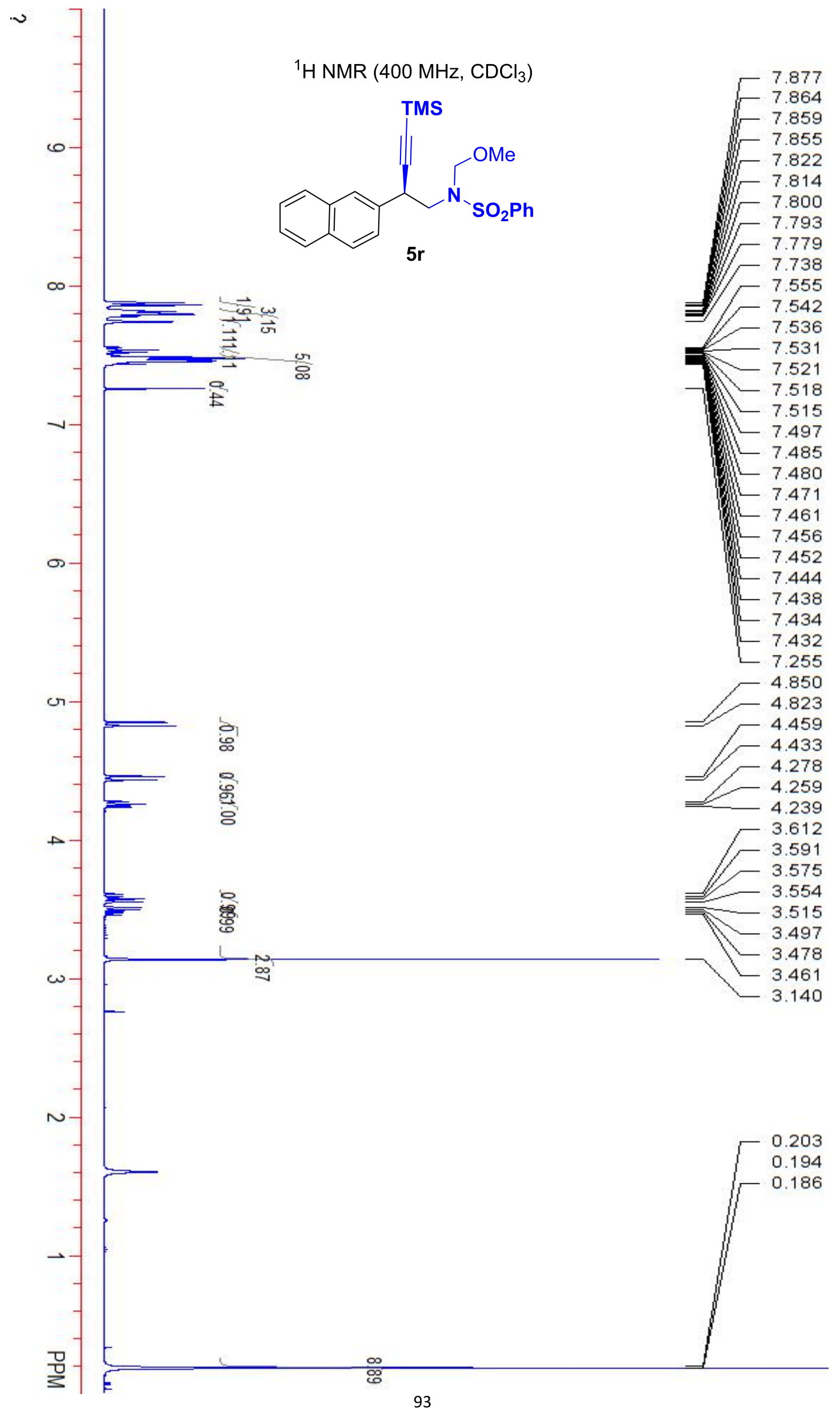




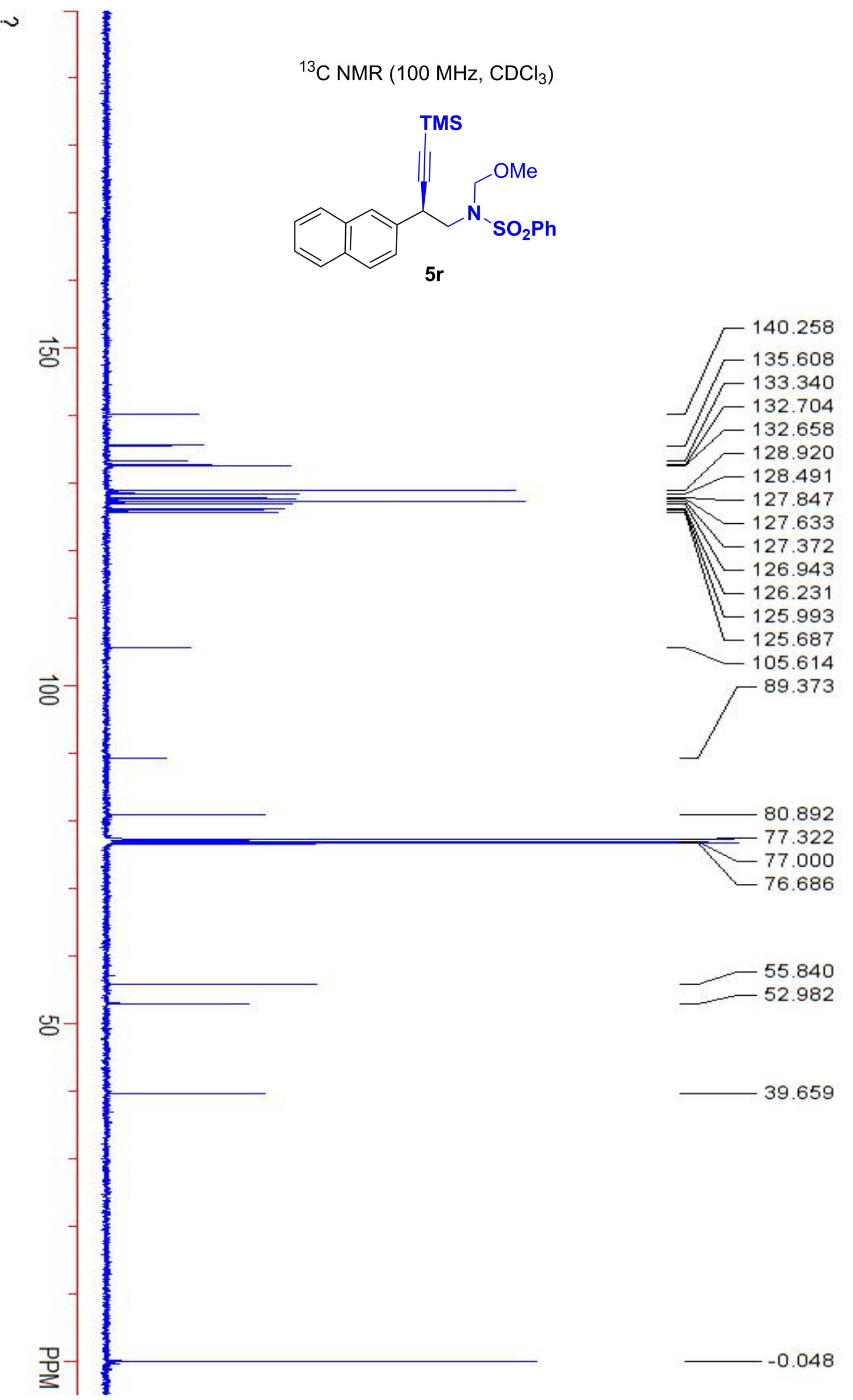




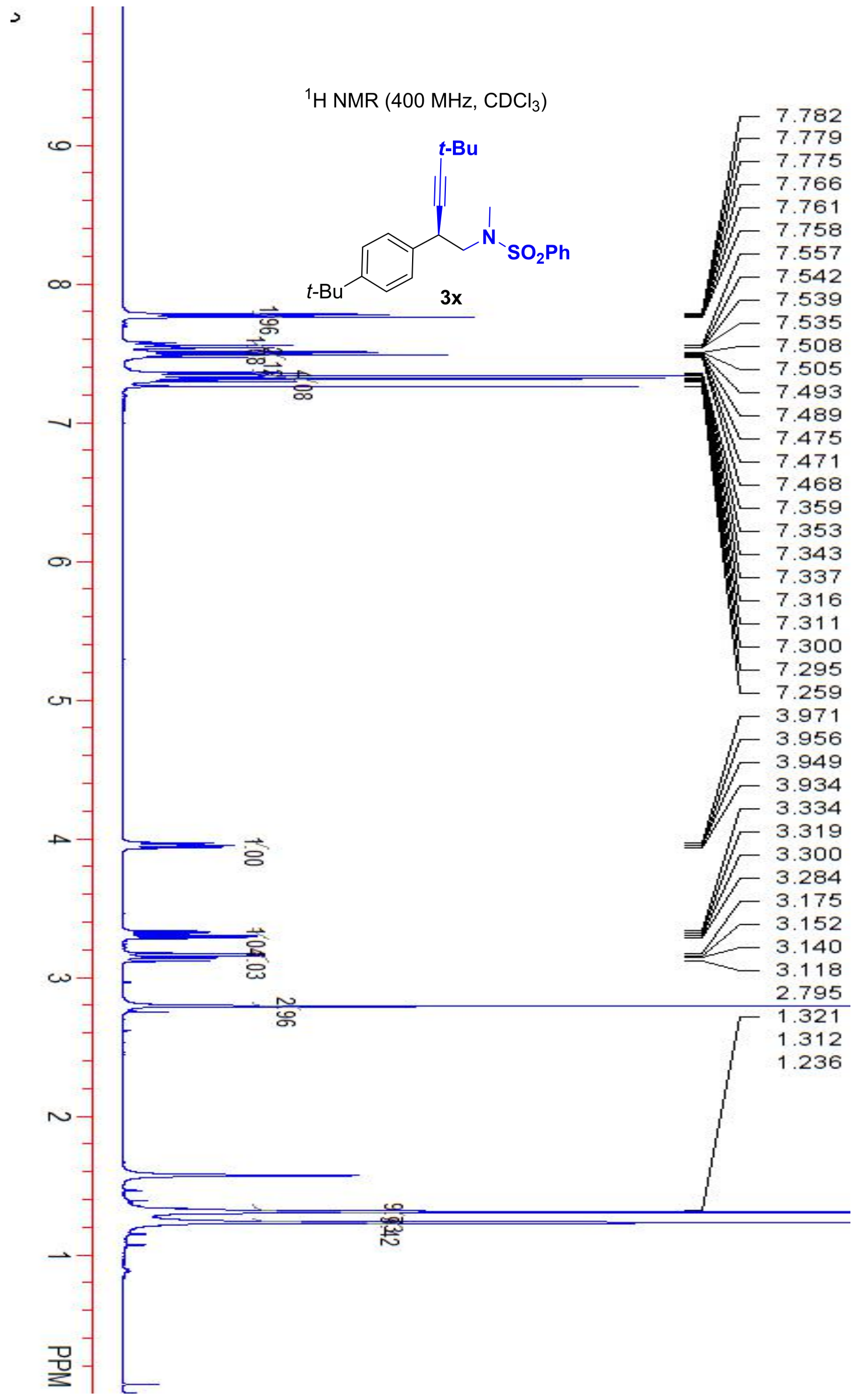




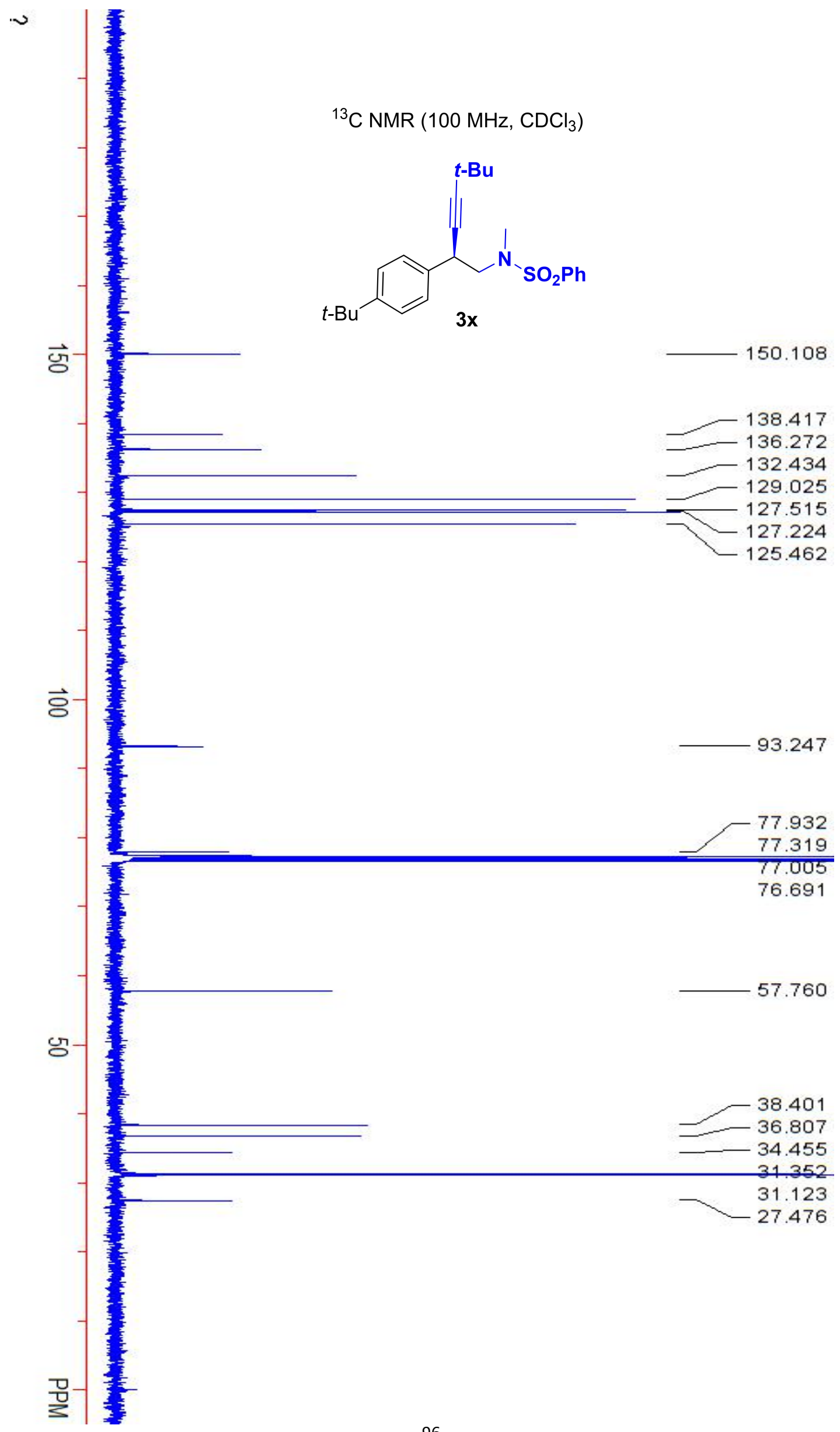




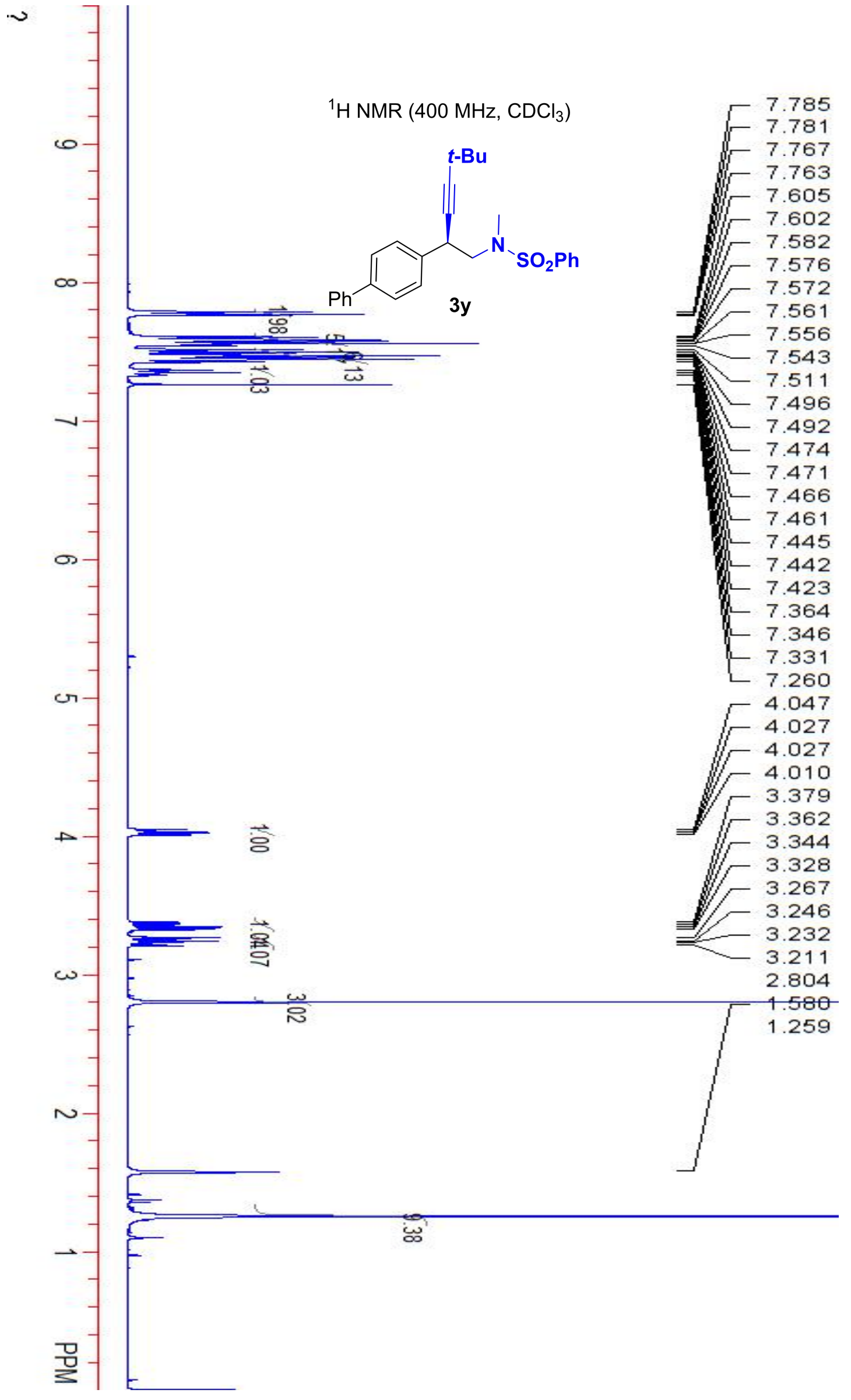




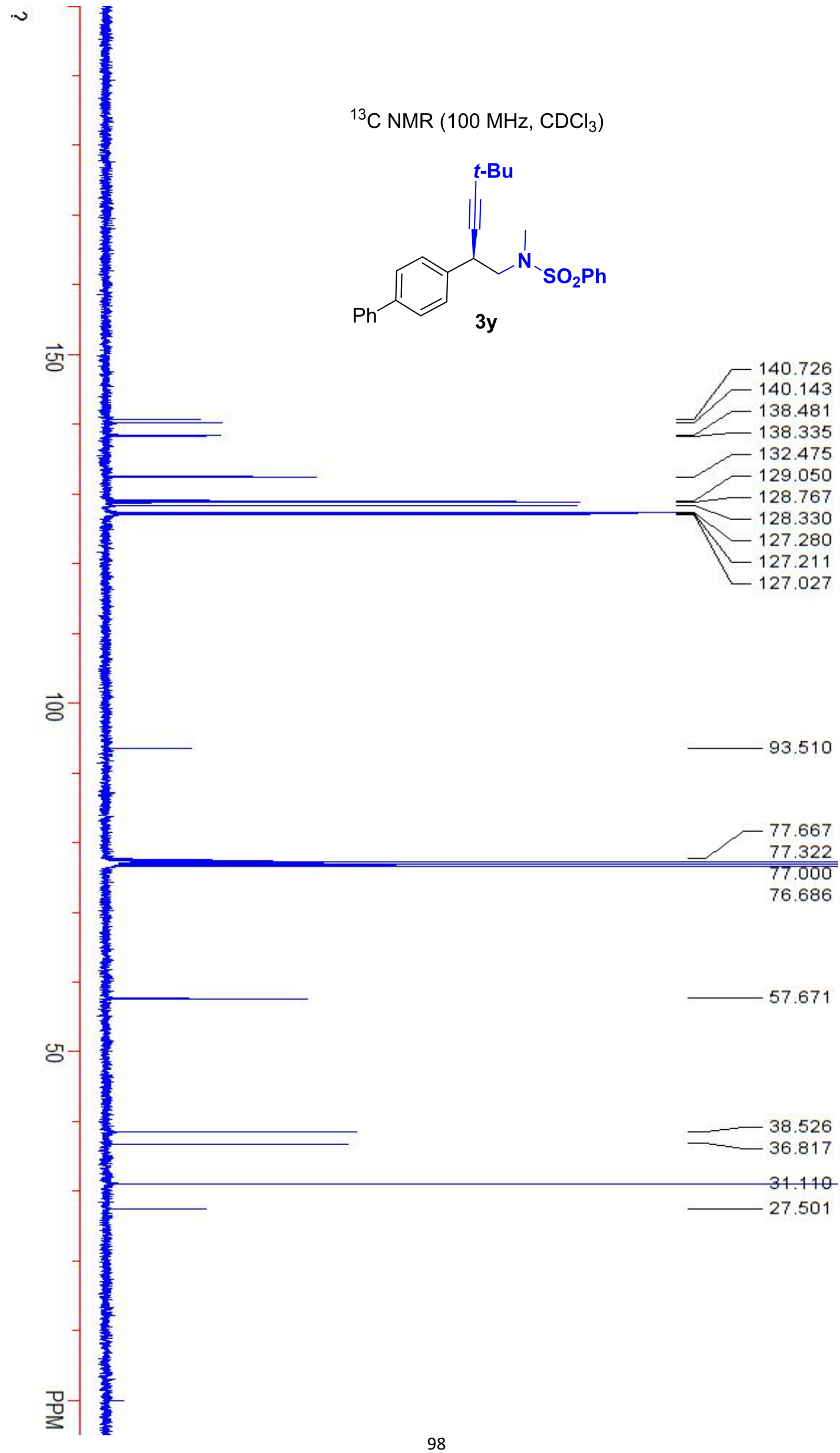




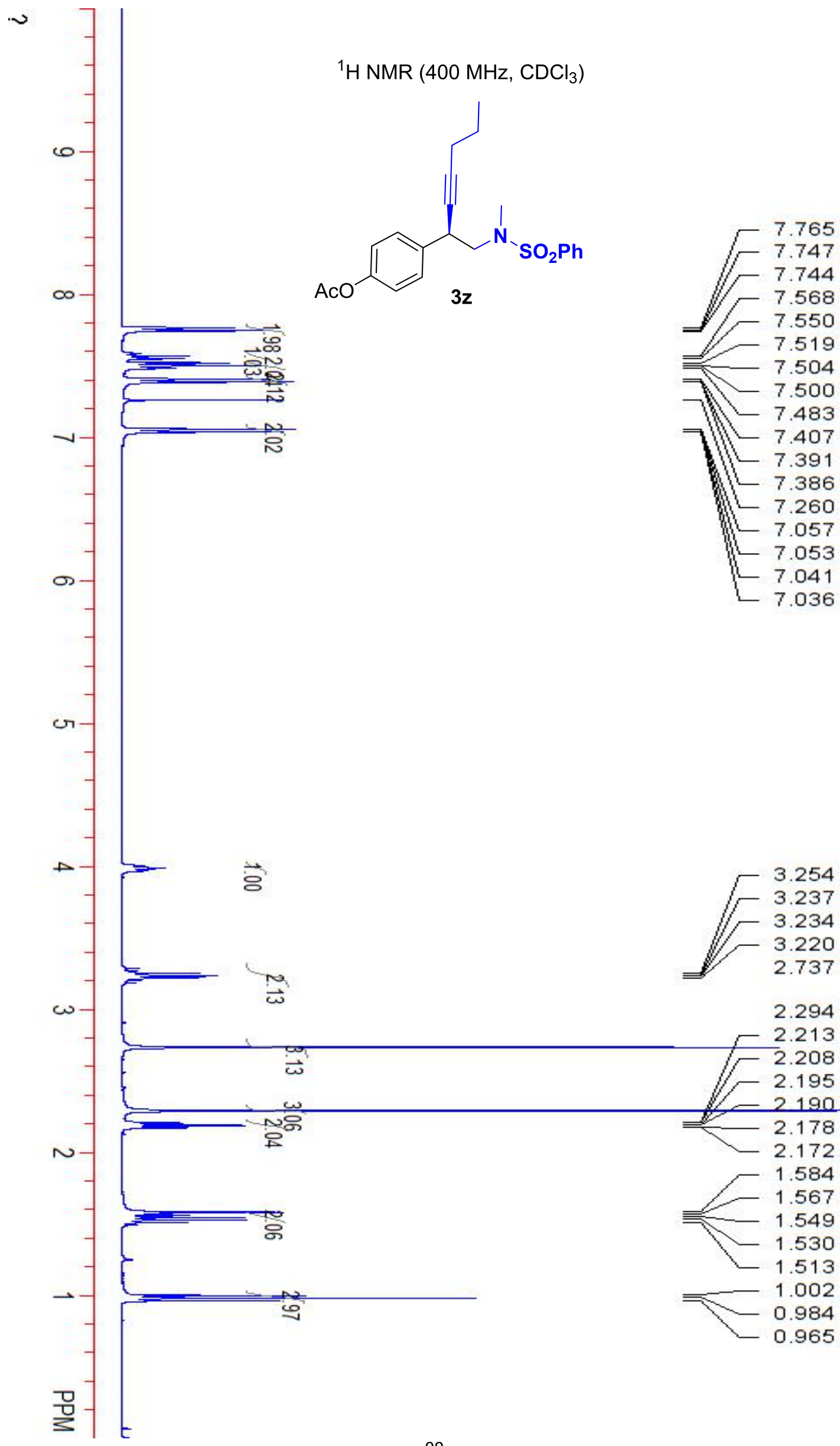




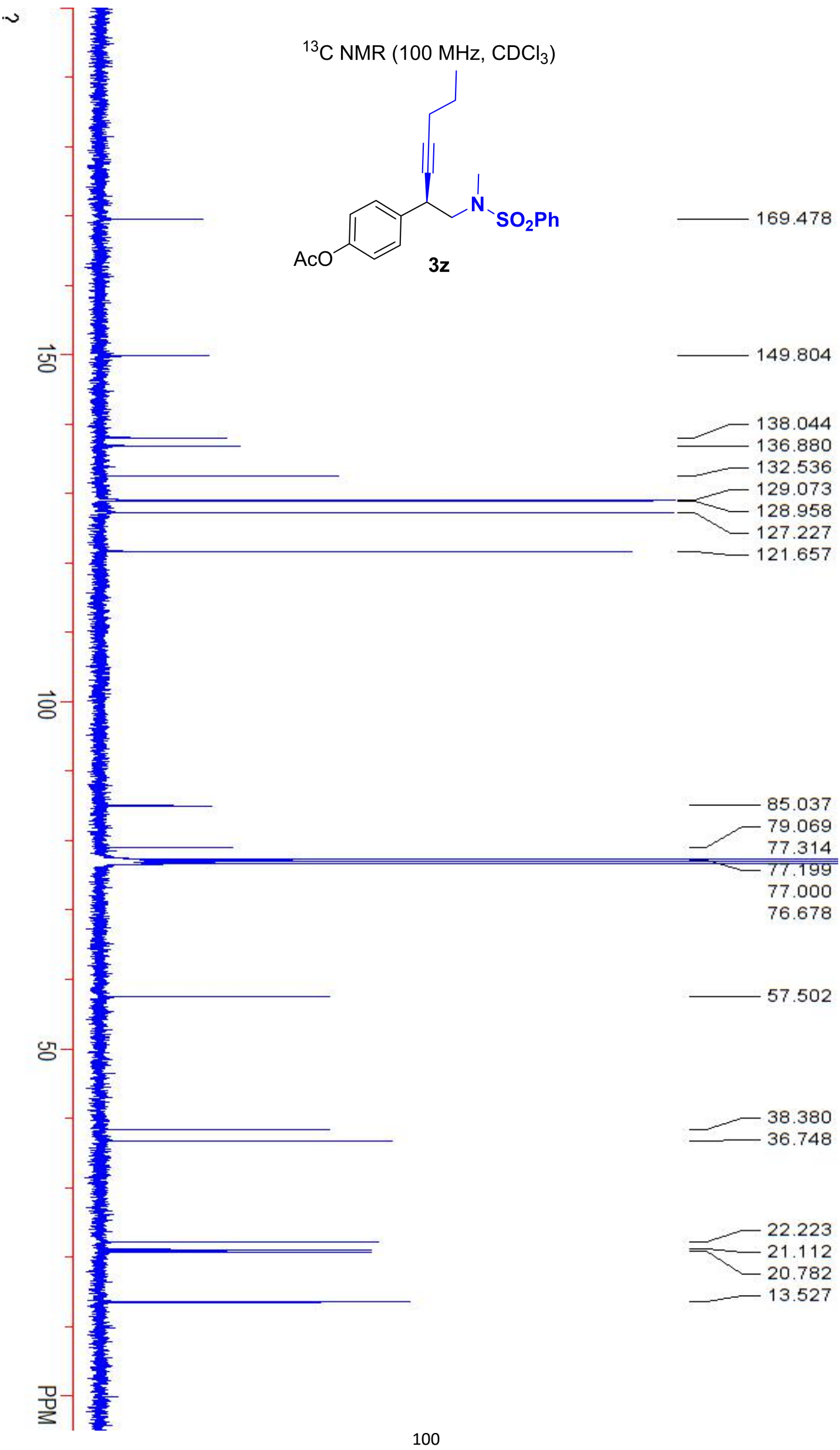




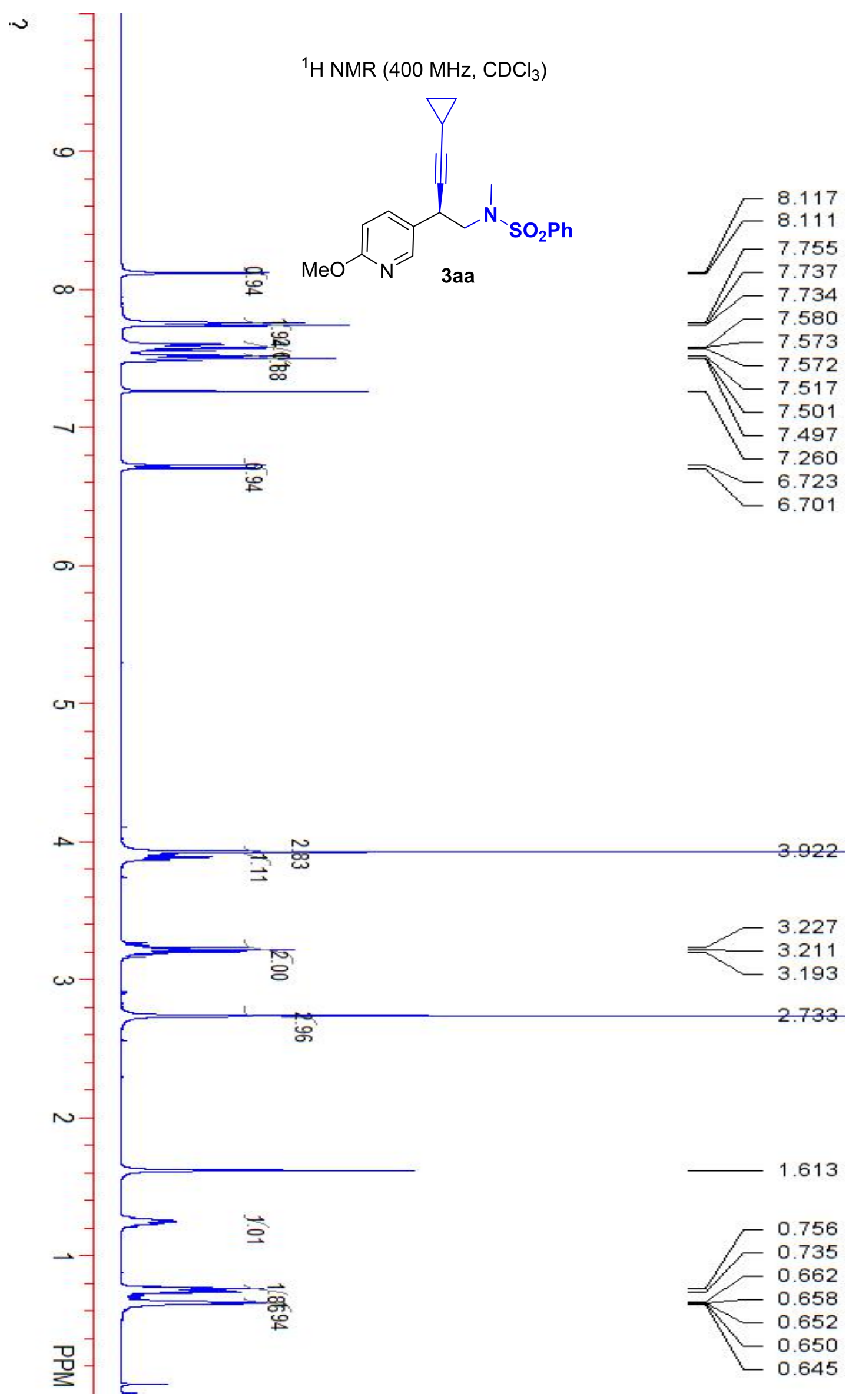




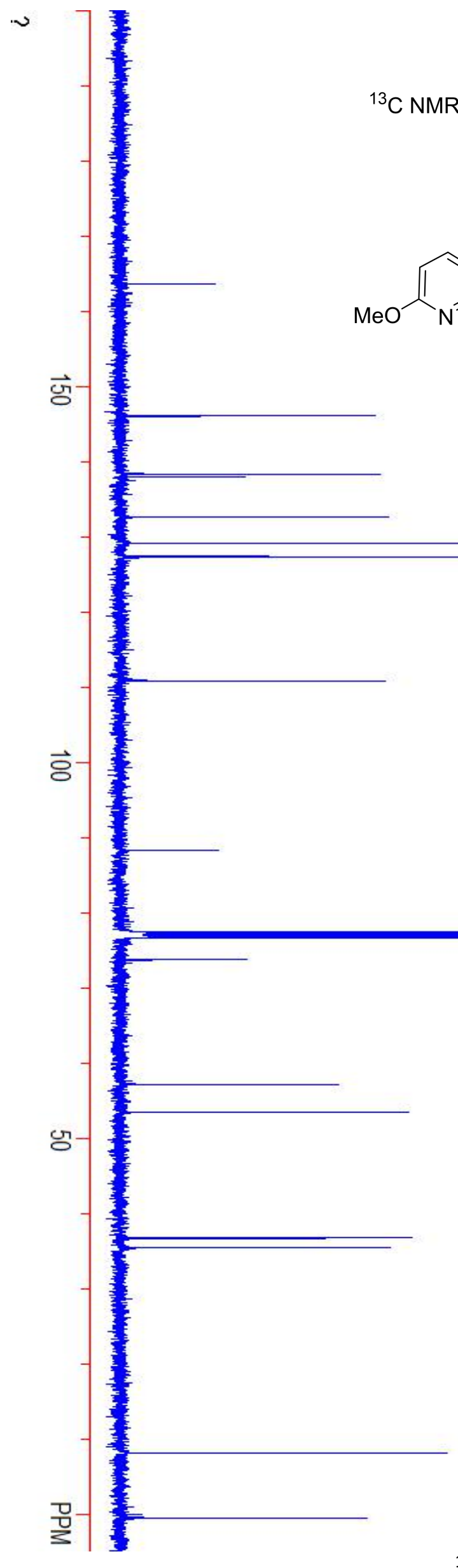

146.012

$-138.305$

137.960

132.605

129.088

127.426

127.219

110.801

88.216

77.322

77.207

76.686

73.667

57.104

53.434

36.656

35.369

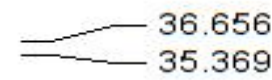

8.111

8.080

$-0.508$ 


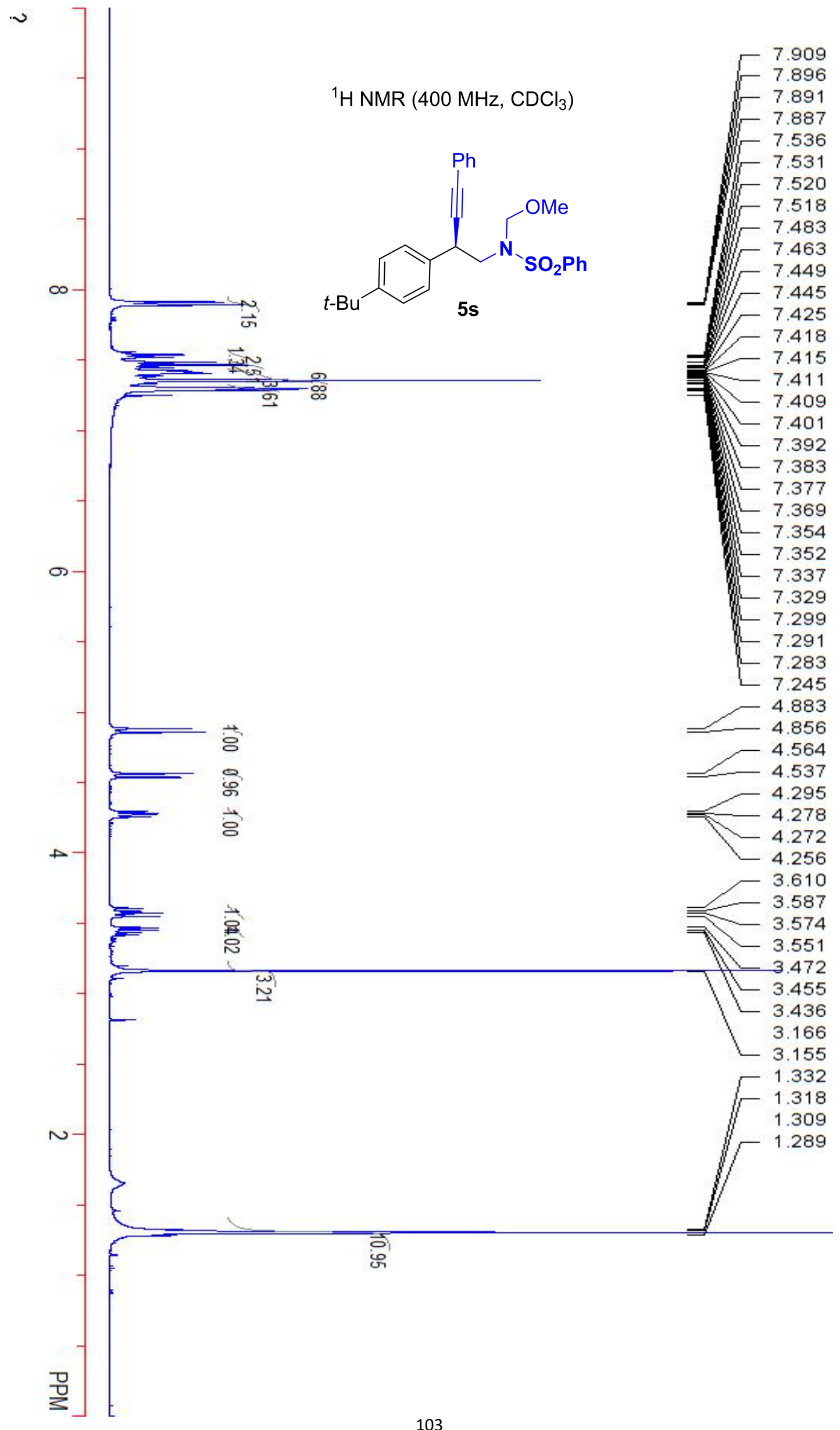




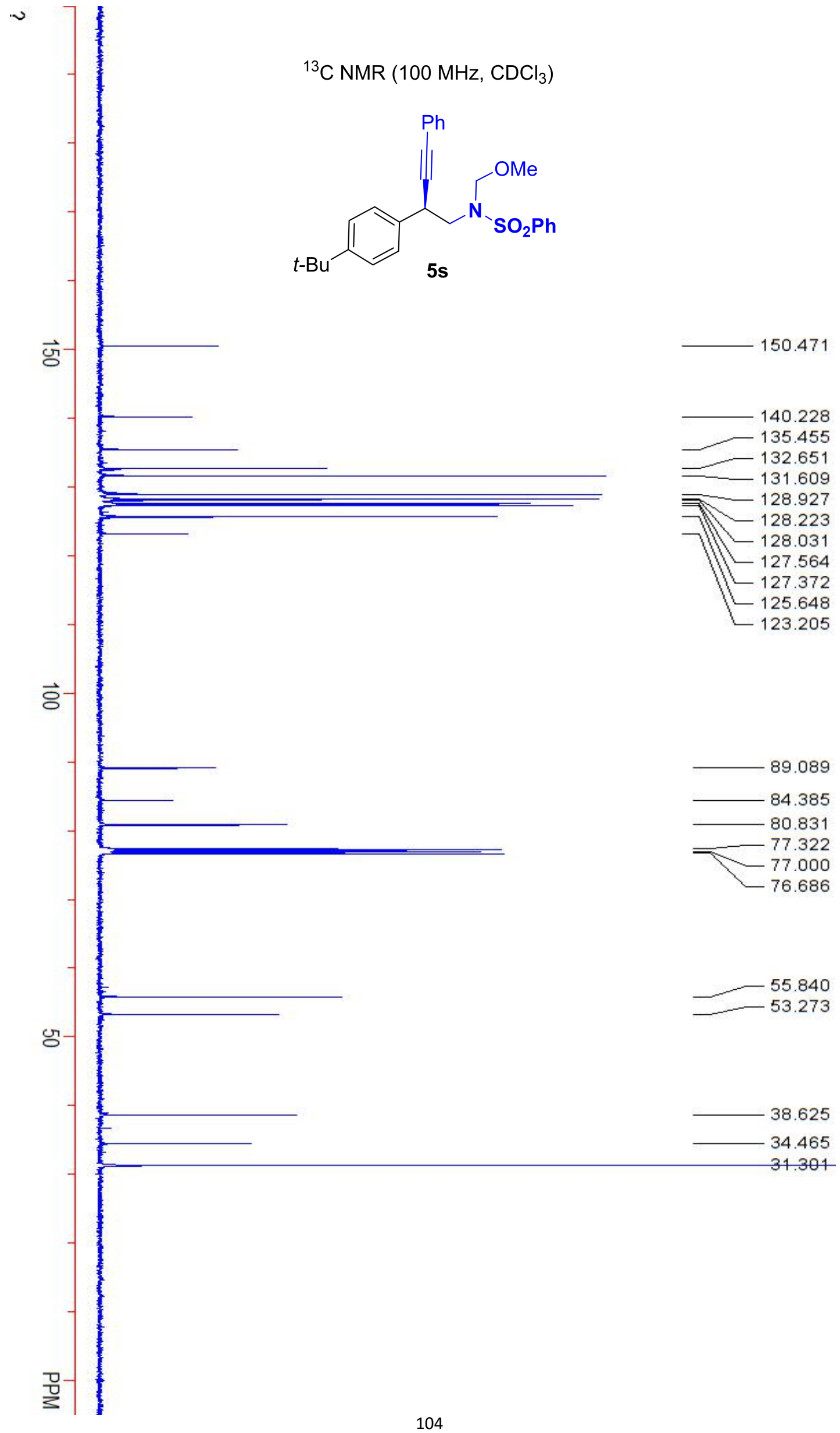




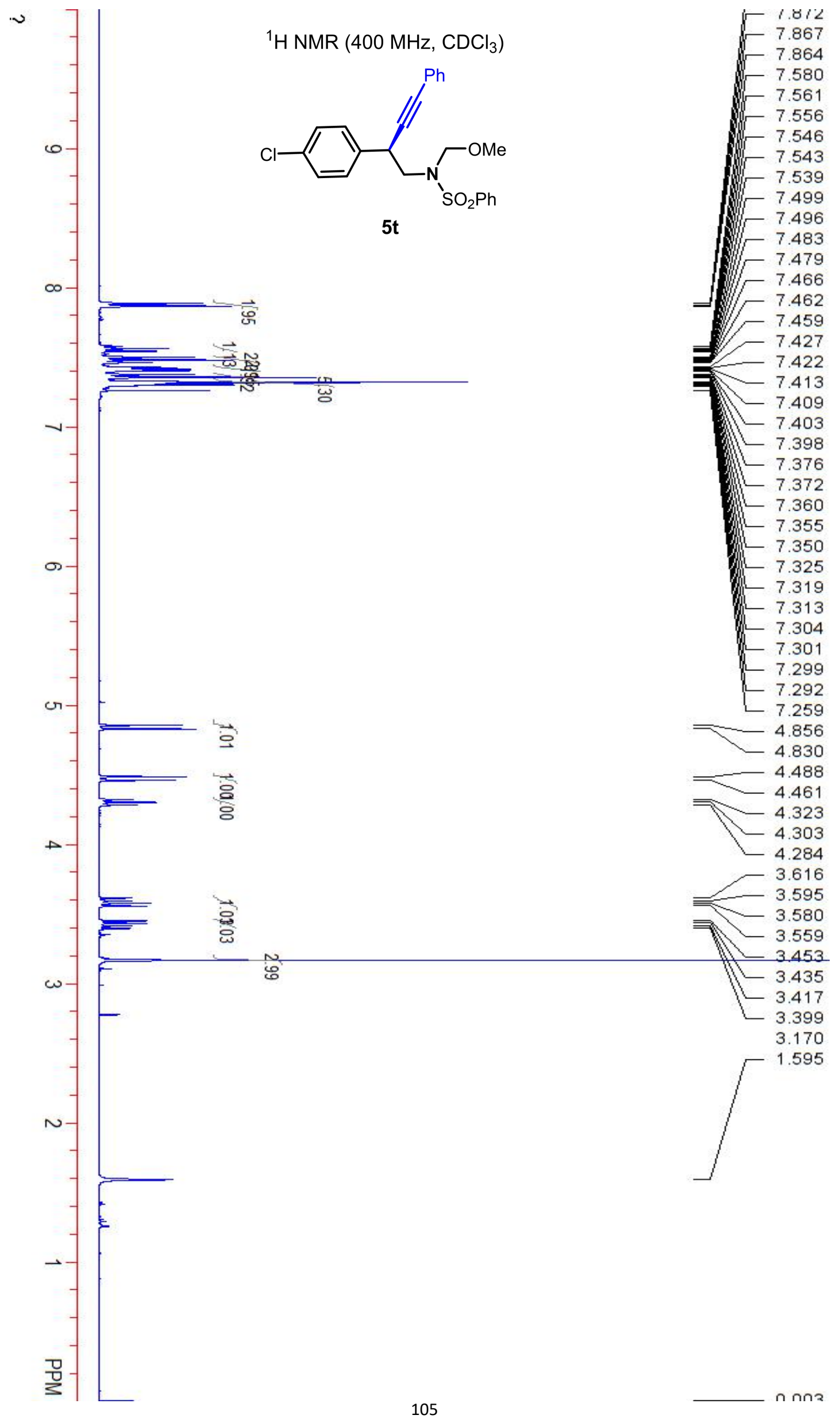


$\check{\check{J}}$ ${ }^{13} \mathrm{C}$ NMR $\left(100 \mathrm{MHz}, \mathrm{CDCl}_{3}\right)$

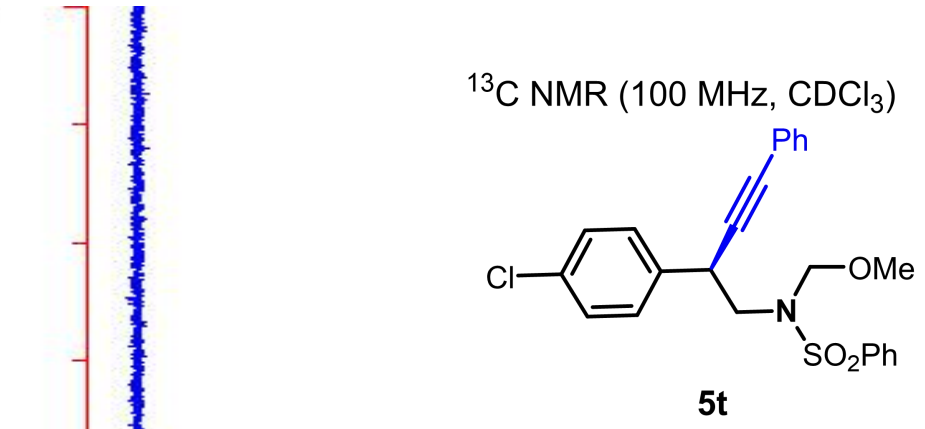

$\vec{g}$

88.201

84.883

80.968

77.000

76.686

둉

55.901

53.227

믄

38.503 


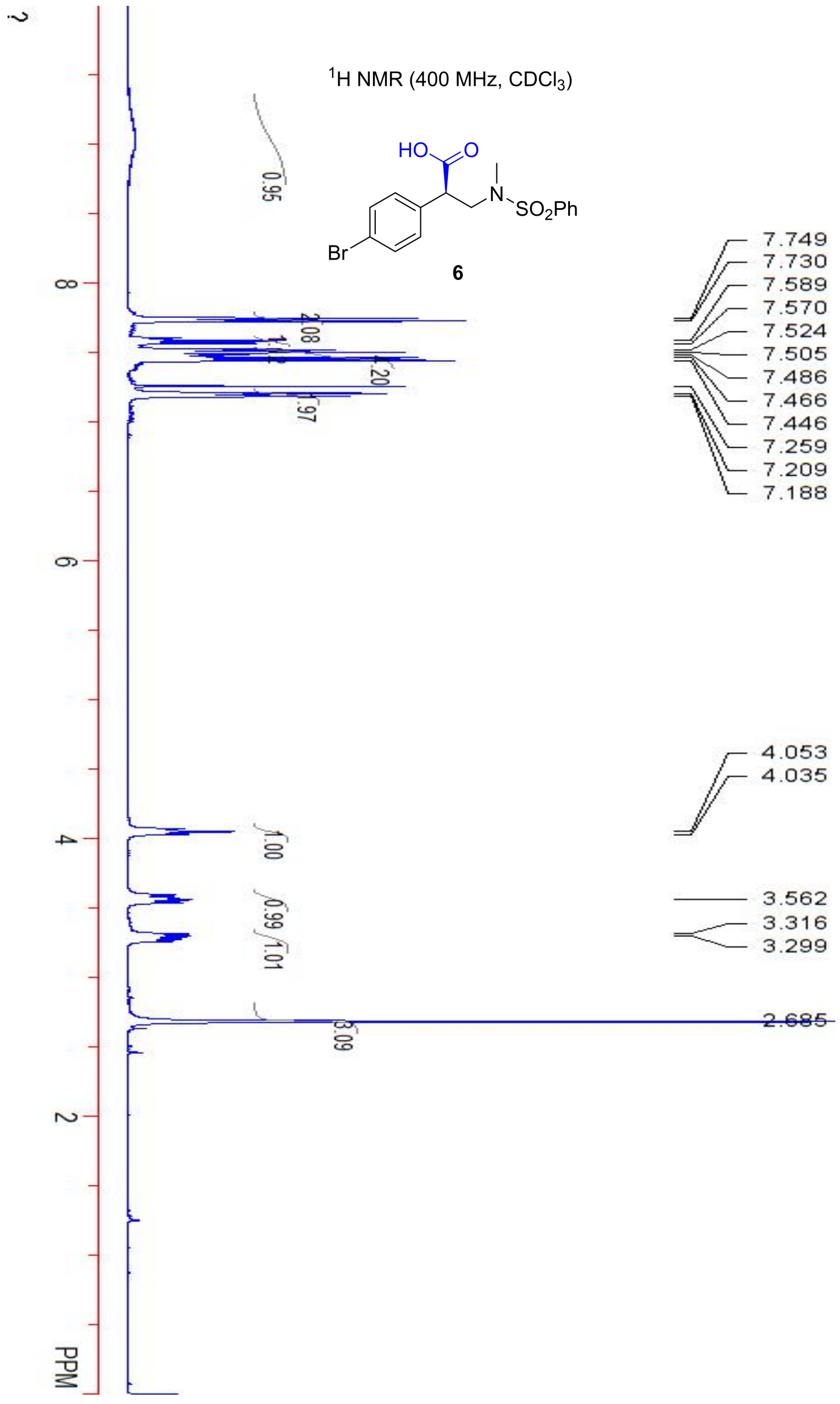




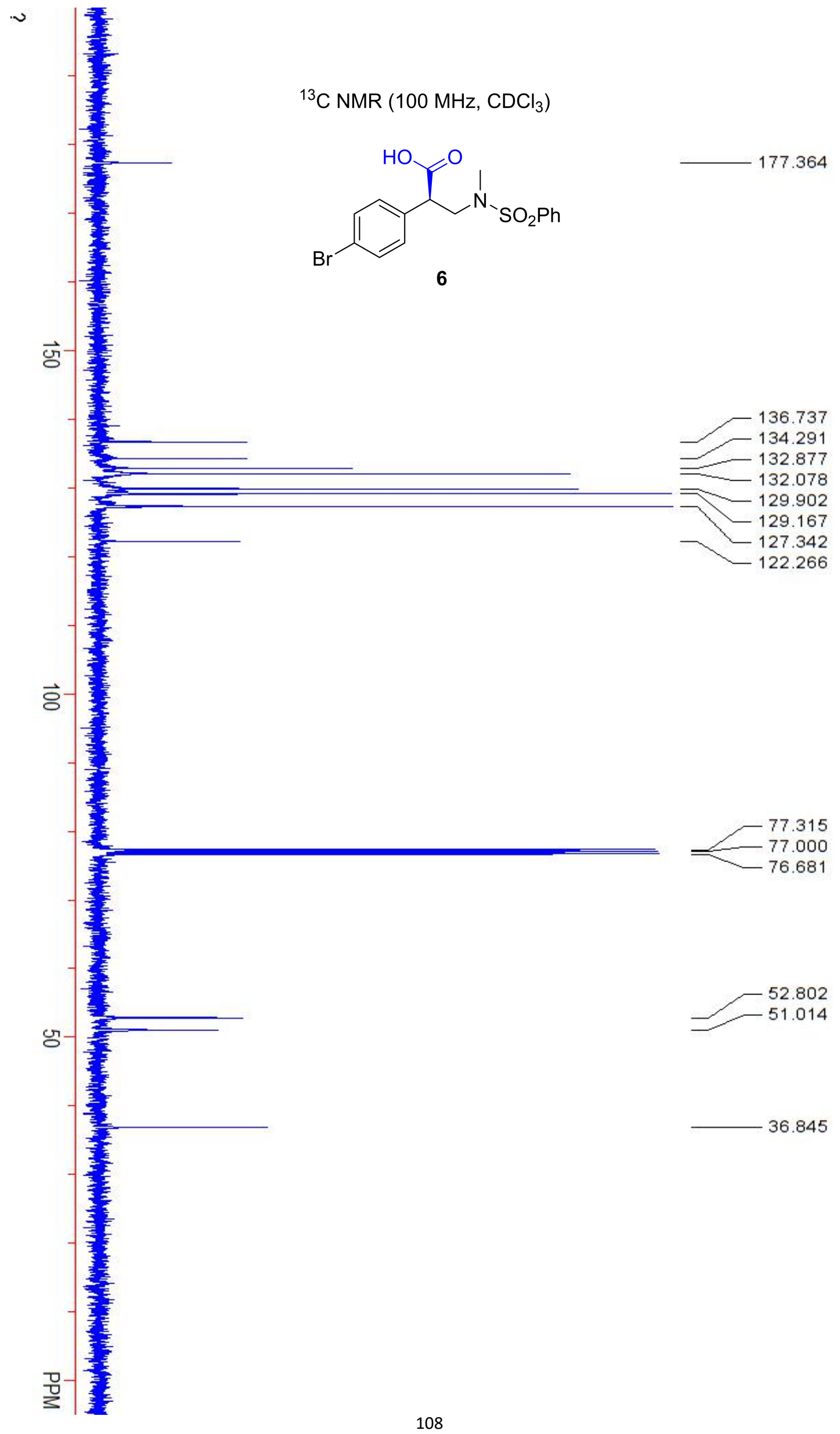




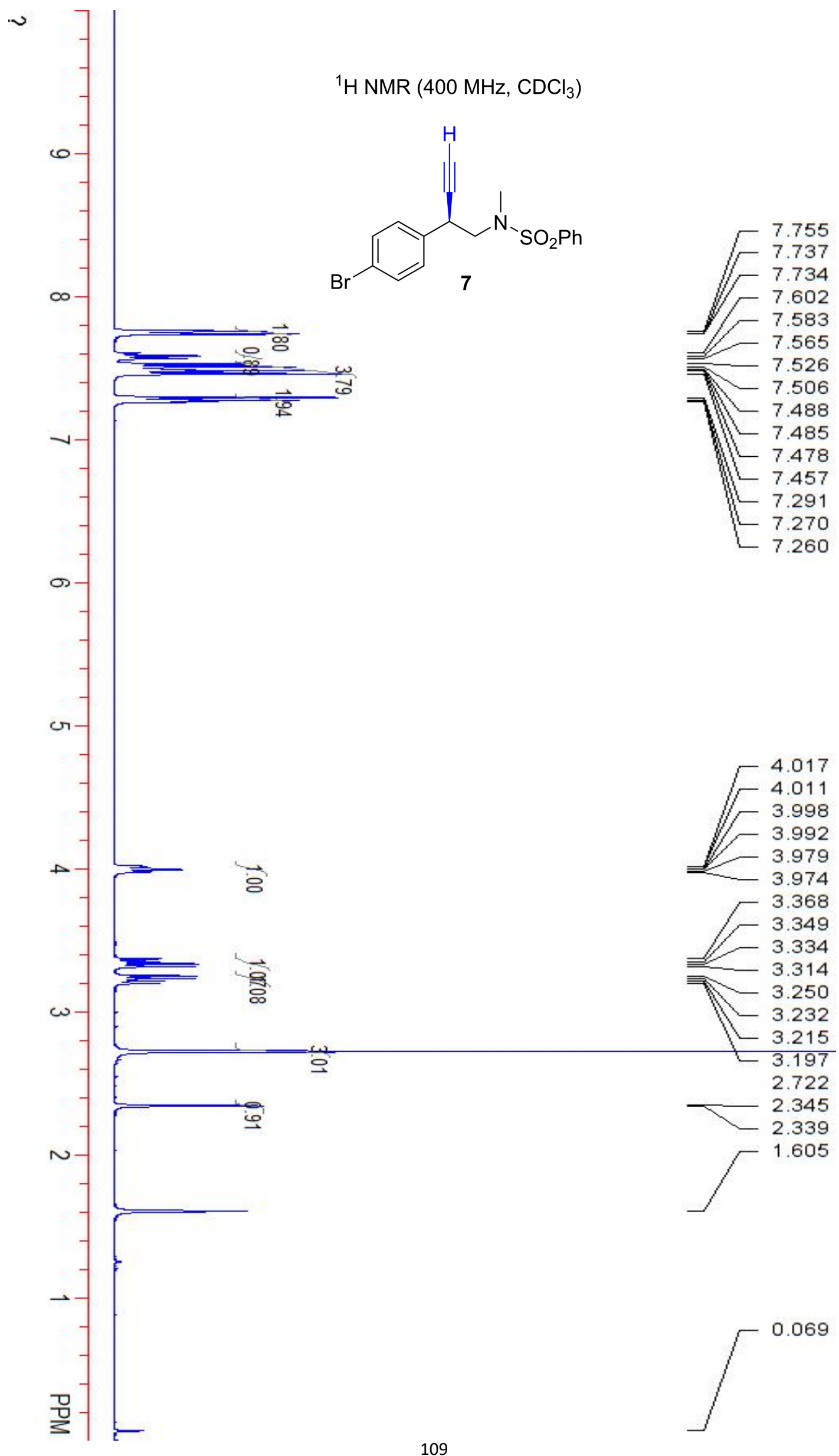




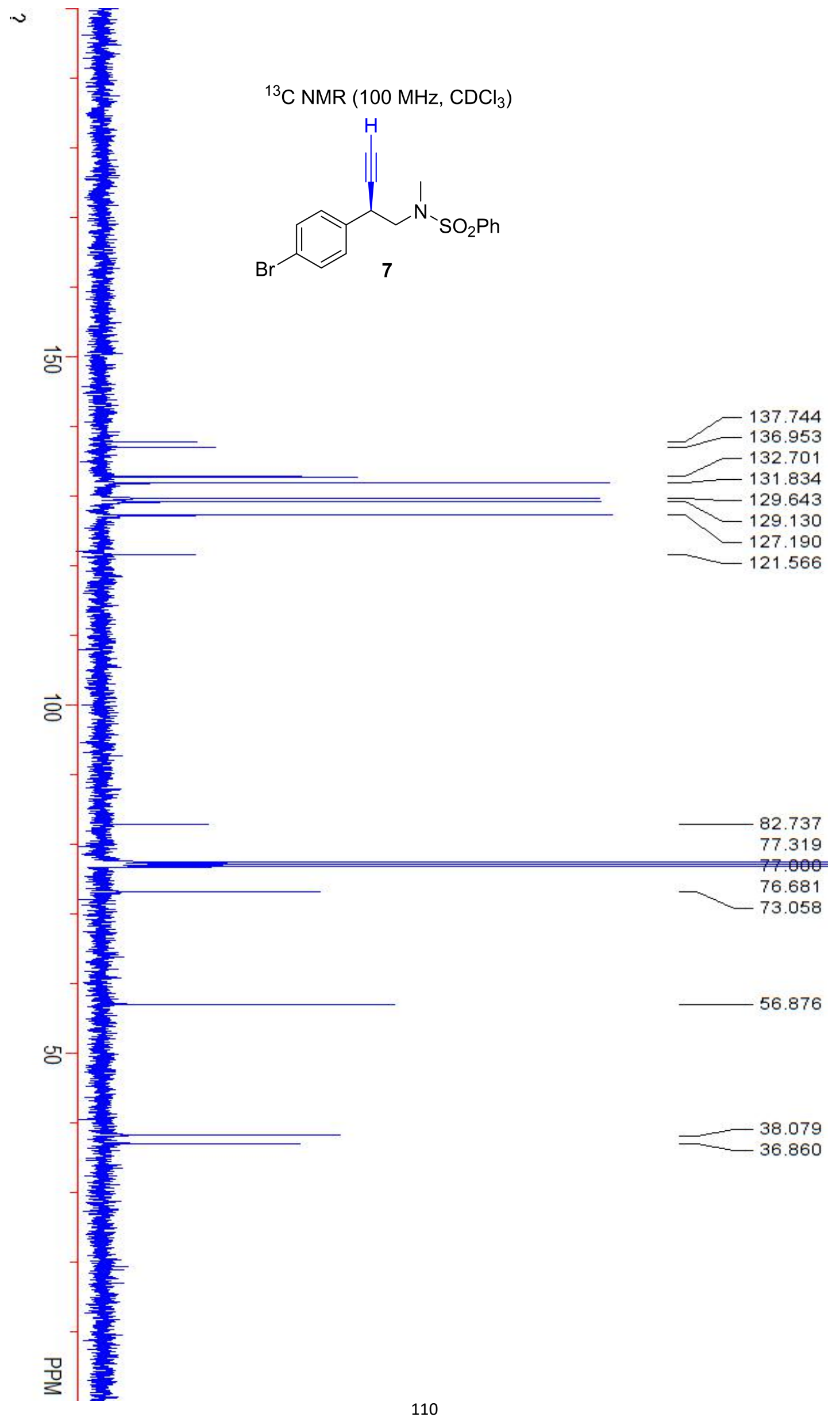




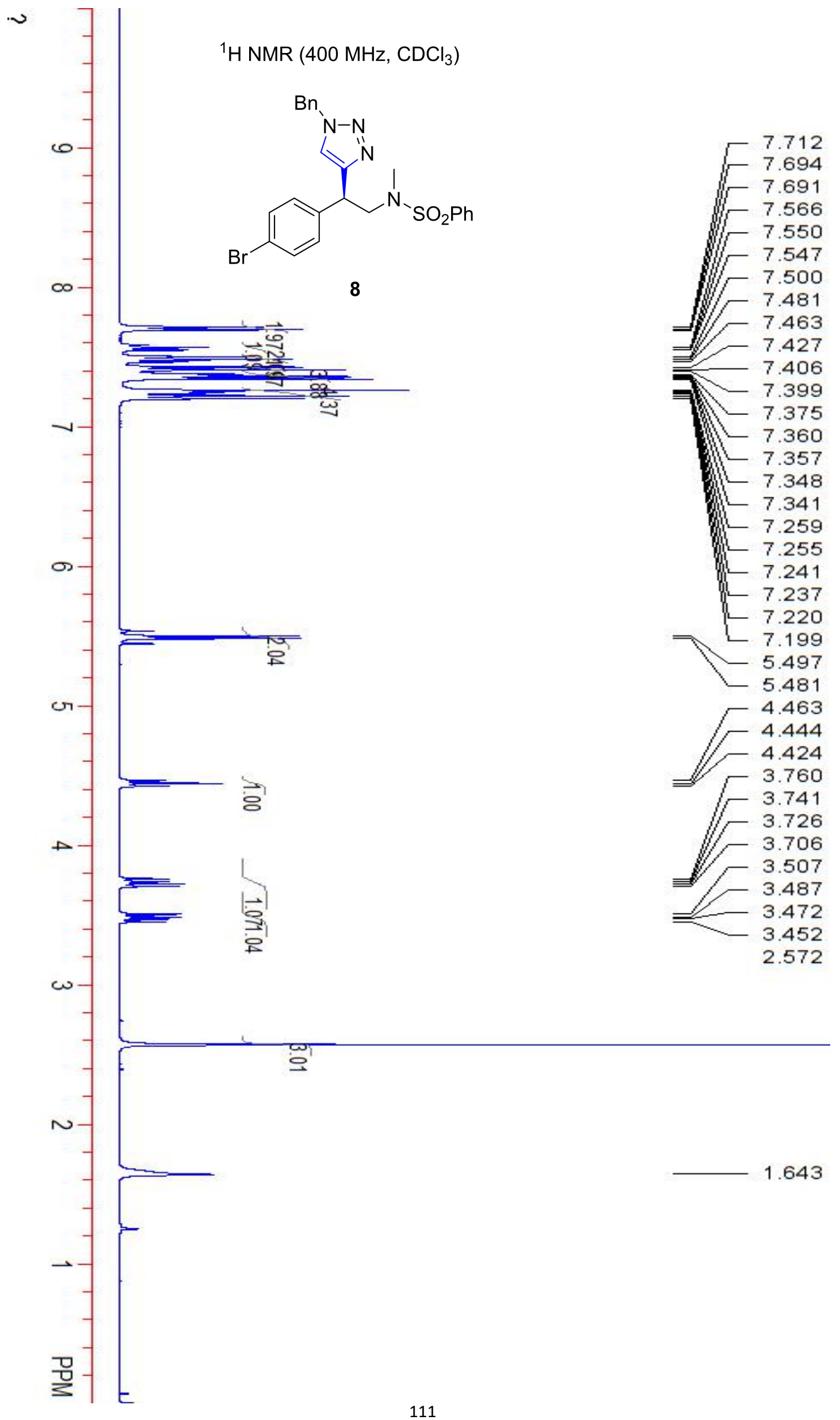




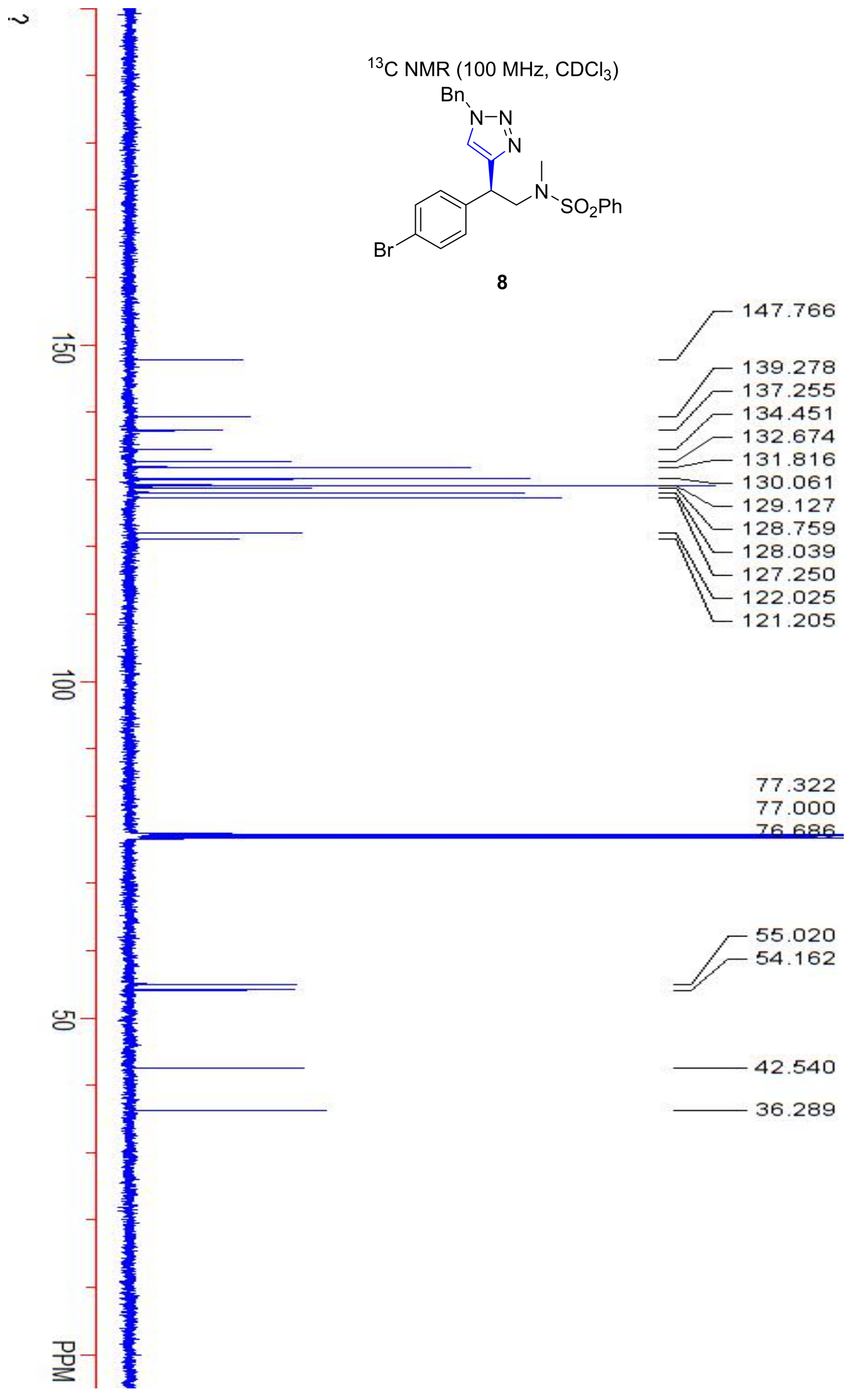




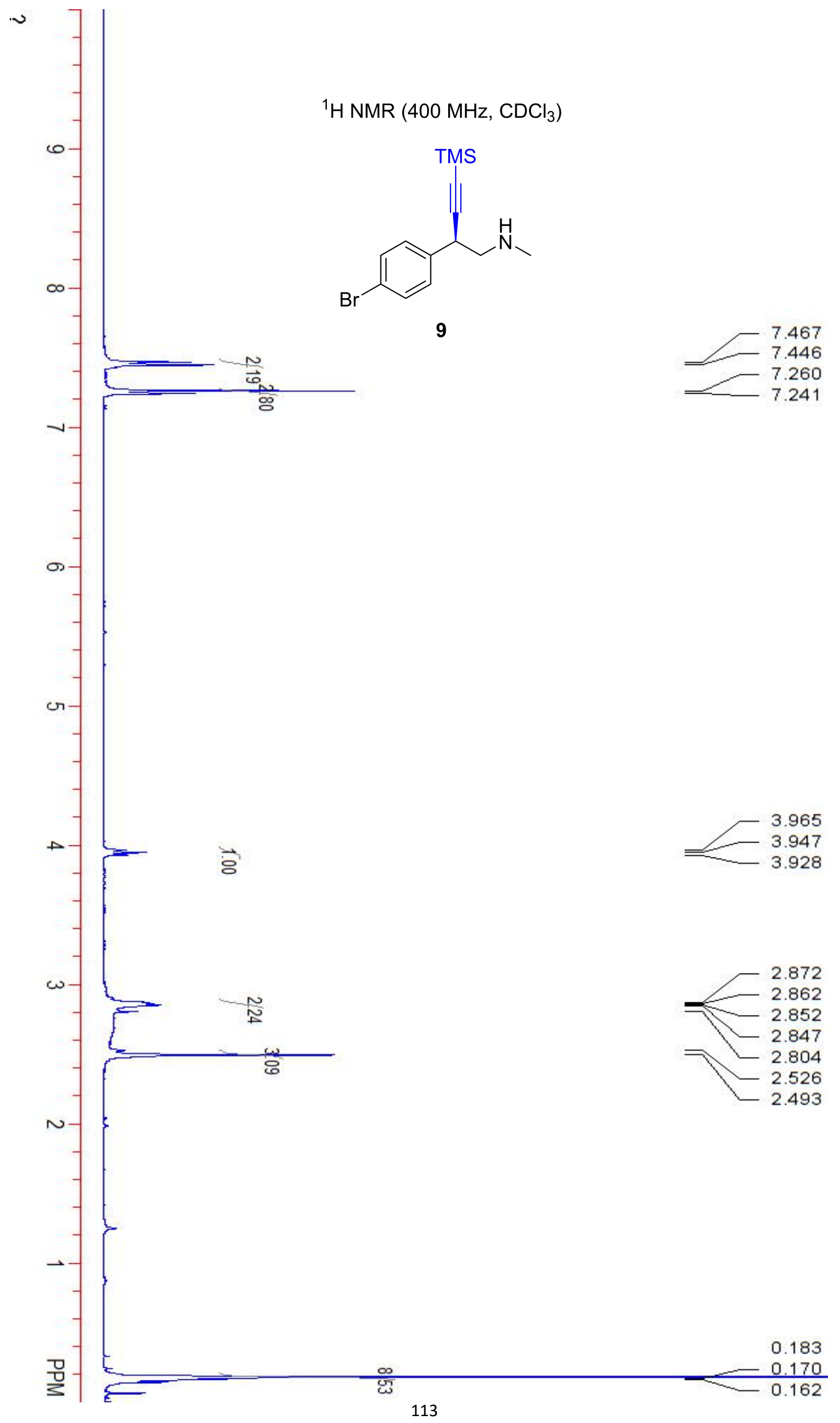




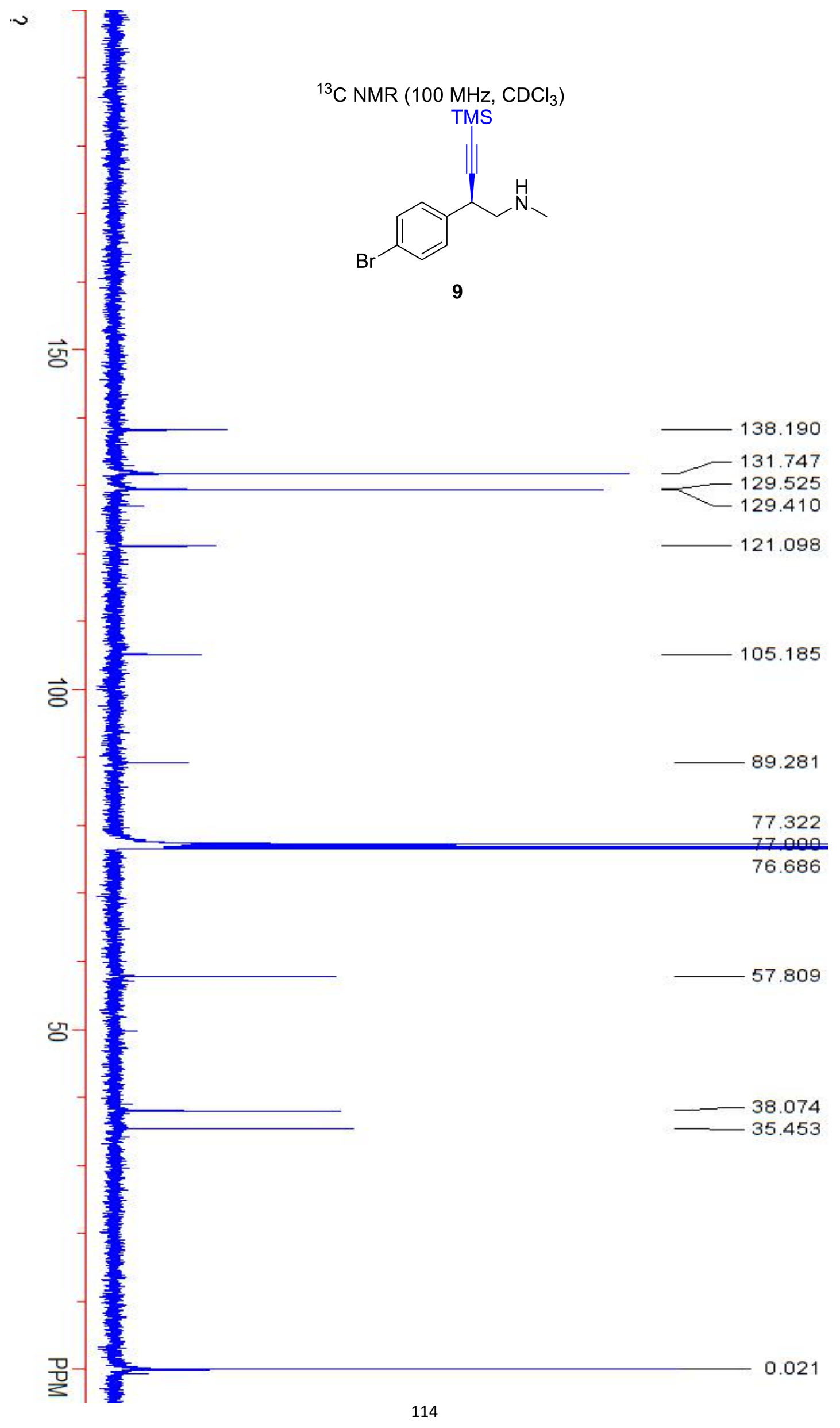




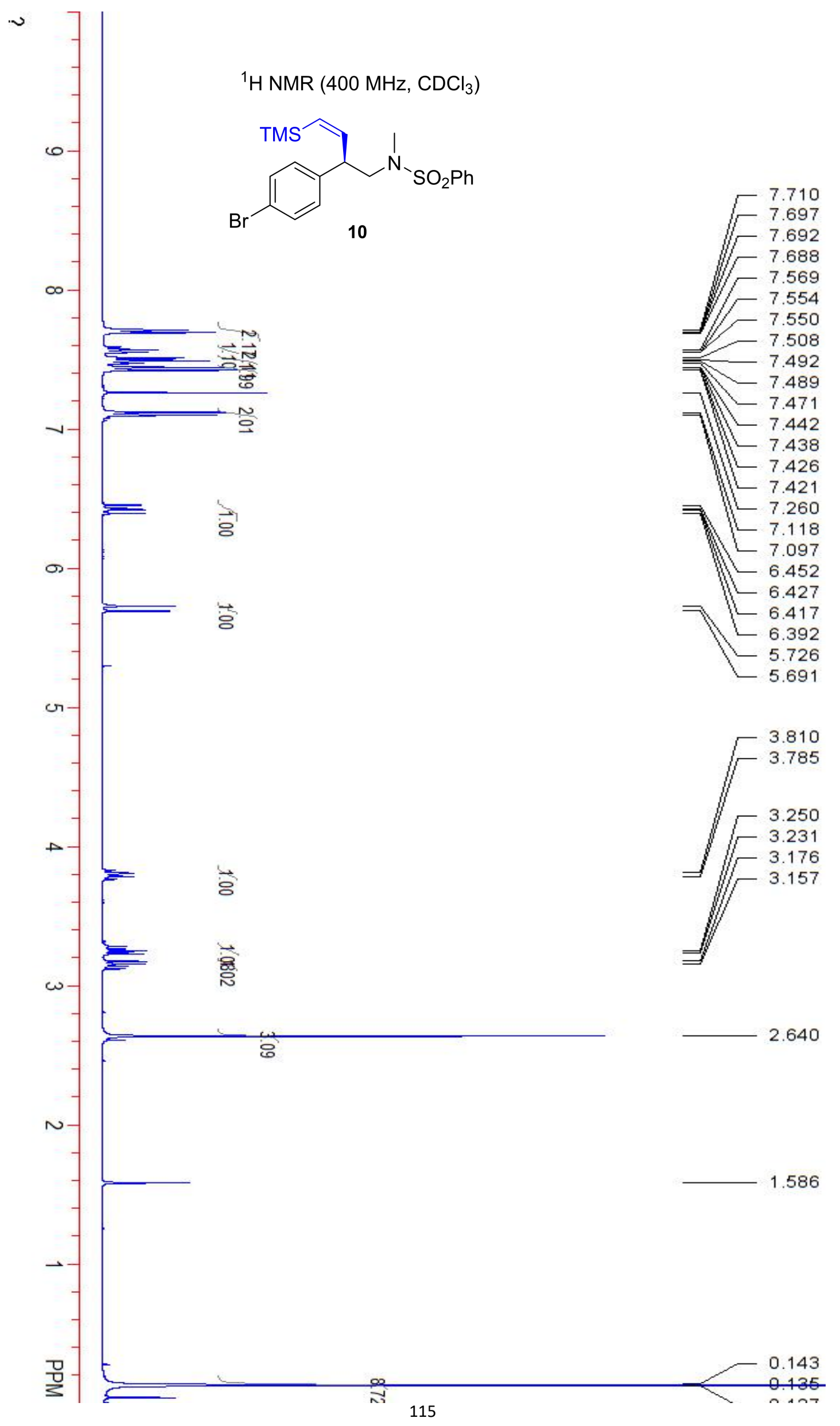



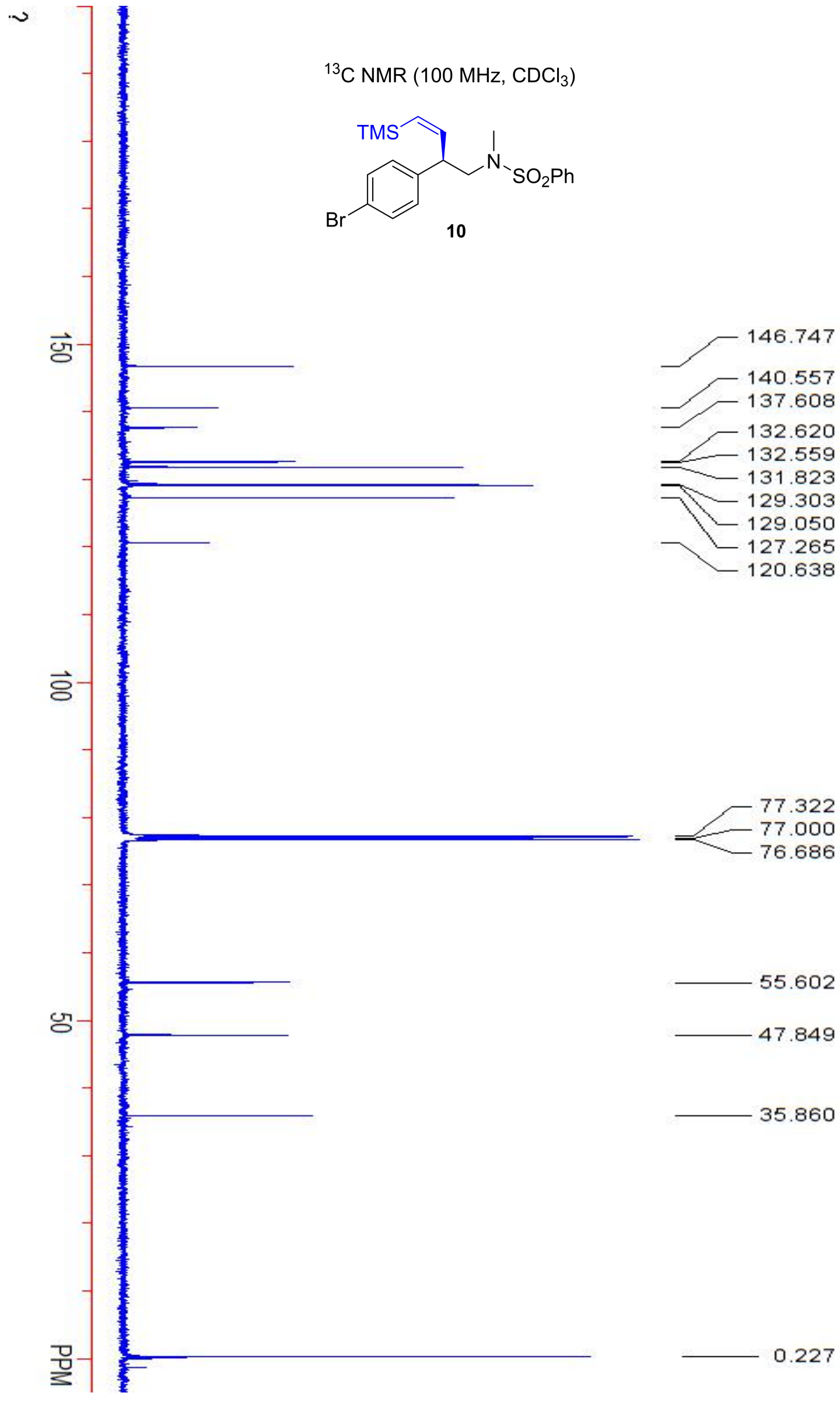


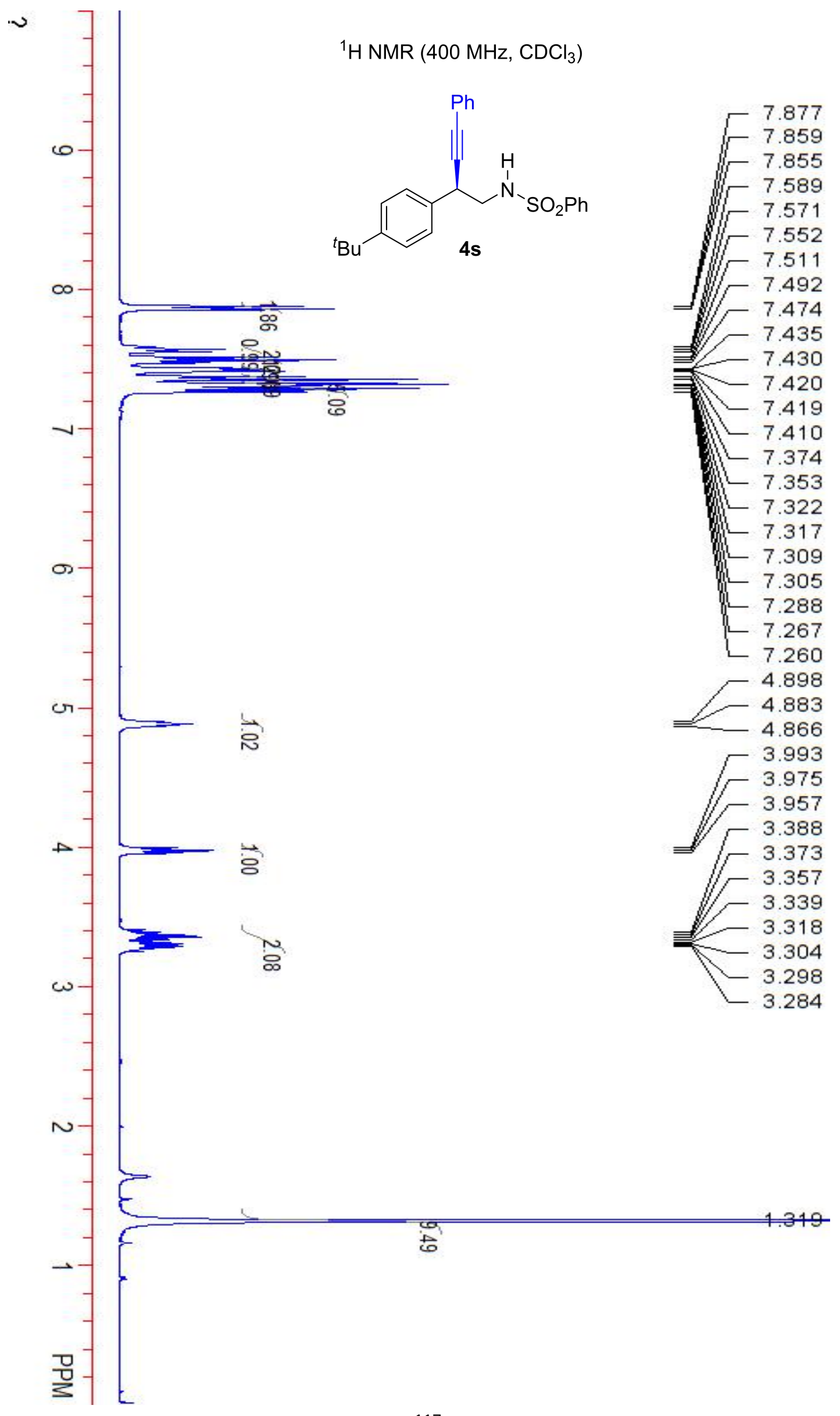




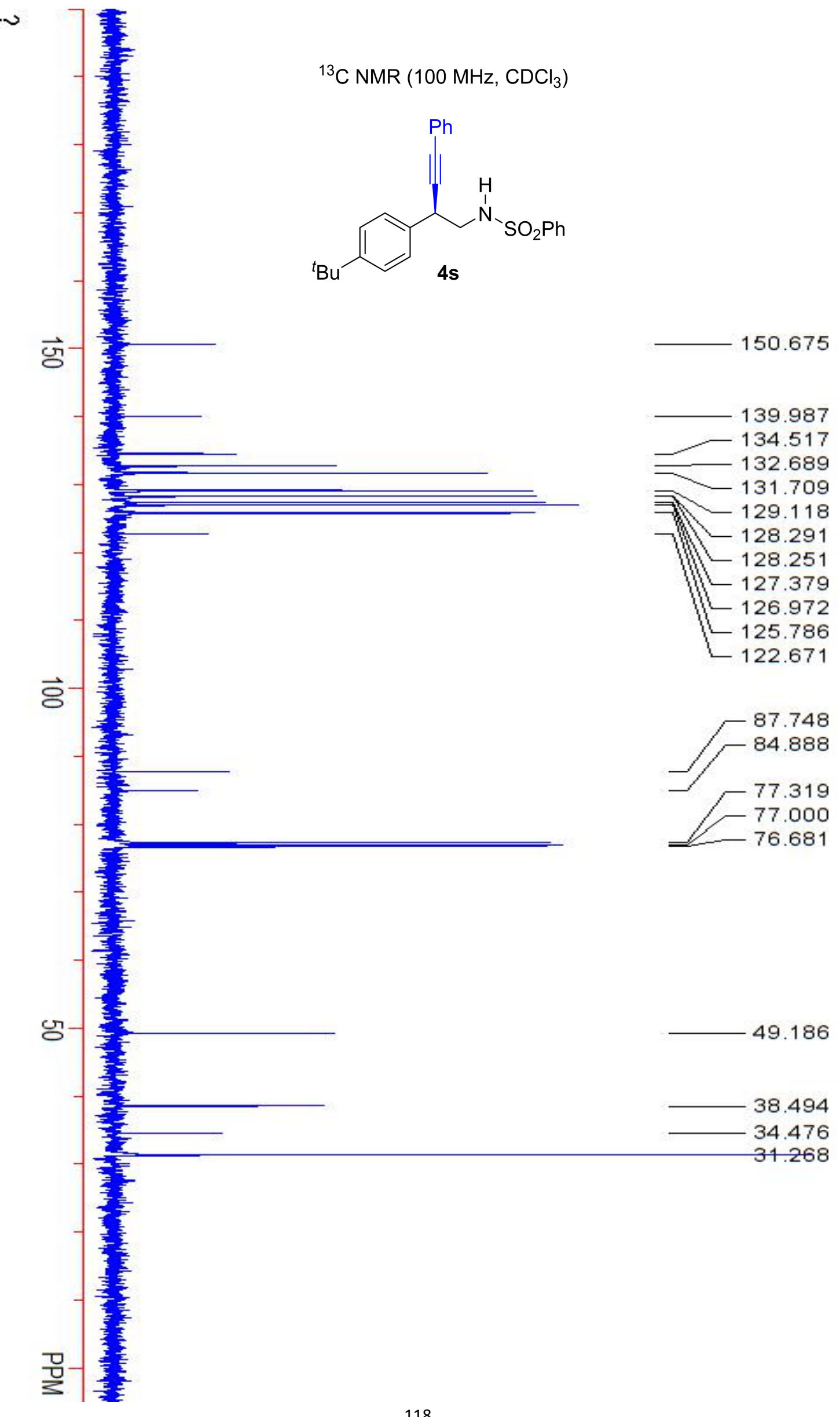




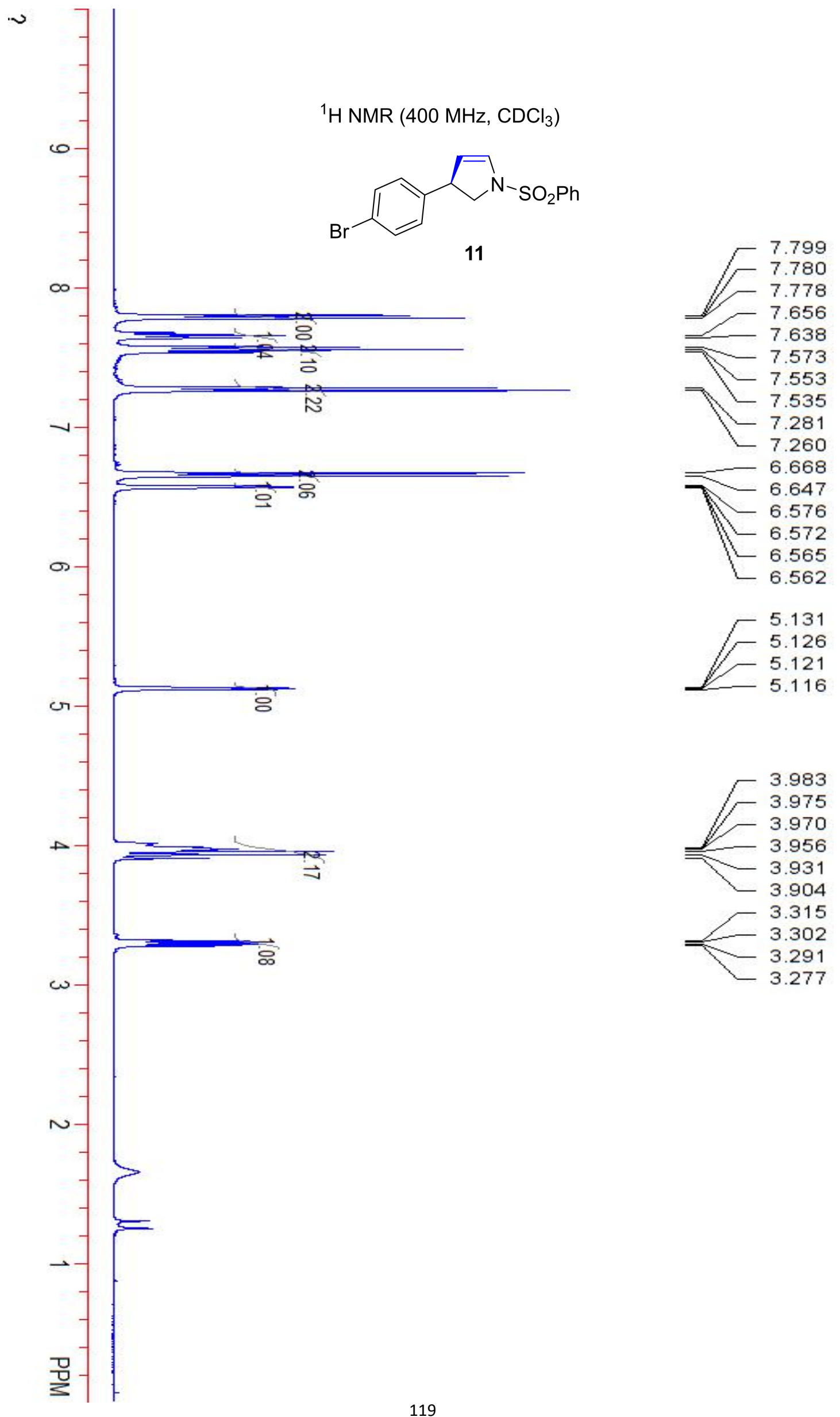




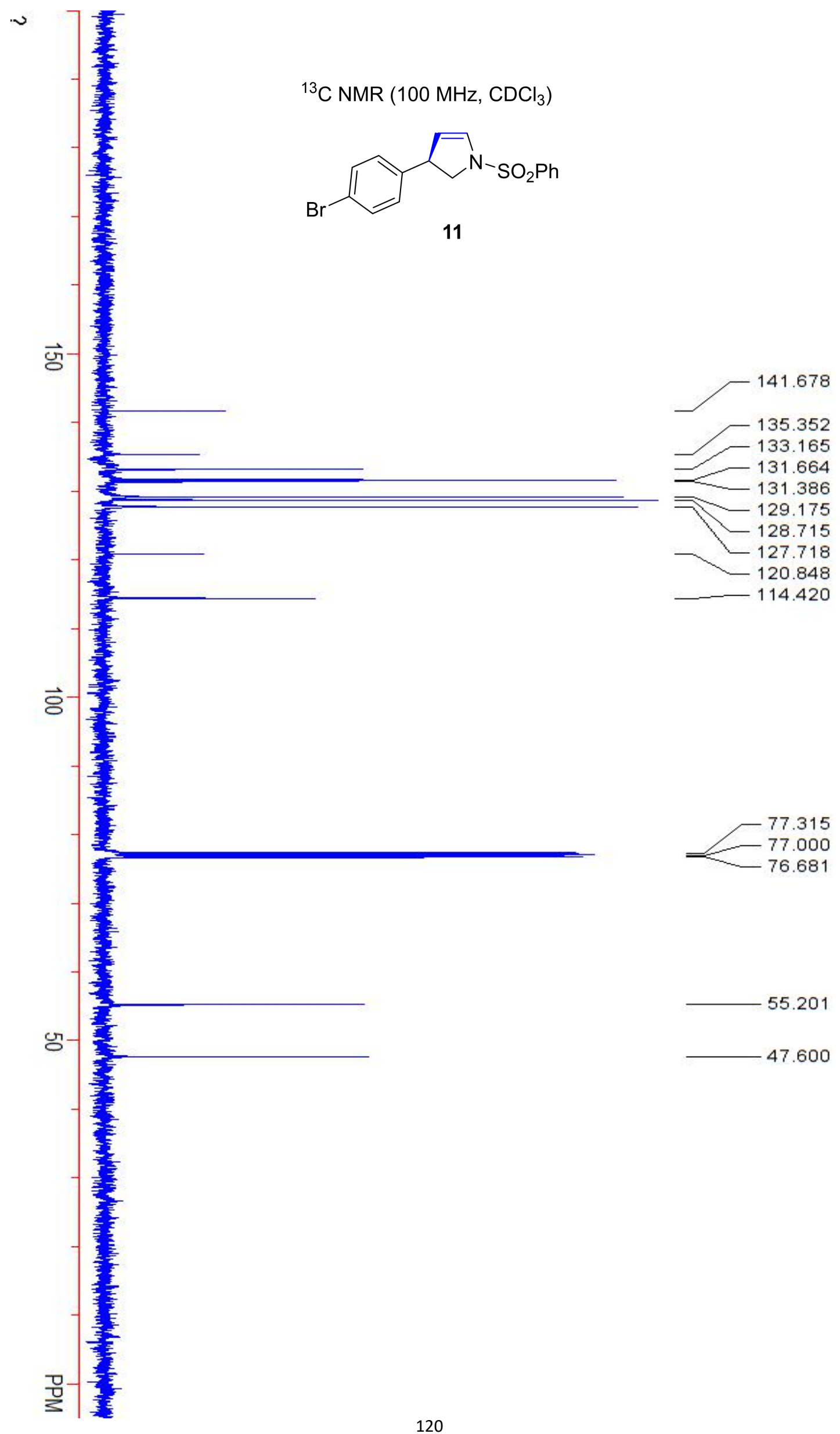




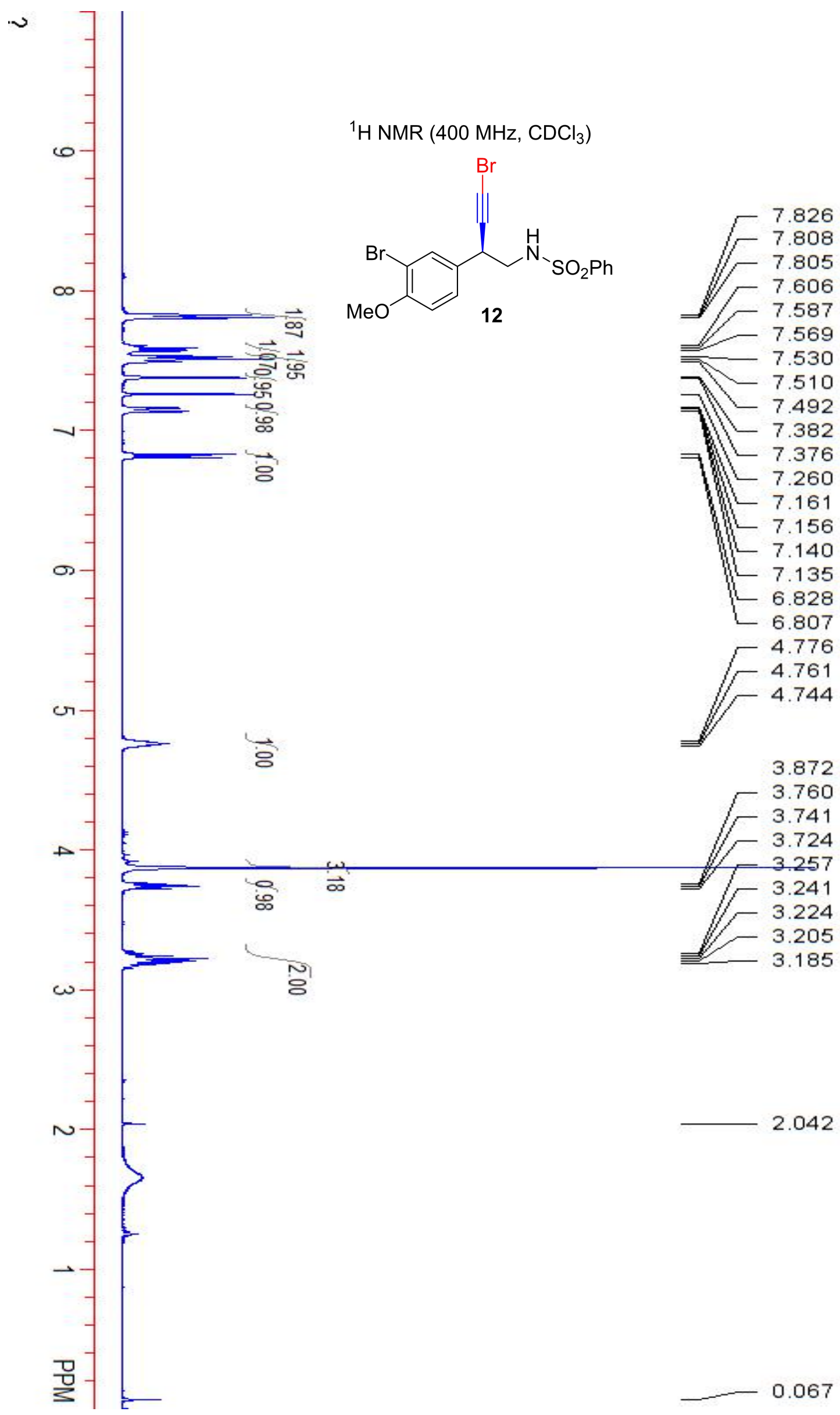




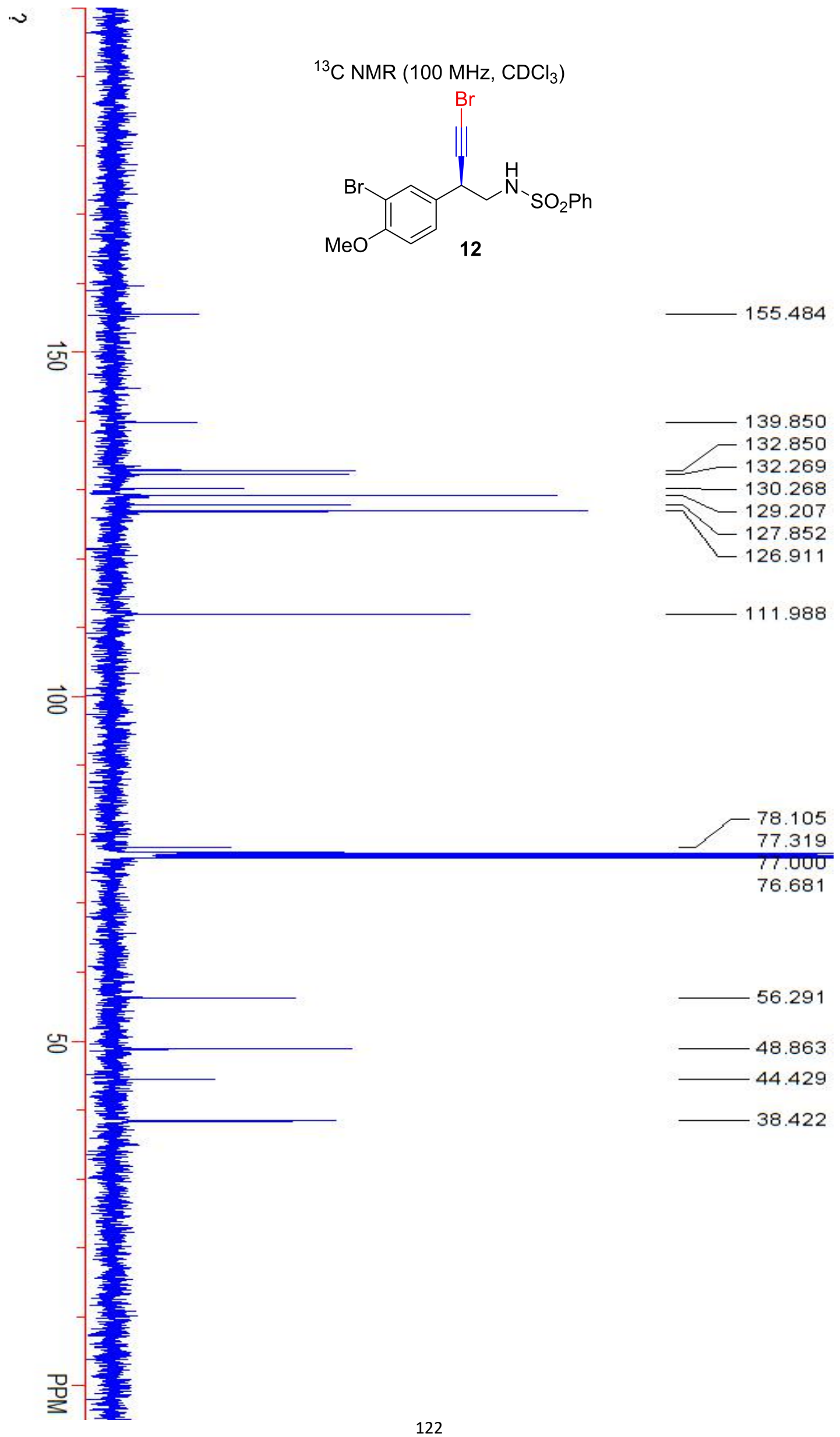




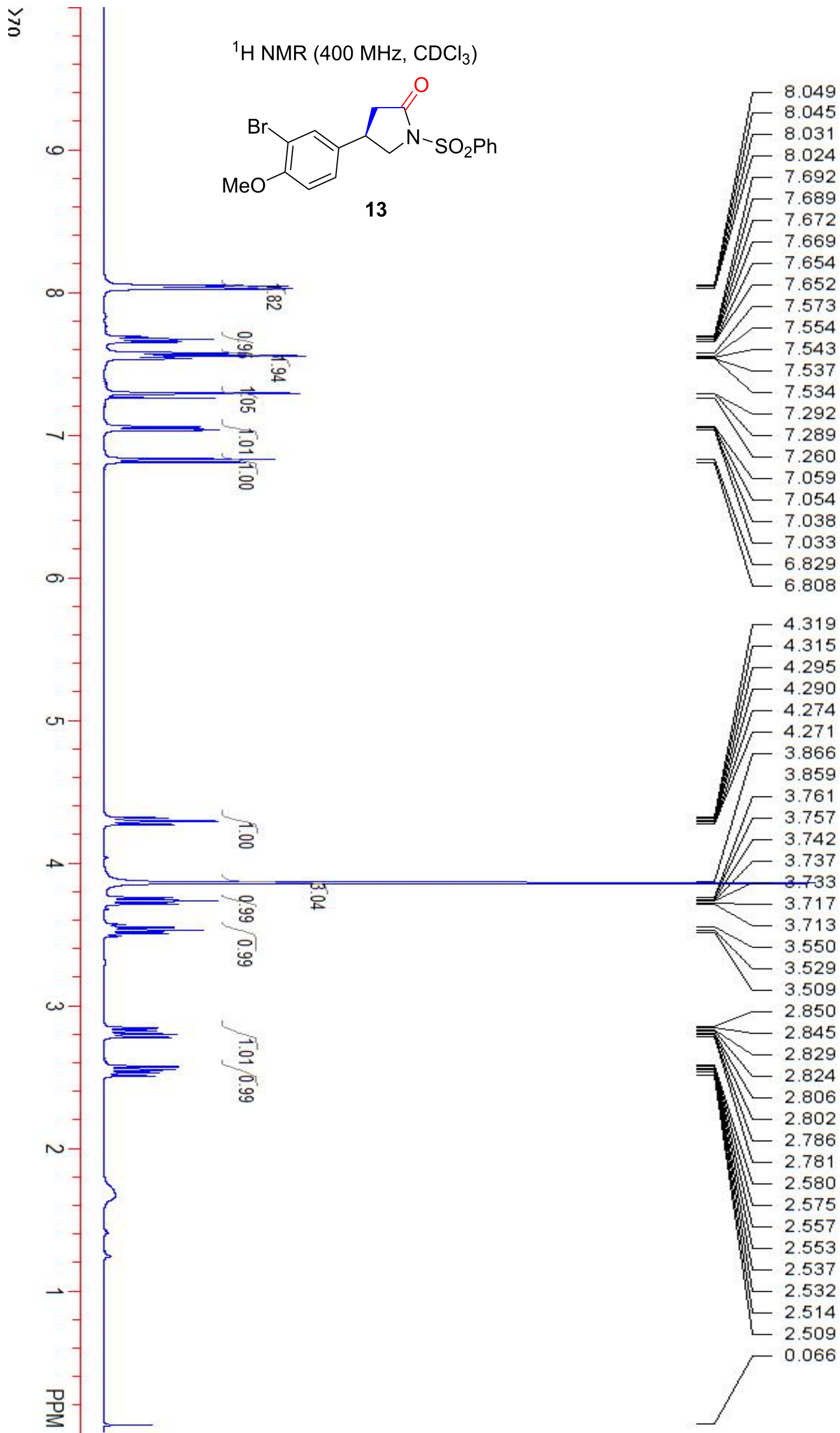




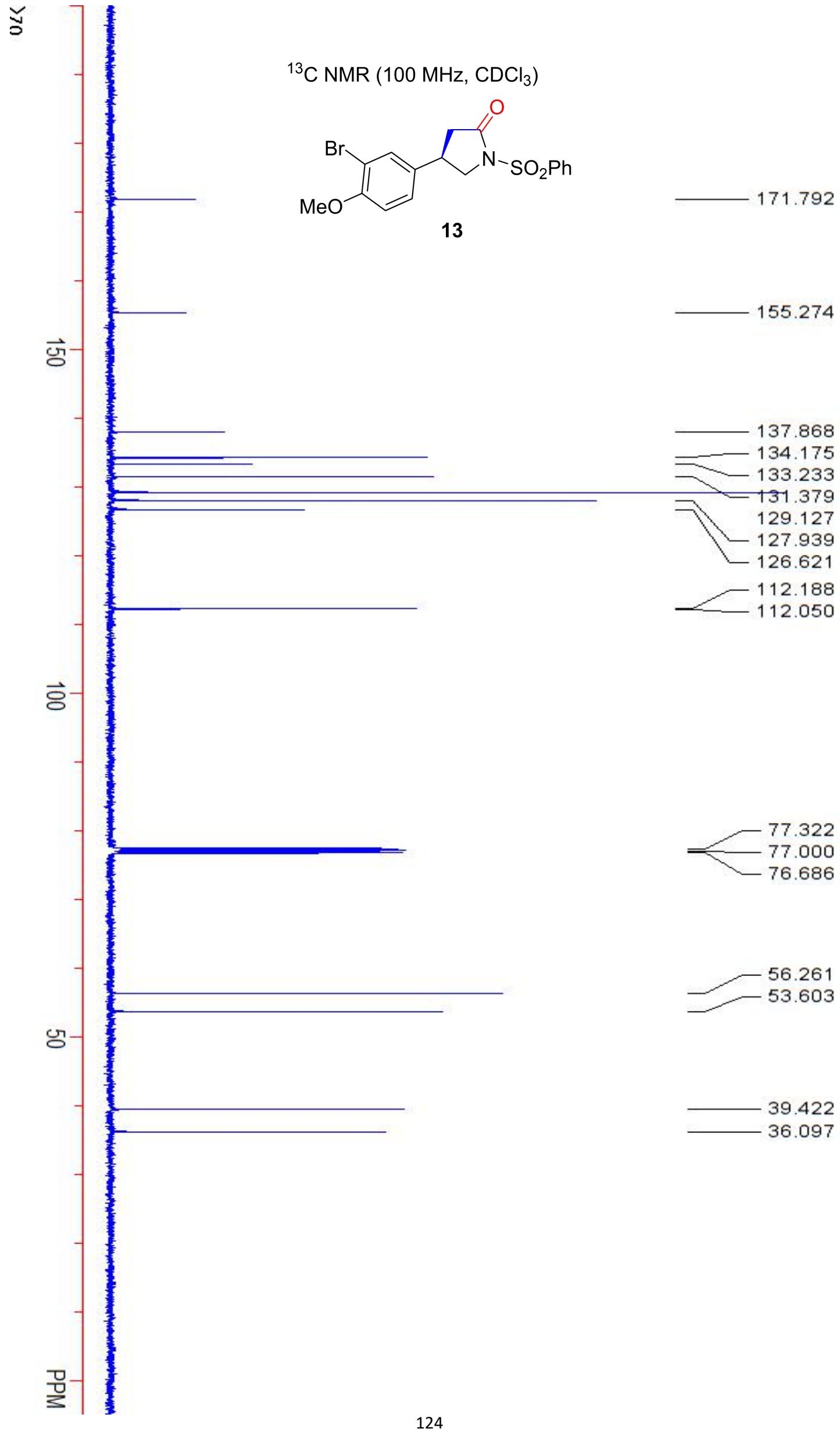




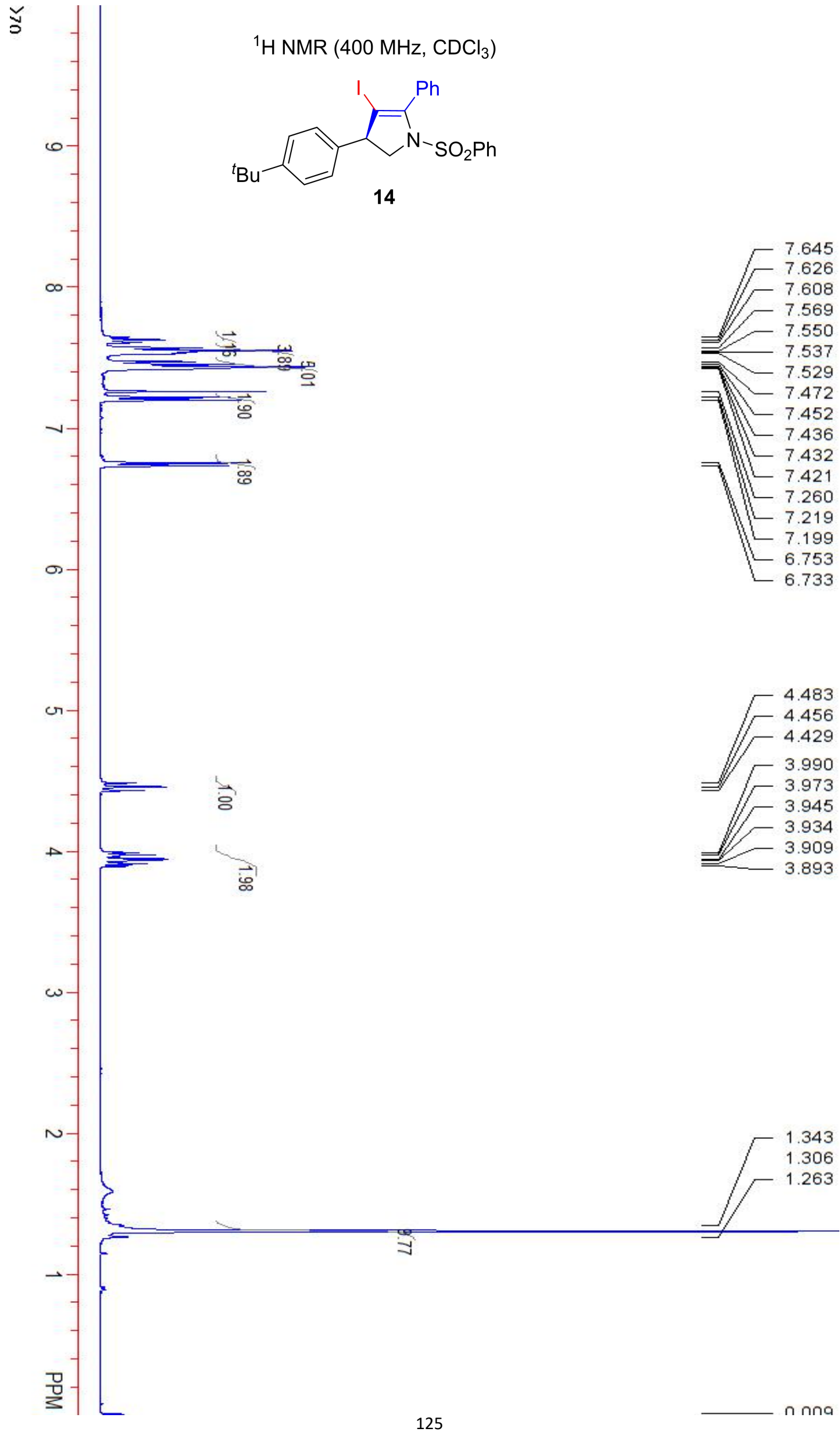




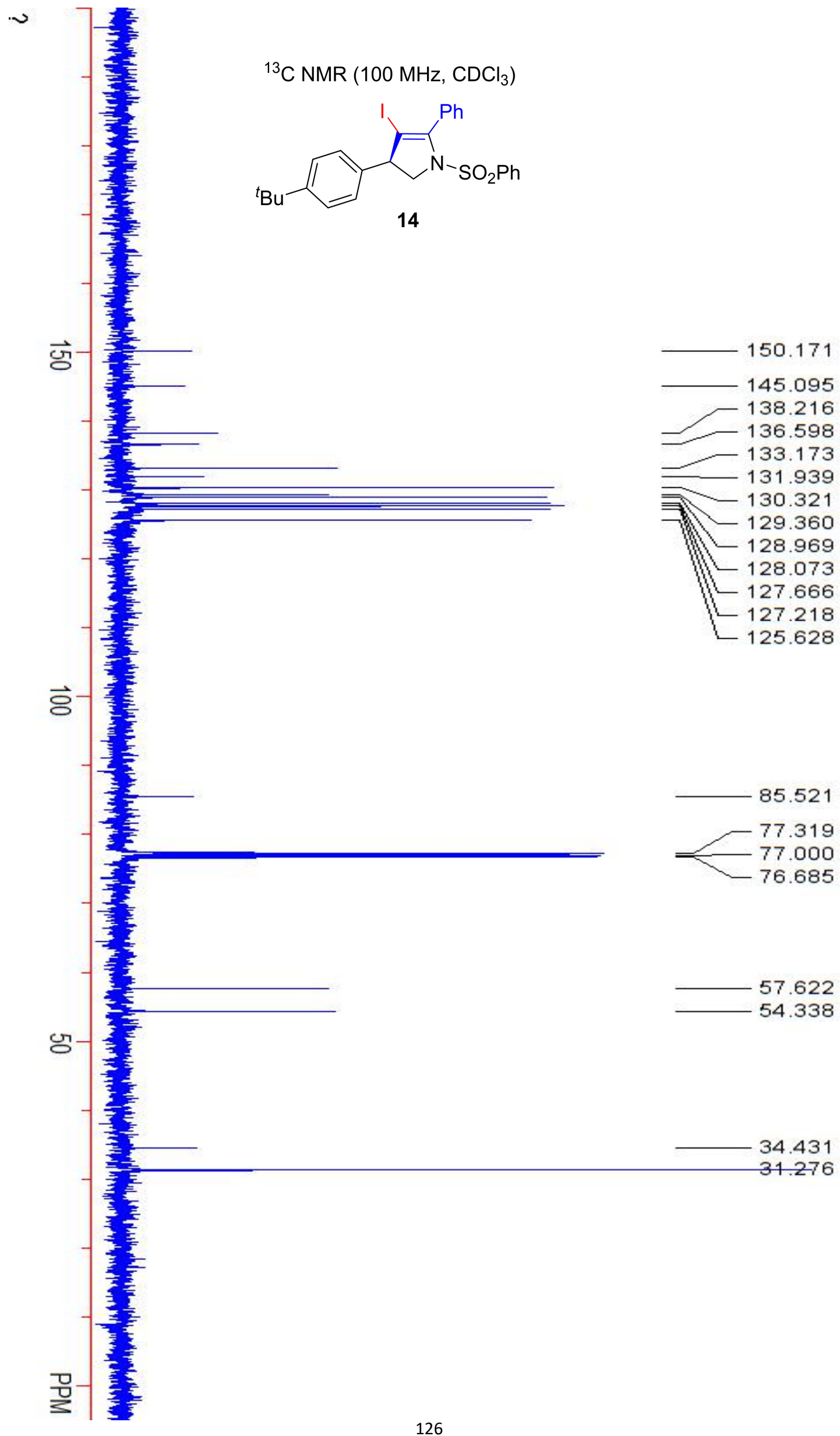




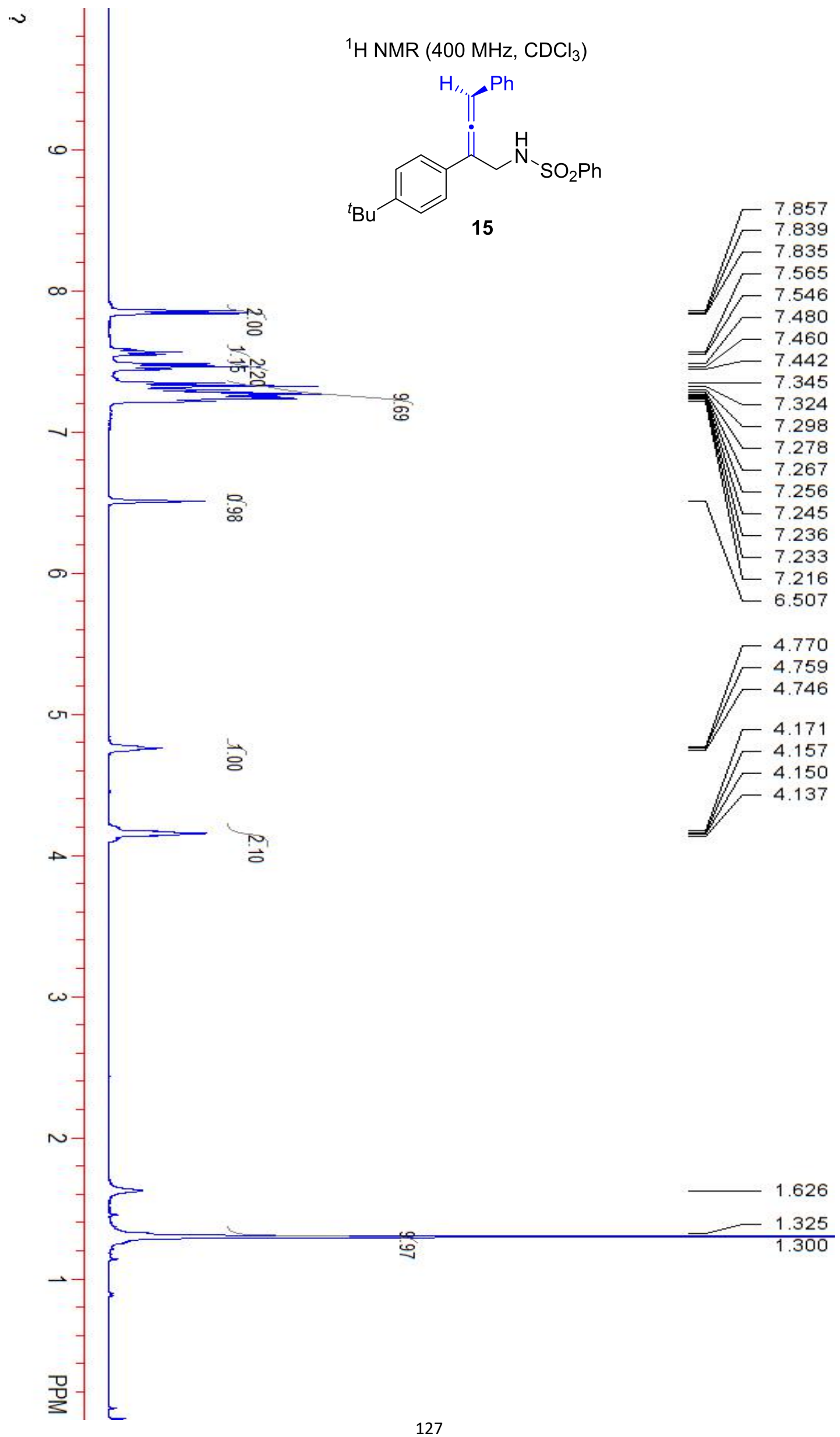




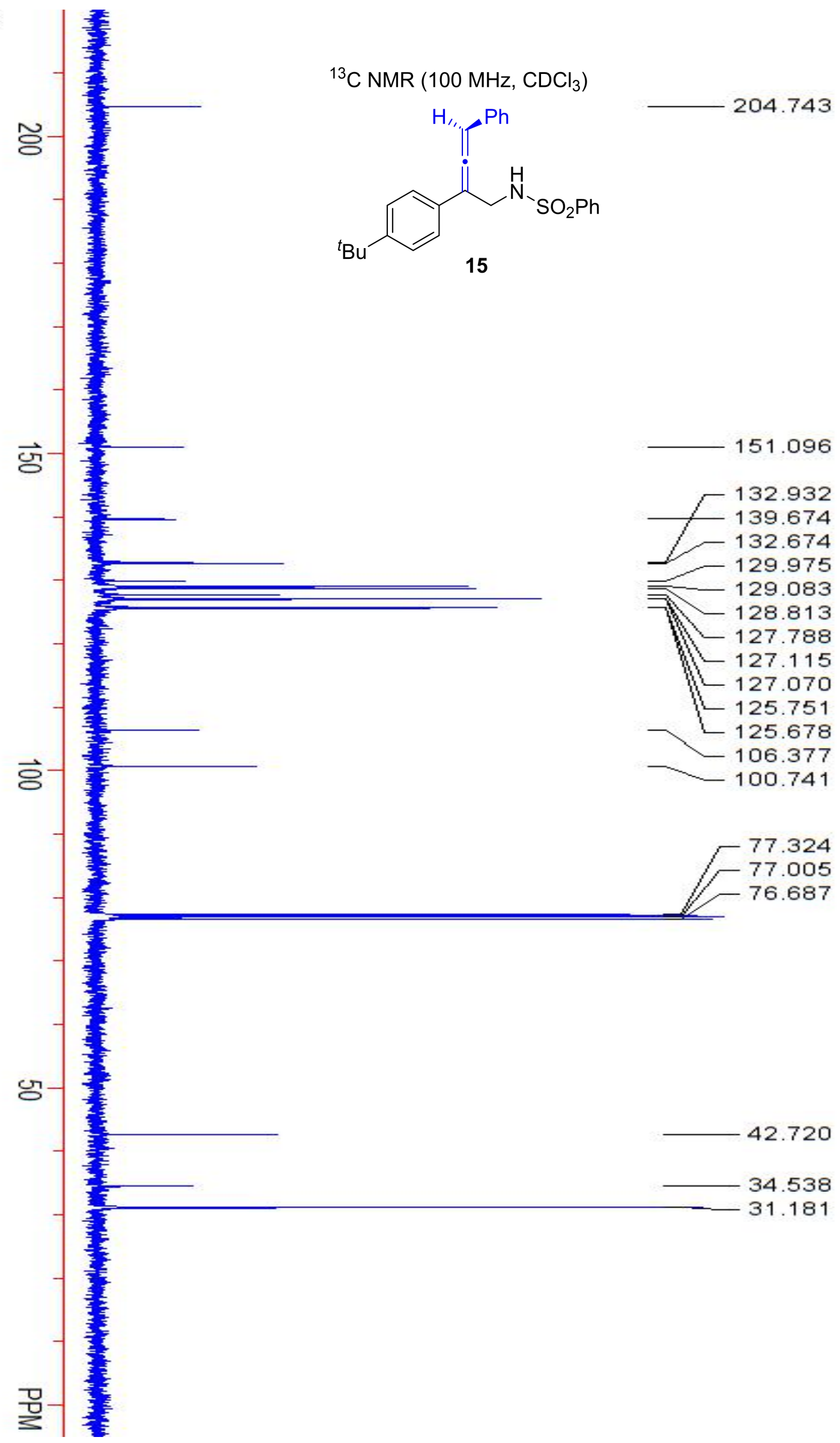



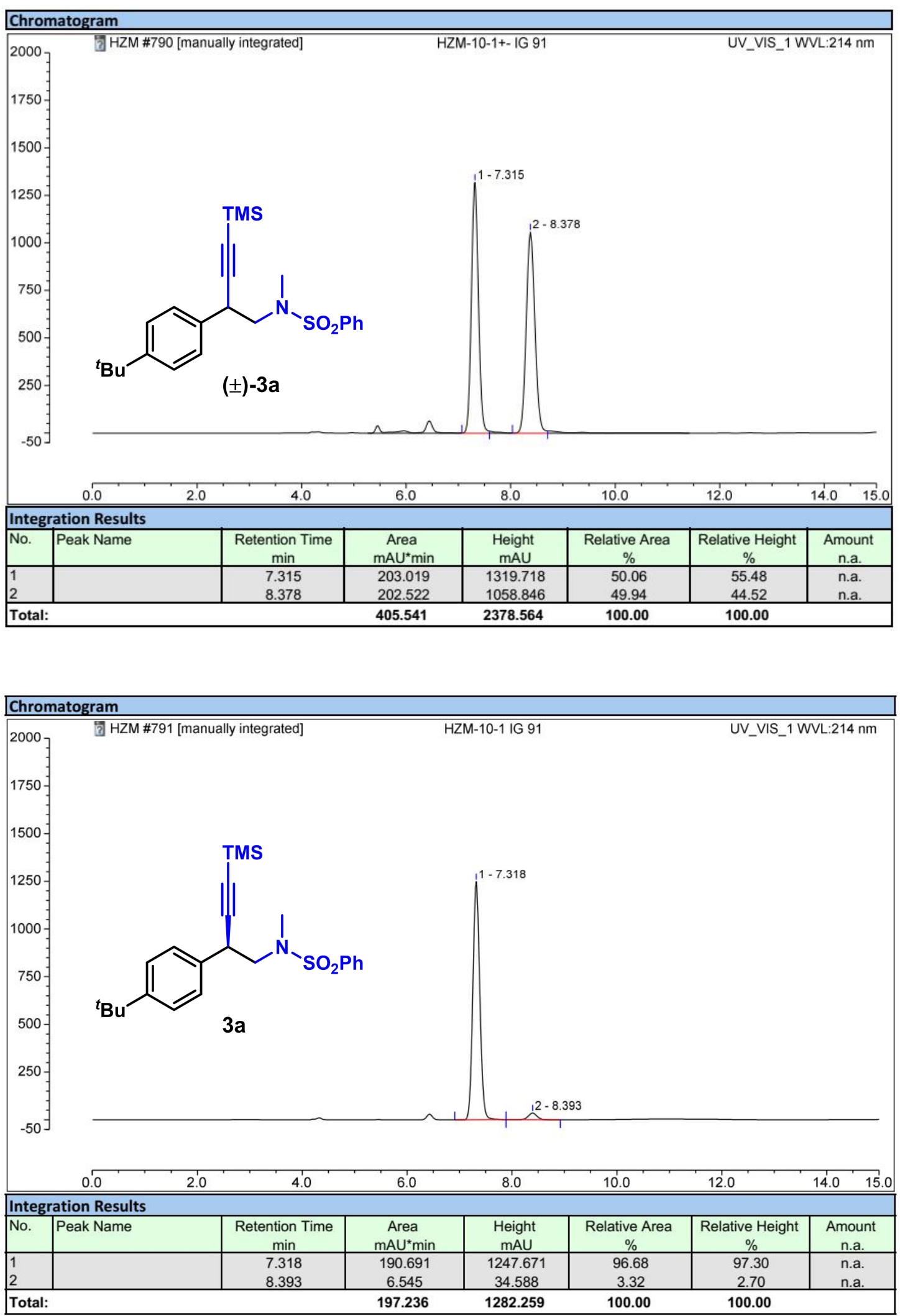

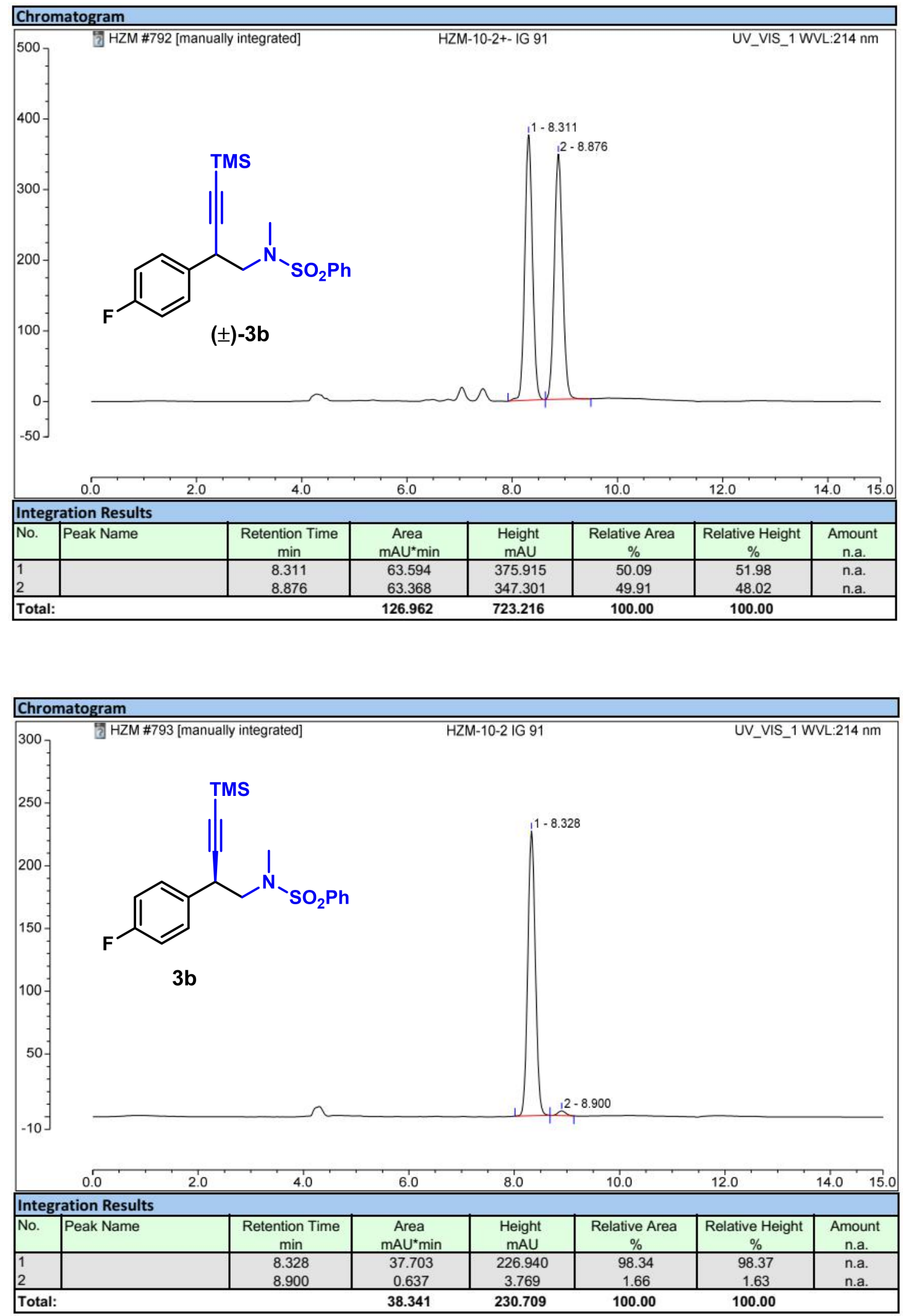

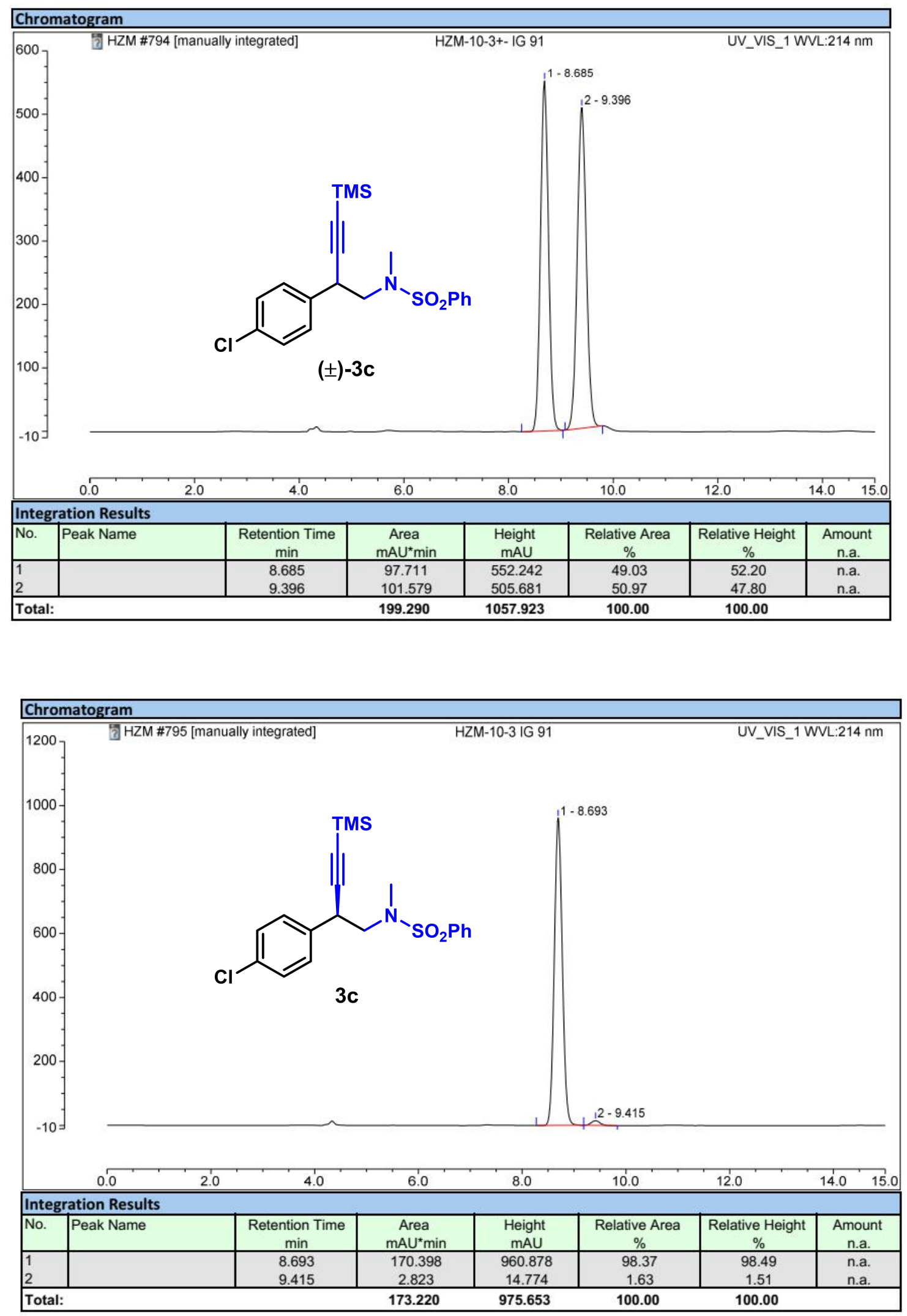

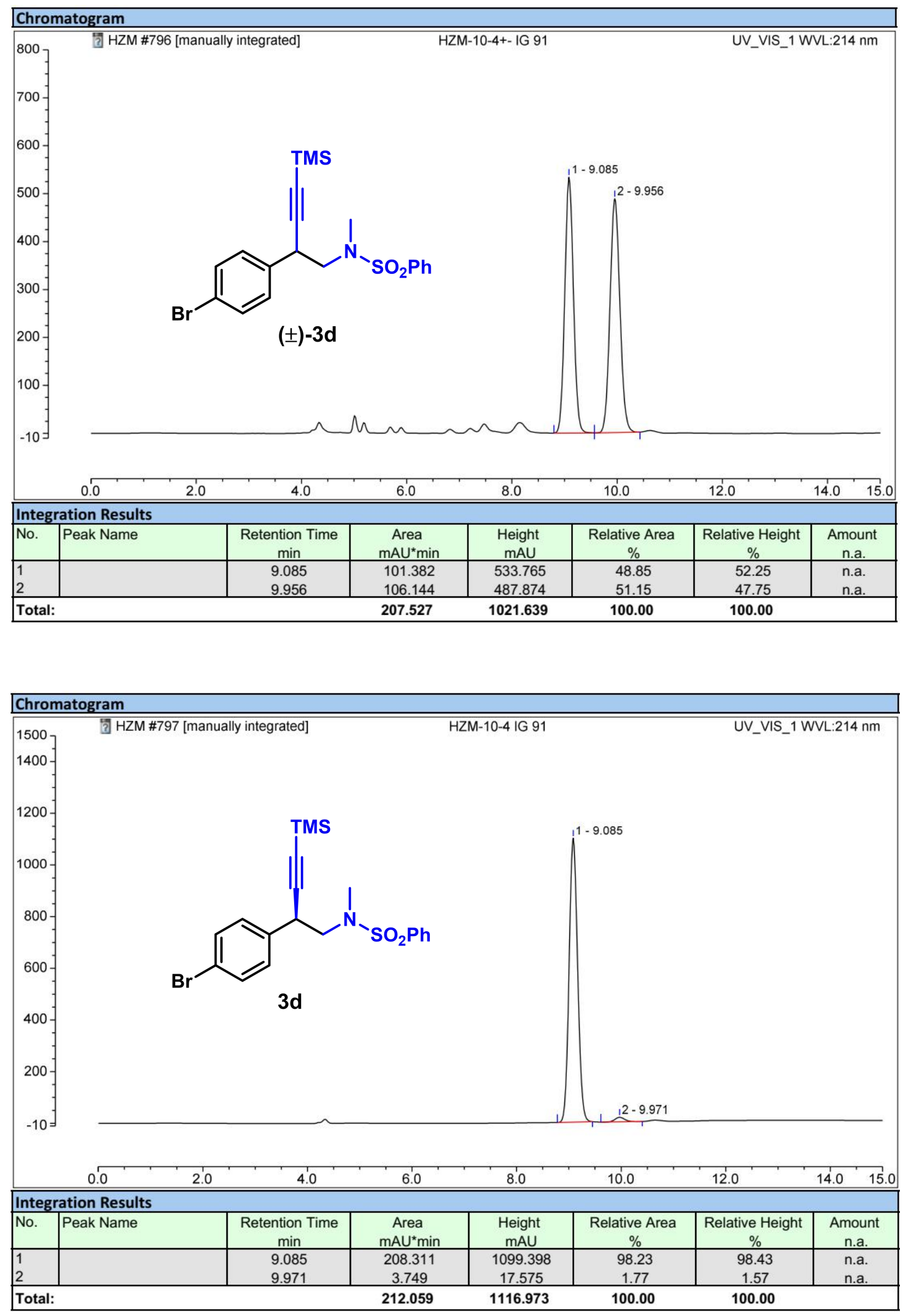

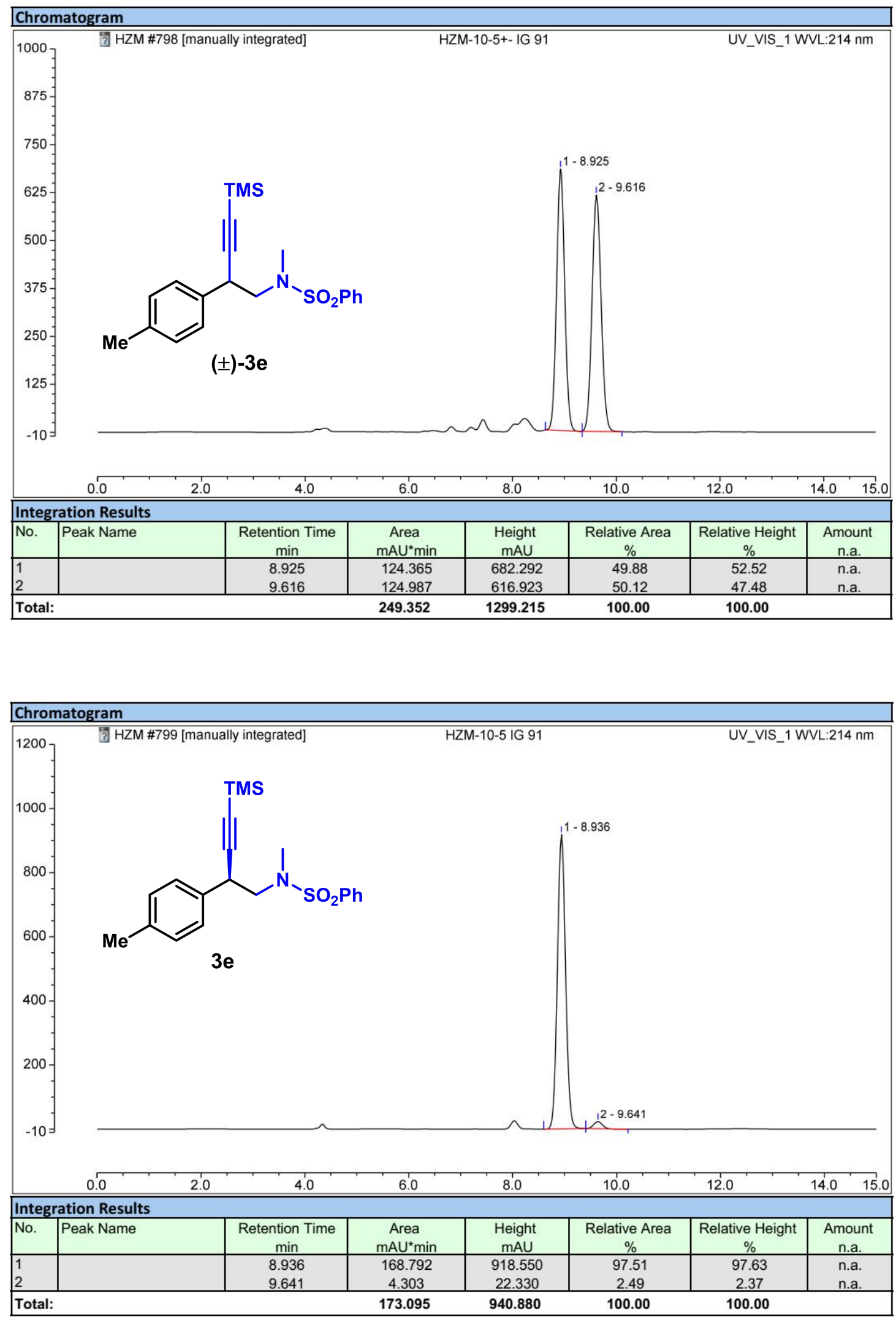

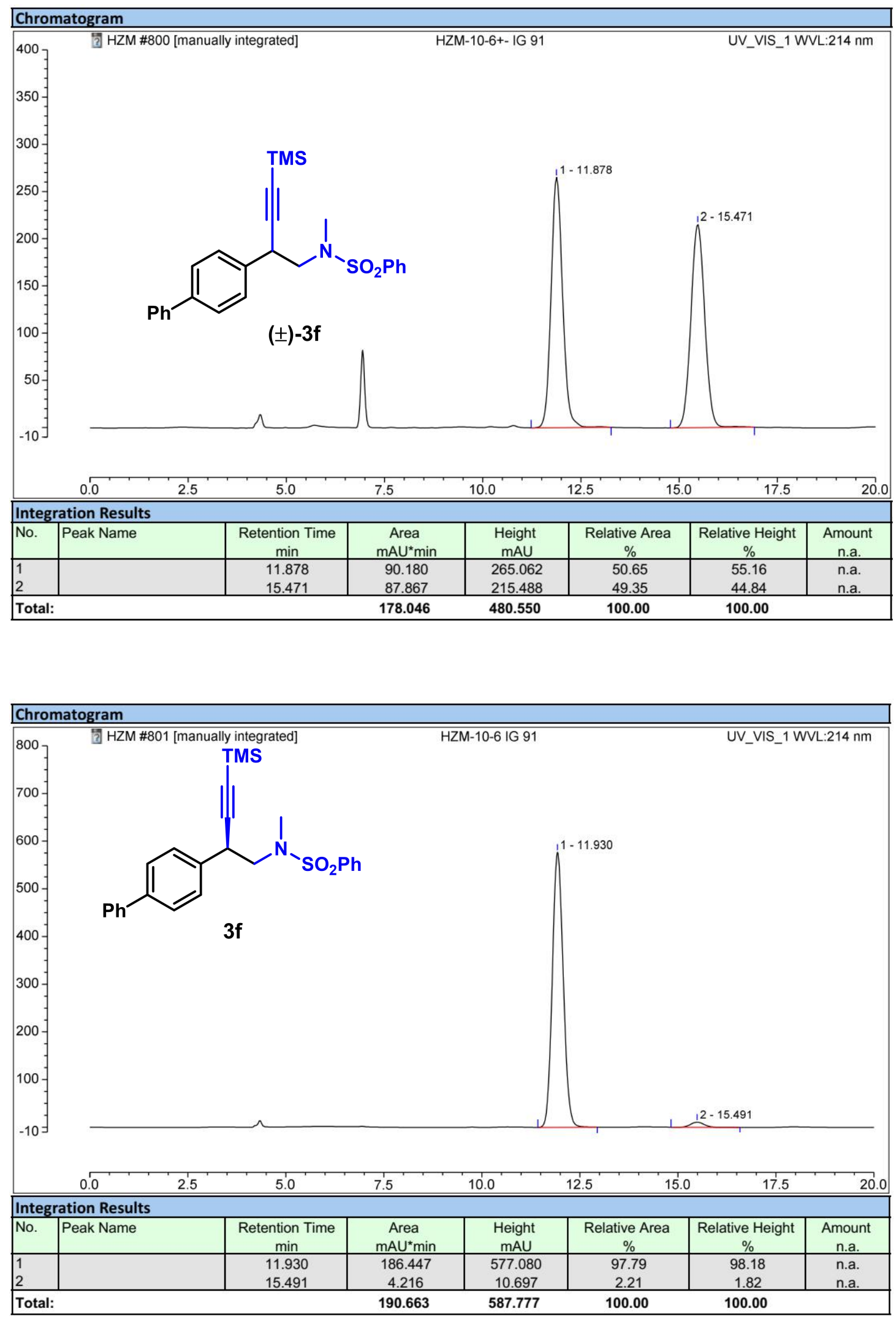

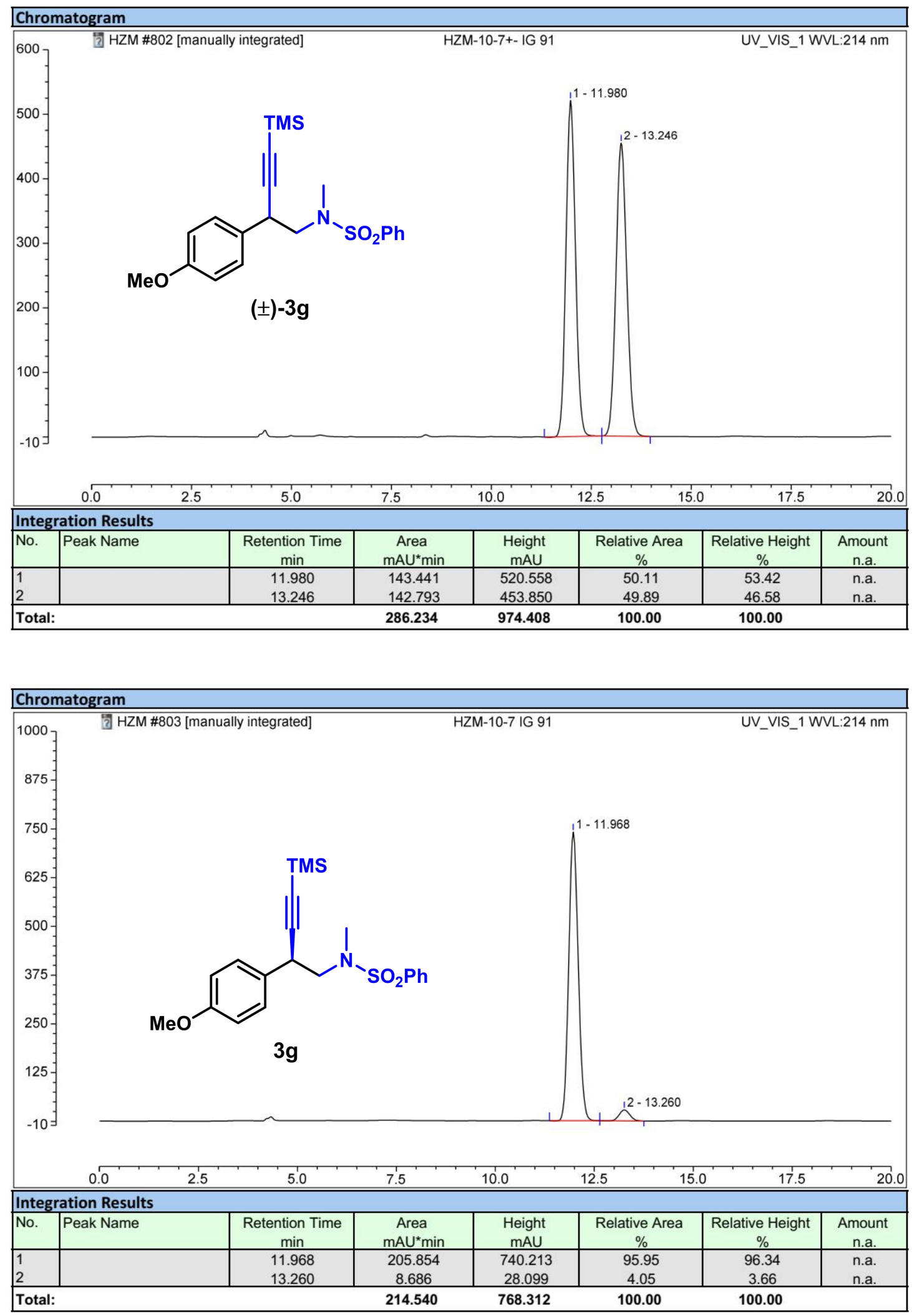

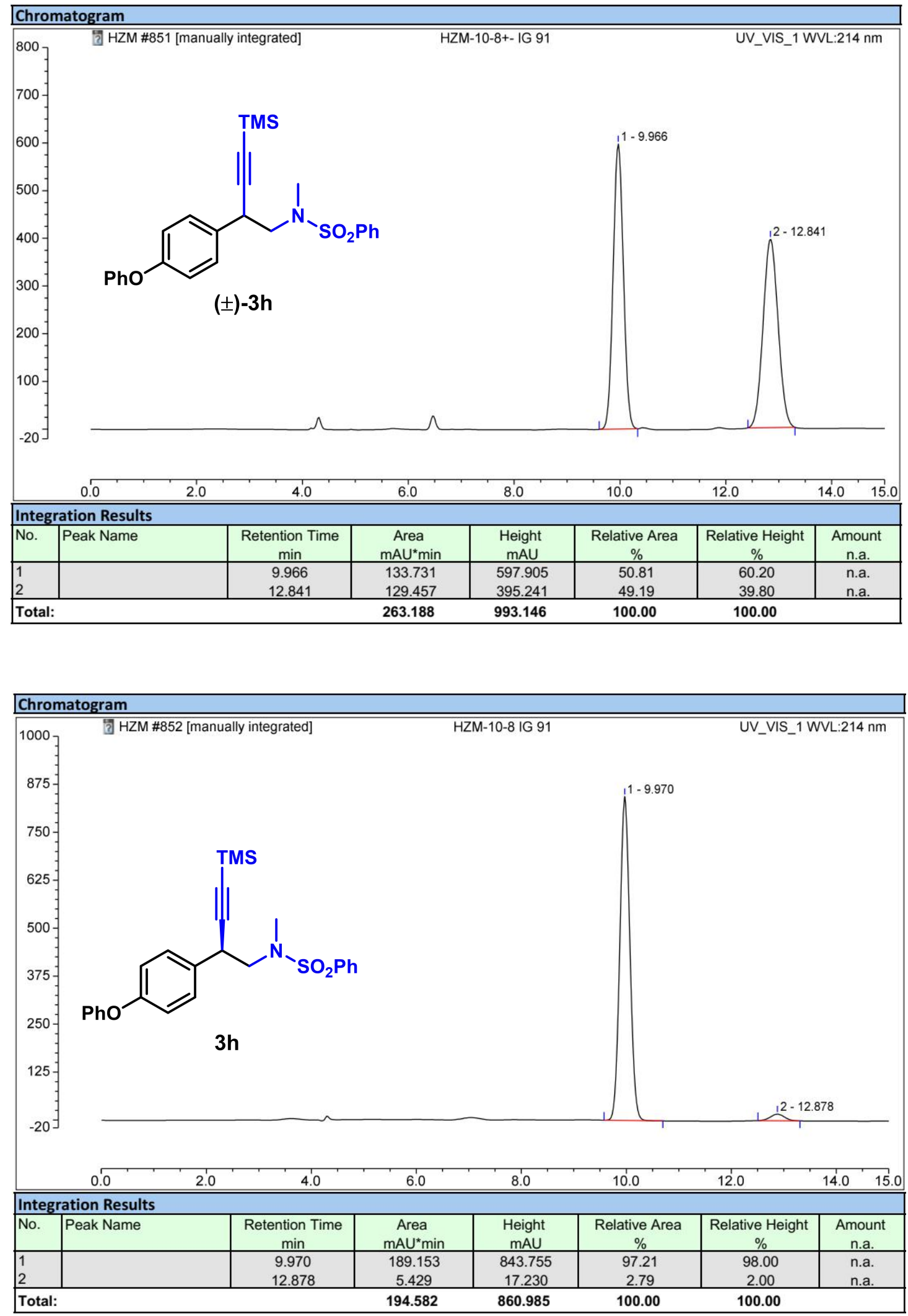

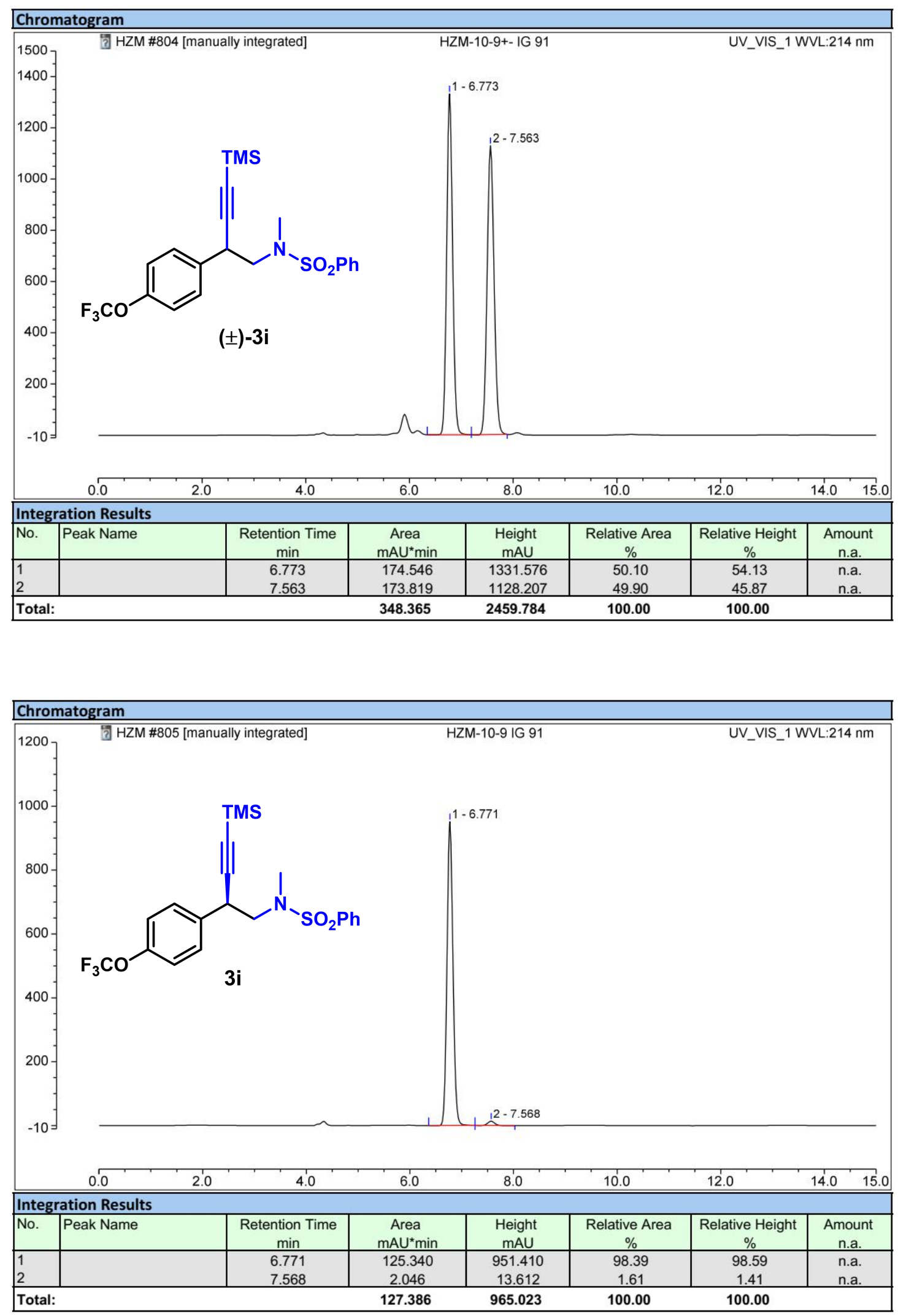

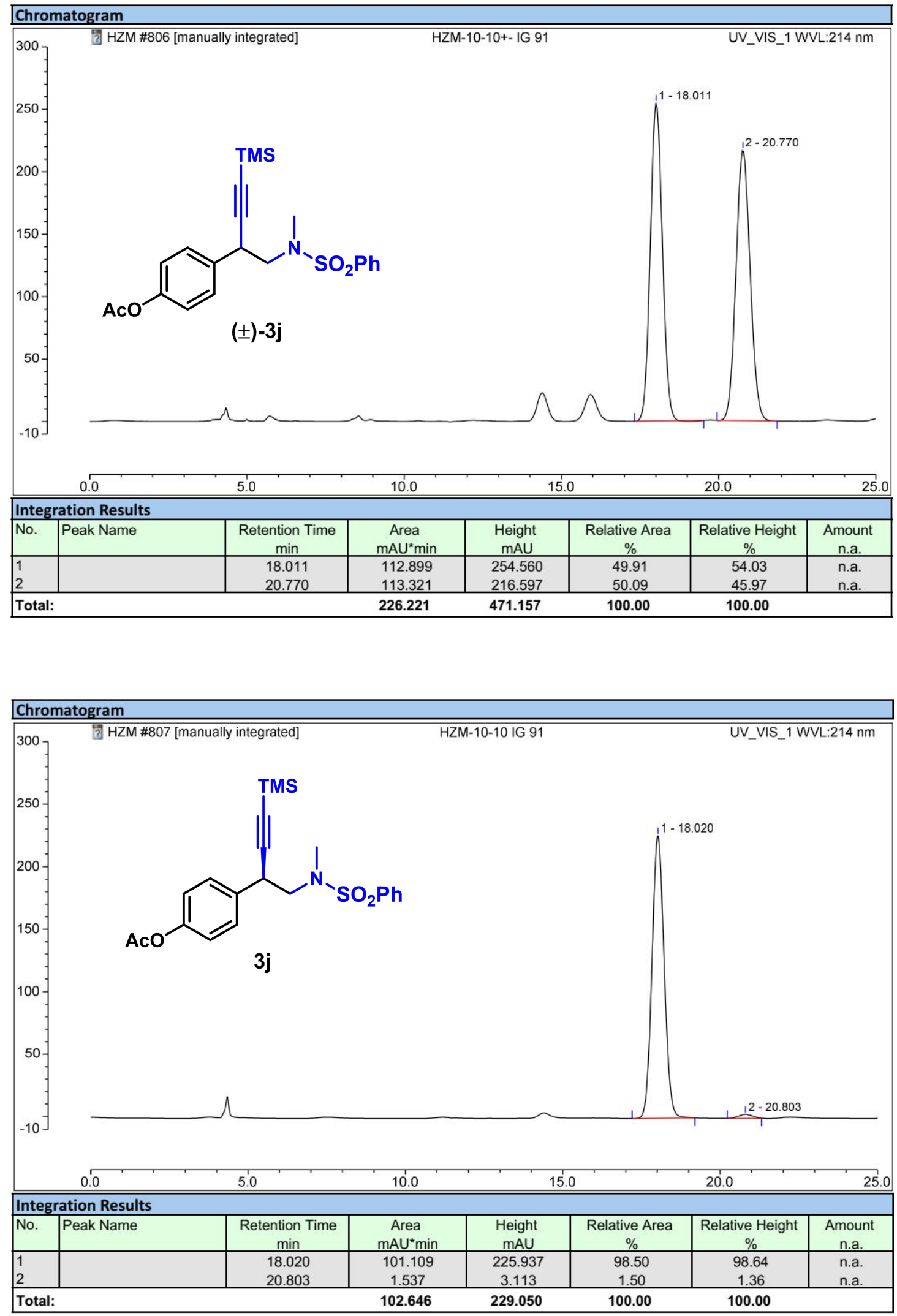

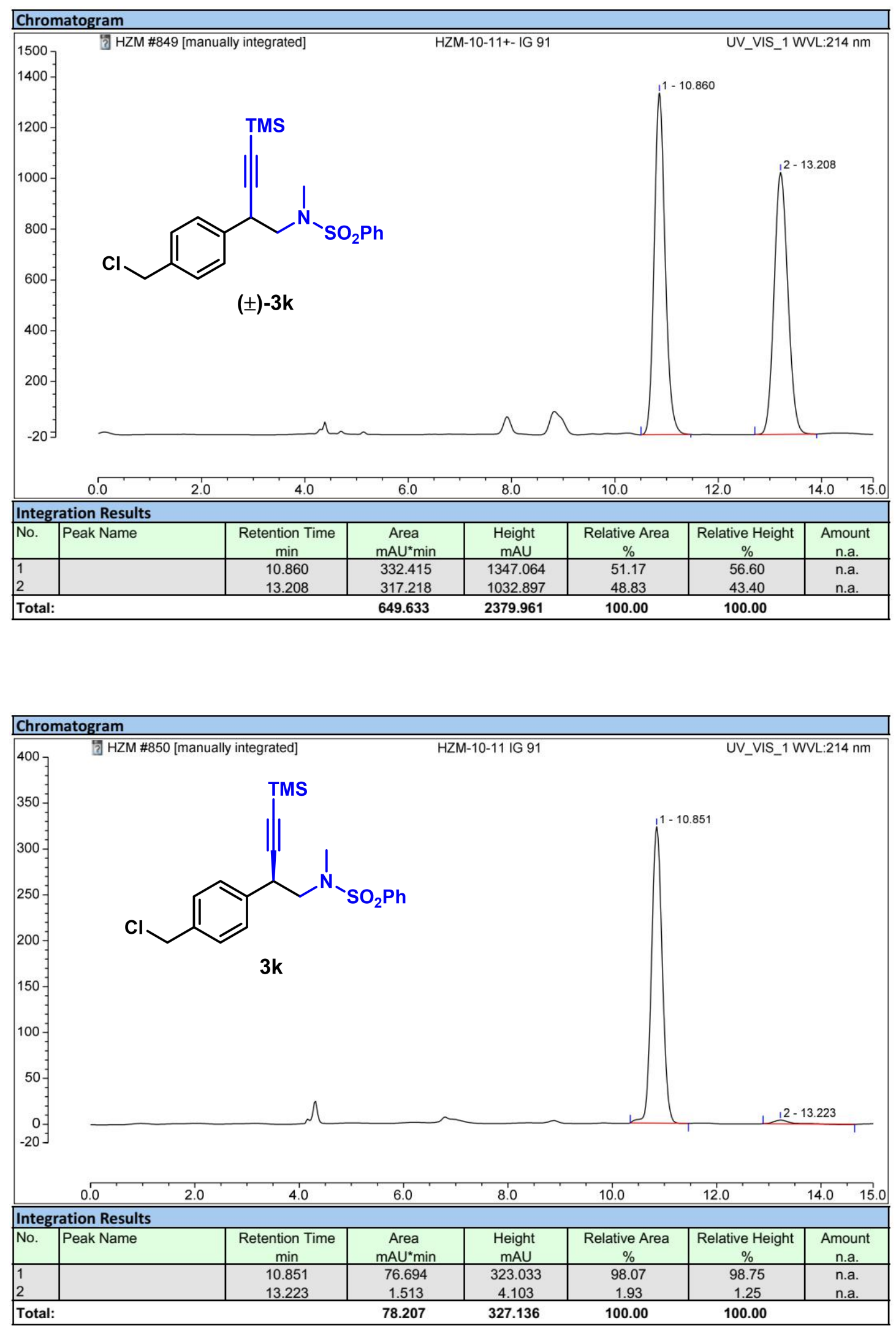

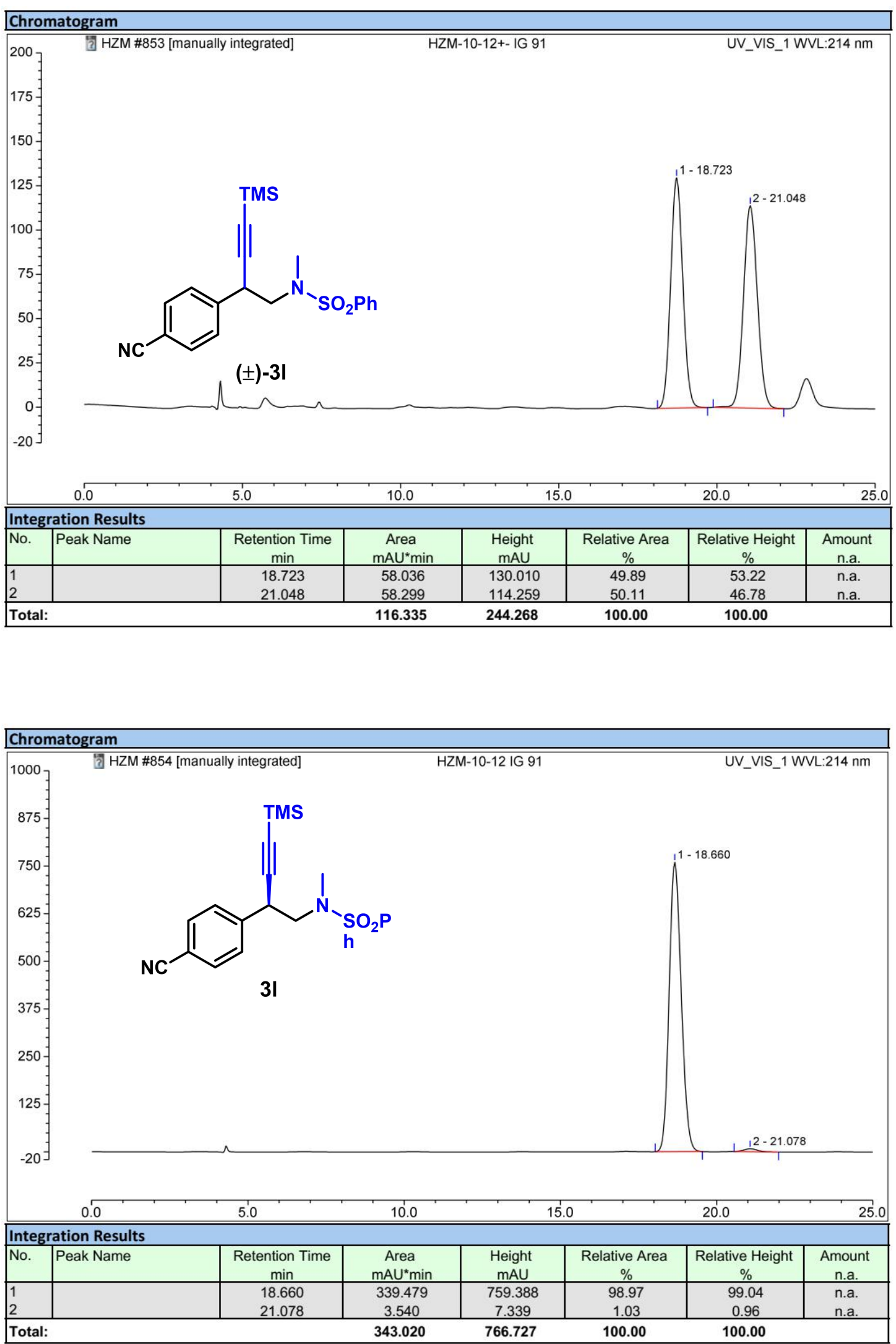

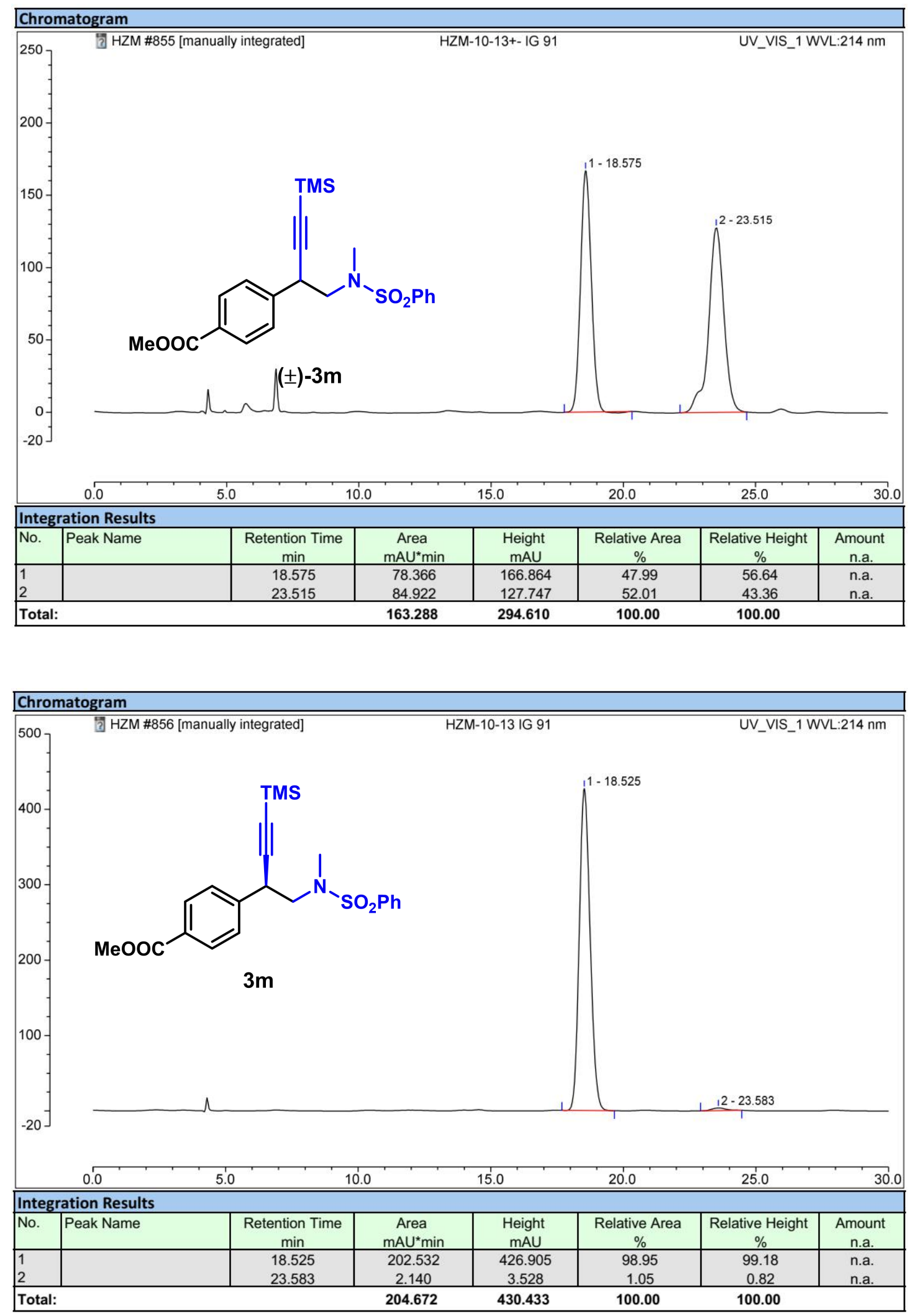

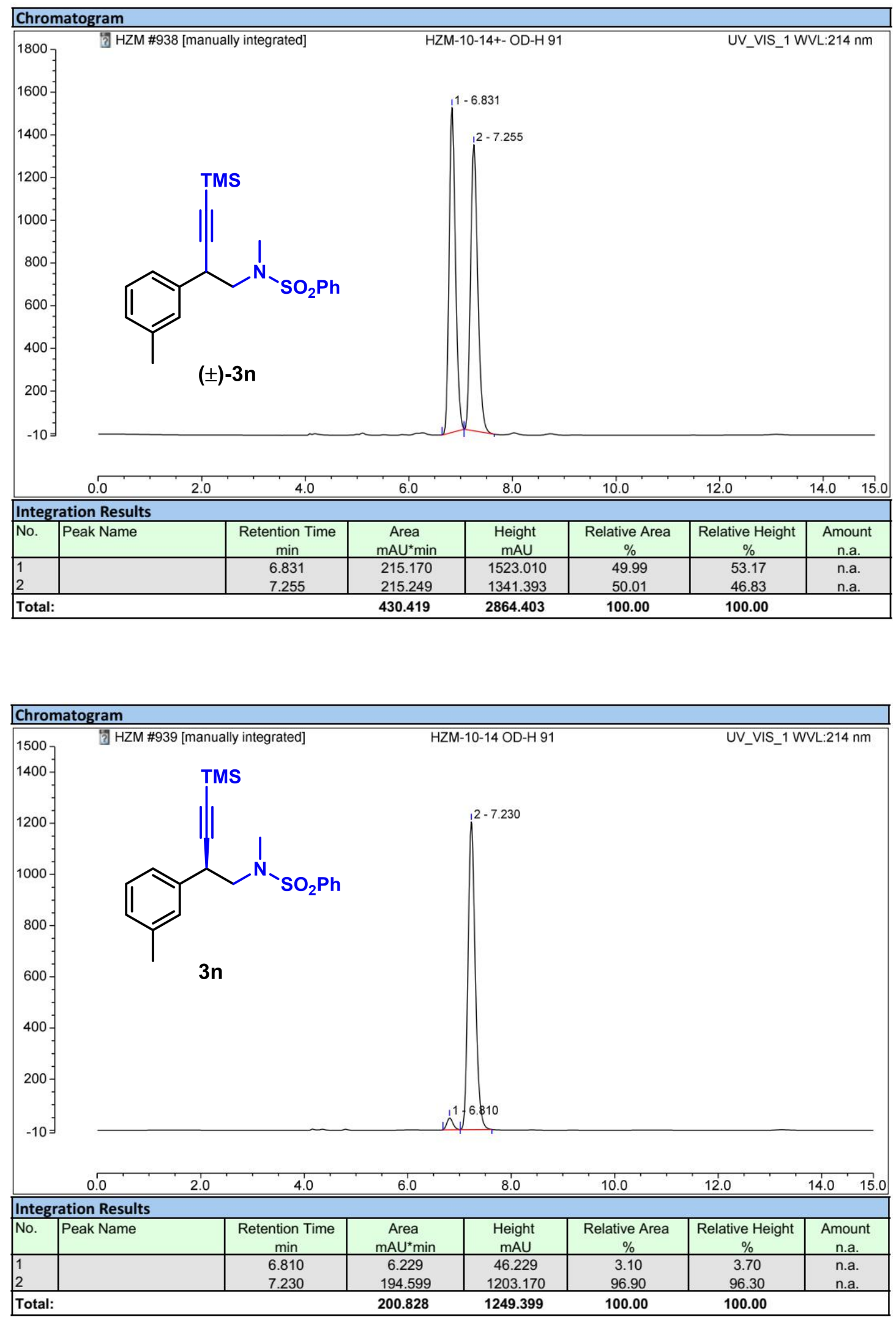

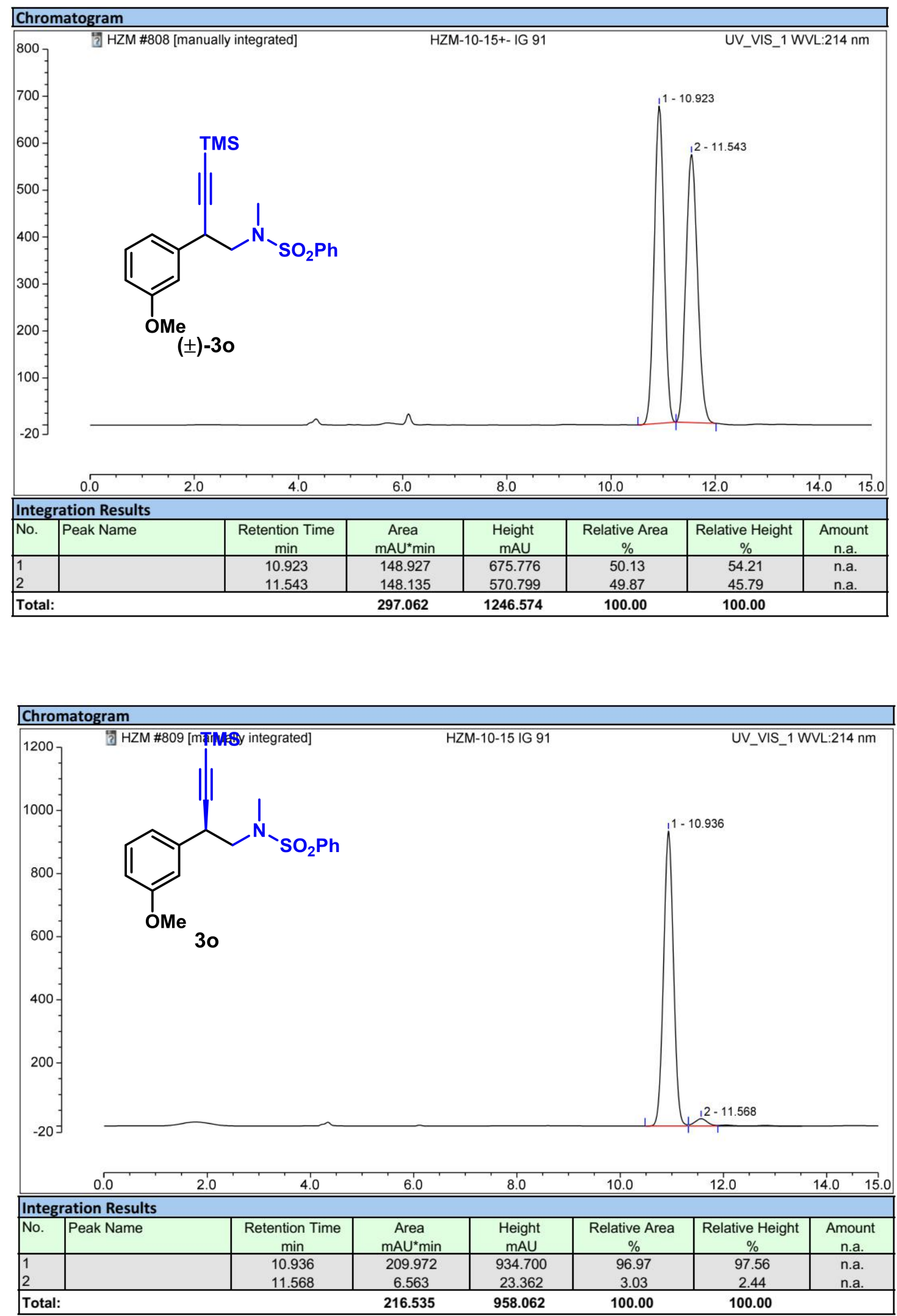

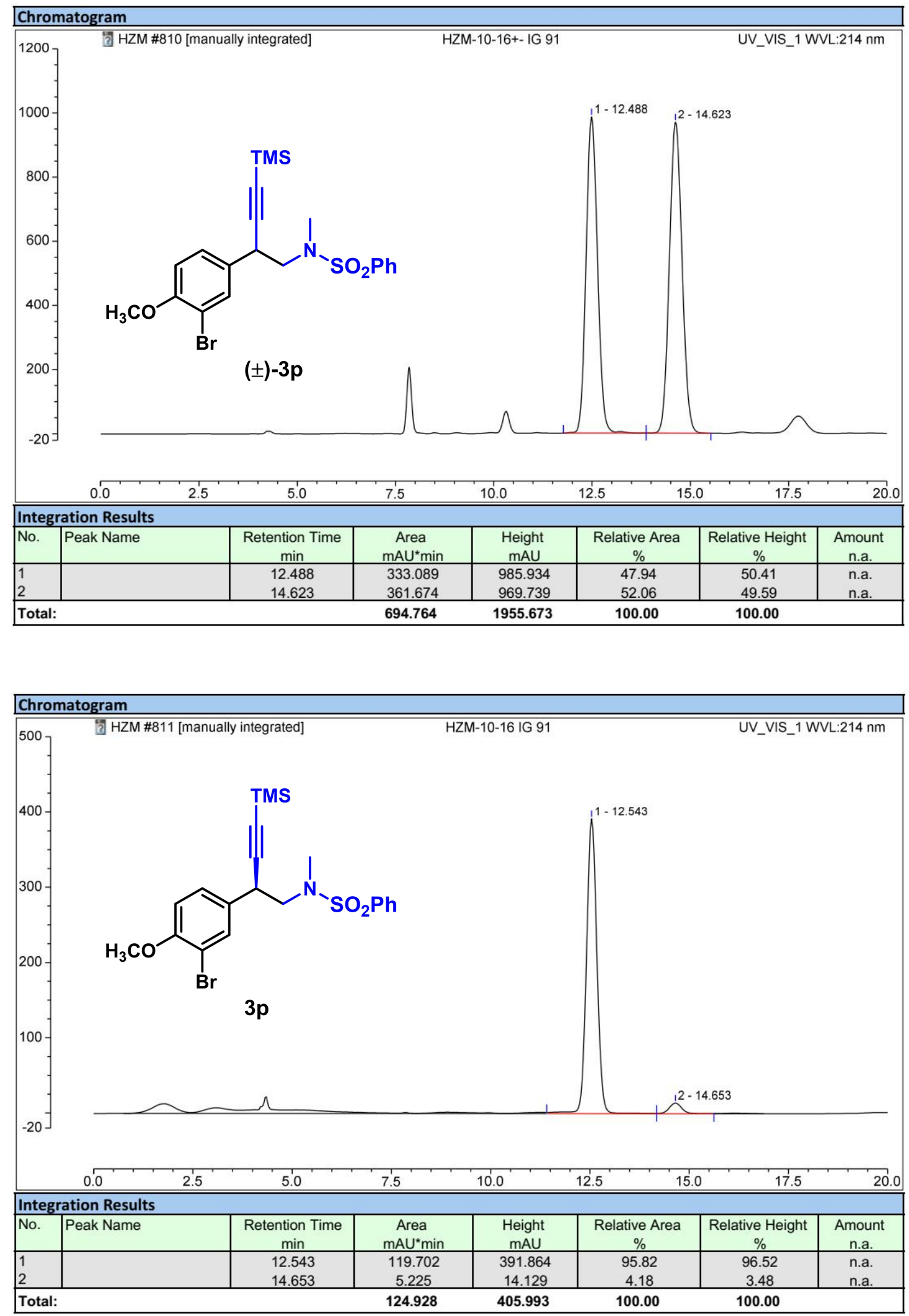

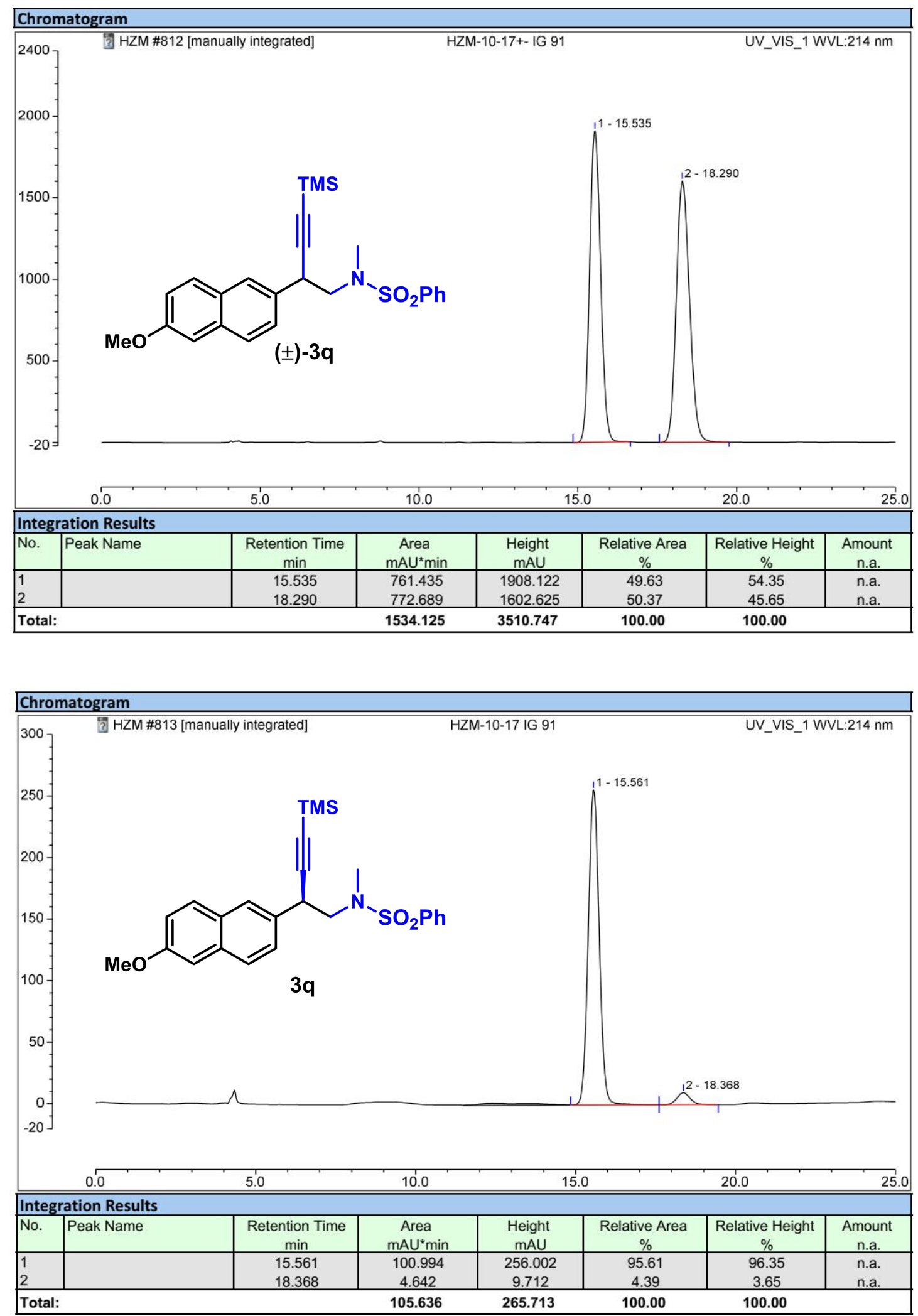

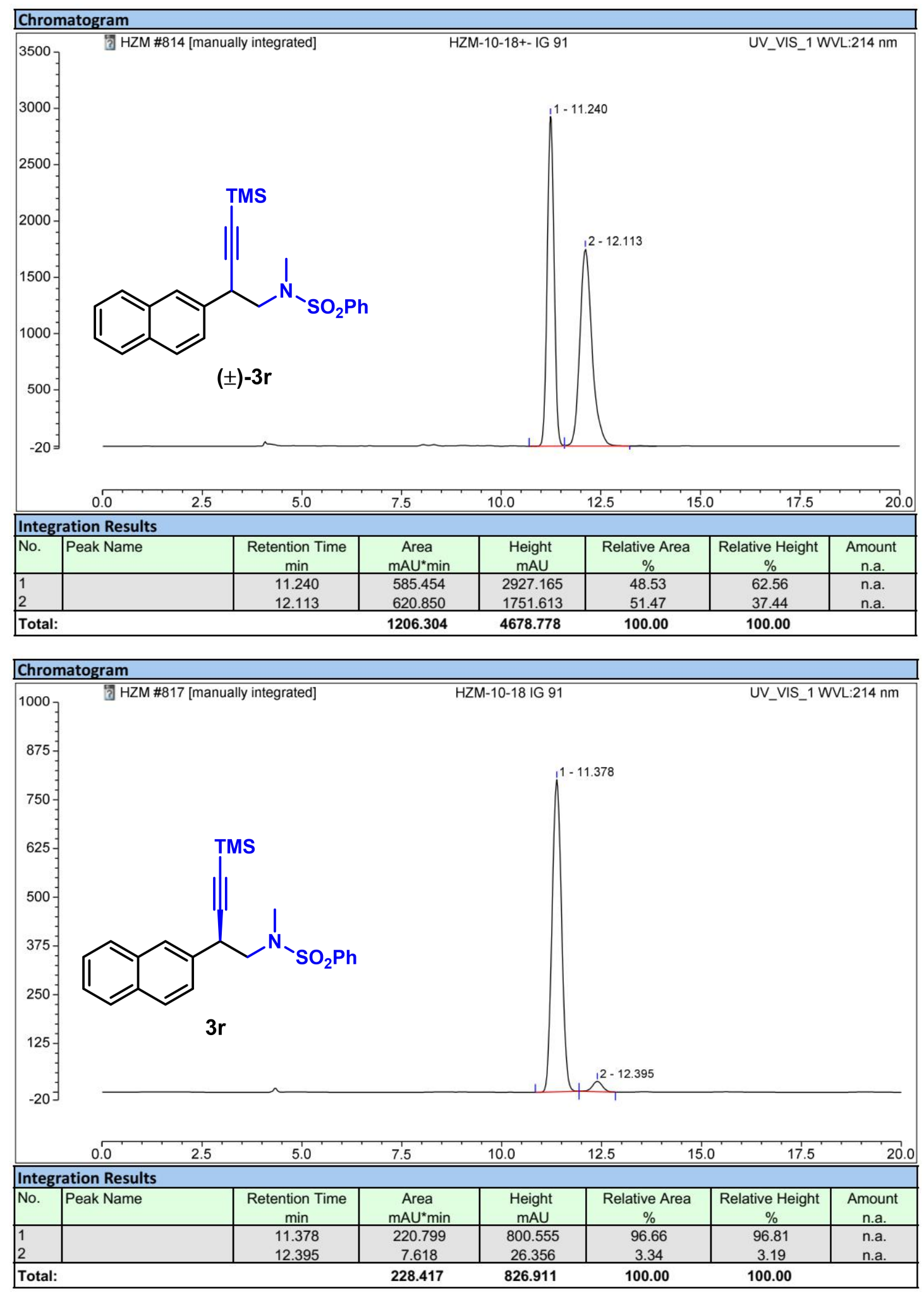

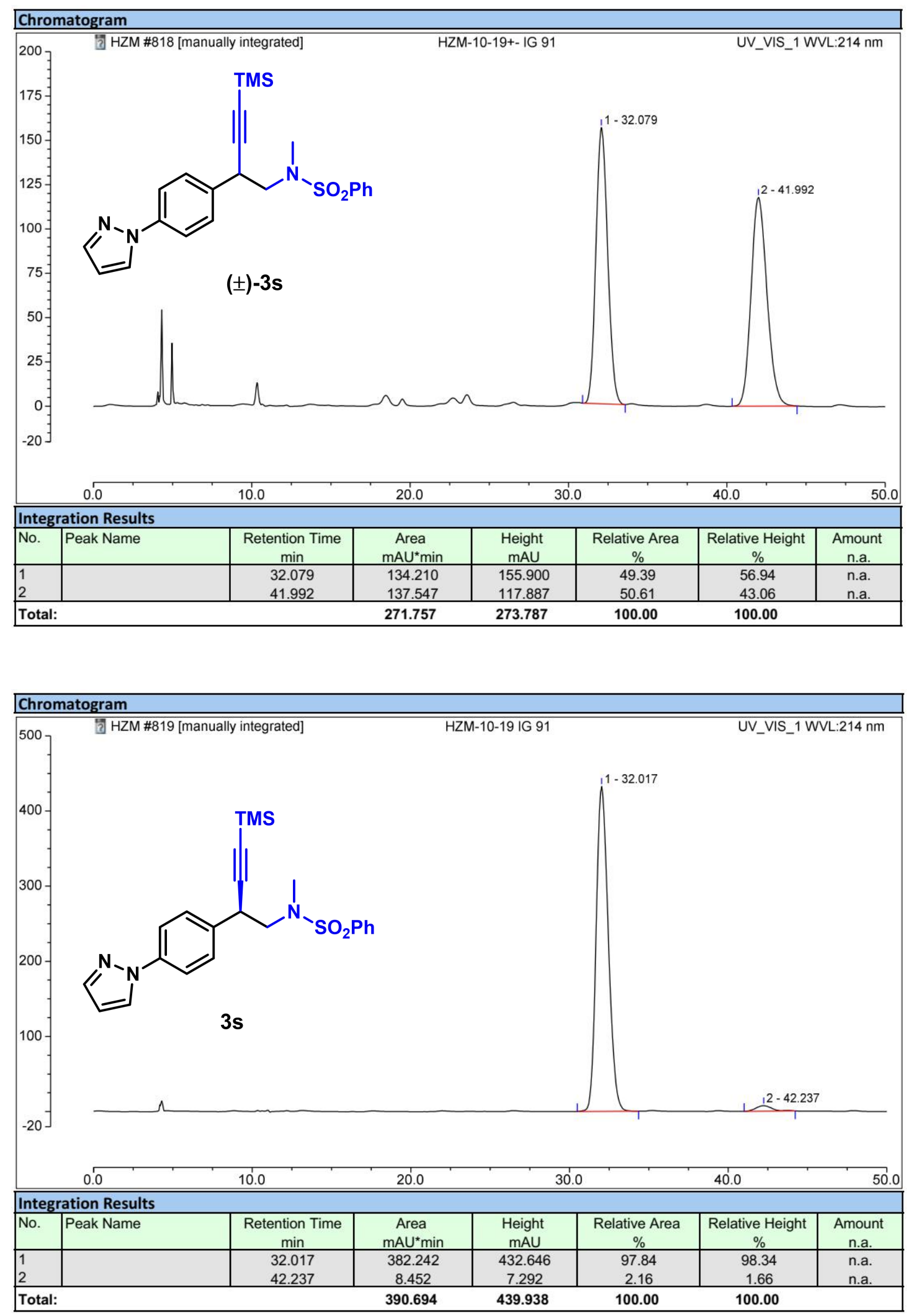

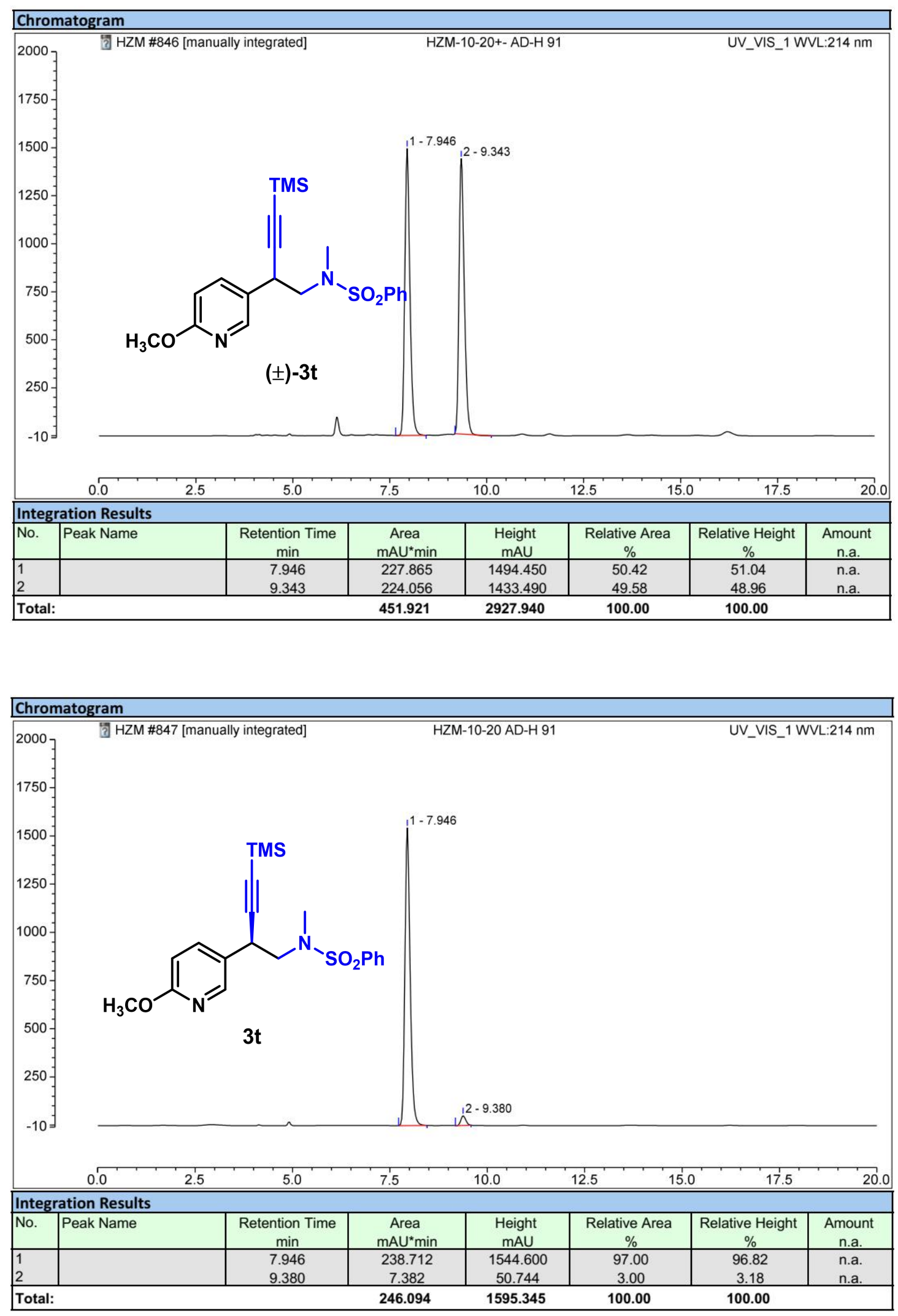

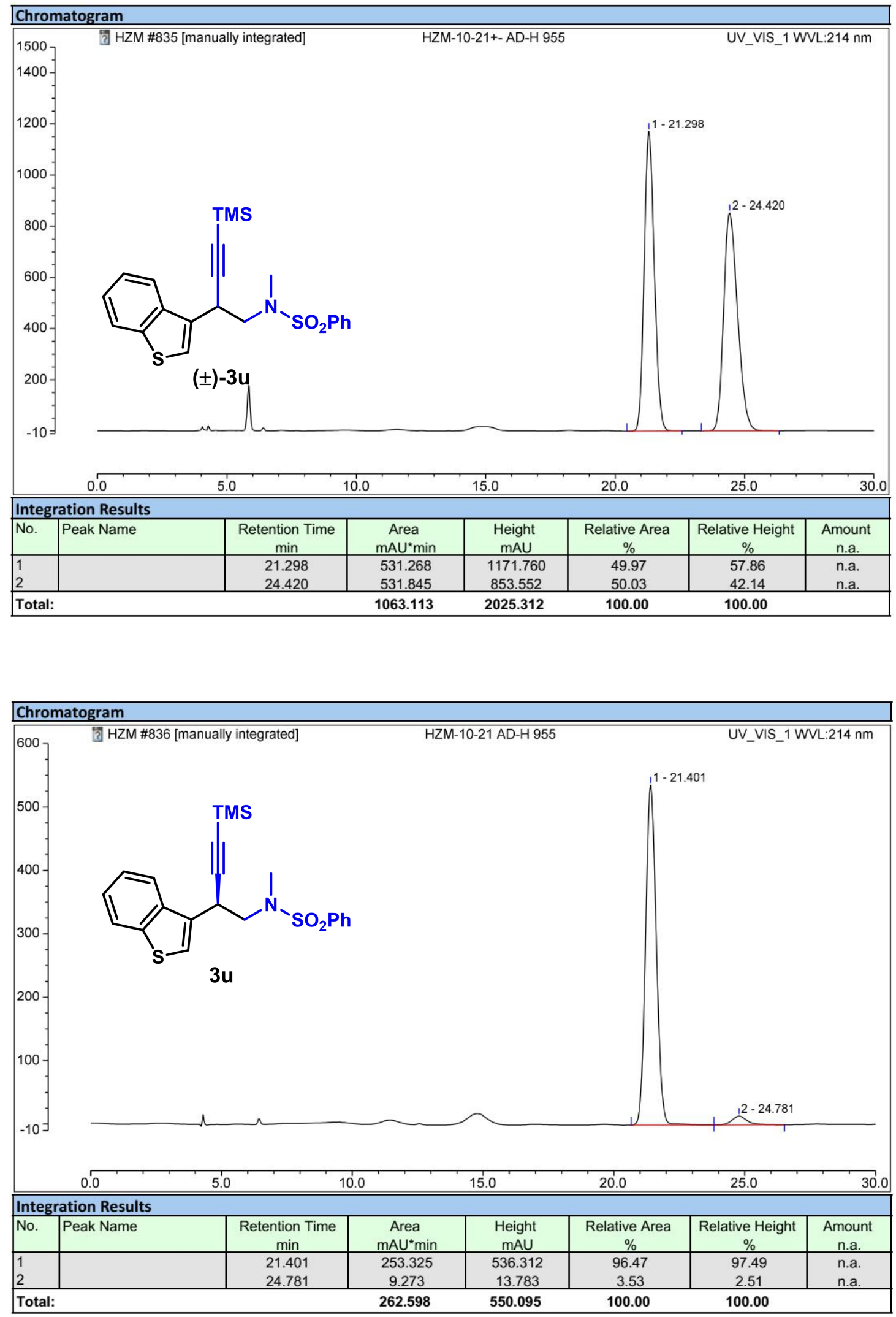

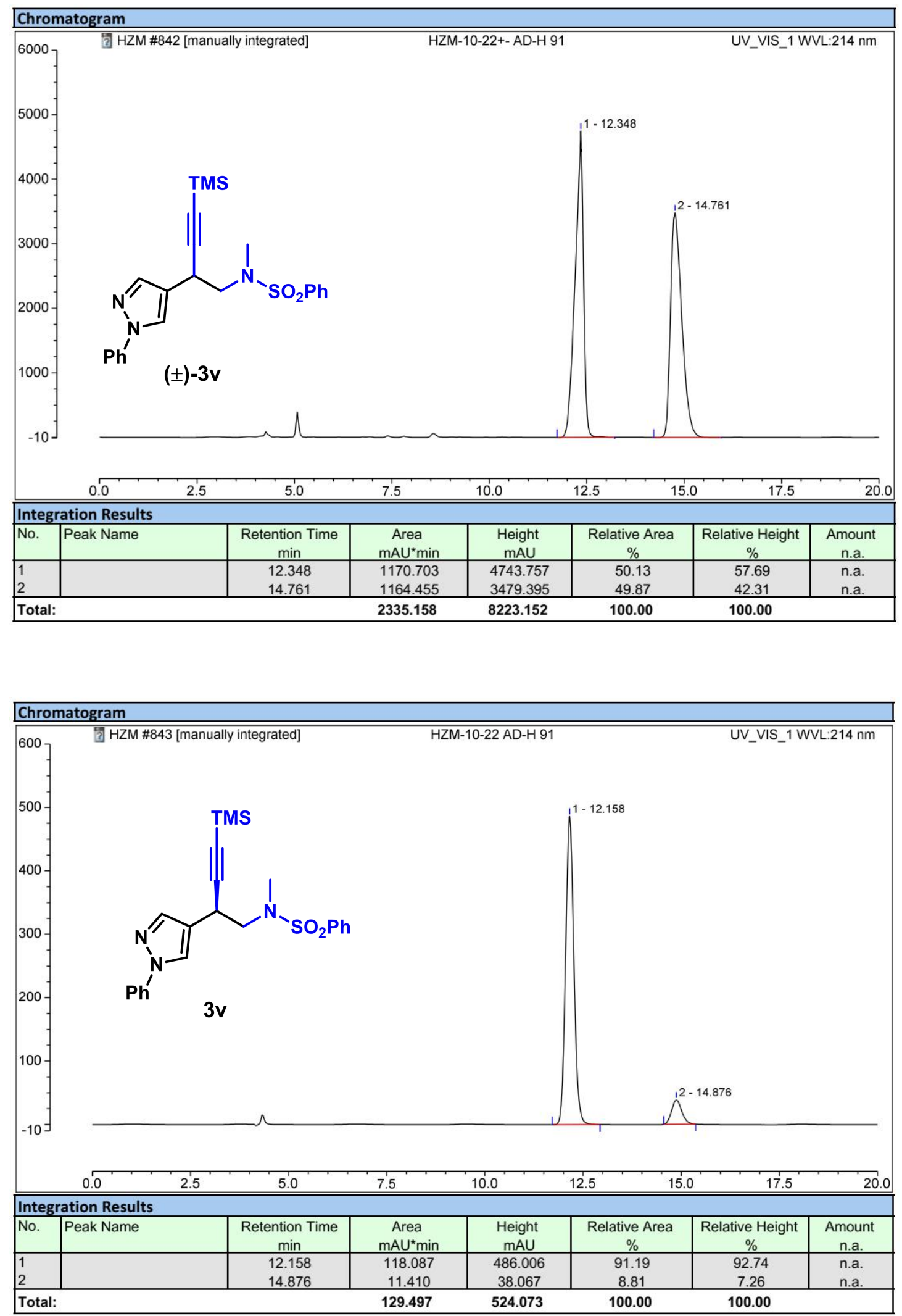

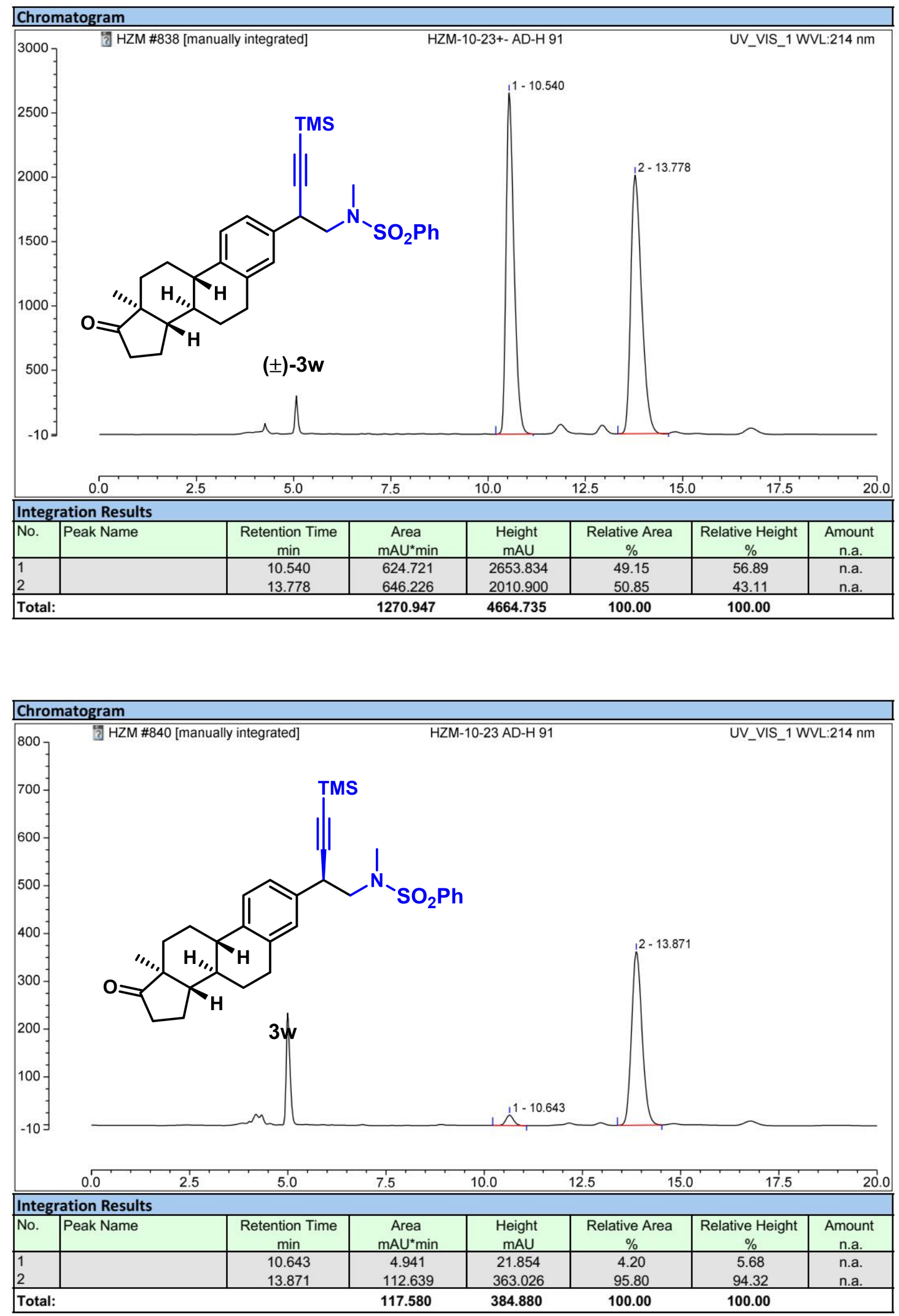

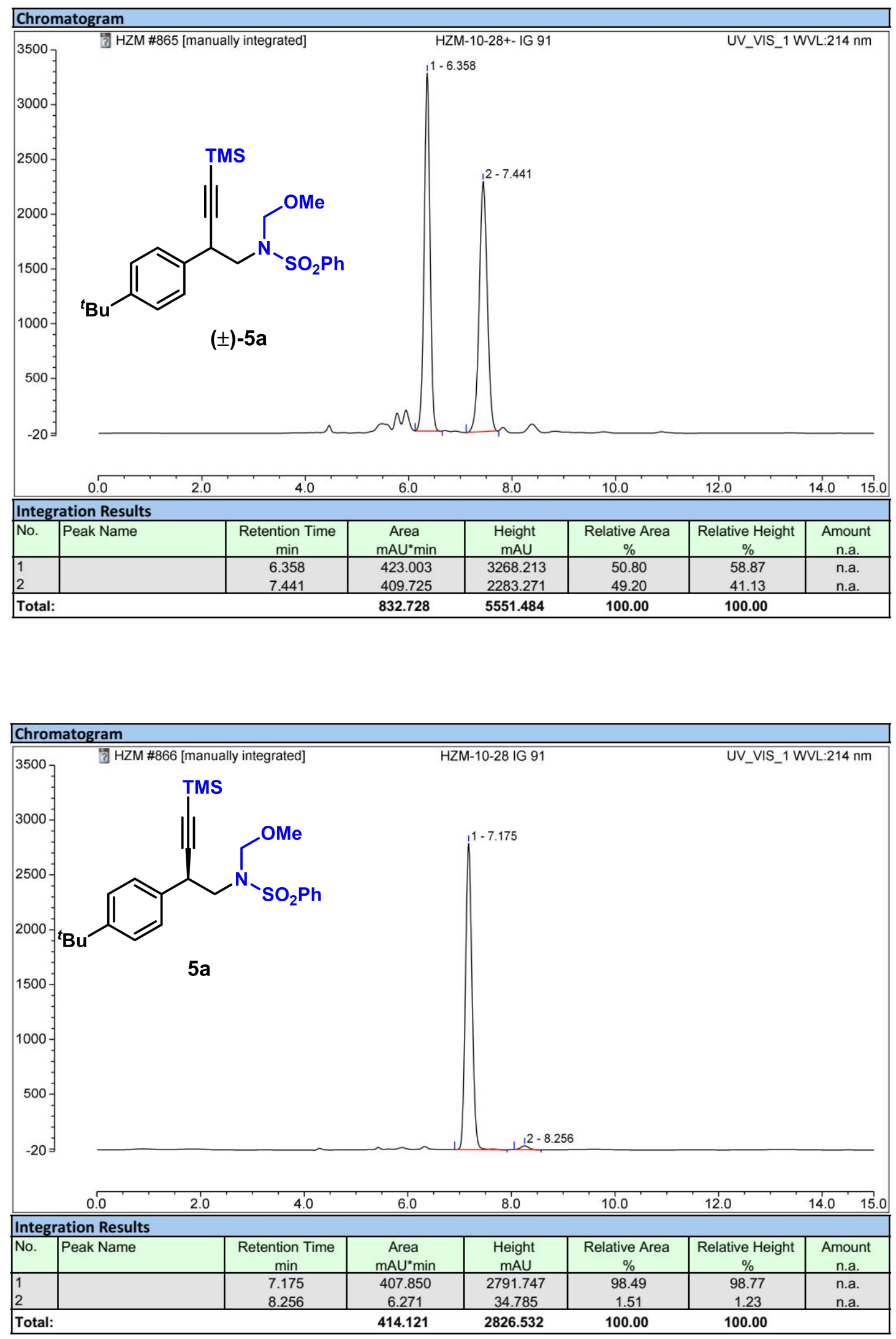

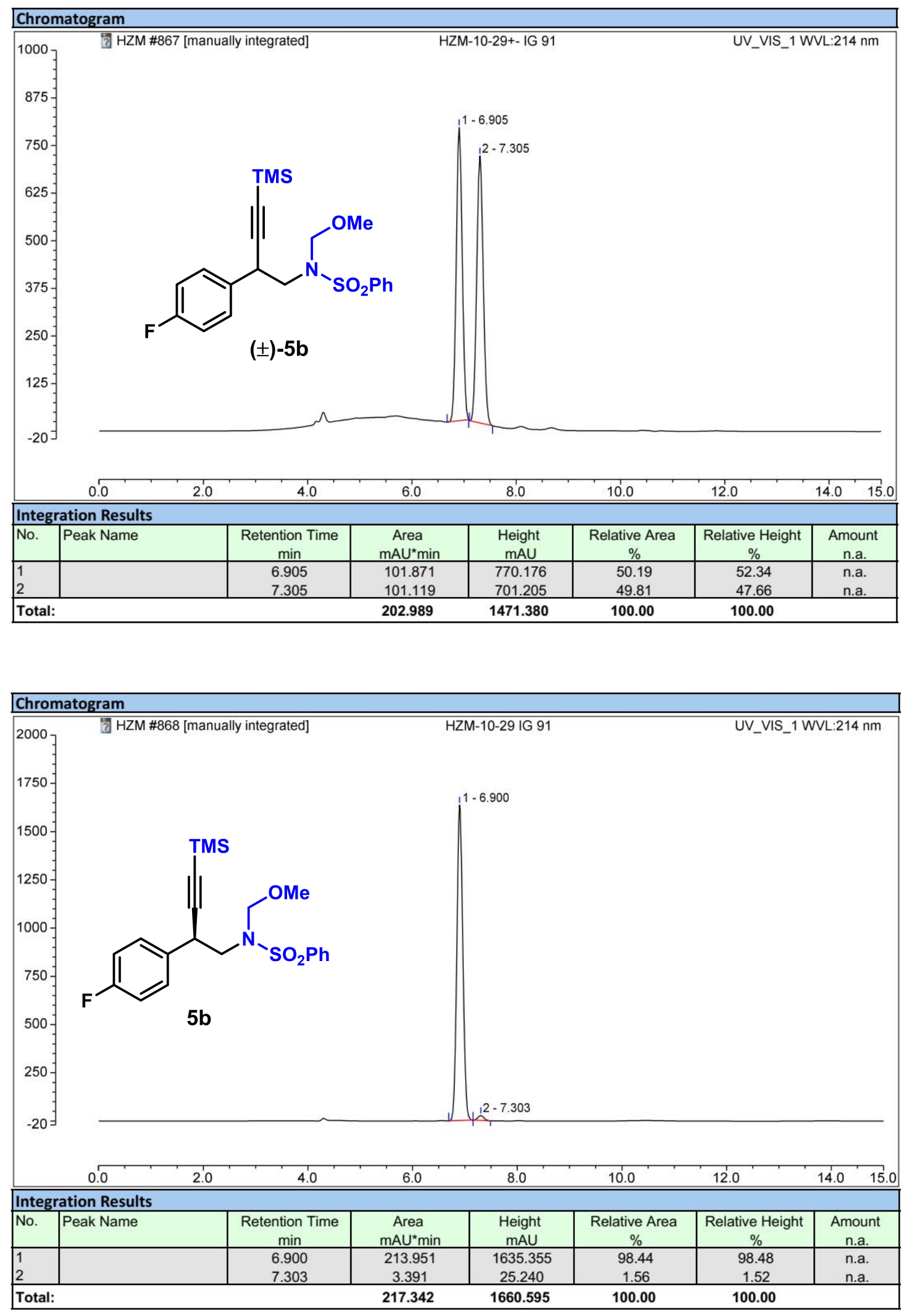

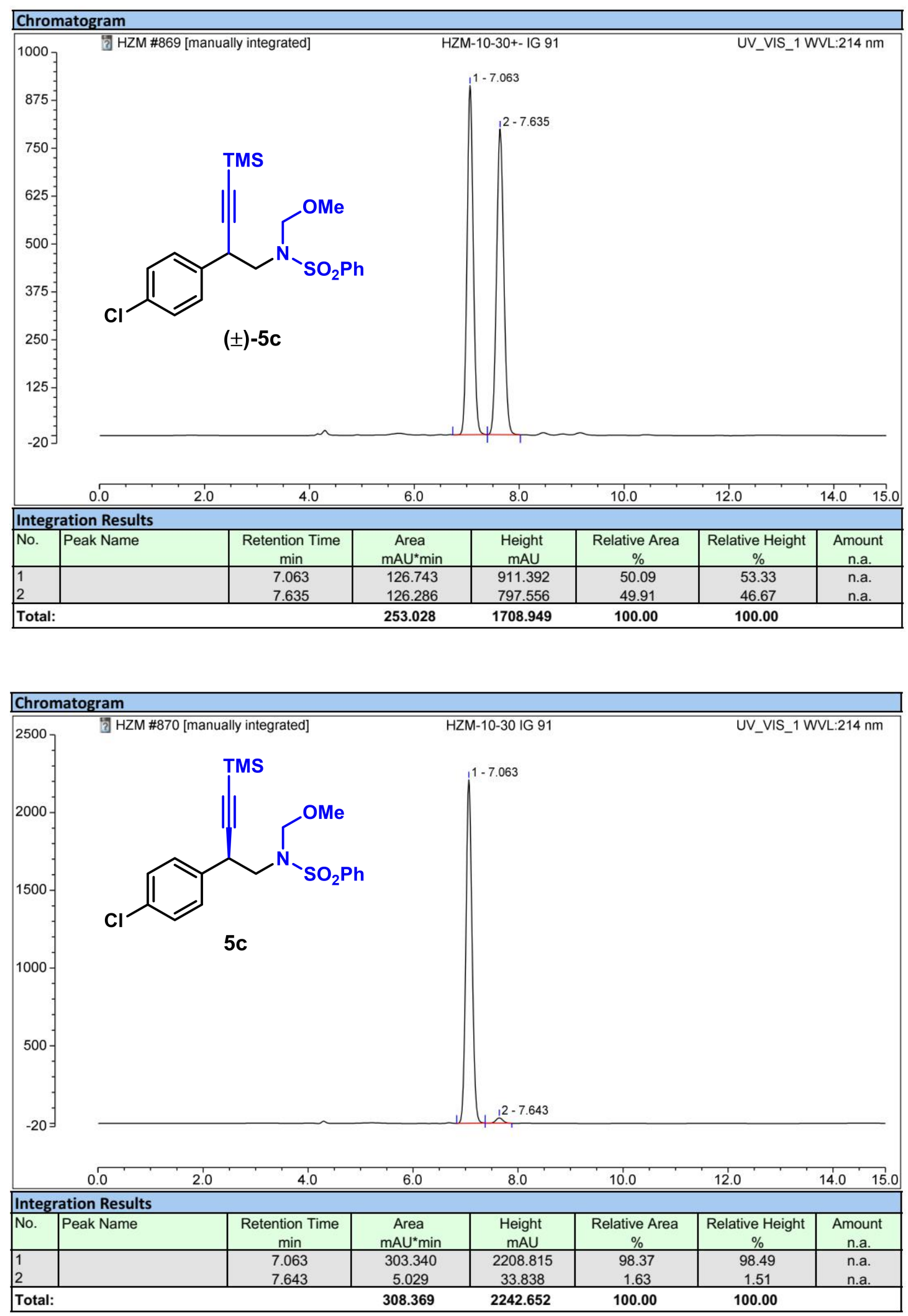

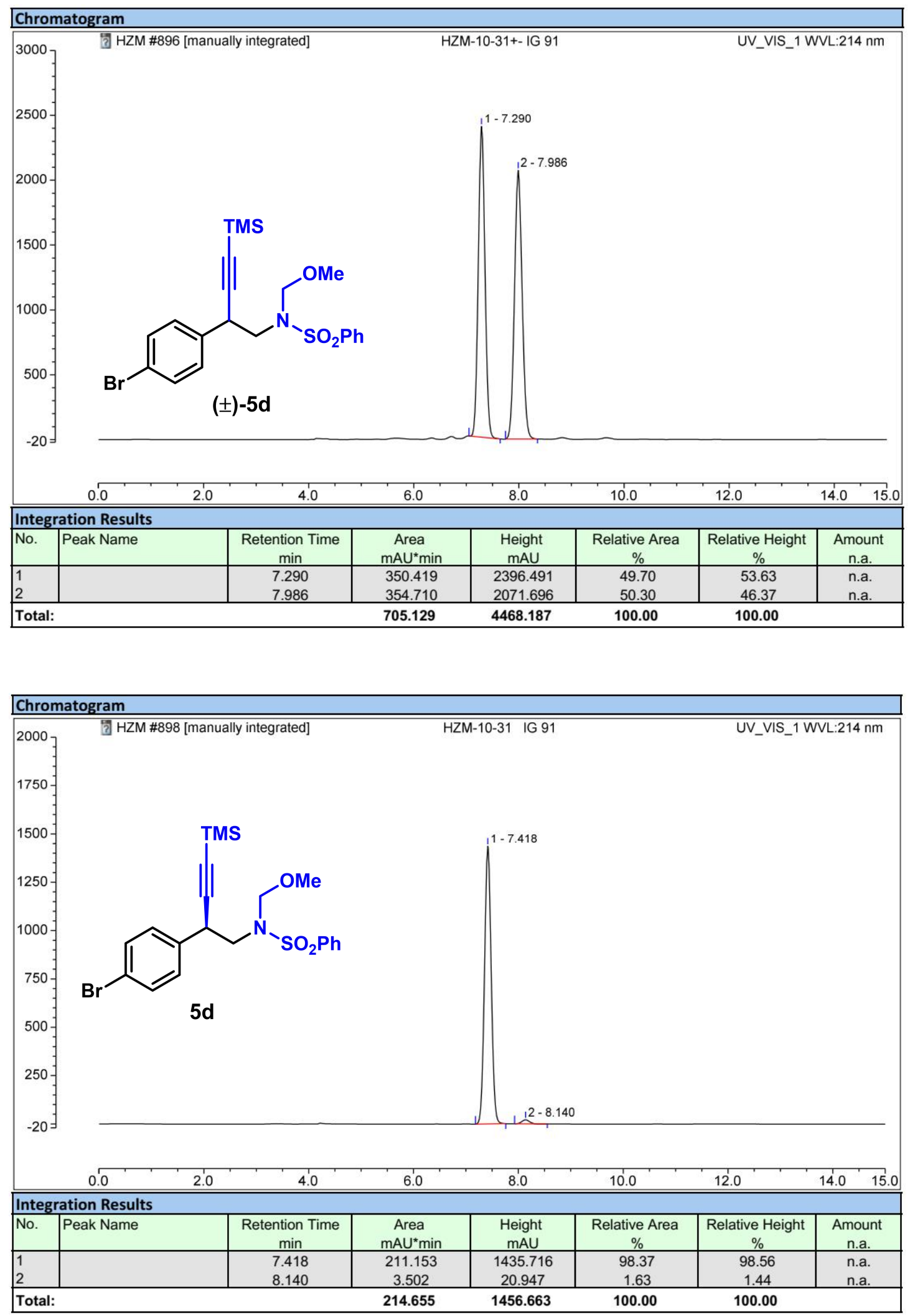

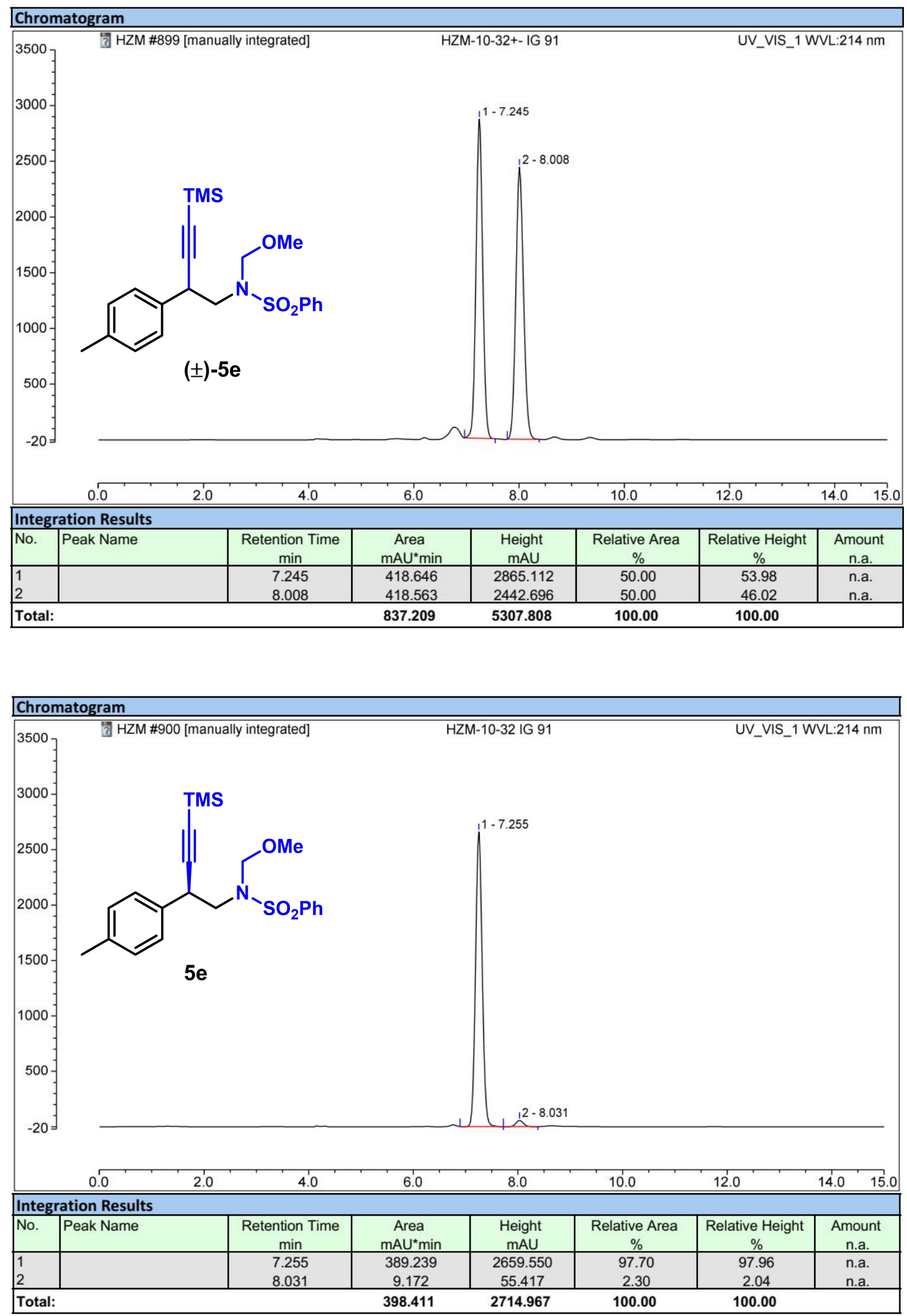

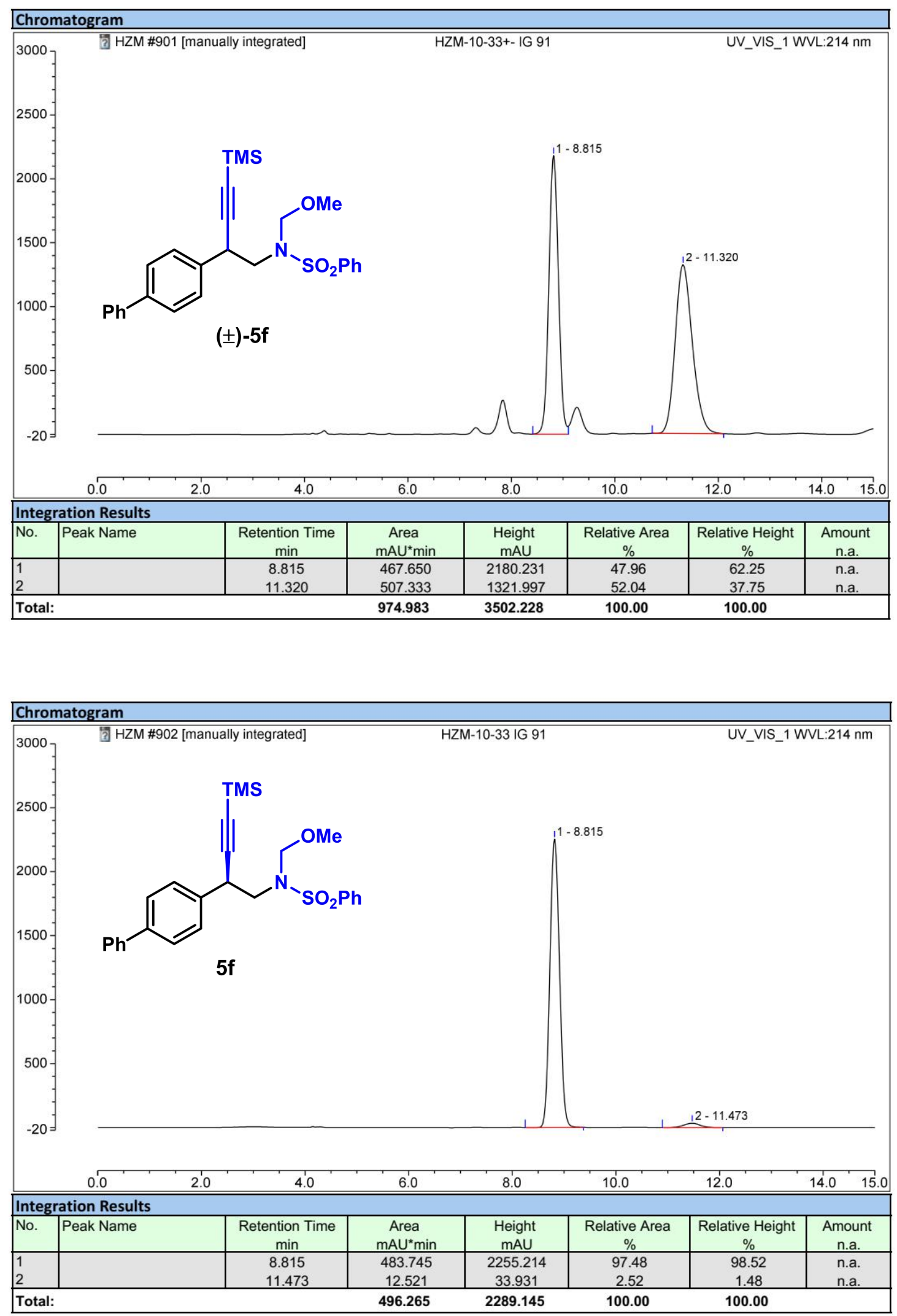

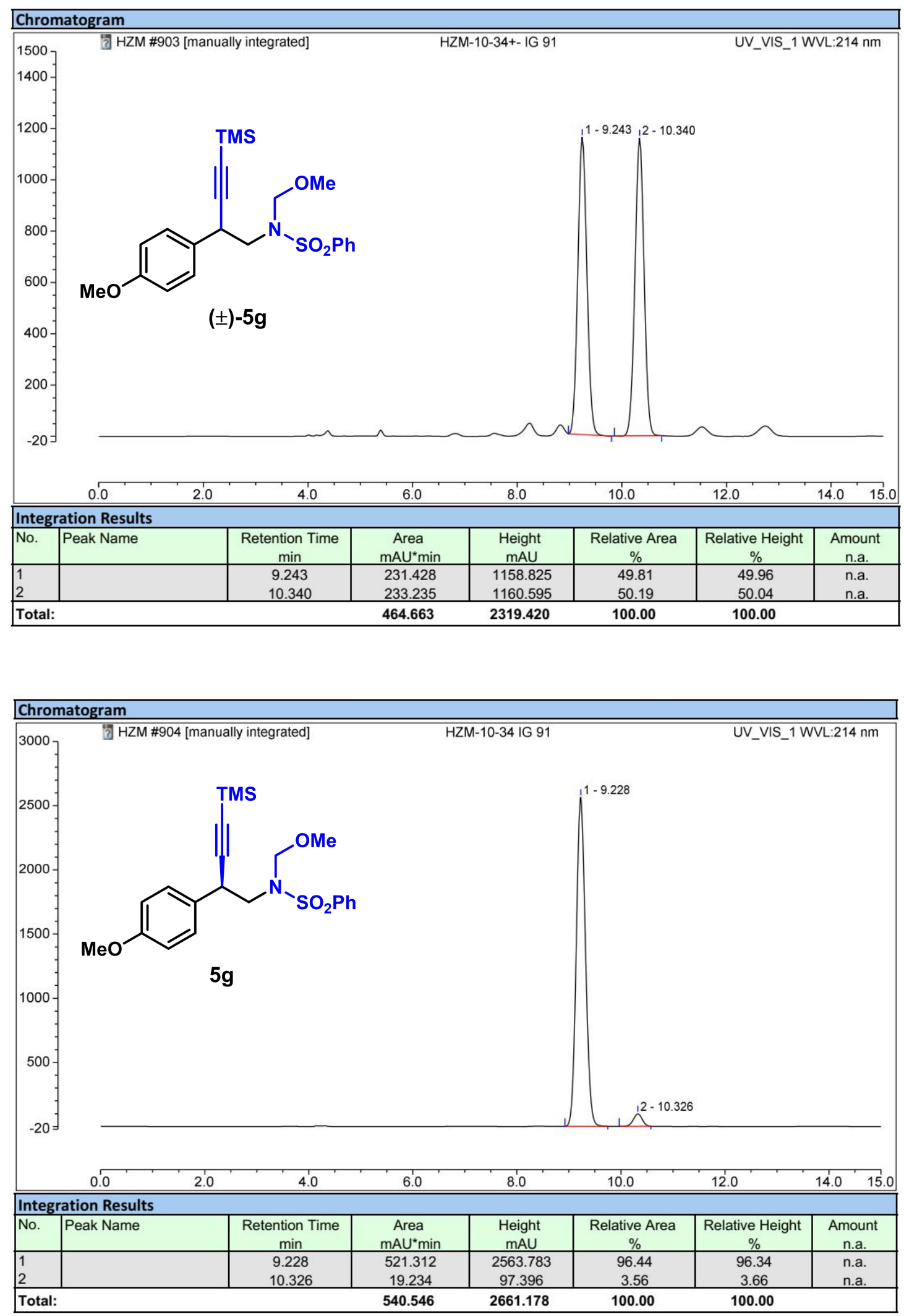

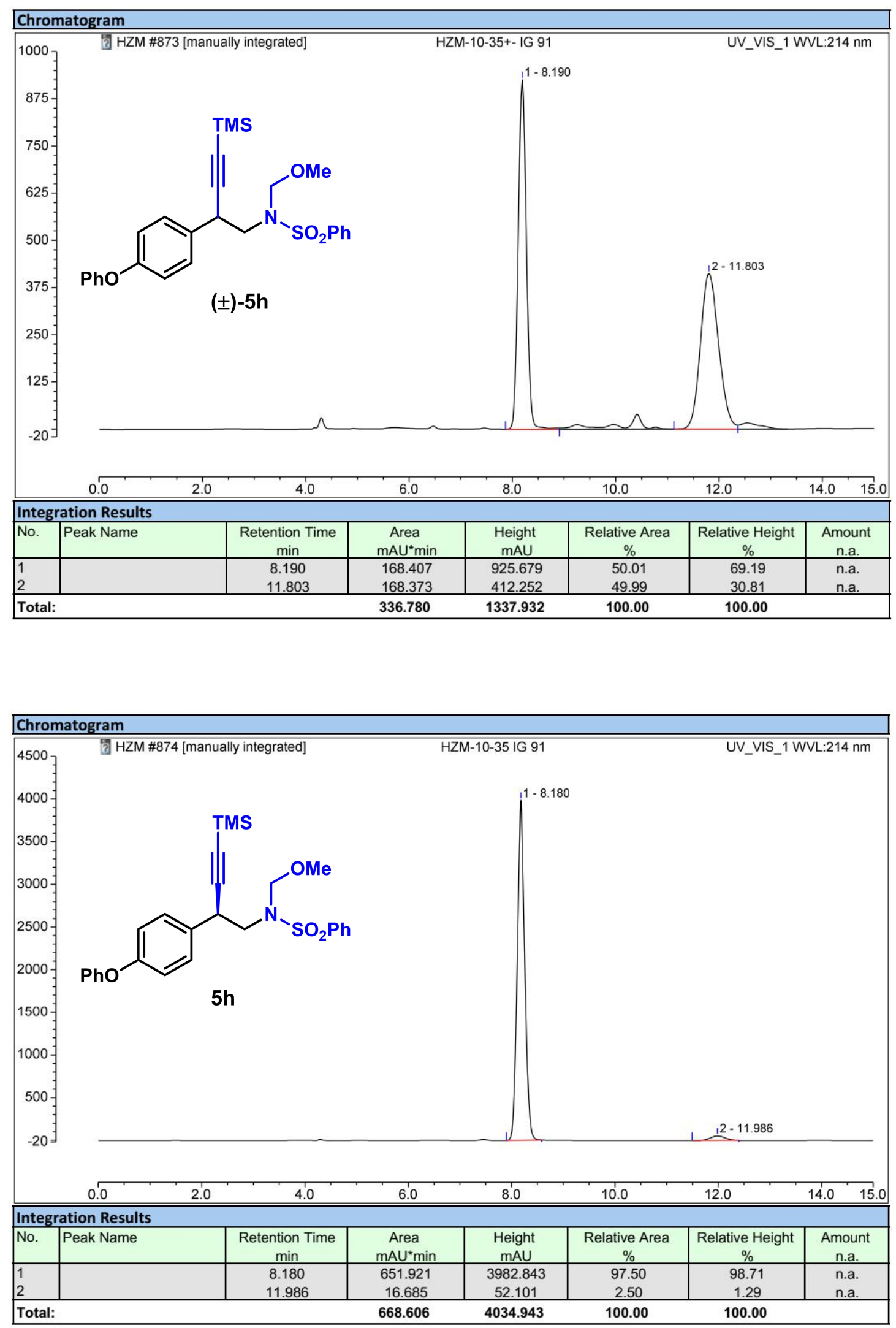

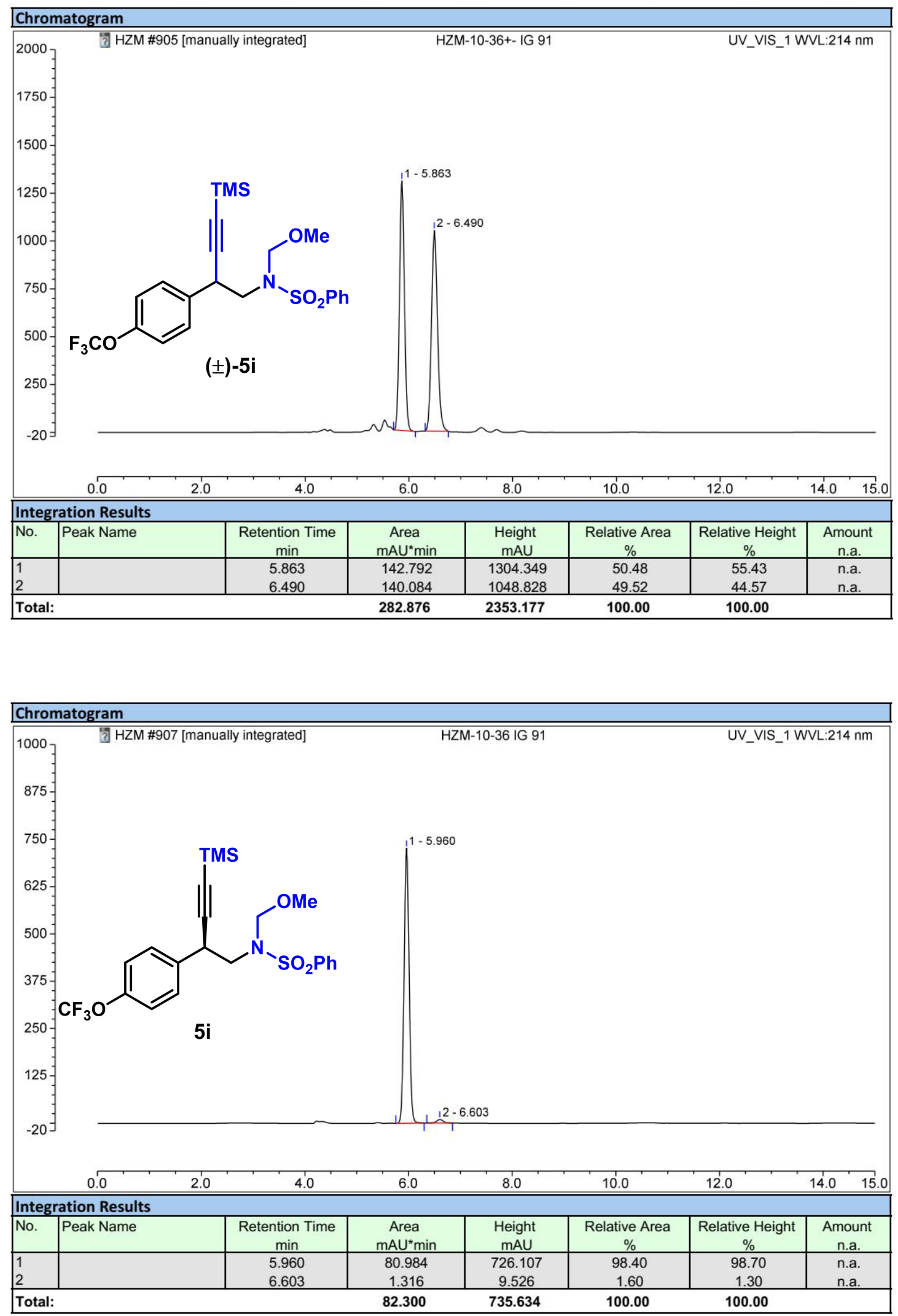

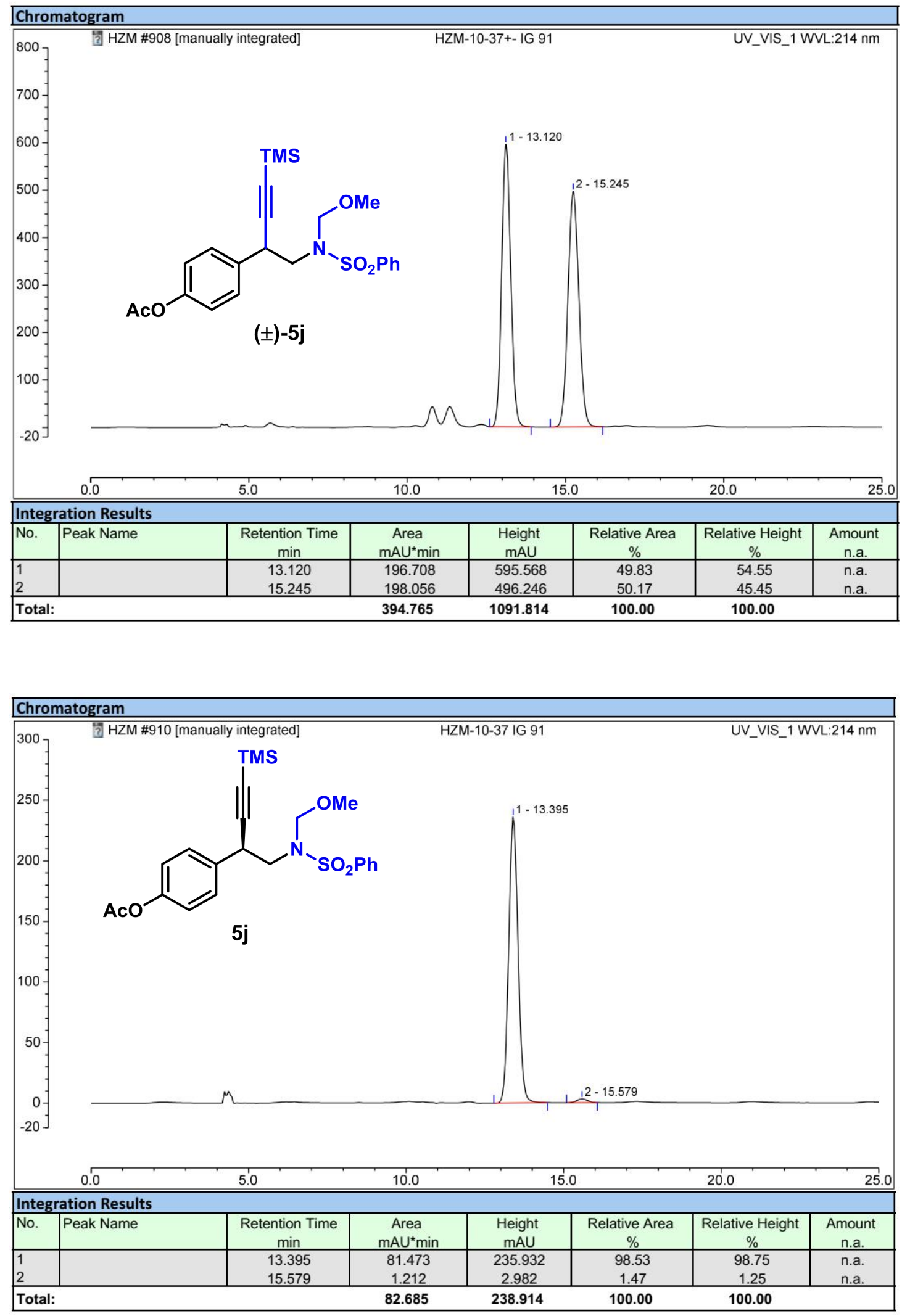

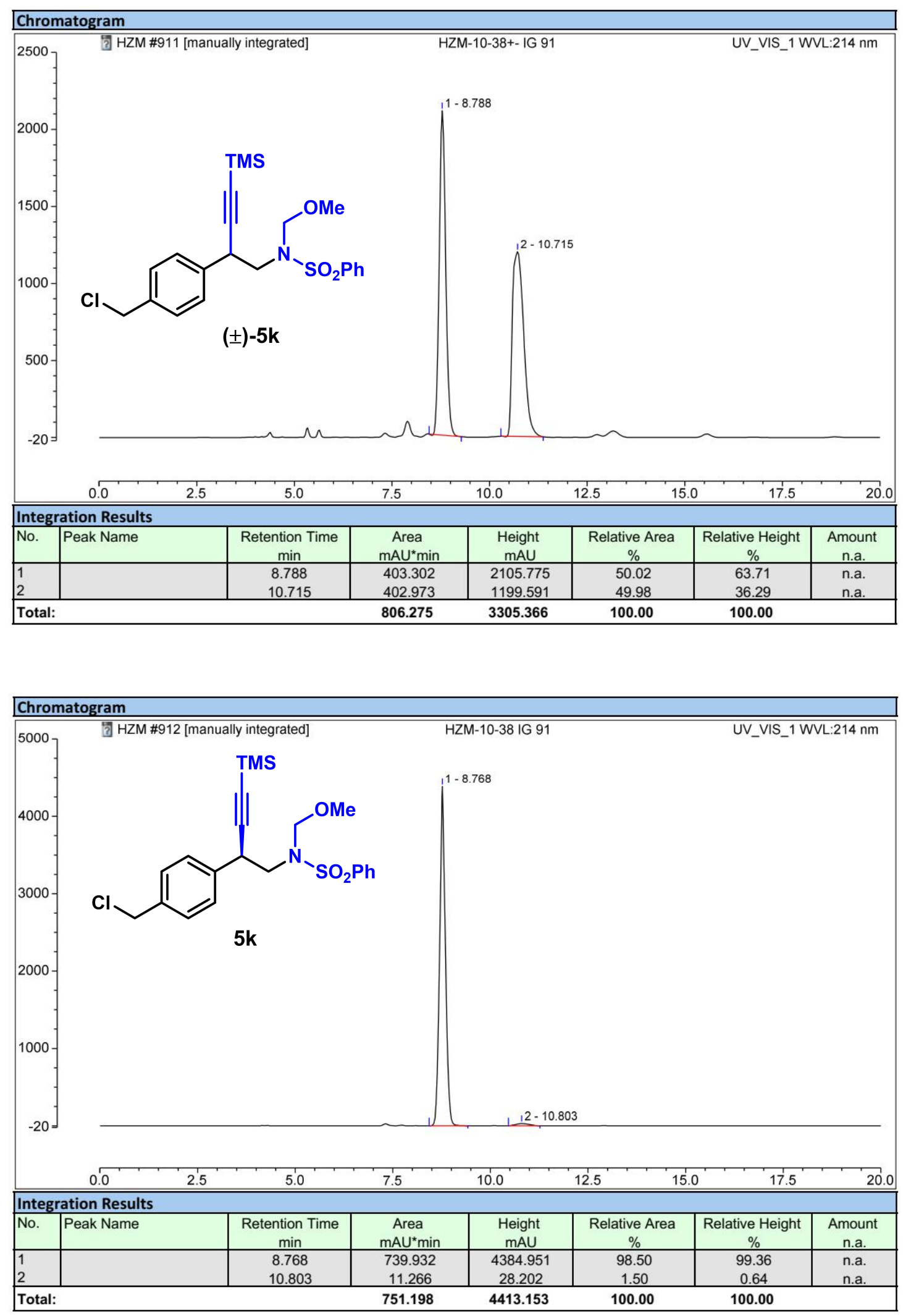

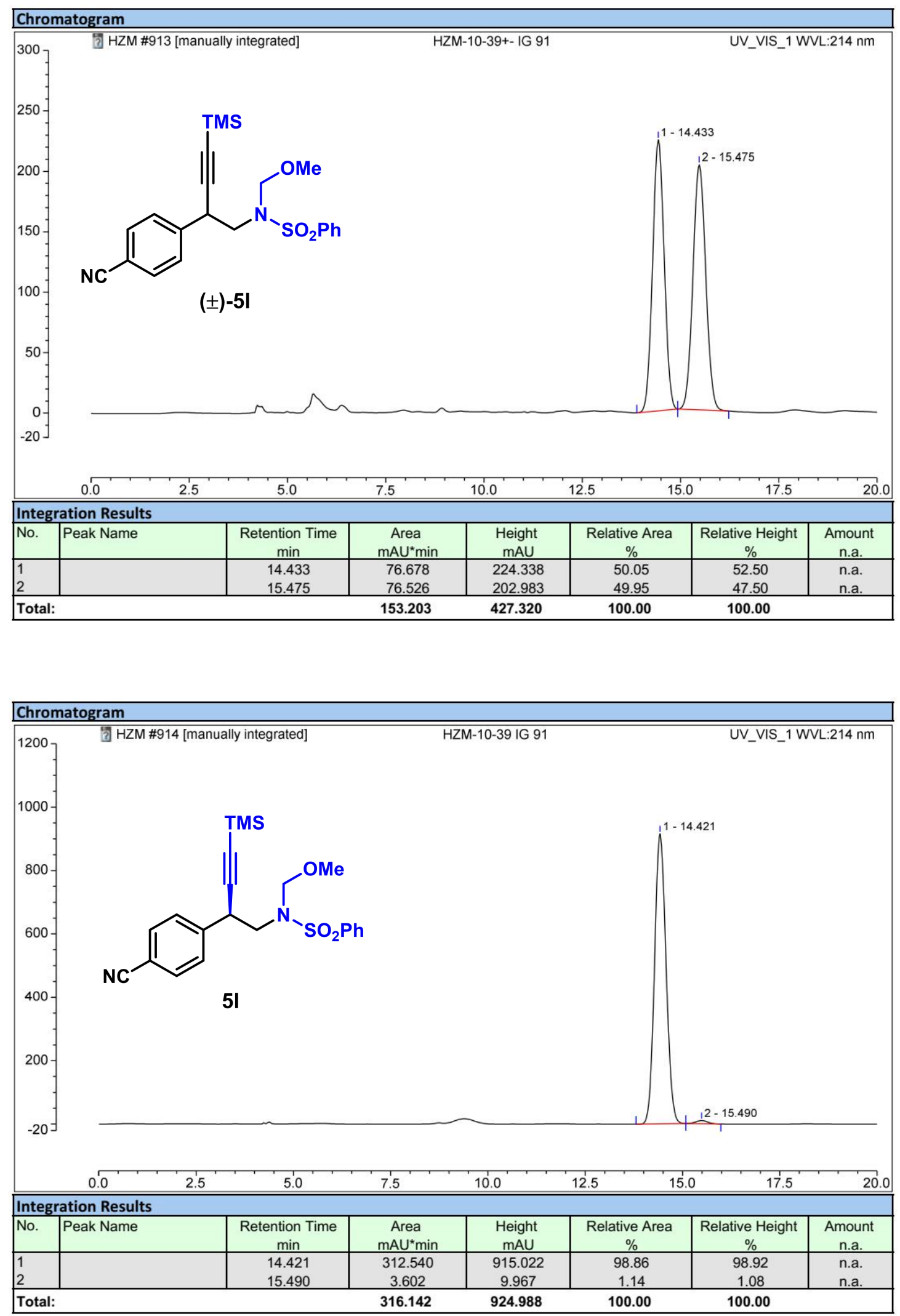

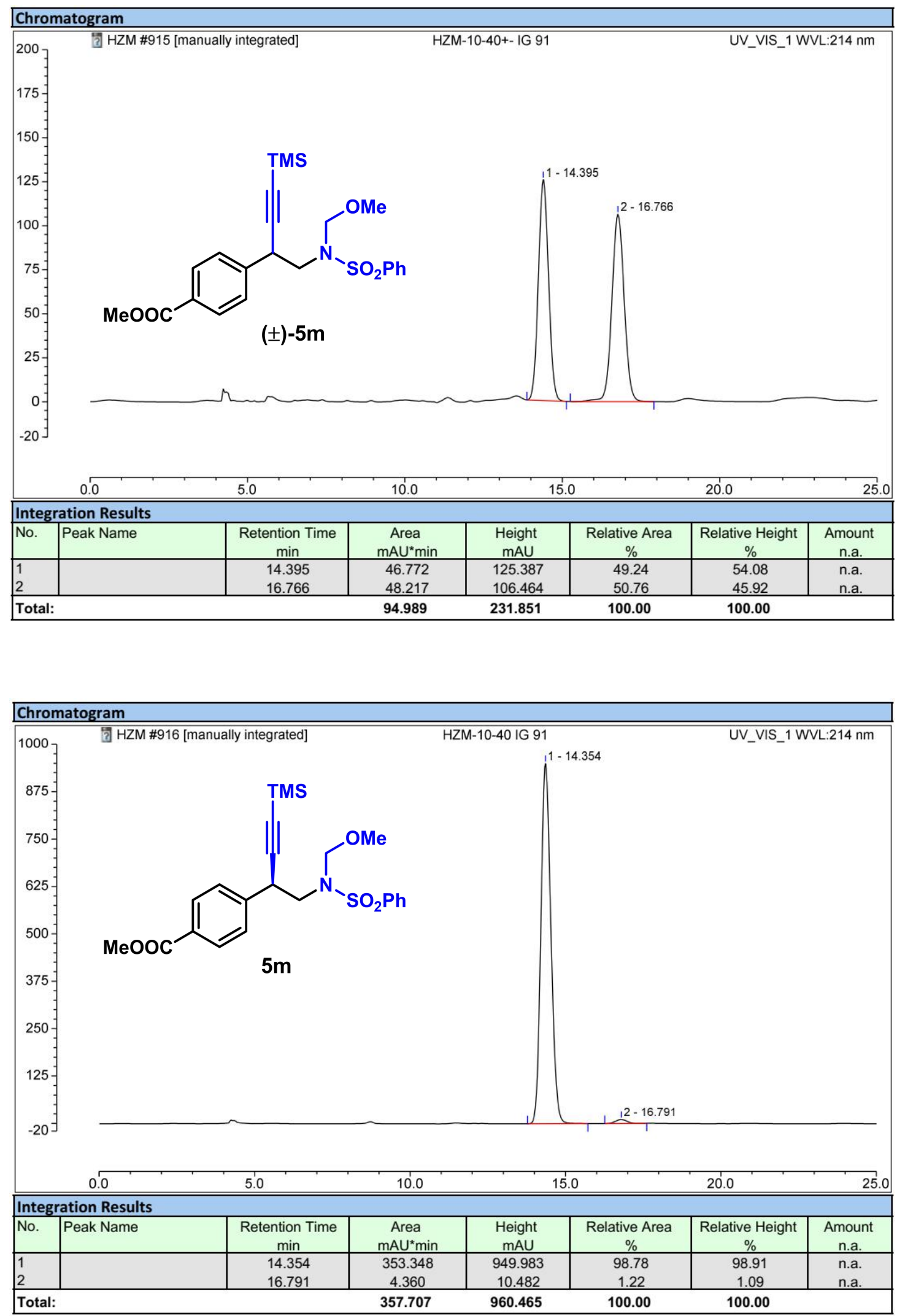

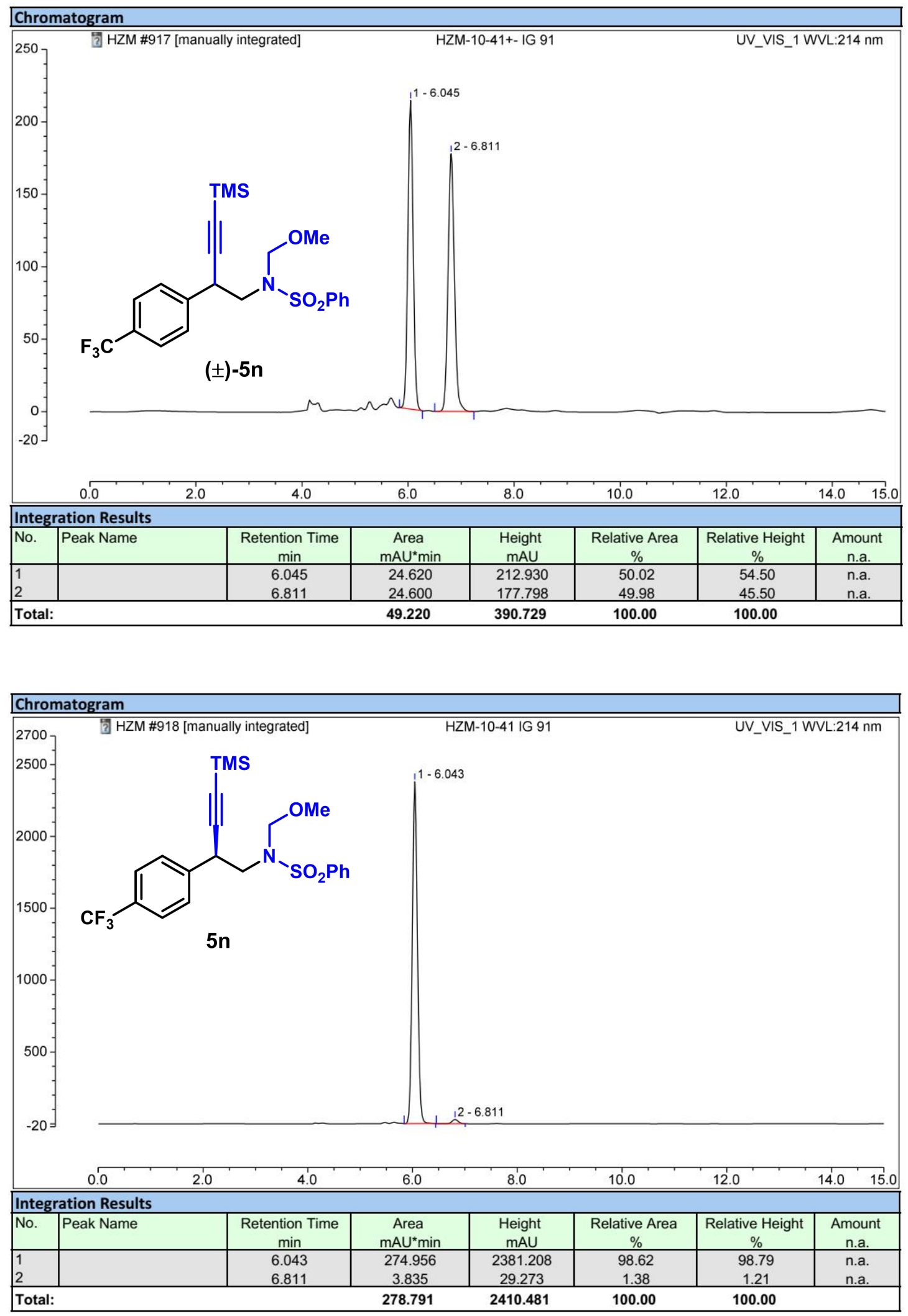

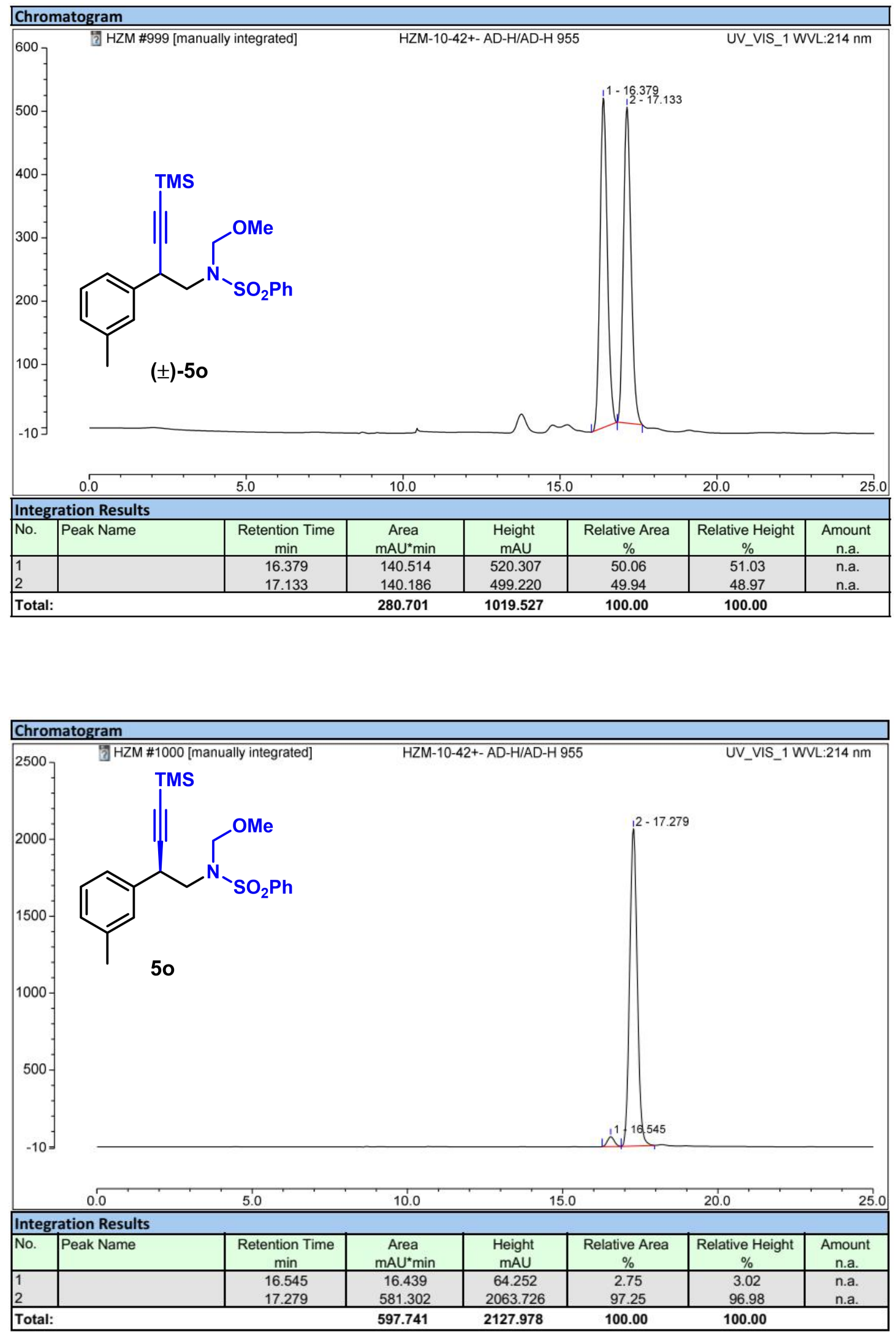

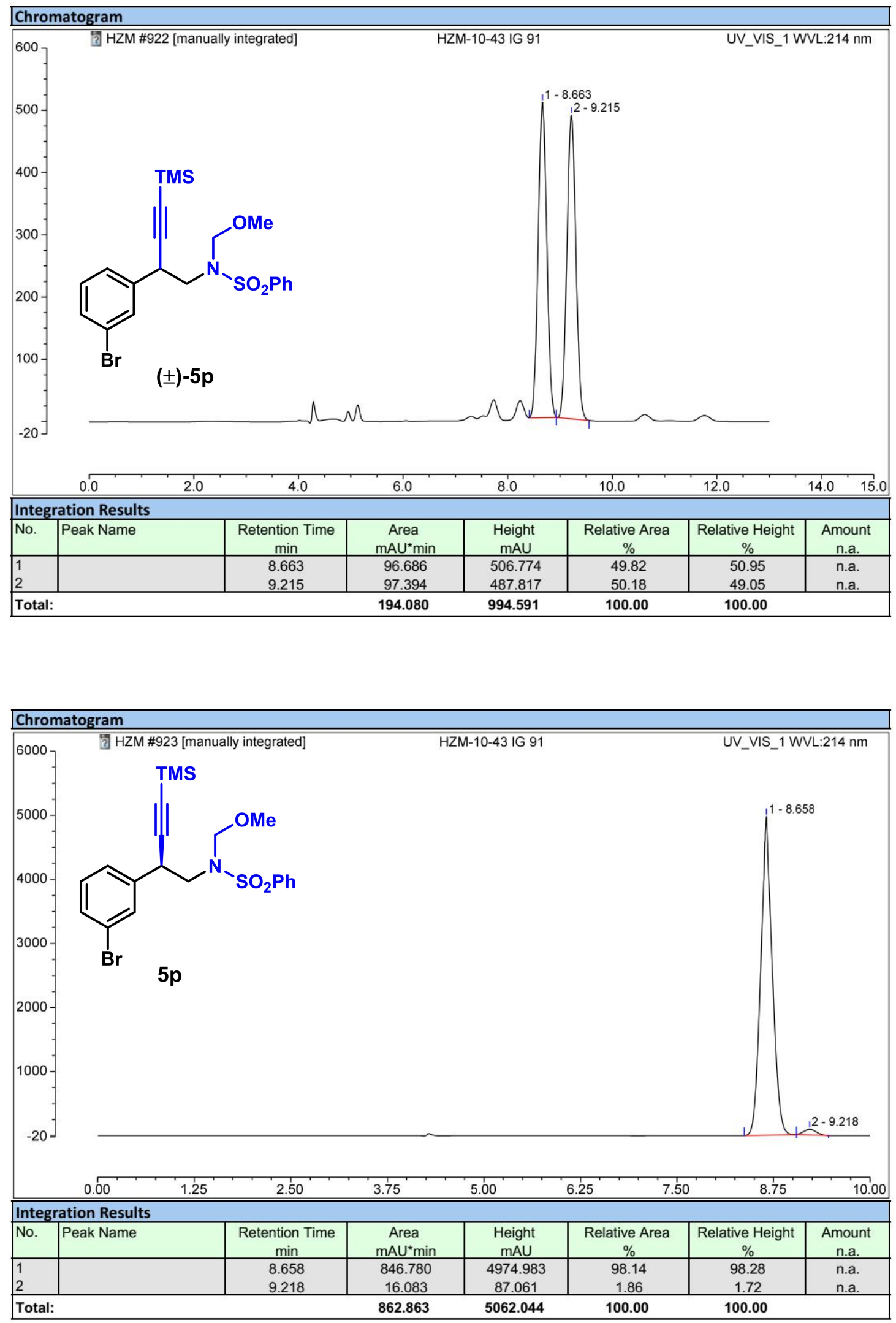

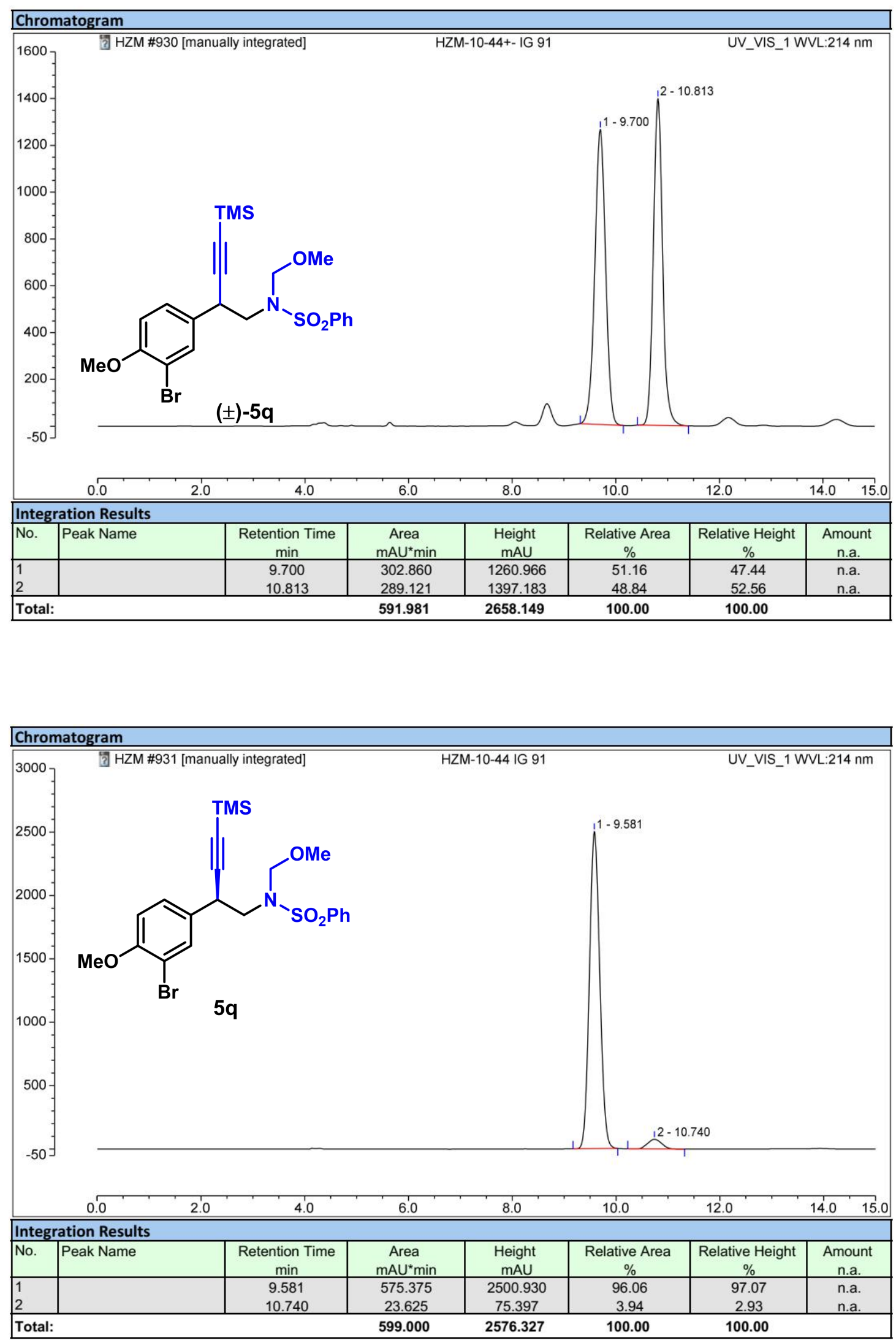

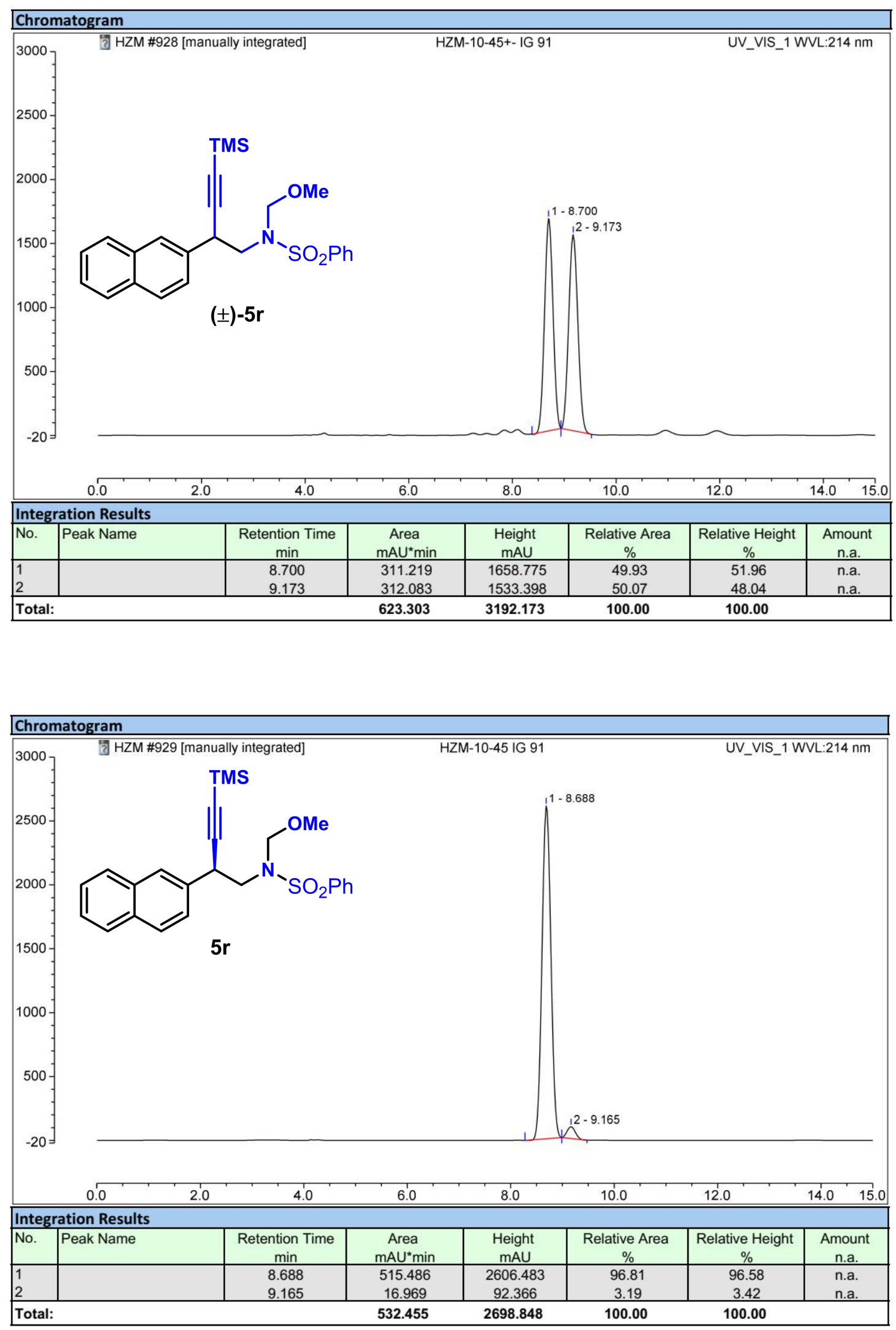

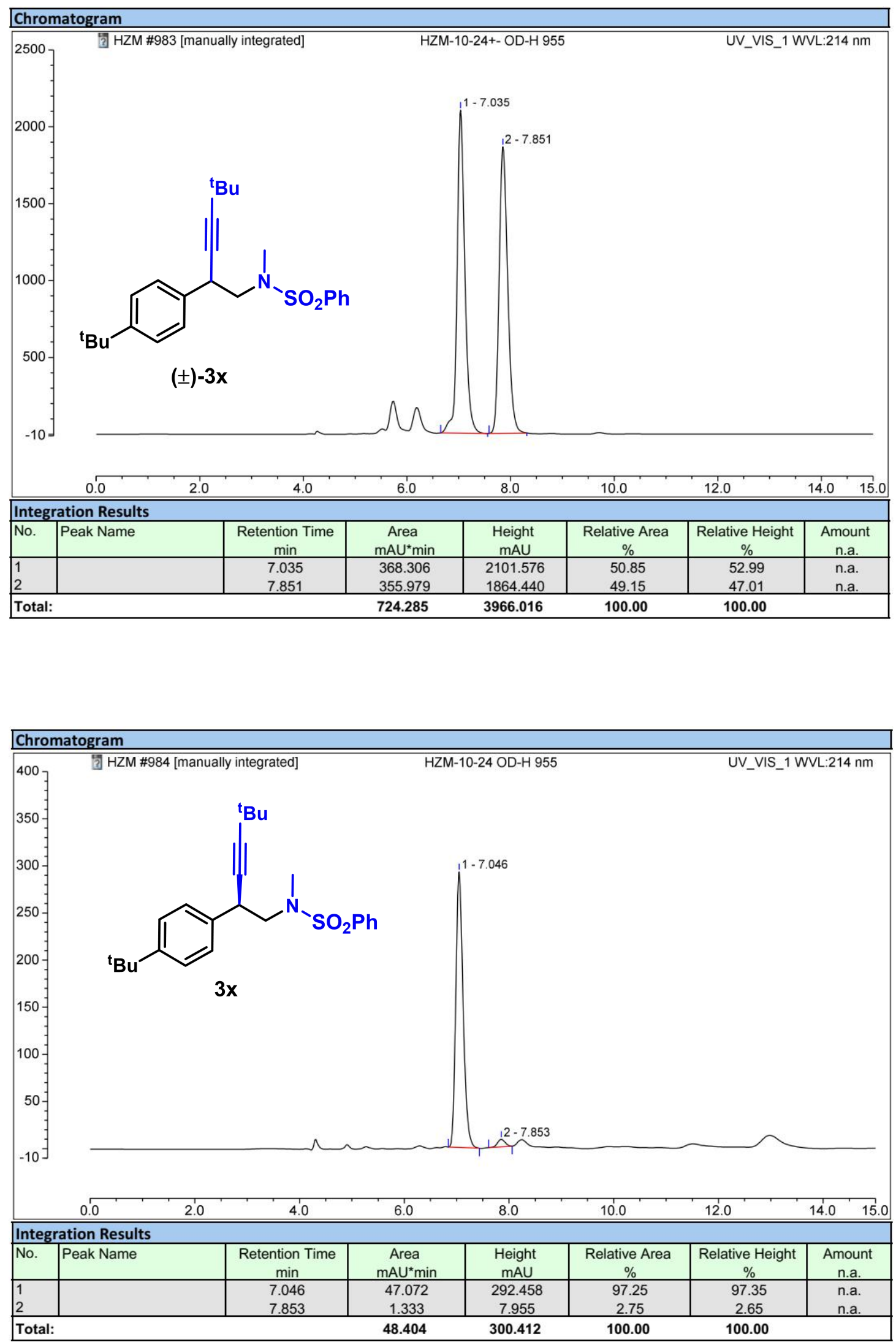

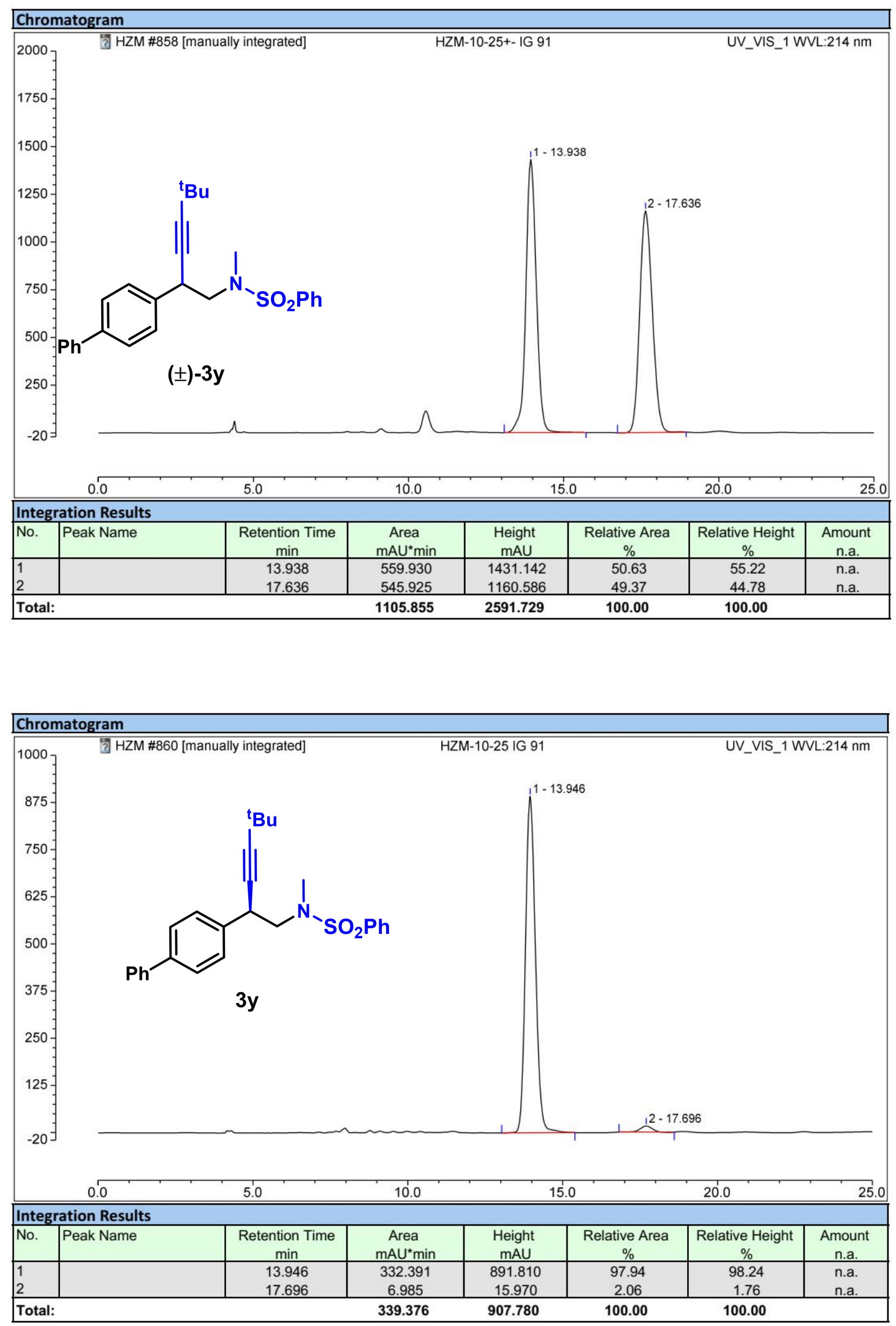

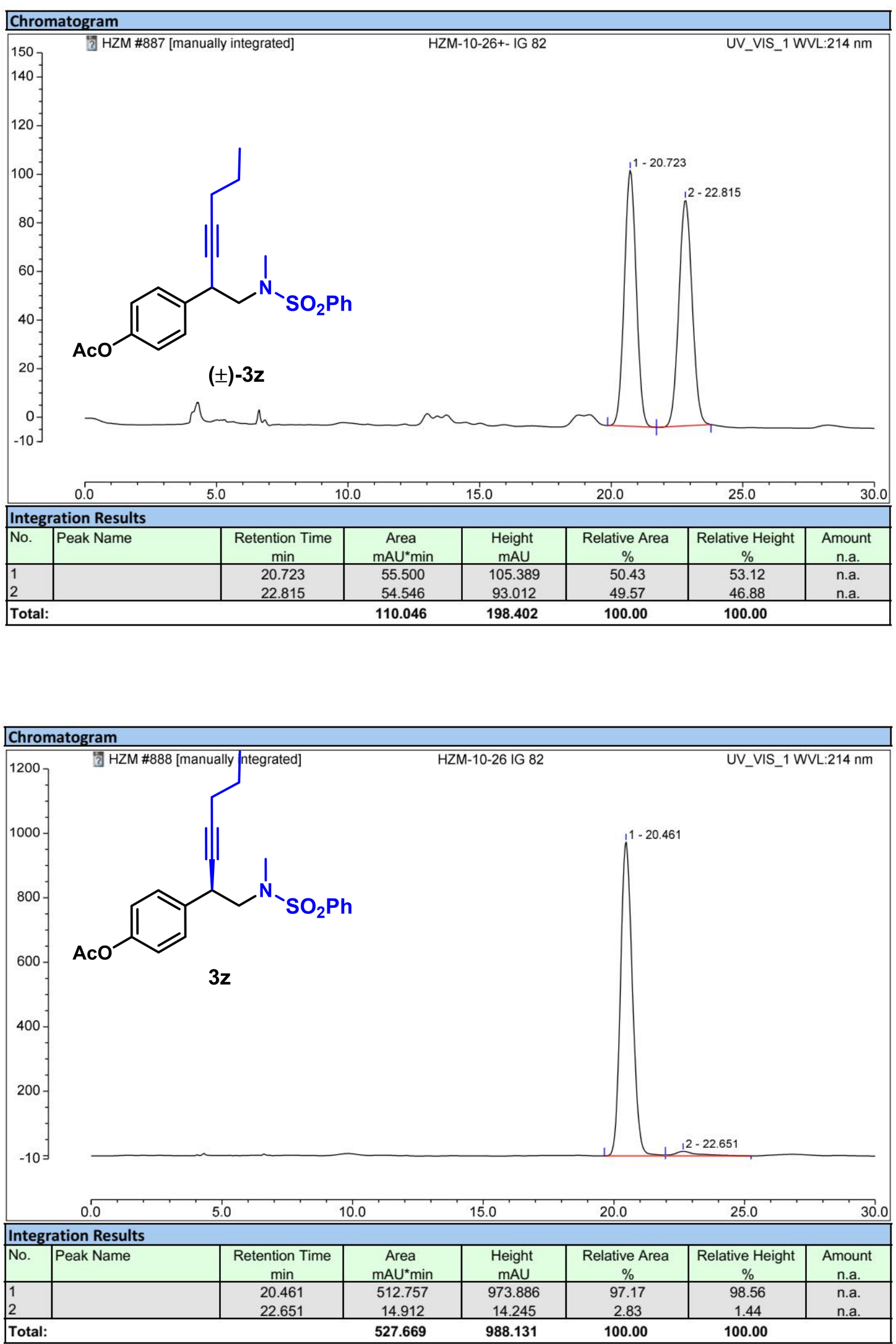

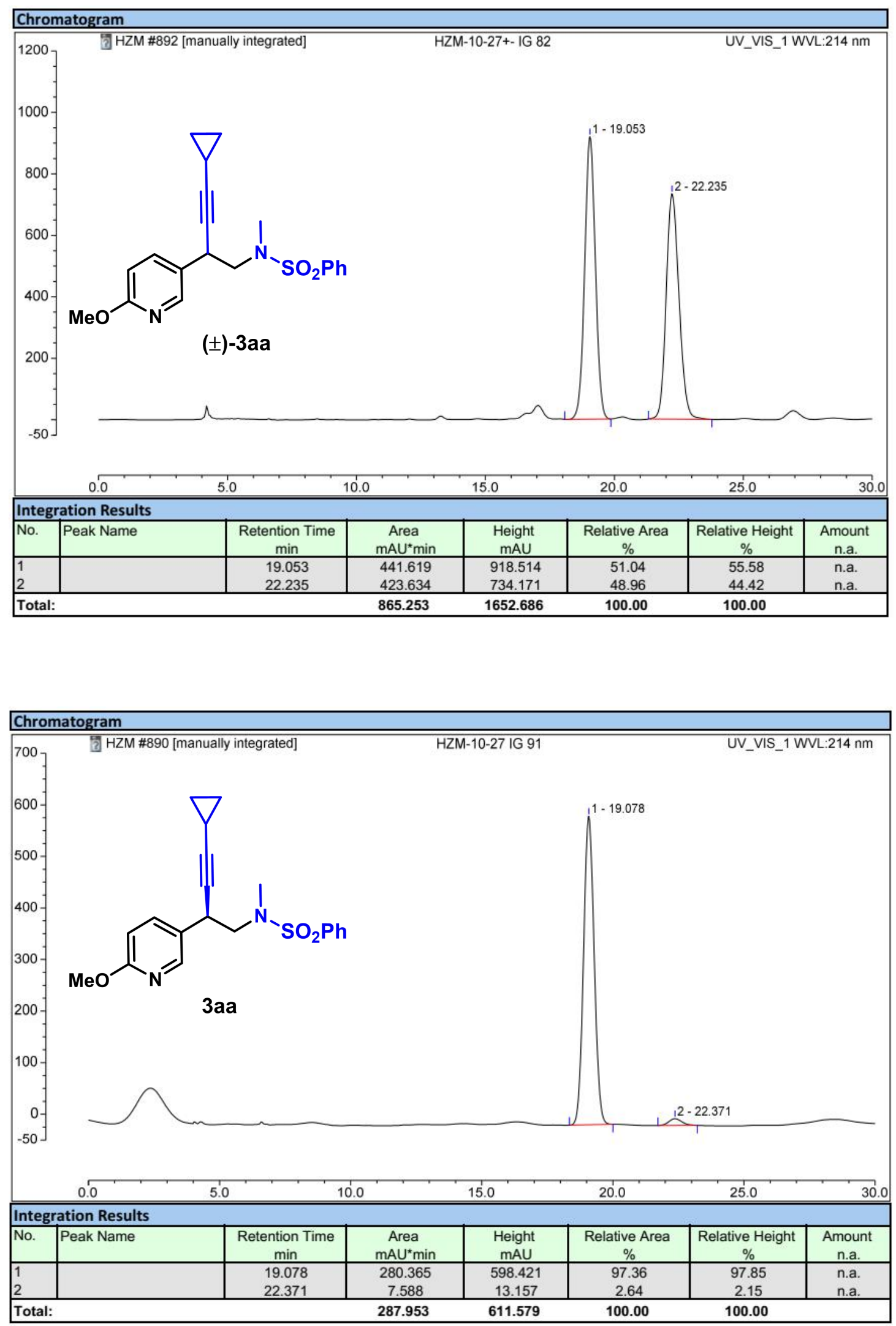

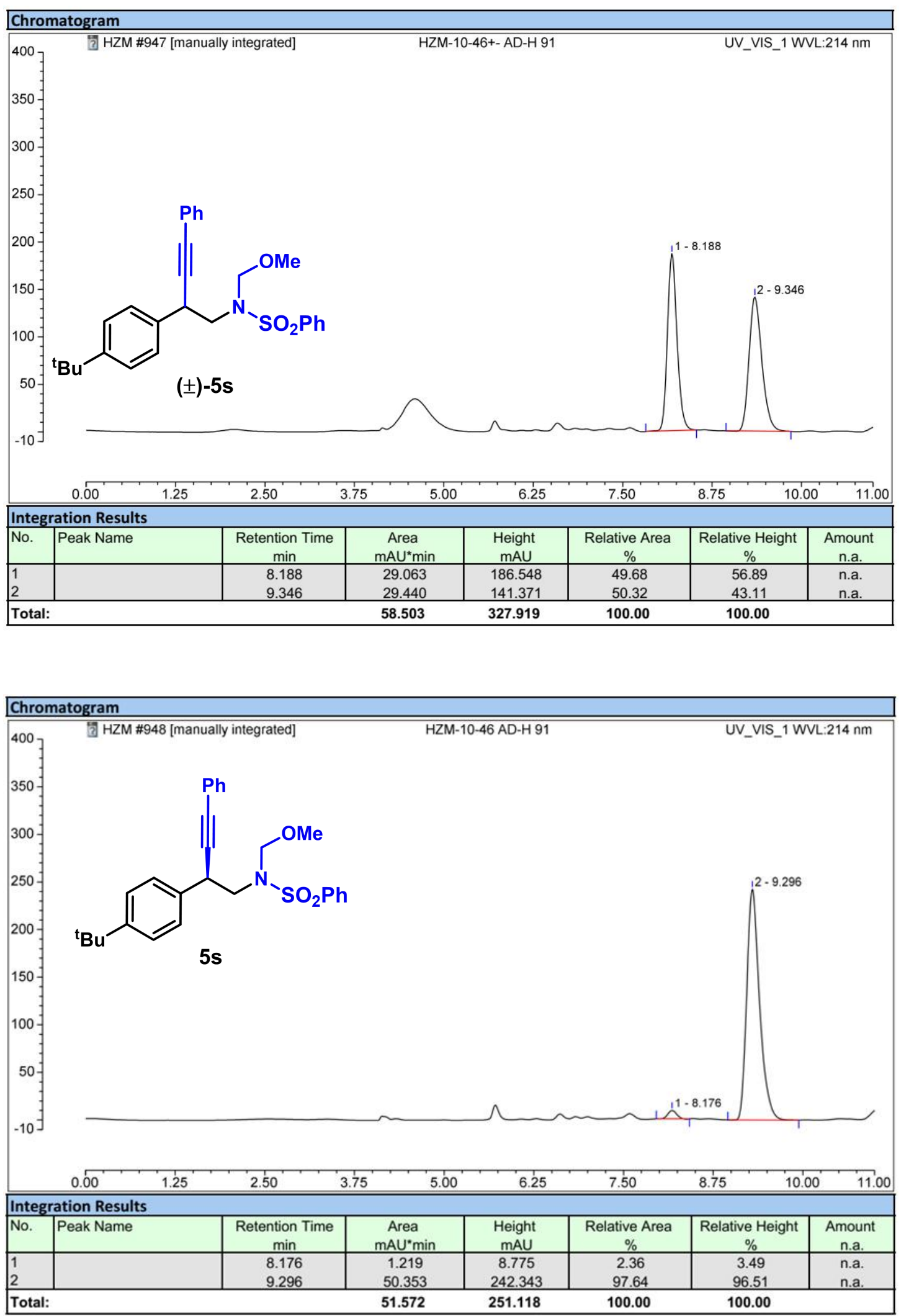

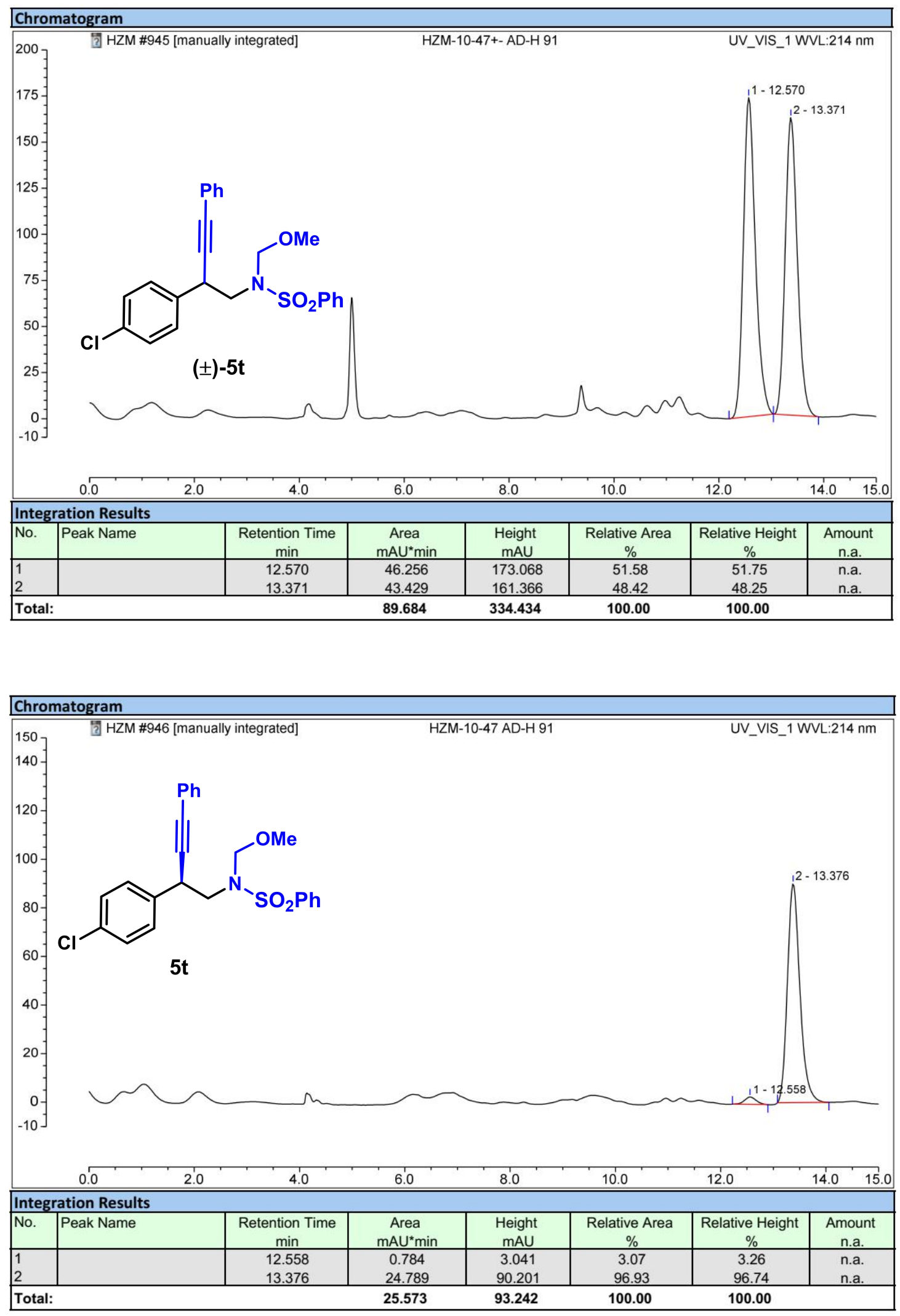


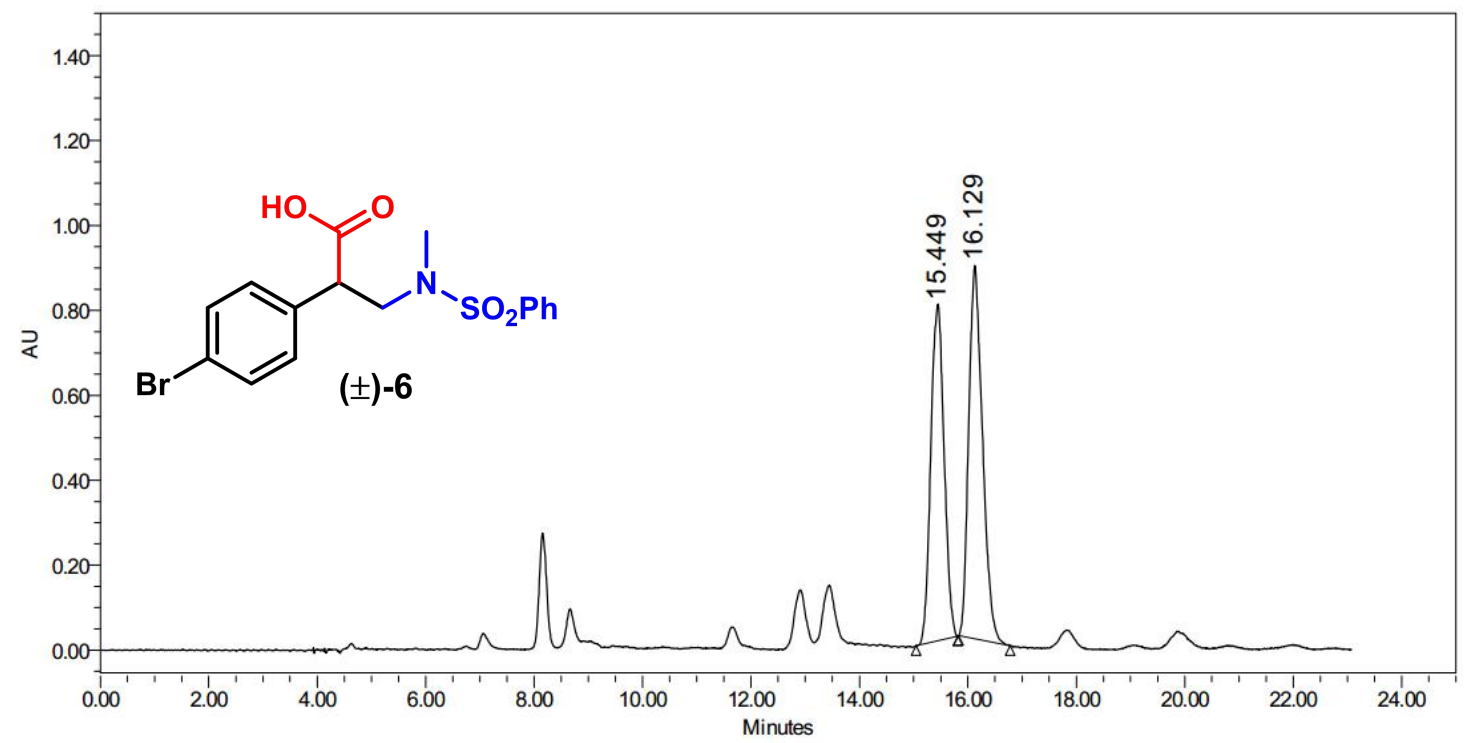

Peak Results

\begin{tabular}{|c|c|c|c|r|}
\hline & RT & Area & Height & \% Area \\
\hline 1 & 15.449 & 14486928 & 792639 & 48.29 \\
\hline 2 & 16.129 & 15509768 & 879463 & 51.71 \\
\hline
\end{tabular}

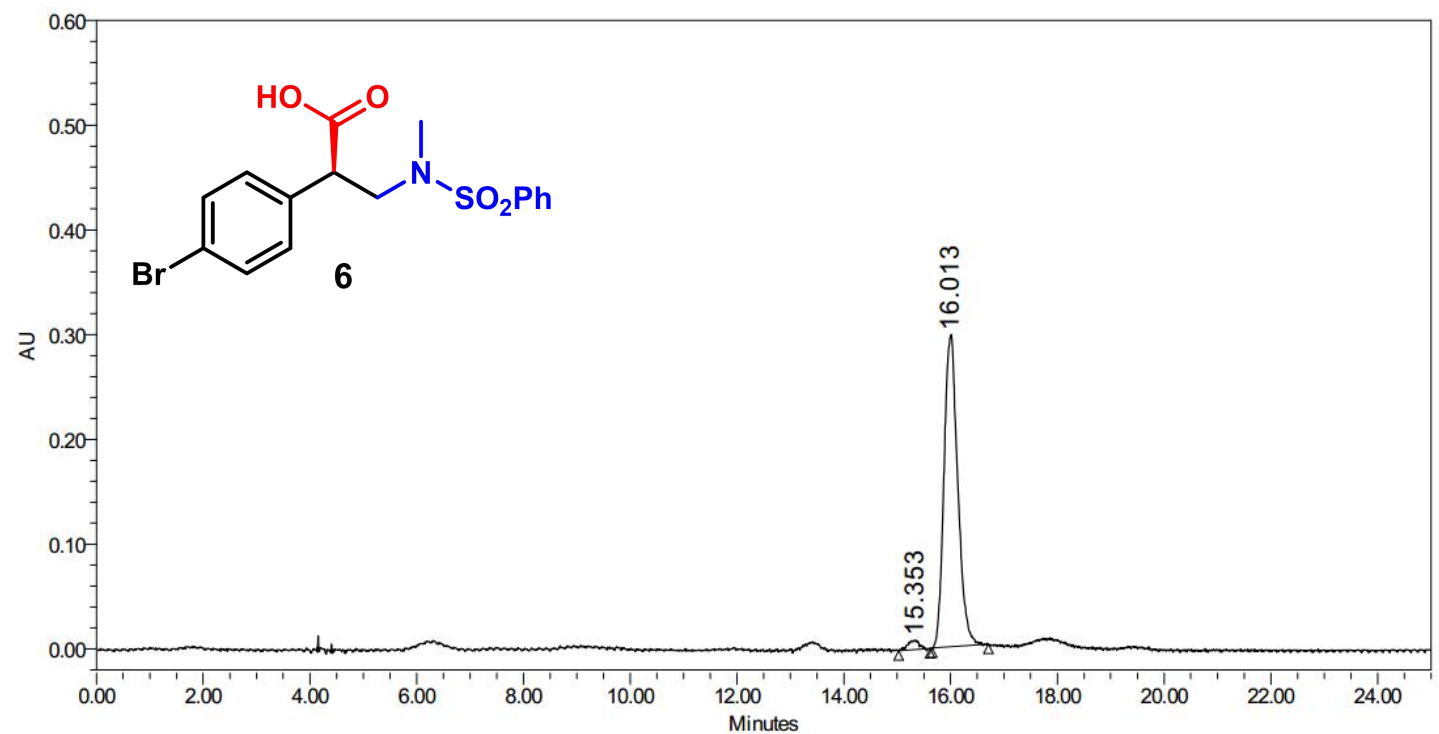

Peak Results

\begin{tabular}{|r|c|c|r|r|}
\hline & RT & Area & Height & \% Area \\
\hline 1 & 15.353 & 137625 & $911 \mathrm{C}$ & 2.52 \\
\hline 2 & 16.013 & 5315627 & 298174 & 97.48 \\
\hline
\end{tabular}



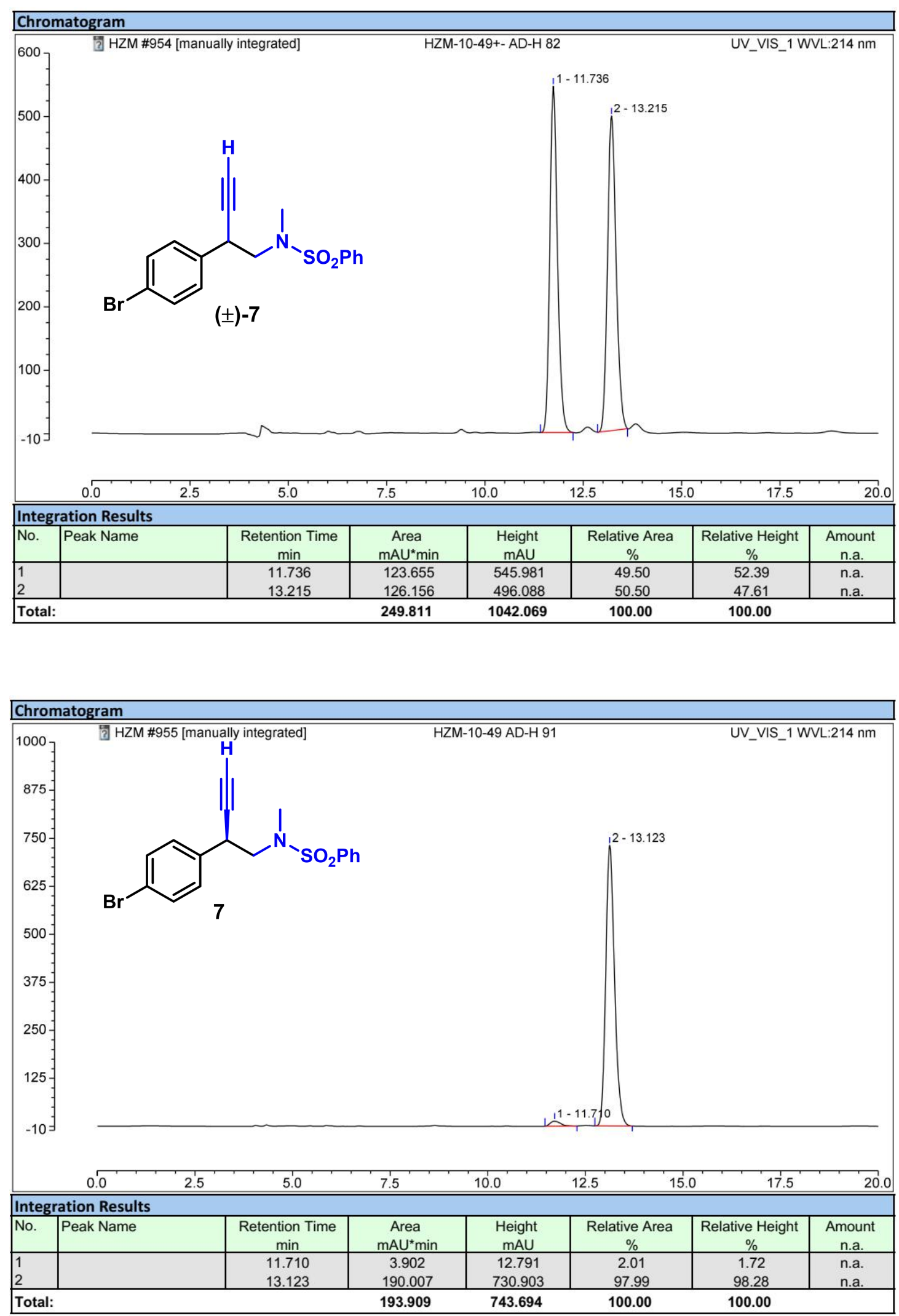


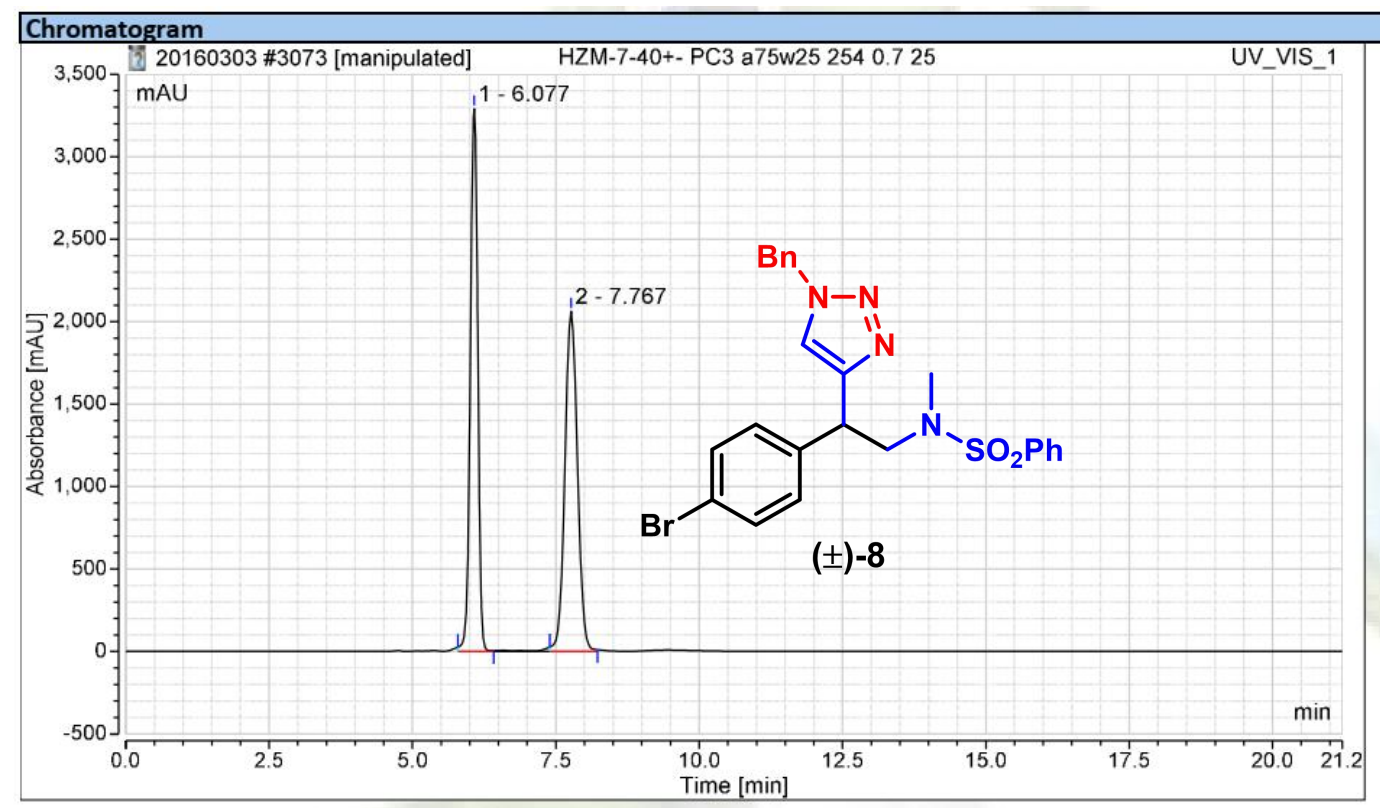

\begin{tabular}{|c|c|c|c|c|}
\hline \multicolumn{5}{|c|}{ Integration Results } \\
\hline No. & $\begin{array}{c}\text { Retention Time } \\
\text { min }\end{array}$ & $\begin{array}{c}\text { Area } \\
\mathrm{mAU}^{*} \mathrm{~min}\end{array}$ & $\begin{array}{c}\text { Height } \\
\text { mAU }\end{array}$ & $\begin{array}{c}\text { Relative Area } \\
\% \\
\end{array}$ \\
\hline 1 & 6.077 & 495.4509 & 3291.6599 & 48.608 \\
\hline 2 & 7.767 & 523.8223 & 2063.7217 & 51.392 \\
\hline \multicolumn{2}{|c|}{ Total: } & 1019.273 & 1401.998 & 100.000 \\
\hline
\end{tabular}

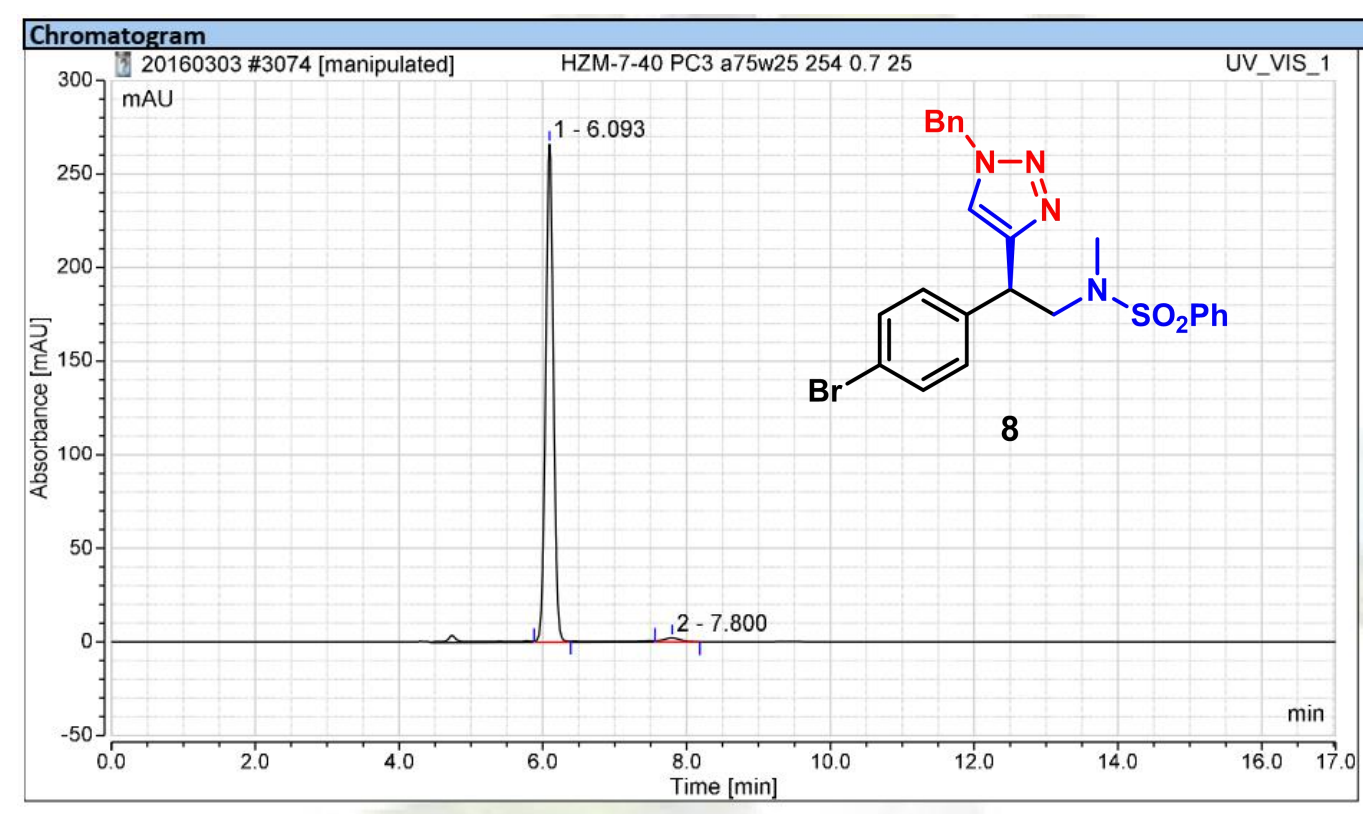

\begin{tabular}{|l|c|c|c|c|}
\hline \multicolumn{4}{|l|}{ Integration Results } \\
\hline No. & $\begin{array}{c}\text { Retention Time } \\
\text { min }\end{array}$ & $\begin{array}{c}\text { Area } \\
\text { mAU*min }\end{array}$ & $\begin{array}{c}\text { Height } \\
\text { mAU }\end{array}$ & $\begin{array}{c}\text { Relative Area } \\
\%\end{array}$ \\
\hline 1 & 6.093 & 33.6034 & 266.0853 & 98.320 \\
2 & 7.800 & 0.5742 & 2.1805 & 1.680 \\
\hline Total: & $\mathbf{3 4 . 1 7 8}$ & 1401.998 & 100.000 \\
\hline
\end{tabular}



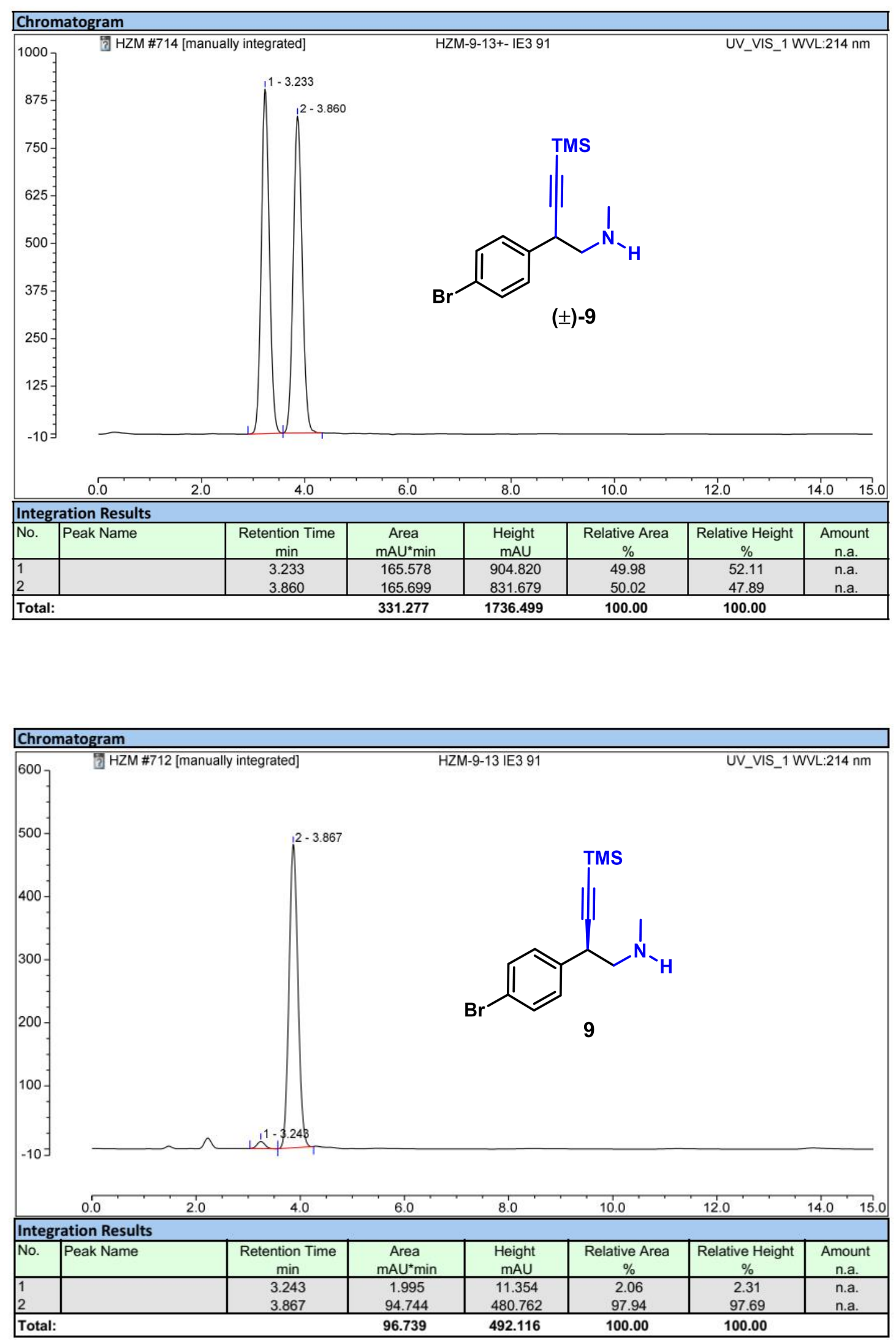

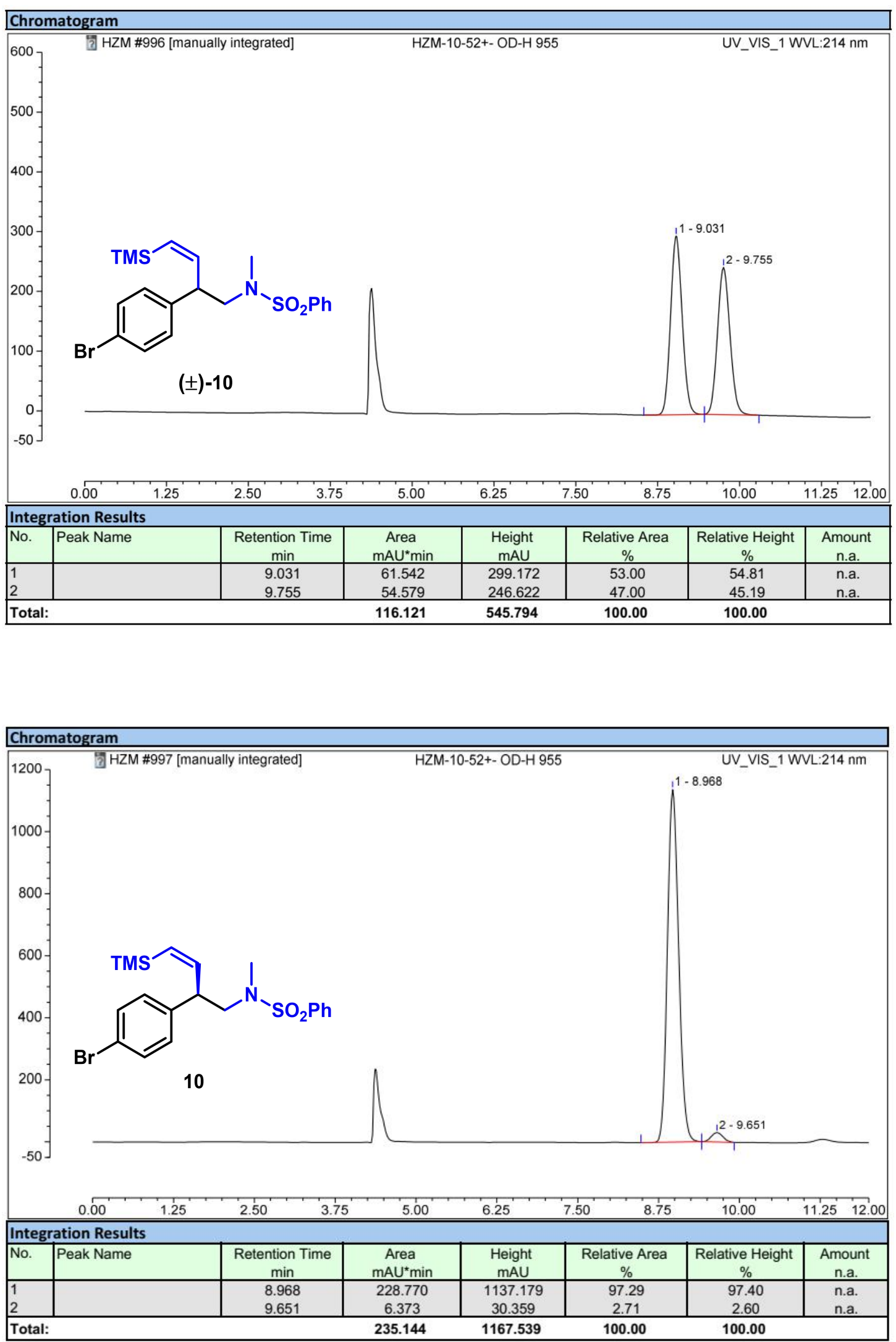

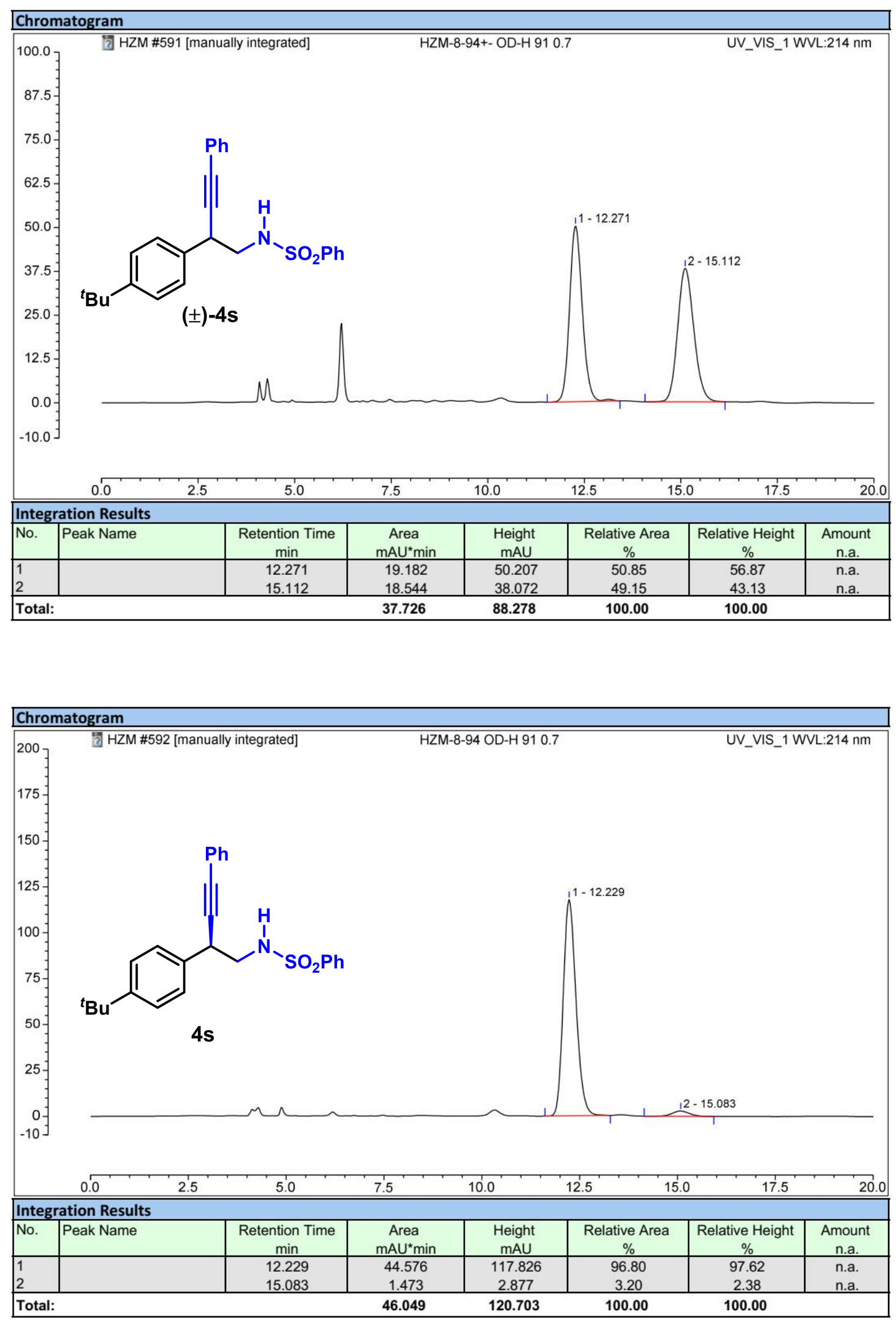

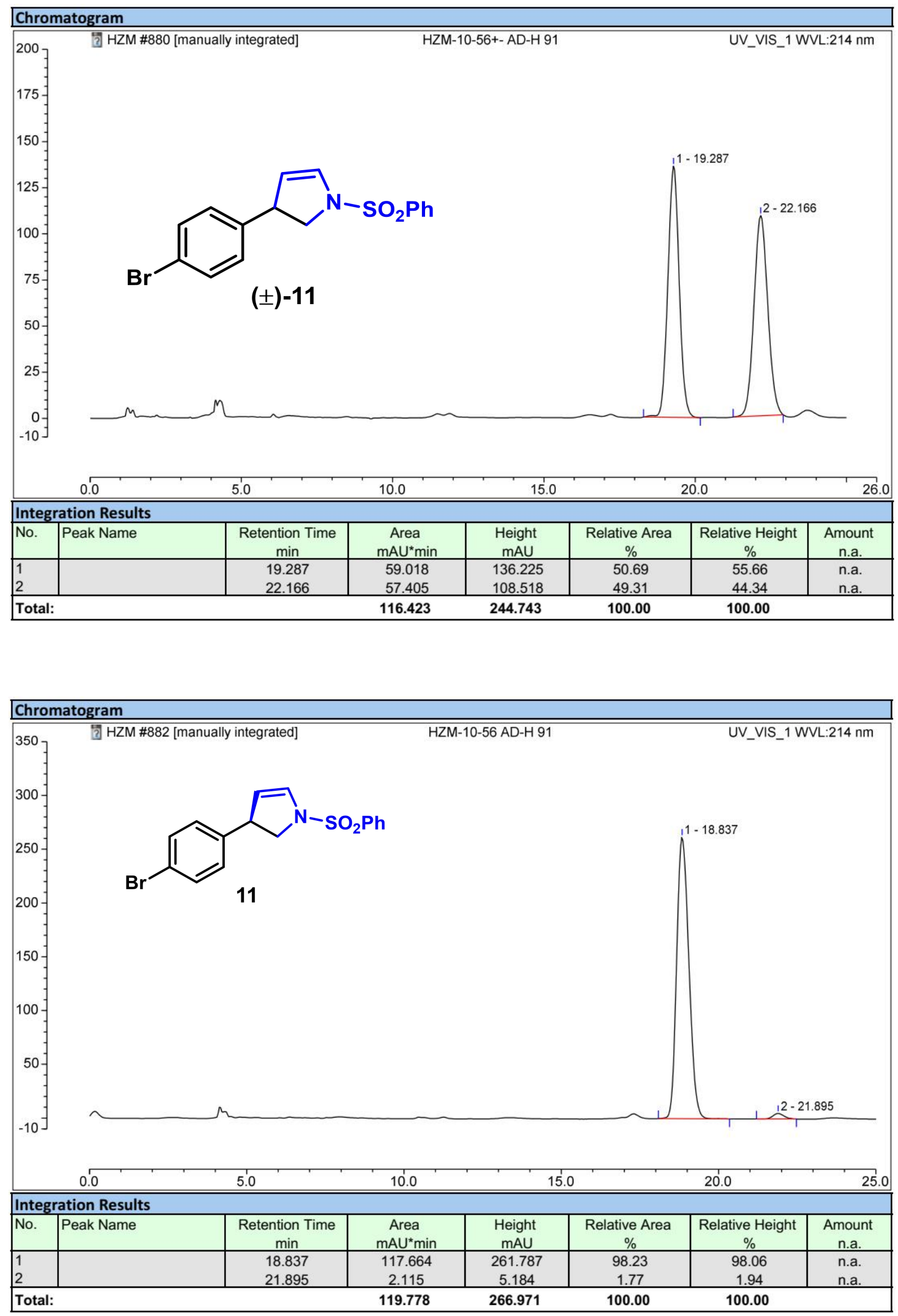

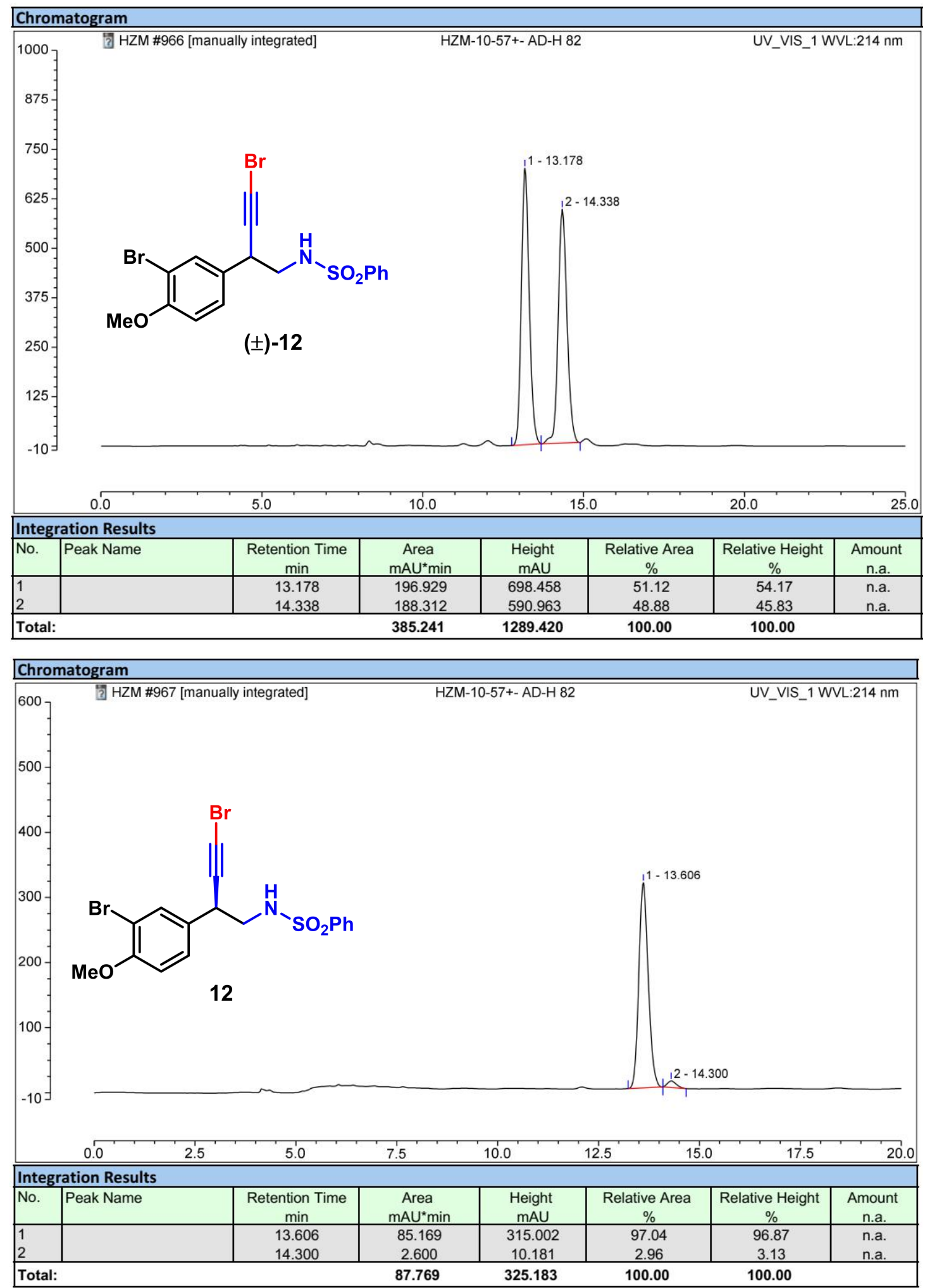


\begin{tabular}{|c|c|c|c|}
\hline & SAMPLE & INFORMATION & \\
\hline Sample Name: & $\mathrm{H} \square \mathrm{M} 9-58+\mathrm{PA} 2 \mathrm{ATMB} 2140.7$ & Acquired By: & System \\
\hline Sample Type: & Unknown & Sampe Set Name: & 20190001 \\
\hline Val: & $1: F, 7$ & Acq Method Set: & 1008 \\
\hline Injection\#. & 1 & Processing Method & 1 \\
\hline Irjection Valume: & $500 \mathrm{u}$ & Chand Name: & PDA C1 214rm@4.8m \\
\hline Rn Time: & 100.0 Mrutes & Proc. Orri. Descr: & PDA 011 214rm@4.8rm \\
\hline Date Acquired & 4/2/20194:47:26 PMCST & & \\
\hline Date Processed & 4/3/20193:26.51 PMCST & & \\
\hline
\end{tabular}

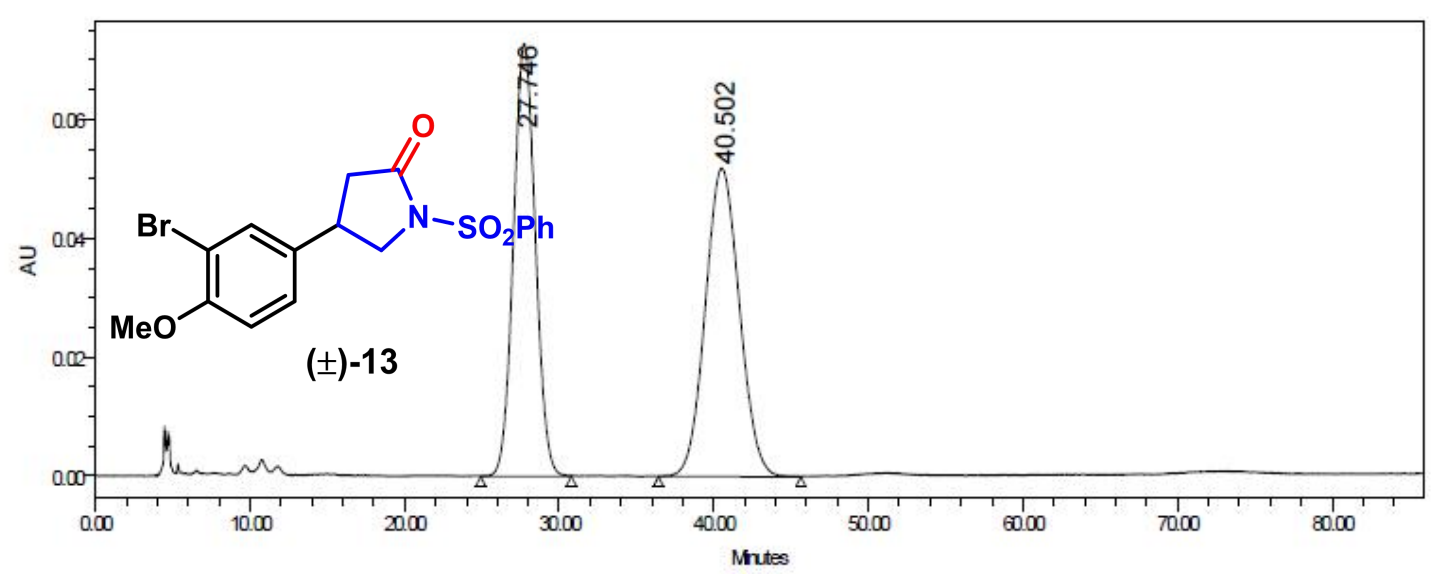

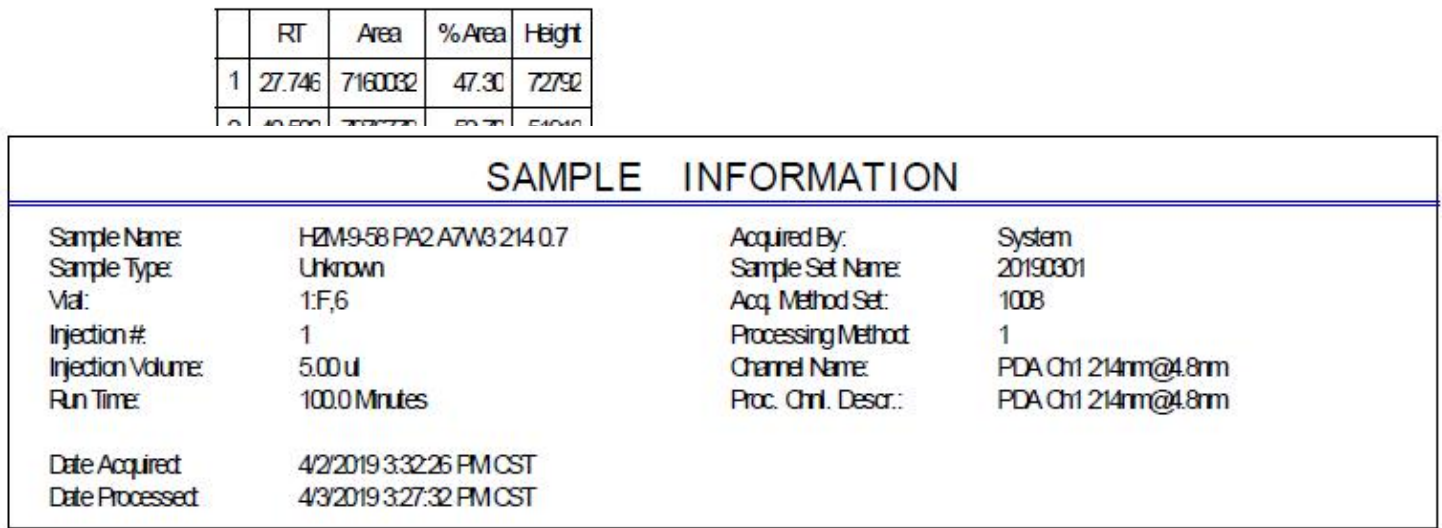

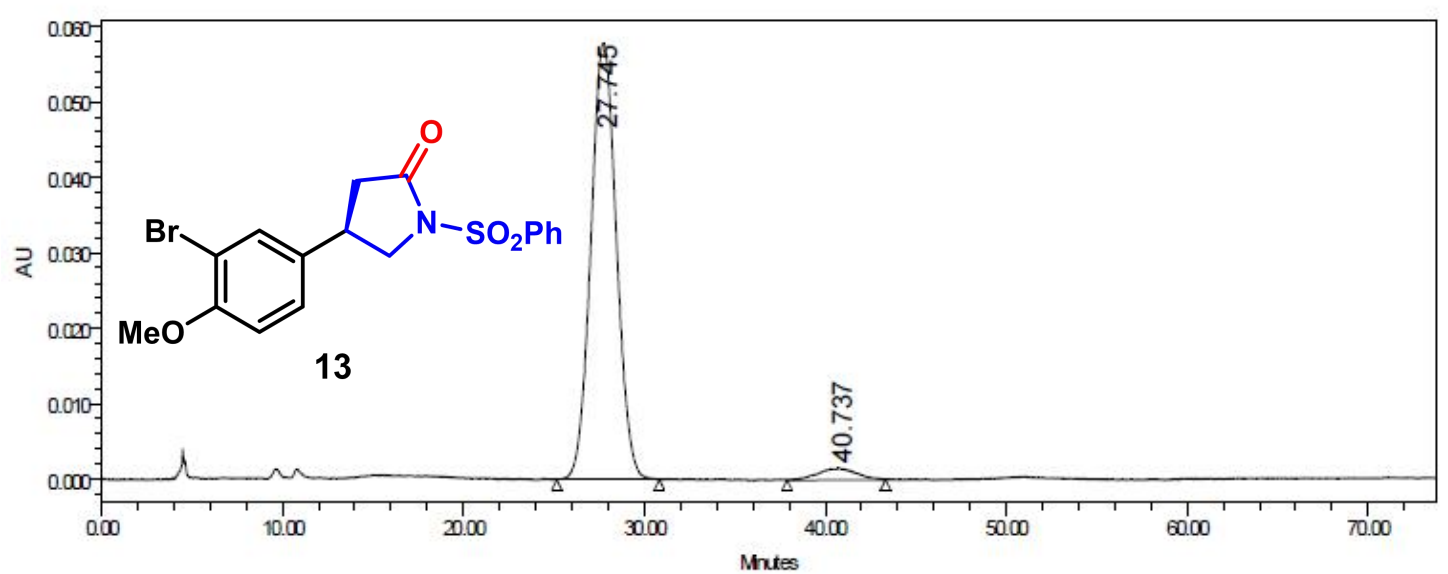

\begin{tabular}{|c|c|c|r|r|}
\hline & Rा & Area & \%Area & Heigt \\
\hline 1 & 27.745 & 5680023 & 96.07 & 57887 \\
\hline 2 & 40.737 & 232144 & 398 & 1568 \\
\hline
\end{tabular}



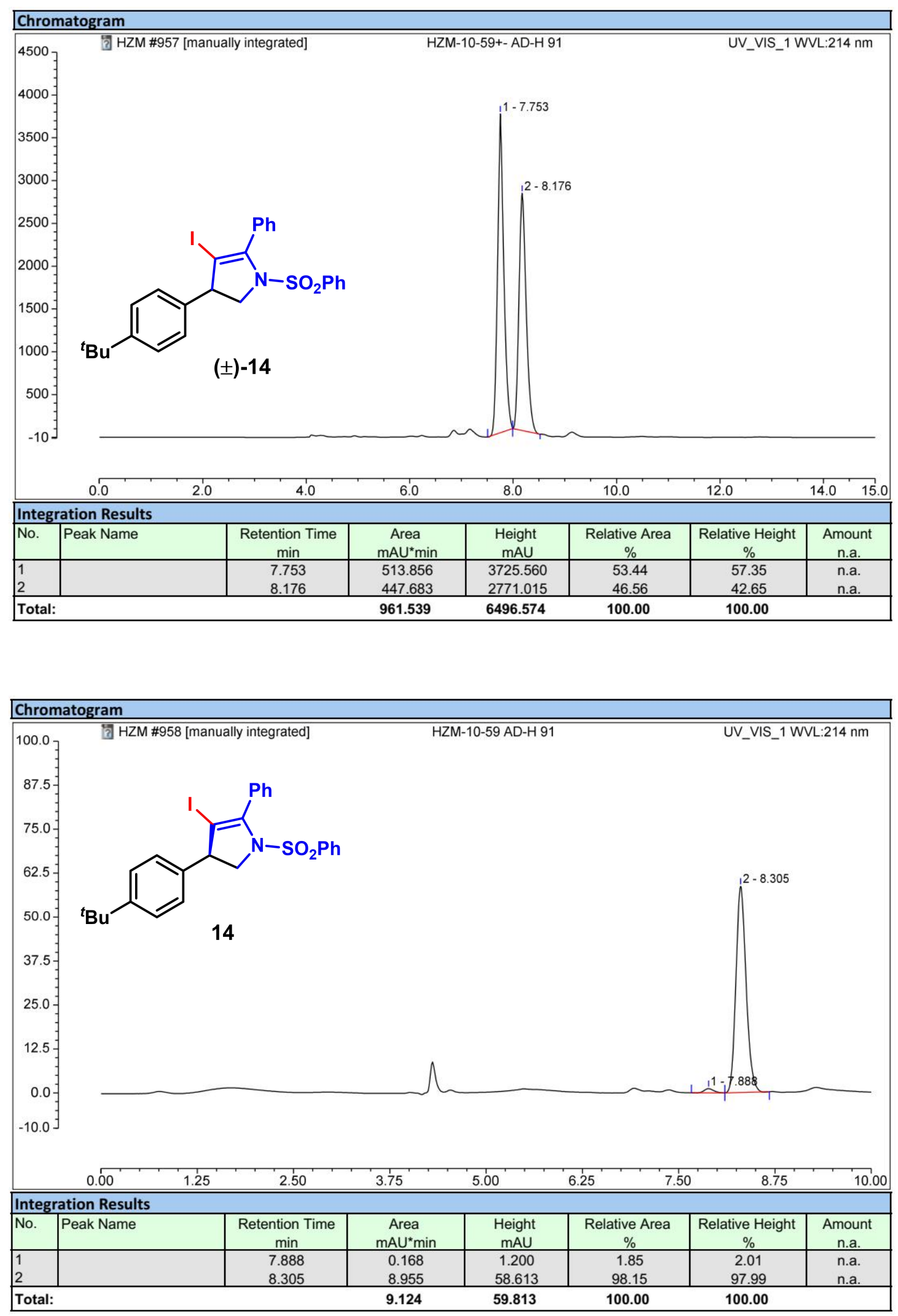

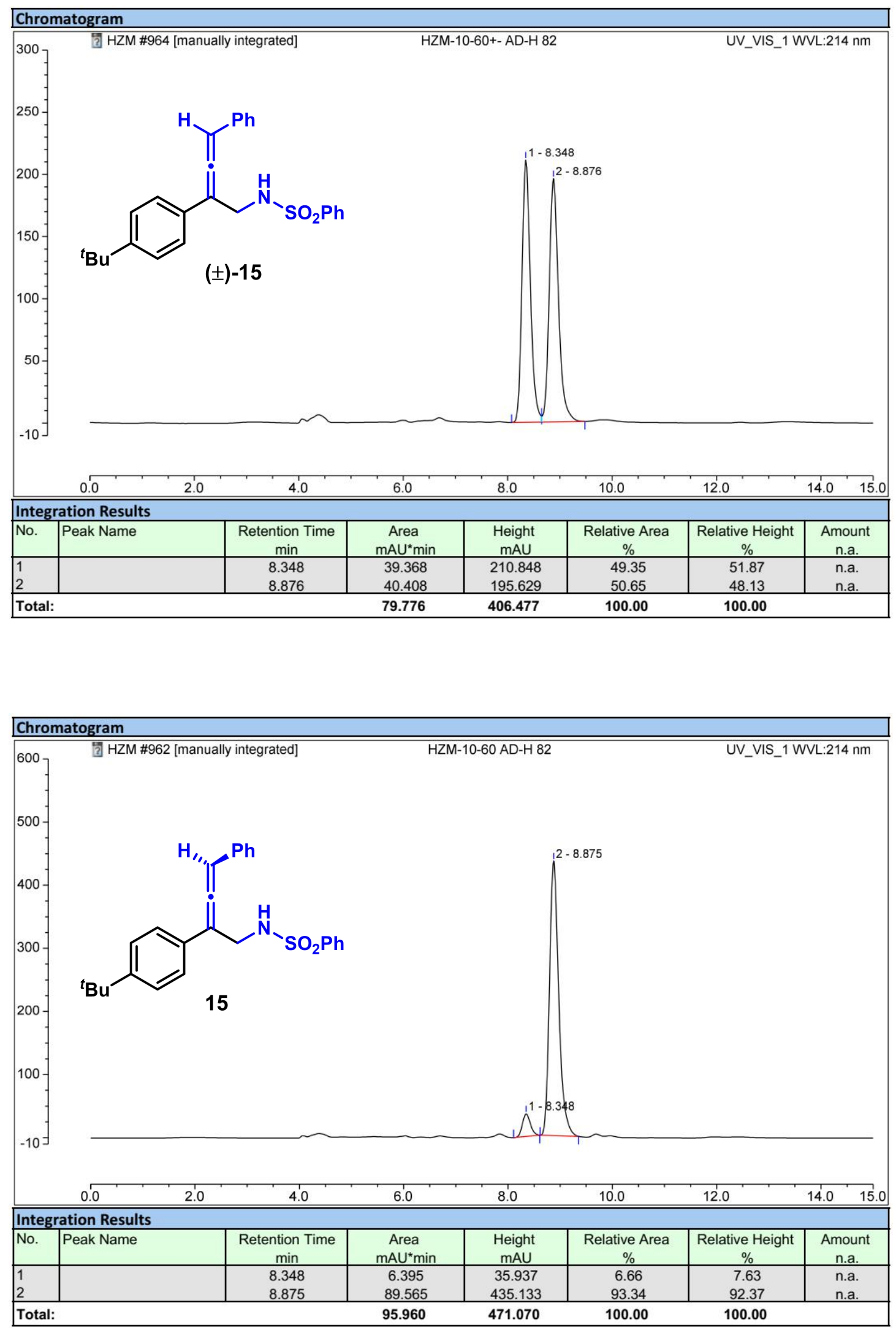
